\title{
ADVANCED UNDERGROUND GAS STORAGE CONCEPTS REFRIGERATED-MINED CAVERN STORAGE
}

FINAL DRAFT REPORT

DOE CONTRACT NUMBER DE-AC26-97FT34349-01

SUBMITTED BY:

PB-KBB INC.

11757 KATY FREEWAY, SUITE 600

HOUSTON, TX 77079

SEPTEMBER 1998 


\title{
ADVANCED UNDERGROUND GAS STORAGE CONCEPTS REFRIGERATED-MINED CAVERN STORAGE \\ FINAL DRAFT REPORT
}

\begin{abstract}
Limited demand and high cost has prevented the construction of hard rock caverns in this country for a number of years. The storage of natural gas in mined caverns may prove technically feasible if the geology of the targeted market area is suitable; and economically feasible if the cost and convenience of service is competitive with alternative available storage methods for peak supply requirements. It is believed that mined cavern storage can provide the advantages of high delivery rates and multiple fillwithdrawal cycles in areas where salt cavern storage is not possible. In this research project, PB-KBB merged advanced mining technologies and gas refrigeration techniques to develop conceptual designs and cost estimates to demonstrate the commercialization potential of the storage of refrigerated natural gas in hard rock caverns. Five regions of the U.S.A. were studied for underground storage development and PB-KBB reviewed the literature to determine if the geology of these regions was suitable for siting hard rock storage caverns. Area gas market conditions in these regions were also studied to determine the need for such storage. Based on an analysis of many factors, a possible site was determined to be in Howard and Montgomery Counties, Maryland. The area has compatible geology and a gas industry infrastructure for the nearby market populous of Baltimore and Washington D.C..
\end{abstract}

As Gas temperature is lowered, the compressibility of the gas reaches an optimum value. The compressibility of the gas, and the resultant gas density, is a function of temperature and pressure. This relationship can be used to commercial advantage by reducing the size of a storage cavern for a given working volume of natural gas. This study looks at this relationship and and the potential for commercialization of the process in a storage application. A conceptual process design, and cavern design were developed for various operating conditions. Potential site locations were considered and a typical plant layout was developed. In addition a geomechanical review of the proposed cavern design was performed, evaluating the stability of the mine rooms and shafts, and the effects of the refrigerated gas temperatures on the stability of the cavern.

Capital and operating cost estimates were also developed for the various temperature cases considered. The cost estimates developed were used to perform a comparative market analysis of this type of gas storage system to other systems that are commercially used in the region of the study. 
This report was prepared as an account of work sponsored by an agency of the United States Government. Neither the United States Government nor any agency thereof, nor any of their employees, makes any warranty, express or implied, or assumes any legal liability or responsibility for the accuracy, completeness, or usefulness of any information, apparatus, product, or process disclosed, or represents that its use would not infringe privately owned rights. Reference herein to any specific commercial product, process, or service by trade name, trademark, manufacturer, or otherwise does not necessarily constitute or imply its endorsement, recommendation, or favoring by the United States Government or any agency thereof. The views and opinions of authors expressed herein do not necessarily state or reflect those of the United States Government or any agency thereof. 
User Note:

The following Table of Contents, List of Tables, and List of Figures are provided with text links to the associated section, table or figure. By clicking on the appropriate text the cursor will move to the appropriate document page.

\section{TABLE OF CONTENTS}

Section TITLE

LIST OF TABLES

LIST OF FIGURES

LIST OF CONCEPTUAL DRAWINGS

EXECUTIVE SUMMARY

$1 \quad$ INTRODUCTION

2

LITERATURE SEARCH FOR SELECTING TARGET AREAS

3

SELECTED PROCESS AND CAVERN DESIGN PARAMETERS

4

CHILLING COMPRESSED NATURAL GAS TO MINIMIZE STORAGE SPACE

5

PROCESS CONCEPTUAL DESIGN

6

SITE GEOLOGY

CAVERN CONCEPTUAL DESIGN

8

GEOMECHANICAL REVIEW OF PROPOSED CAVERN DESIGN FOR STORAGE OF REFRIGERATED NATURAL GAS

9

HEALTH AND SAFETY

10

CONSTRUCTION COST ESTIMATES AND SCHEDULES

11

OPTIMIZATION

12

EVALUATION OF SUCCESS CRITERIA

13

APPENDICES

CONCEPTUAL DRAWINGS

COST ESTIMATE DETAIL

REFERENCES 


\section{LIST OF FIGURES}

$\underline{\text { Figure }}$

2-1 Physiographic Map of Maryland

4-1 Natural Gas Compressibility Factor

4-2 Gas Volume vs. Cavern Pressure

6-1 Prospective Natural Gas Storage Cavern Area

6-2 Stratigraphic Column of Howard County, Maryland

8-1 Schematic of Axisymmetric Model of Storage Mine

8-2 Finite Element Mesh of Storage Mine

8-3 Estimate of Maximum Design Span for Permanently Unsupported Man-made Openings

8-4 Tunnel Support Chart for Categories of Support

8-5 Underground Excavation Stability as a Function of Induced Stresses and Rock Mass Quality

8-6 Influence of Pillar Width-to-height Ratio on Average Pillar Strength

8-7 Stresses Acting on a 10-Foot-Diameter Shaft at 3,000-Foot Depth in 10,000 psi Granite

8-8 Stresses Acting on a 18-Foot Diameter Shaft at 3,000-Foot Depth in 10,000 psi Granite

8-9 DRZ Predicted by SPECTROM-32 Around a 10-Foot-Diameter Shaft at 3,000-Foot Depth in 10,000 psi Granite

8-10 DRZ Predicted by SPECTROM-32 Around a 18-Foot-Diameter Shaft at 3,000-Foot Depth in 10,000 psi Granite

8-11 Temperature Contours at Time 0 and 30 Days after Filling with Gas at $-28.9^{\circ} \mathrm{C}$

8-12 Temperature Contours at 1 and 5 Years after Filling with Gas at $-28.9^{\circ} \mathrm{C}$

8-13 Mohr-Coulomb Factor-of-Safety Contours at 0 and 30 Days after Filling with Gas at $-28.9^{\circ} \mathrm{C}$

8-14 Mohr-Coulomb Factor-of-Safety Contours at 1 and 5 Years after Filling with Gas at $-28.9^{\circ} \mathrm{C}$

8-15 Maximum Principal Stress Contours at 0 and 30 Days after Filling with Gas at $-28.9^{\circ} \mathrm{C}$

8-16 Maximum Principal Stress Contours at 1 and 5 Years after Filling with Gas at $-28.9^{\circ} \mathrm{C}$ 


\section{LIST OF FIGURES (Continued.)}

\section{Figure}

8-17 Mohr-Coulomb Factor-of-Safety Contours Before and After Drawdown from Maximum to Minimum Gas Pressure

8-18 Maximum Principal Stress Contours Before and After Drawdown from Maximum to Minimum Gas Pressure

8-19 Schematic of Axisymetric Model of Storage Caverns

8-20 Finite Element Model of Storage Cavern

8-21 Cooling Load Required to Maintain Storage Cavern at $-20^{\circ} \mathrm{F}$

8-22 Temperature Contours Around Mine at 1 and 10 Years 


\section{LIST OF CONCEPTUAL DRAWINGS}

(IN APPENDICES)

\begin{tabular}{|c|c|}
\hline $861-G G-001$ & Electrical Symbol Diagram \\
\hline 861-GG-002 & Piping \& Instrument Symbol Diagram \\
\hline 861-GG-003 & List of Drawings \\
\hline 861-GP-001 & General Facility Layout \\
\hline 861-GP-002 & General Equipment Layout \\
\hline $861-\mathrm{AC}-001$ & Office/Control Building Elevation \\
\hline 861-AC-002 & Office/Control Building Plan \\
\hline 861-ED-001 & One Line Drawing - Conceptual Design (1 of 3) \\
\hline 861-ED-002 & One Line Drawing - Conceptual Design (2 of 3) \\
\hline 861-ED-003 & One Line Drawing - Conceptual Design (3 of 3) \\
\hline 861-LB-004 & Two Shaft Mine Showing Development and Benching Headings \\
\hline 861-LB-005 & Shaft Outfitting During Construction \\
\hline 861-LB-006 & Mine General Arrangement \\
\hline 861-LB-007 & General Cavern Layout - 2,500' Depth \\
\hline 861-LB-008 & General Cavern Layout - 3,000' Depth \\
\hline 861-LB-009 & Gas Distribution System in Mine - 3,000 ft Depth \\
\hline 861-LB-010 & Section 'A-A' 3000' Depth \\
\hline 861-MD-001 & Process Flow Diagram \\
\hline 861-MD-002 & Meter Skid \\
\hline 861-MD-003 & Gas Compression System \\
\hline 861-MD-004 & Molecular Sieve Dehydrator \\
\hline 861-MD-005 & Regeneration Gas System \\
\hline 861-MD-006 & Refrigeration System \\
\hline 861-MD-007 & Storage Cavern and Heater \\
\hline 861-MP-001 & Compressor Building Plan \& Elevation \\
\hline
\end{tabular}




\section{ADVANCED UNDERGROUND GAS STORAGE CONCEPTS REFRIGERATED-MINED CAVERN STORAGE FINAL DRAFT REPORT}

\section{EXECUTIVE SUMMARY}

Over the past 40 years, cavern storage of LPG's, petrochemicals, such as ethylene and propylene, and other petroleum products has increased dramatically. In 1991, the Gas Processors Association (GPA) lists the total U.S. underground storage capacity for LPG's and related products of approximately 519 million barrels ( 82.5 million cubic meters) in 1,122 separate caverns. Of this total, 70 are hard rock caverns and the remaining 1,042 are caverns in salt deposits. However, along the eastern seaboard of the U.S. and the Pacific northwest, salt deposits are not available and therefore, storage in hard rocks is required.

Limited demand and high cost has prevented the construction of hard rock caverns in this country for a number of years. The storage of natural gas in mined caverns may prove technically feasible if the geology of the targeted market area is suitable; and economically feasible if the cost and convenience of service is competitive with alternative available storage methods for peak supply requirements. Competing methods include LNG facilities and remote underground storage combined with pipeline transportation to the area.

It is believed that mined cavern storage can provide the advantages of high delivery rates and multiple fillwithdrawal cycles in areas where salt cavern storage is not possible. In this research project, PB-KBB merged advanced mining technologies and gas refrigeration techniques to develop conceptual designs and cost estimates to demonstrate the commercialization potential of the storage of refrigerated natural gas in hard rock caverns.

DOE has identified five regions, that have not had favorable geological conditions for underground storage development: New England, Mid-Atlantic (NY/NJ), South Atlantic (DL/MD/VA), South Atlantic (NC/SC/GA), and the Pacific Northwest (WA/OR). PB-KBB reviewed published literature and in-house databases of the geology of these regions to determine suitability of hard rock formations for siting storage caverns, and gas market area storage needs of these regions.

Many factors were analyzed in the selection of possible storage sites. These included available gas transmission pipelines, proximity to metropolitan areas, accessible power and water, proximity to environmentally sensitive areas, rock types, potential disposal sites for excavated material, and a sufficient water table for the storage formation. Based on this analysis, suitable geology for a possible site was found in Howard and Montgomery Counties, Maryland. Areas in this region have sufficient extent, are isotropic in nature, and are of high quality with excellent mechanical and physical properties for mined storage caverns. This area is also near commercial gas transmission lines that serve both Baltimore and Washington D.C.

Based upon the general site selection, the design parameters for the storage facility were developed. The 
compressibility of natural gas, and the resultant gas density, is a function of temperature and pressure. At a given temperature, the compressibility of gas reaches an optimum value as shown in Figure 4-1. This relationship can be used to commercial advantage by reducing the size of a storage cavern for a given working volume of natural gas. As the temperature is lowered, the gas density increases, allowing more gas storage in a given size of cavern. The decreased cavern costs for the lower temperatures, requires an investment in refrigeration equipment, and will have recurring refrigeration energy and maintenance costs. Although the mass of stored gas is greatest for any given pressure at the minimum operating temperature, the amount of heat influx into the cavern is greater at lower temperatures requiring more refrigeration. Temperatures of $+20^{\circ} \mathrm{F}, 0^{\circ} \mathrm{F}$ and $-20^{\circ} \mathrm{F}$ were considered in the analysis. The minimum temperature, $-20^{\circ} \mathrm{F}$, was selected since commonly available carbon steel piping materials may be specified at the design conditions.

The final site design for this study consists of a mined cavern of approximately 37 million cubic feet at a depth of 3000 feet for gas stored at a temperature of $-20^{\circ} \mathrm{F}$ and a maximum pressure of $1250 \mathrm{psig}$. This would provide a working storage gas volume of five billion standard cubic feet. The surface site for the process facilities requires approximately four acres, with additional two to three acres necessary for the mine shafts and mining operation. Drawing 861-GP-001 shows a typical facility layout. A conceptual process design was developed that includes process equipment for gas measurement, compression, dehydration, refrigeration, and withdrawal gas heating. Equipment was sized for receipt and delivery rates of 250 million standard cubic feet per day, which provides a 20 day fill or withdrawal cycle for the five billion standard cubic feet of working gas storage.

The conceptual design of the mined cavern was prepared to demonstrate that a facility can be feasibly constructed, without the requirement for unique or unproven construction techniques, and to provide a basis for the cost estimate and construction schedule. The actual construction of such a facility will require a comprehensive geotechnical feasibility study performed at the site to determine subsurface geologic conditions as a prerequisite for a detailed design. Conventional state-of-the-art mining techniques were assumed for the conceptual design and are detailed in the report body. Consideration was given to optimum shaft and room sizes for the assumed formation and depth to assure mine stability. In addition a geomechanical review of the proposed cavern design was performed by RESPEC, evaluating the stability of the mine rooms and shafts, and the effects of the refrigerated gas temperatures on the stability of the cavern. The results of the study suggest the thermal effects do not have a large impact on the stability of the properties of the granite. Section 9 of the report discusses the health and safety aspects of the process design and the cavern, with attention given to emergency conditions and protective devices and procedures.

A rough order of magnitude cost estimate was developed for the facility for the optimum case considered. The cost summary is shown in Table 10-8. The facility is estimated to cost $\$ 173$ million or approximately $\$ 34.50$ per million standard cubic feet of base gas stored. This is based on five billion standard cubic feed of working gas. The mining costs were estimated to be $\$ 20$ per barrel of mined space developed. The 
annual operating costs depend upon local labor rates and energy costs, however a range of costs are presented in Tables 10-9 and 10-10 based on anticipated energy usage and plant labor requirements. Table 10-11 presents a summary of the major operating costs for the facility, based on energy costs of $\$ 2.50$ per million BTUs.

The cost estimates developed were used to perform a comparative market analysis of this type of gas storage system to other systems that are commercially used in the region of the study. Table 12-1 compares the unit capital costs for several existing storage projects of various systems in the proposed study area. Capital costs of the Refrigerated Mined Cavern (RMC) project are substantially higher than the comparison group, however some differences in systems should be noted. The RMC project provides multiple high capacity peaking cycles per year as compared to the single cycle of some of the existing systems, particularly LNG. The ability to cycle several times per year allows the costs to be spread over a larger volume of gas, reducing unit costs of service. Table 12-2 summarizes rates for a series of LNG and salt storage projects, compared to a 15-year levelized rate for the RMC project. 


\section{Section 1 \\ INTRODUCTION}

The service that a natural gas cavern can provide is the modern equivalent of the old gas holder operations. Recent trends in market and natural gas delivery terms, encountered by gas distribution companies today, suggest that cavern storage of natural gas merits close examination.

The high-energy prices and resultant conservation (lower thermostat setting, better insulation, etc.) have resulted in new patterns in consumption of natural gas. Although consumption per household, as a result of conservation, has fallen, several distribution companies have experienced that, on extra cold days, the conservation ethic disappears and additional gas is used which results in very high peak-day send outs.

Thus, many distribution companies that have maintained their annual space-heating load over the past few years (by adding more customers to compensate for conservation) are experiencing a disproportionately high needle peaking requirements. Cavern storage of natural gas provides singular sendout characteristics which suit such requirements, without the environmental, code compliance and gas compatibility problems, or feedstock supply and price uncertainty encountered by LNG or propane/air.

Over the past 40 years, cavern storage of LPG's, petrochemicals, such as ethylene and propylene, and other petroleum products has increased dramatically. In 1991, the Gas Processors Association (GPA) lists the total U.S. underground storage capacity for LPG's and related products of approximately 519 million barrels (82.5 million cubic meters) in 1,122 separate caverns. Of this total, 70 are hard rock caverns and the remaining 1,042 are caverns in salt deposits. However, along the eastern seaboard of the U.S. and the Pacific northwest, salt deposits are not available and therefore, storage in hard rocks is required.

Because of the limited demand and high cost, hard rock caverns have not been built in this country for a number of years. The storage of natural gas in mined caverns will be successful if it can be proven to be technically feasible given the geology of the targeted market area; and economically feasible if the cost of service can be justified based on needs of the market and the flexibility of operation to meet peak needs, that cavern storage can provide, compared to alternative storage methods if available. The latter would include LNG facilities that are being installed or investigated in many areas, and remote underground storage combined with pipeline transportation to the area.

LNG facilities are particularly costly and only provide for a single storage cycle per year, whereas cavern storage can be cycled a number of times depending on design criteria. The large number of salt cavern projects both in the producing and market areas in recent years have proven the desirability and cost effectiveness of such high delivery, multiple cycle capability. It is believed that mined cavern storage can provide these same advantages in those areas where the development of salt cavern storage is not possible. Since the last hard rock caverns were constructed, advanced mining techniques and modern rock mechanics technology have been introduced and perfected that have the potential to reduce the cost of constructing 
hard rock storage caverns. Also, the technology and equipment used to refrigerate natural gas is proven, and in a storage application, can significantly reduce the physical volume of space required to store a given quantity of gas. For example, refrigerating the gas to $-40^{\circ} \mathrm{F}$ would reduce the required space by $50 \%$, a significant potential savings in mining costs.

In this research project, PB-KBB merged advanced mining technologies and gas refrigeration techniques to develop conceptual designs and cost estimates to demonstrate the commercial potential of storage of refrigerated natural gas in hard rock caverns. The storage of refrigerated natural gas in hard rock mined caverns will be successful if:

- It can be demonstrated that the capabilities available fit the hourly, daily, weekly and seasonal gas load variations for both conventional gas markets and electric-generated plant markets.

- $\quad$ Costs of service for single- and multi-cycle storage with mined caverns are favorable compared to out-of-region storage/pipeline and LNG alternatives.

For this project, an in-house literature search was conducted to target regions which may require underground storage, but may not have either large salt deposits or suitable brine disposal facilities. The Gas Research Institute 1994 Topical Report entitled "Future Seasonal Natural Gas Loads and Gas Delivery Capacity Requirements in the Lower-48 United States" provided an indication of the combined peaking and market area gas storage needs by 2010 in areas primarily along the eastern seaboard of the U.S. and the Pacific Northwest, areas which have rock formations in which mined cavern storage can be installed near the point of use. The areas reviewed included New England, Mid-Atlantic (NY/NJ), South Atlantic (DL/MD/VA), South Atlantic (NC/SC/GA) and the Pacific Northwest. However, since 1994 there has been significant asset development activity in most of the regions which would temper or alter the conclusions of the 1994 study. Based on the review of the geological literature and the potential for storage, this project targeted the DL/MD/VA region for further study. 


\title{
Section 2
}

\section{LITERATURE SEARCH FOR SELECTING TARGET AREAS}

DOE has identified five regions, based on the Gas Research Institute 1994 Topical Report entitled "Future Seasonal Natural Gas Loads and Gas Delivery Capacity Requirements in the Lower-48 United States," that do not have favorable geological conditions for underground storage development. These regions are:

\author{
New England \\ Mid-Atlantic (NY/NJ) \\ South Atlantic (DL/MD/VA) \\ South Atlantic (NC/SC/GA) \\ Pacific Northwest (WA/OR)
}

Published literature and in-house databases relating to the geology of these regions were reviewed for the purpose of determining suitability of hard rocks for siting storage caverns, which could provide combined peaking and market area gas storage needs of these regions. Furthermore, since 1994 there has been significant asset development activity in most of the regions that might temperature or alter the conclusions of the 1994 study. Therefore, in-house databases developed since 1994 were reviewed to update each region's capacity situation.

The purpose of this study was to select one target area for the research study relating to refrigerated-mined cavern storage.

\section{General Requirements for Storage Sites}

The following are some of the general requirements for storage sites:

- $\quad$ Proximity to transportation systems, such as pipeline, that are to be used for bringing in or shipping out the stored gas to minimize the extent of new pipelines construction. This is of particular importance in areas where approval of new pipeline rights of way is often difficult to obtain.

- More advantageously, and especially for meeting the peaking needs, the storage space would be created near a marketing area, such as a metropolitan area or a strategically located point from which thickly populated areas may be served. Market centers, with their access to multiple pipeline interconnections and supplies, provide a natural platform for gas trading, risk management and opportunity for arbitrage. Storage in Market Center is a multi-purpose resource, such as to support short-term gas loans, gas balancing, and peaking services ("Natural Gas 1996 - Issues and Trends," Energy Information Administration, Dec. 1996). 
- $\quad$ Adequate electric power and water supply should be available for storage

- $\quad$ Construction site should be easily accessible

- $\quad$ Congested areas should be avoided, especially environmentally sensitive areas (i.e., natural, state, and local parks, monuments, reservoirs, etc., and areas zoned "residential")

- Suitability of rock for storage - All rock types must be tested locally for site suitability

(a) The cavern host rock should be as impervious and free of fractures as possible to minimize leakage.

(b) The rock should be strong enough requiring little or no artificial support of the cavern roof for the given dimensions. Stronger the rock type, the larger the size of the cavern that can be constructed.

(c) The rock should be uniform and should have little or no jointing, faults and other discontinuities such as shear zone. This impacts the strength of the rock, leakage potential and the dimensions of the underground openings.

(d) For economic reasons, the rock should be easy to excavate for the shafts and underground caverns.

(e) The rocks through which the shaft will pass should not be incompetent or be heavy waterbearing, since water control in shaft sinking would require stabilization techniques such as grouting, or freezing, which are expensive.

(f) Shale and siltstone have been most favorable types of sedimentary rocks because they are impervious, and relatively easy to excavate. However, these rocks require extensive artificial supports, such as roof bolts.

(g) Igneous and metamorphic rocks are also impervious, could form tight caverns and are strong enough to have self-supporting roofs of the caverns. Large size caverns can be constructed in these types of rocks.

- $\quad$ Availability of space nearby for disposal of the excavated material.

- $\quad$ Sufficient water table to maintain a positive hydrostatic head at the pressures used for storage.

\section{New England Region}

The following information is taken from a paper by Oswald Farquhar of the University of Massachusetts ("Favorable Bedrock Formations for Deep, Man-made Caverns in New England (USA)" - Rockstore 77). 
The principal rocks of New England belong to four time sequences - Precambrian, late Precambrian to Middle Ordovician, Silurian through Middle Devonian, and Late Paleozoic.

Farquhar considers about 90 formations as suitable for caverns; however, further data is still required to confirm site location. He considers half a dozen rock types as potentially favorable, viz., granite, gabbro, gneiss, massive schists, diorite and amphibolite. Granitic rocks are the most common, with uniaxial compressive strength varying from 1000 to $2500 \mathrm{~kg} / \mathrm{cm}^{2}$. They comprise about one-quarter of the whole region, one or more favorable units being located closest to most industrial and population centers where peak power need exists.

C. W. Wolfe of Boston University ("Underground Storage of Liquid Petroleum Hydrocarbons in the United States," Research and Coordinating Committee, Interstate Oil Compact Commission) believes that only the northeastern part of Massachusetts around Boston, containing the Cambridge formation is suitable for cavern location. The formations consist of Devonian or carboniferous siltstones, conglomerate tillite, lavas and tuffs.

Lloyd J. French of the State Development Commission of Connecticut believes that lack of suitable geological maps make it virtually impossible to locate and evaluate suitable structures.

The 1994 GRI study forecasted a new peaking market area storage need of 269 MMCFD and neew annual delivery or pipeline capacity needs of 1,130 MMCFD by the year 2010. Since the time of that study, approximately 978 MMCFD of pipeline expansion projects have been announced into the region, reducing the total net requirement to approximately 421 MMCFD. These include 90 MMCFD of expansion at DOMAC LNG, 510 MMCFD of new pipeline capacity in the form of the Maritimes and Northeast project, 200 MMCFD of Iroquois pipeline expansion, and 178 MMCFD of Portland Natural Gas Transmission capacity.

New market area, refrigerated hard rock peaking storage capacity into New England would compete with expansion LNG and opportunities to expand new and existing pipeline paths planned for the region. Assuming that the proposed projects detailed above are placed into service, the 2010 net requirement for new deliverability is reduced to a total of 421 MMCFD. Moreover, any incremental need is likely to require more pipeline capacity relative to peaking capacity, given the relatively low overall percentage of peaking/market area storage need to pipeline need as identified in the GRI study.

\section{$\underline{\text { Mid-Atlantic (NY/NJ) }}$}

\section{New York}

Storage in salt beds already exists, or is either undergoing construction, or is planned. Two projects are in operation.

Much of east central and western New York is underlain by shale beds, which could be suitable for mined 
storage. The Middle Devonian Hamilton shale beds are fine-grained, medium gray to black and calcareous in varying degrees and contain several limestone beds. The Tully limestone over most of the area is a uniform, thick bed of dense limestone, which would form a suitable roof for a mined shale cavity.

The following description for locating caverns in hard rock are taken from W. Lynn Kreidler, Senior Petroleum Geologist of New York State Science Service, report to Research and Coordinating Committee of Interstate Oil Compact Commission.

New York State has two main areas of hard rocks in which storage caverns are possible. One of the areas is the Adirondack Mountains or northeastern New York. The other area is the "Hudson Highlands." This is a section in southeastern New York, which takes in parts of Duchess, Putnam, Rockland, Orange and Westchester counties. The "Hudson Highlands" of Precambiran gneiss which extend from New England southward into New Jersey, and intersect the Hudson River in the area of West Point, NY. Other areas of outcrop of the Precambiran gneiss are along the east side of the Hudson River in Westchester County and extend to the south into Bronx County.

A mined storage cavity in the gneiss would be expensive compared to salt caverns, but the factor of nearness of these rocks to the metropolitan consumer area would serve to counterbalance the construction costs. The cavern must be sealed to prevent leakage through cracks or fissure caused by minor faulting or shearing.

New Jersey

New Jersey has hundreds of steel tanks storing hydrocarbons all along the navigable waters of the Delaware and Arthur kills. This type of storage on the ground surface is expensive and is unsafe, and thus, there would be a greater need for large, economic and safe underground storage in the area.

The following information on probable rock deposit for potential storage site is taken from the report of Meredith Johnson, State Geologist of New Jersey to the Interstate Oil Compact Commission.

Limestone is a relatively strong rock, and a cavern located in this rock will require little or no roof support, provided the cavern is located in an area not heavily faulted. For the Metropolitan New York area, the nearest limestone is at Peapack, some 25 miles from Newark. The Phillipsburg-Easton area is also underlain by limestone.

Some caverns have been constructed in shale. However, control measures must be undertaken in order to prevent sloughing of the shale around the opening. Much of the metropolitan area surrounding Paterson, passaic, Newark, Elizabeth and New Brunswick is underlain by Triassic shale and sandstone. Triassic sandstones are not very porous, their permeability being due to the fracture systems, which traverse them, just as with shale. Structurally sandstones are stronger than shales.

Part of the Martinsburg argillaceous rock has been metamorphosed to slate. It is stronger than shale and 
a cavern, excavated in this material, would require little support. The slatey portion of the Martinsburg is found within two beds of rock extending northeastward form Delaware and Slateford on the Delaware River.

Granite rocks are very strong and a cavern excavated in this type of rock will stay open for a very long time and would require very little, if any artificial support. However, these rocks have been subjected to regional stresses, which have developed a number of crisscross fractures. Regions of heavy fracturing and faulting must be avoided for storage caverns. Many sites in the Highlands could be suitable where the unweathered crystalline rock of this type is relatively impermeable.

At Trenton there is a gabbro rock which is dense, impervious and very strong. A storage cavern in it will not require any support. Much more widespread in their occurrence are the dikes and sills of diabase, and flows of basalt, - all of Triassic age - which are found near Lambertville, on the Delaware, and in many a hill and ridge between the Delaware and the Hudson. The largest of these is the palisades - Rock Hill Sill which could provide the storage needs of the Bergen Hill - New York area. The full thickness of the Palisades sill is 900 to $1000 \mathrm{ft}$.

The $1994 \mathrm{GRI}$ study forecasted a new peaking/market area storage need of approximately 1.4 BCFD and a new pipeline capacity need of approximately 1.1 BDFC by 2010 . However, since that time, this region has been the focus of the majority of new asset development activity in the U.S. At present, there are at least four new pipeline capacity projects planned for the region, including Market Link (Independence, Niagara Expansion) at BCFD, Spectrum/Exclsior at 500 MMCFD, Eastern Express at 500 MMCFD, and Millenium Pipeline at 650 MMCFD. The net effect of these 2.65 BCFD of projects is to effectively reduce the regional need to zero, or slightly negative as depicted in Table 2-2.

While it is unlikely that all of these projects will be successfully developed, their presence and sheer magnitude of number tends to place even more pressure on any new market area storage proposals that might come forward for the region.

\section{$\underline{\text { South Atlantic (DL/MD/VA) }}$}

\section{Delaware}

Not much information is available regarding the rock type suitable for cavern location. John H. Groot, State Geologist, has recommended further investigation by core test hole drilling and pressure testing, especially in the Cockeyville marble.

\section{Maryland}

The following geological information is taken from the publication entitled "Preliminary Design Study of Underground Pumped Hydro and Compressed-Air Energy Storage in Hard Rock," Volume 5, EM-1589, Vol. 5, Research Project 1081-1 DOE/ET 5047-5. (See Figure 2-1) 
The State is divided into five distinct physiographic provinces ranging from east to west, these being the Coastal Plain, Piedmont, Blue Ridge, Valley and Ridge and Appalachian Plateau.

The Coast Plain consists of porous and water-bearing sedimentary rocks, and is not considered to be a viable site because of difficulty of interpretation beneath the thick coastal sediments. Similarly, the Valley and Ridge and Appalachian Plateau are not satisfactory because they are sedimentary rocks, have low compressive strength, have high permeability, are folded and faulted. 


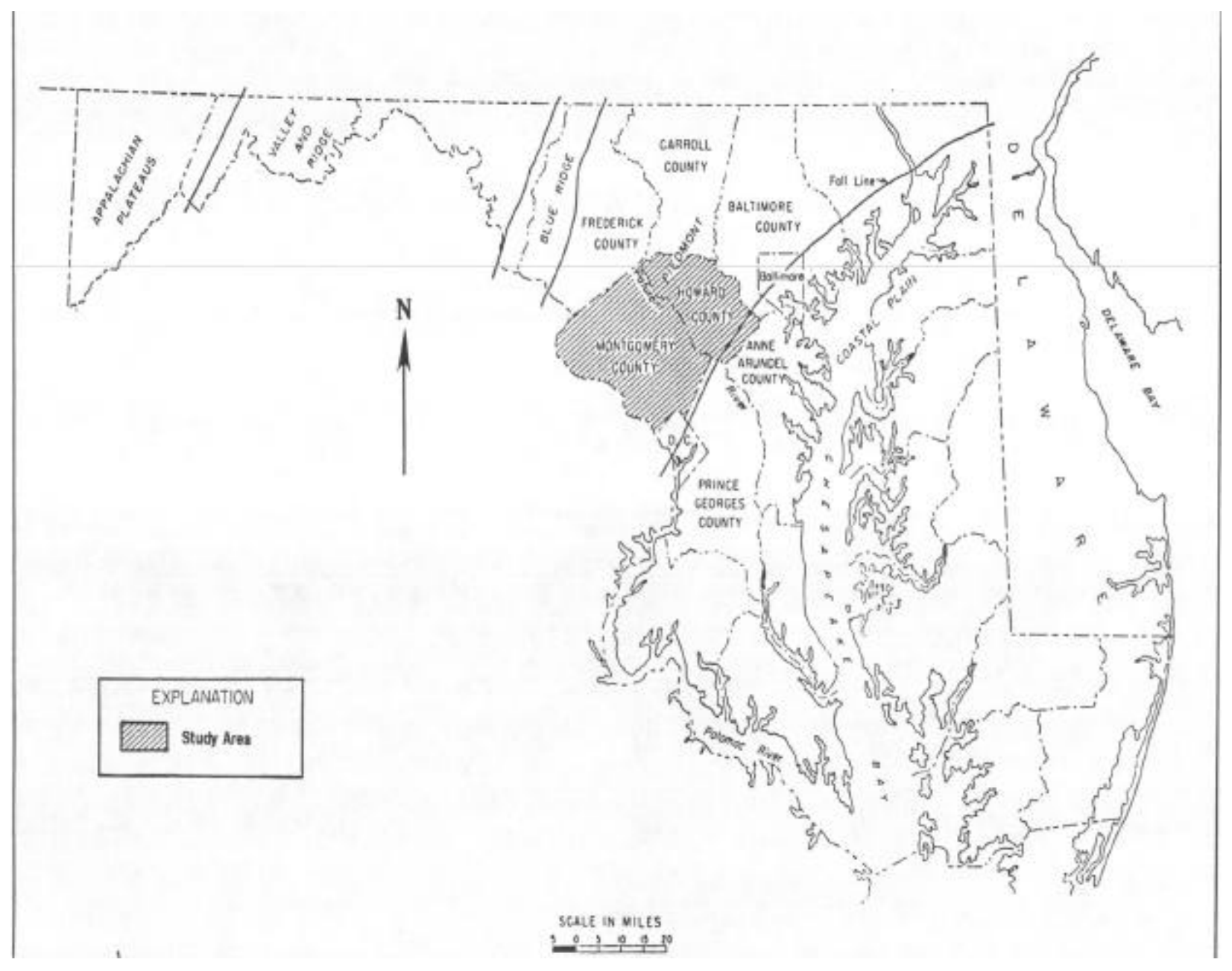

FIGURE 2-1. Physiographic Map of Maryland 
The Piedmont extends westward from the Coastal Plain to the Blue Ridge, a distance of approximately 40 miles. The stratigraphic sequence of the Maryland Piedmont ranges from the crystalline rocks of Precambrian basement to Triassic sedimentary rocks. The Precambrian basement rocks of the Baltimore Gneiss complex are overlain by the metamorphic rocks of the Glenarm series, a series of late Precambrian schists, gneisses, marbles, etc. These rocks are in turn intruded by a series of Paleozoic age igneous intrusive ranging from granites to basalt.

The Blue Ridge Province extends from the Catocin Mountains on the east to South Mountain on the west. Structurally, the Blue Ridge is a predominant uplifted anticline. Its core consists of granodiorite and biotite granite gneisses.

The more favorable rock types that fall within the desirable ranges of physical and mechanical characteristics are the younger intact granites and high-grade metamorphic rocks such as gabbros, granodiorites and gneisses. Many of these rocks are massive, isotropic in nature and are of high quality with excellent mechanical and physical properties for sustaining large underground openings.

The seismicity of Maryland was found to be extremely low. There are no known active faults within the area.

\section{Peaking Needs of Delaware/Maryland/Virginia}

The 1994 GRI study forecasted a need for 450 MMCFD of new peaking/market area storage capacity and 803 MMCFD of new pipeline capacity by 2010 .

While there are no relatively modest pipeline expansions for the area on the books by Columbia Gas Transmission and CNG totaling 272 MMCFD, there appears to be little or no efforts underway to develop new peaking/market area storage capacity in the region. However, it is important to remember the possibility that an overbuilt downstream market, such as New York/New Jersey would be able to offer a number of peaking services to upstream markets via displacement. This would tend to de-emphasize the need for new peaking storage into this region in favor of new pipeline capacity needed to meet the annual delivery capacity requirement.

New market area and peaking storage would tend to compete with services from new pipelines downstream offered back to the region via displacement. Once these projects are built into the New York and New Jersey region to meet annual or baseload needs, the incremental cost of redelivering the services back upstream are very low.

Virginia

Very little information is available on the suitable rock type for storage cavern location.

South Atlantic (NC/SC/GA)

North Carolina 
The Piedmont and Mountain Provinces of North Carolina are underlain with igneous and metamorphosed rocks. However, the suitability of any rock type for cavern location has not been determined due to the lack of field investigations.

\section{$\underline{\text { South Carolina }}$}

No features in the State have been identified as suitable for storage caverns.

\section{$\underline{\text { Georgia }}$}

Storage caverns could be located in the crystalline formations, such as Stone Mountain, near Atlanta. However, more detailed information is lacking.

\section{Peaking Needs of North Carolina/South Carolina/Georgia}

The 1994 GRI study predicted a peaking market area storage need of approximately 1.2 BCFD and new annual delivery capacity needs of approximately 700 MMCFD.

Two significant LNG projects, Pine Needle and Etowah, have been announced for the region along with a number of relatively small expansions/additions to the Transco delivery system. Pipe Needle, located in North Carolina, represents an incremental 400 MMCFD of vaporization capacity, Etowah, a recently announced project proposed for Polk County, Georgia would have a design capability of 450 MMCFD. The three Transco expansions collectively account for 347 MMCFD of incremental capacity. The net effect is to reduce the overall capacity need of the region as outlined in the GRI study to about 681 MMCFD. It is important to note however that new LNG projects can often encounter high levels of resistance both with respect to permitting and customer acceptance and this should be accounted for making an assessment of the likelihood of success of such proposals. Overall, this area appears to offer significant promise for a new peaking/market area storage facility.

\section{Pacific Northwest (WA/OR)}

\section{Washington}

Storage caverns could be located in the granitic rock areas close to the transportation facilities. These areas are north of Spokane. However, not much information is available on faults, fissure or cracks in these rocks. Shale is another possibility with the western part of the state.

\section{$\underline{\text { Oregon }}$}

No information is available on the suitability of any rock for storage cavern locations.

\section{Peaking Needs of Washington/Oregon/ldaho}

The GRI study called for 401 MMCFD of new market area/peaking storage capacity and 366 MMCFD of new 
pipeline capacity by 2010 .

Various expansion projects have been announced that could largely satisfy the needs of this region. Northwest Pipeline is planning an expansion of its system through the Columbia River Gorge to serve needs west of the Cascades (approximately 250 MMCFD). Expansions are also proposed for Jackson Prairie and Mist Storage (WA and OR, respectively) totaling 294 MMCFD. Finally, an LNG project sized at 250 MMCFD vaporization capacity is proposed for the Sumas, WA area. This project would compete with the Northwest Pipeline expansion project and/or the 215 MMCFD BC Gas Southern Crossing project proposed for southern British Columbia. The total deliverability of these projects, excluding Southern Crossing, is 694 MMCFD, reducing the net need for new capacity to approximately 70 MMCFD.

\section{$\underline{\text { CONCLUSIONS }}$}

Based on the 1994 Report of Gas Records Institute (Table 2-1) it would appear that the most desirable region for further study should be the Mid-Atlantic (NY/NJ) area which has the highest peaking needs of the five regions. On the basis of that study and the geological information, the optimum site should be the West Point area in New York which is close to the Columbia Gas and the Algonquin Transmission Lines, serving many metropolitan areas.

The 1994 GRI study takes a comprehensive look at need for pipeline capacity and peaking/market area storage by region through the year 2010. Since its publication in 1994, a number of new proposals for expanding existing facilities and/or building new facilities have come forward.

The New York/New Jersey market is the most competition laden in terms of new proposals. New England shows a need for capacity, but this is likely to be dominated by a need for pipeline or year-round capacity relative to peaking capacity. Several new proposals for the Pacific Northwest region reduce the net need significantly. Either South Atlantic region would appear to be a good candidate for new projects, as evidenced by the recent announcement and development of two new LNG proposals for the NC/SC/GA area (Table 2-2).

For the South Atlantic (DL/MD/VA) region, the Piedmont rocks of Maryland are the most suitable rock types for location of a storage cavern. Ellicott City Granodiorites have sufficient extent, are isotropic in nature, are of high quality with excellent mechanical and physical properties for storage caverns. The Ellicott City area is close to the Transcontinental Gas Pipeline, Columbia Gas Transmission Lines, Fredrick Gas Col. Line, Washington Gas and Light CO., and the CNG Transmission. It will serve both Baltimore and Washington D.C. area. This site is therefore recommended for further study for the location of a refrigerated mined gas storage cavern. 
Table 2-1

Summary of 2010 Peaking and Market Area Gas Storage Requirements of Selected Regions of the US (1994)

\begin{tabular}{|l|c|}
\multicolumn{1}{|c|}{ Region } & $\begin{array}{c}\text { Peaking/Market Area Storage Needs } \\
\text { (MMCF/day) }\end{array}$ \\
\hline New England & 269 \\
\hline Mid Atlantic (NY/NJ) & 1,352 \\
\hline South Atlantic (DL/MD/VA) & 450 \\
\hline South Atlantic (NC/SC/GA) & 1,190 \\
\hline Pacific Northwest (WA/OR) & 401 \\
\hline
\end{tabular}

Source: GRI Topical Report - Future Seasonal Natural Gas Loads and Gas Delivery Capacity Requirements in the Lower 48 United States (1/94)

Table 2-2

1994 Edition of the Baseline Projection

\begin{tabular}{|l|c|c|c|c|}
\hline & $\begin{array}{c}\text { New } \\
\text { Peaking/Market } \\
\text { Area Storage } \\
\text { Needs, 2010 (1) } \\
\text { (MMCFD) }\end{array}$ & $\begin{array}{c}\text { New Annual } \\
\text { Delivery Capacity } \\
\text { Needs, 2010 } \\
\text { (MMCFD) }\end{array}$ & $\begin{array}{c}\text { Planned or } \\
\text { Completed } \\
\text { Pipeline \& } \\
\text { Expansion } \\
\text { Projects, 1994- } \\
1997 \text { (2) } \\
\text { (MMCFD) }\end{array}$ & $\begin{array}{c}\text { Net Requirement } \\
\text { (MMCFD) }\end{array}$ \\
\hline $\begin{array}{l}\text { New England } \\
\text { (ME/VT/NH/MA/CT/RI) }\end{array}$ & 269 & 1,130 & 978 & 421 \\
\hline Mid Atlantic (NY/NJ) & 1,412 & 1,158 & 2,650 & 981 \\
\hline $\begin{array}{l}\text { South Atlantic } \\
\text { (DL/MD/VA) }\end{array}$ & 450 & 803 & 272 & 681 \\
\hline $\begin{array}{l}\text { South Atlantic } \\
\text { (NC/SC/GA) }\end{array}$ & 1,190 & 688 & 11,197 & 73 \\
\hline $\begin{array}{l}\text { Pacific Northwest } \\
\text { (WA/OR/ID) }\end{array}$ & 401 & 366 & 695 & 980 \\
\hline
\end{tabular}

Note: (1) Assumed "high bound" on peak shaving

(2) DOE/EIA Natural Gas 1996 Issues and Trends (December, 1995) and in-house data. 


\section{Section 3}

\section{SELECTED PROCESS AND CAVERN DESIGN PARAMETERS}

The process design parameters selected for this study are as follows:

$\begin{array}{ll}\text { Maximum gas pressures: } & 1,080-1,250 \text { psi } \\ \text { Minimum gas pressures: } & 250 \mathrm{psig} \text { and } 100 \mathrm{psig} \\ \text { Operating temperatures: } & -20^{\circ} \mathrm{F}, 0^{\circ} \mathrm{F} \text { and }+20^{\circ} \mathrm{F} \\ \text { Cavern depth: } & 2,500-3,000 \text { feet } \\ \text { Operating pressure gradient: } & 0.433 \mathrm{psi} / \mathrm{ft} \\ \text { Working gas volume: } & 5 \text { Billion Standard Cubic Feet (BSCF) } \\ \text { Gas withdrawal rate: } & 250 \text { Million Standard Cubic Feet per Day (MMSCFD) } \\ \text { Gas injection rate: } & 250 \text { MMscfd } \\ \text { Incoming gas temperature: } & 50^{\circ} \mathrm{F} \text { to } 80^{\circ} \mathrm{F} \\ \text { Dehydration: } & \text { Water content reduction from } 7 \mathrm{lbm} / \mathrm{MMscf} \text { to } \\ & <1 \mathrm{lbm} / \mathrm{MMscf} \text { prior to chilling (TEG or Mole Sieve- } \\ & \text { type) } \\ \text { Production casing diameter: } & 20 \text { inch OD (0.500" wall) }\end{array}$

The design parameters were selected based on cavern operating experience as well as an understanding of the limitations of the geology with respect to cavern depth. Industry experience with mining operations in hard rock would suggest limiting the cavern depth to approximately 2,500 - 3,000 feet. The maximum operating pressure of the cavern is determined by specifying a maximum pressure gradient equal to 95 percent of the hydrostatic head of water, $0.433 \mathrm{psi} / \mathrm{ft}$.

Generally, crack or fissures occur naturally in rock. Water is usually found in these cracks or fissures. Natural gas stored underground may be prevented from leaking from a hard rock cavern via the cracks or fissures by storing the gas at no more than a $0.433 \mathrm{psi} / \mathrm{ft}$ gradient which is equal to a pressure of approximately 1,250 psig for the cavern at the selected depth of 3,000 feet below ground.

A higher maximum cavern pressure would reduce the required cavern size for a given mass of stored gas. In theory, increasing the cavern depth would allow for a higher gas storage pressure, allowing for a smaller cavern; however, the cost of cavern construction at a depth deeper than 3,000 feet would likely be prohibitive. Another means for increasing the mass of stored gas, without increasing the storage pressure, is lowering the gas temperature and maintaining the lower temperature in the cavern. The lower temperature results in a more favorable gas compressibility, i.e., the gas is more efficiently packed.

Three temperatures were considered in the analysis: $+20^{\circ} \mathrm{F}, 0^{\circ} \mathrm{F}$ and $-20^{\circ} \mathrm{F}$. The minimum temperature, $20^{\circ} \mathrm{F}$, was selected since most commonly-available carbon steel piping materials may be safely subjected 
to the required maximum operating pressure and external stresses. At lower temperatures, special metallurgy may be required. At any given pressure in the operating pressure range of the cavern, the mass of gas contained is greatest at the lowest of the three operating temperatures.

Although the mass of stored gas is greatest for any given pressure at the minimum operating temperature, the amount of heat influx into the cavern is greater at lower temperatures than at higher temperatures. Maintaining a $-20^{\circ} \mathrm{F}$ cavern temperature will require more refrigeration than at $+20^{\circ} \mathrm{F}$; therefore, there is an economic trade-off. A larger, unrefrigerated cavern will have higher construction costs than a smaller, refrigerated cavern. A refrigerated cavern will require refrigeration equipment and will have recurring refrigeration energy and maintenance costs.

Two minimum, or "cushion gas" pressures were considered: 100 psig and 250 psig. Maintaining a minimum cushion of gas in the cavern may reduce the influx of subsurface water via cracks and fissures in the surrounding rock. A higher cushion gas pressure may also eliminate the need for recompressing the gas as it is withdrawn. Also, a higher minimum gas pressure results in a higher minimum gas density and greater storage well deliverability. Since the storage well must deliver 250 MMSCFD, a higher minimum gas pressure will ensure adequate well deliverability as the cavern pressure approaches a minimum.

A lower minimum cavern pressure results in a smaller cavern size requirement for a given mass of working gas. "Working gas" is defined as the useable volume of stored gas or the total stored gas volume, minus the "cushion gas". A lower minimum cavern pressure means less cushion gas and a lower overall "total" gas volume (total gas volume $=$ working gas volume + cushion gas volume), for a given working gas volume. Both the lower and higher minimum cavern pressures will likely result in required gas recompression. Typical transmission pipelines operate at pressures greater than 250 psig. Since compressors must be used for gas injection into the cavern, the same compressors may be used for gas recompression requirements during withdrawal.

A gas injection rate of $250 \mathrm{MMscfd}$ was selected, based on a 5 BSCF working gas volume and a 20-day cavern fill rate. The 20-day cavern fill rate is common throughout the gas storage industry. A 250 MMscfd cavern withdrawal rate was selected. The fill and withdrawal rates are maximums and will be used for determining compressor and refrigeration equipment sizing among other things. The temperature of the incoming gas is assumed as ranging from 60 to $80^{\circ} \mathrm{F}$ which is the commonly-found temperature range of gas after being transported long distances via underground pipelines.

Due to the low temperatures anticipated during storage operations, the gas obtained from the gas transmission pipelines may contain too much water. Pipeline industry standards require a water content of not more than $7 \mathrm{lbm} / \mathrm{MMscf}$ of gas. This water content is acceptable as long as the gas temperature remains above 40 to $50^{\circ} \mathrm{F}$. However, since the gas may be cooled to as low as minus $20^{\circ} \mathrm{F}$, additional dehydration will be required prior to refrigerating the incoming gas. 
Upon withdrawal from the cavern, the water content of the gas is expected to be sufficiently low as to not require dehydration.

The production casing diameter (OD) is assumed to be 20 inches. This diameter should prove sufficiently large so as not to result in excessive pressure losses, with a minimum cavern pressure of $250 \mathrm{psig}$ at a maximum temperature of $20^{\circ} \mathrm{F}$.

\section{CAVERN DESIGN PARAMETERS}

I. Number and Type of Shafts

Shaft size and the required number of shafts will be determined based on the hoisting rates to complete the cavern as quickly as possible and provide adequate ventilation. The major constraint would be how fast the broken material from the cavern can be hoisted to the shafts.

II. Shaft Depth

Shaft depths of 2,000, 2,500 and 3,000 ft will be considered with the design for the purpose of cost optimization. The hydrostatic pressure at 3,000 ft depth will be about $1300 \mathrm{psi}$. The lithostatic pressure at this depth will be approximately 3000 psi. The shaft lining will be designed for these loads.

III. Shaft Location

The shafts will be located within a shaft pillar, approximately in the middle of the cavern.

IV. $\quad$ Cavern Size

The cavern will be sized to contain 5 billion SCF of working gas volume a 777 MMSCF of cushion gas at $250 \mathrm{psig}$ and $-20^{\circ} \mathrm{F}$. At a temperature of $-20^{\circ} \mathrm{F}$ and a minimum gas pressure of $250 \mathrm{psig}$, the total cavern volume will be approximately 37 million cubic feet.

V. Ventilation

A ventilation current of $300,000 \mathrm{cfm}$ will be provided for the health and safety of the personnel. Initially, a mine fan with tubing will provide the air. The rooms should be connected by cross-cuts to reduce frictional losses in tubing.

VI. Ground Control

The need for ground control measures will be determined in a rock mechanics study of the strata. Need for rock-bolt pattern will be studied and an optimum design proposed. The need for shotcrete around the cavern for gas storage purposes will also be investigated in the rock mechanics study. 
VII. Disposal of Excavated Material

Surface design will include a pit to dispose of excavated material from the shafts and cavern, until removed from the site.

VIII. Suitable Rock Types

(a) The cavern host rock should be as impervious and free of fractures as possible to minimize leakage.

(b) The rock should be strong enough requiring little or no artificial support of the cavern roof for the given dimensions. Stronger the rock type, the larger the size of the cavern that can be constructed.

(c) The rock should be uniform and should have little or no jointing, faults and other discontinuities such as shear zone. This impacts the strength of the rock, leakage potential and the dimensions of the underground openings.

(d) For economic reasons, the rock should be easy to excavate for the shafts and underground caverns.

(e) The rocks through which the shaft will pass should not be incompetent or be heavy, waterbearing, since water control in shaft sinking would require stabilization techniques such as grouting, or freezing, which are expensive. 


\section{Section 4}

\section{CHILLING COMPRESSED NATURAL GAS TO}

MINIMIZE STORAGE SPACE

\section{BASIC PRINCIPLE}

The compressibility factor of natural gas, and the resultant gas density, is a function of temperature and pressure. When the temperature of natural gas is decreased form normal ambient temperatures, the compressibility factor decreases and the density of the gas increases. At a given temperature, as gas pressure increases, the compressibility factor reaches a minimum value, and then increases with additional pressure. This is shown in Figure 4-1. Figure 4-2 shows the relationship of gas volume to cavern pressure at various storage temperatures, for a fixed cavern special volume. These relationships of volume, temperature, pressure and compressibility are based on the General Gas Law and Charles/Boyles Law:

General Gas Law

$$
\begin{array}{r}
P V=\text { ZNRT } \\
D=1 / V=P / \text { ZNRT }
\end{array}
$$

Where:

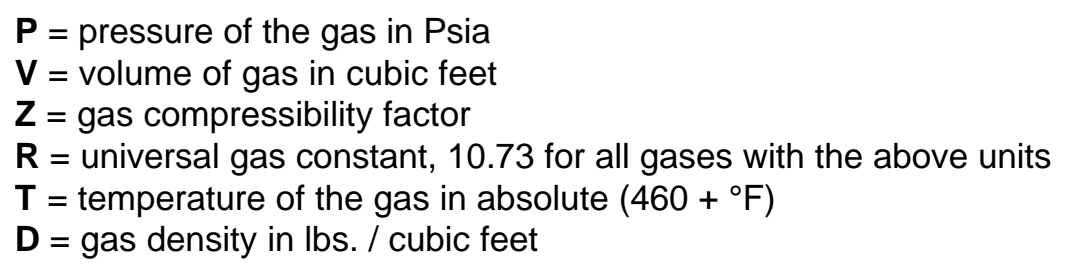

Charles Law

$$
\mathbf{P}_{\mathrm{sc}} \mathbf{V}_{\mathrm{sc}} / \mathbf{T}_{\mathrm{sc}} \mathbf{Z}_{\mathrm{sc}}=\mathbf{P}_{\text {cavern }} \mathbf{V}_{\text {cavern }} / \mathbf{T}_{\text {cavern }} \mathbf{Z}_{\text {cavern }}
$$

Where:

$$
\begin{aligned}
& \mathbf{P}_{\text {sc }}=\text { pressure at standard conditions, psia } \\
& \mathbf{P}_{\text {cavern }}=\text { pressure in the cavern, psia } \\
& \mathbf{V}_{\text {sc }}=\text { volume, cubic feet at standard conditions } \\
& \mathbf{V}_{\text {cavern }}=\text { volume of the cavern in cubic feet } \\
& \mathbf{Z}_{\text {cavern }}=\text { the gas compressibility factor in the cavern at cavern pressure } \\
& \mathbf{Z}_{\text {sc }}=\text { the gas compressibility factor at standard conditions } \\
& \mathbf{T}_{\text {sc }}=\text { temperature, absolute, }\left(460+{ }^{\circ} \mathrm{F}\right) \text { at standard conditions } \\
& \mathbf{T}_{\text {cavern }}=\text { temperature, absolute in the cavern }
\end{aligned}
$$

Rearranging terms to solve for the amount of natural gas in cubic feet at standard conditions, (14.73 psi, and 


\section{Z FACTOR VS PRESSURE}

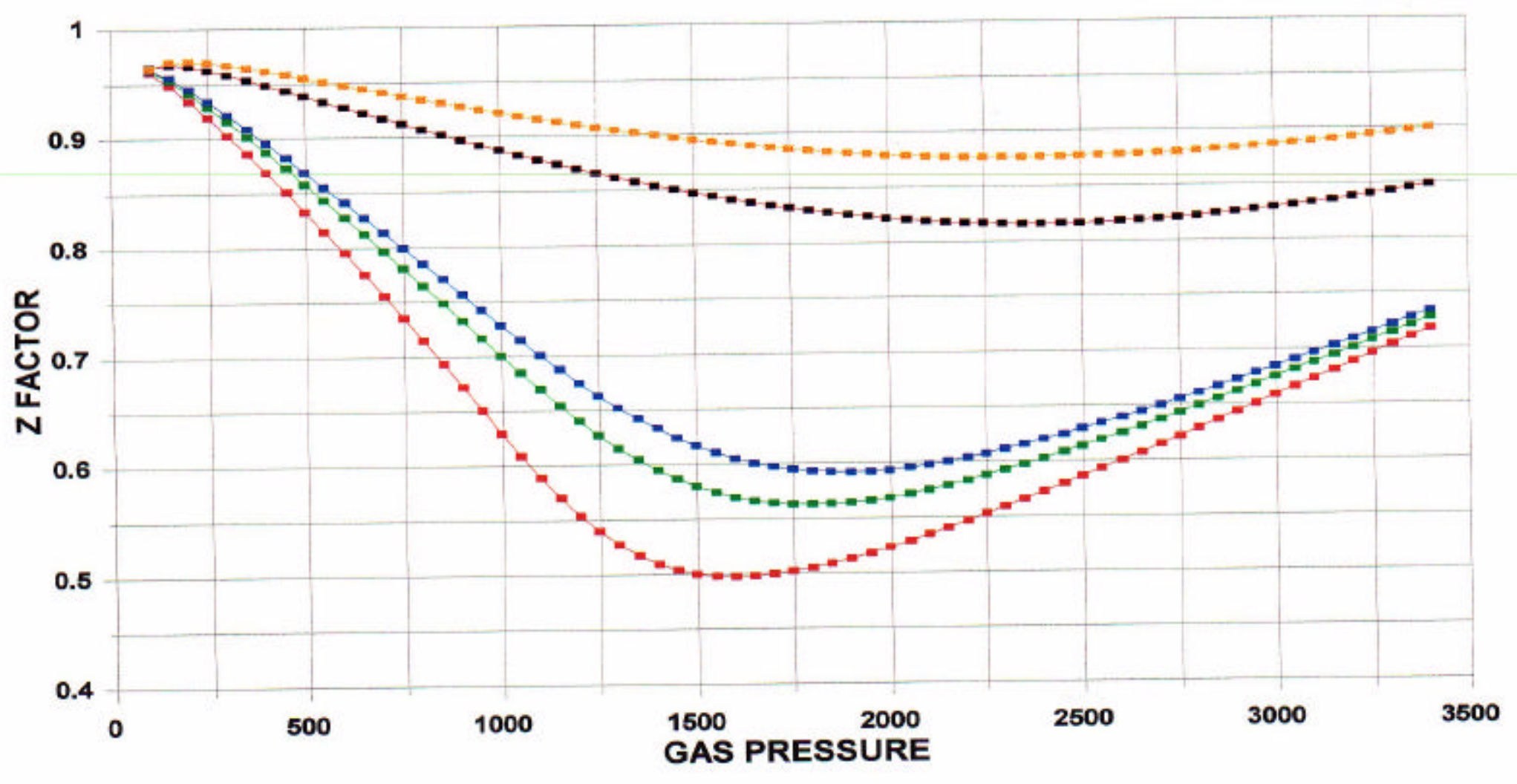

$\because-40 \mathrm{~F}=-20 \mathrm{~F}=-10 \mathrm{~F} \longrightarrow 100 \mathrm{~F}=150 \mathrm{~F}$

Figure 4-1 Graph of Z Factor Vs Pressure 


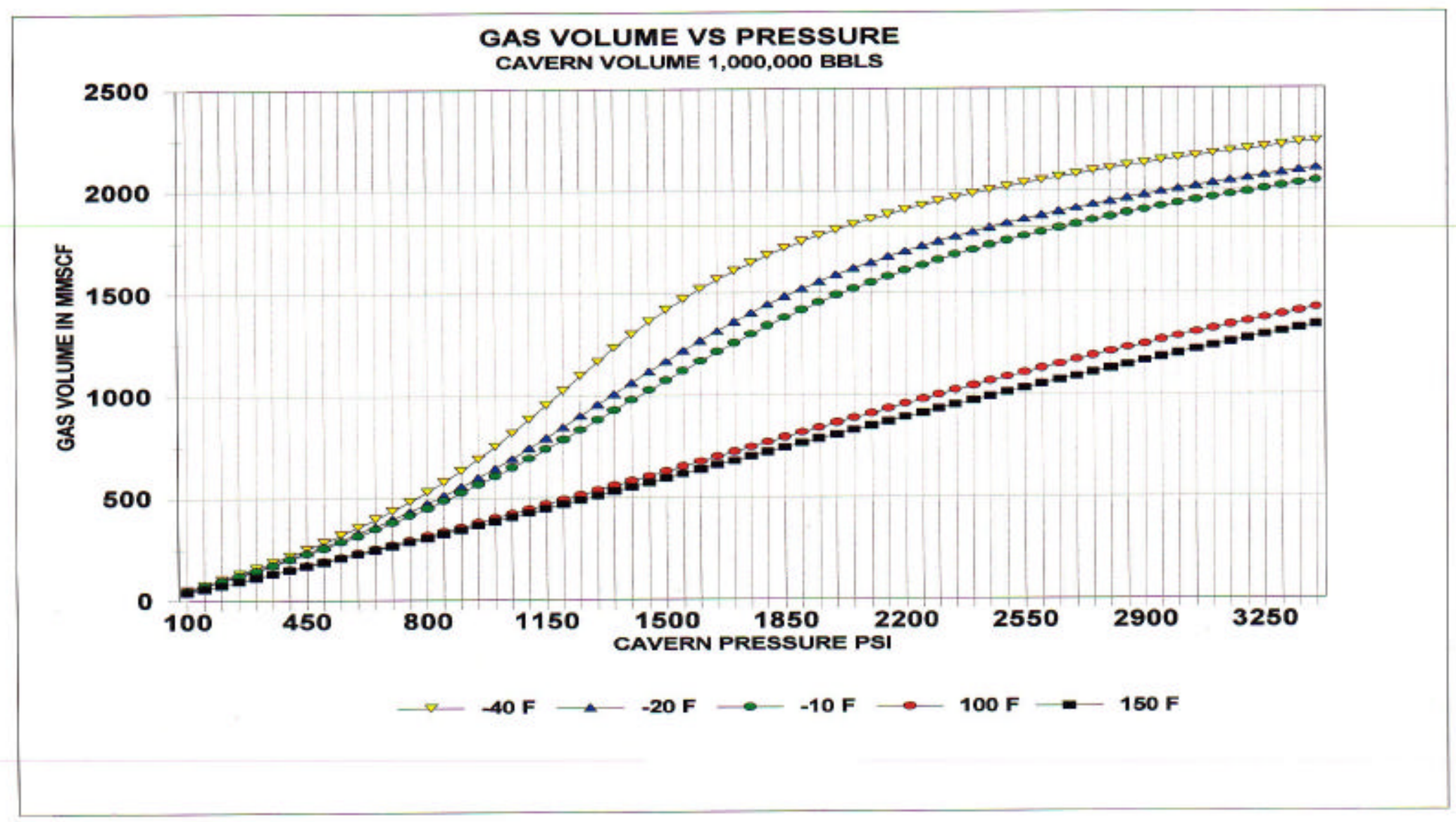

Figure 4-2 Graph of Gas Volume Vs Pressure 
$\left.60^{\circ} \mathrm{F}\right)$.

$$
\left.\mathbf{V}_{\mathrm{sc}}=\left(\mathbf{P}_{\text {cavern }} \mathbf{V}_{\text {cavern }} / \mathbf{T}_{\text {cavern }} \mathbf{Z}_{\text {cavern }}\right) * \mathbf{Z}_{\mathrm{sc}} \mathbf{T}_{\mathrm{sc}} / \mathbf{P}_{\mathrm{sc}}\right)
$$

Referring to the above equation for $\mathbf{V}_{\mathbf{s c}}$ cubic feet of gas stored, the amount of natural gas that can be stored in a given space increases as the temperature and compressibility factor decreases. Or, to store a given amount of gas, at a given pressure, the space (cavern volume) required decreases as the temperature and compressibility decreases.

Assuming that the cavern gas temperature is $100^{\circ} \mathrm{F}$, the cavern volume is $1,000,000$ barrels, and the pressure in the cavern is 1,500 psia, the volume of gas at standard conditions is as follows:

$\mathbf{V}_{\mathrm{sc}}=\left(1,500 \mathrm{psia} * 1,000 \mathrm{bbl} * 5.6146 \mathrm{ft}^{3} / \mathrm{bbl} * 1.0 * 520\right) /(560 * 0.84 * 14.73)$ $=632,038.3$ cubic feet

Based upon the above sample calculations, the amount of gas that can be stored in a 1,000,000-barrel cavern at $-20^{\circ} \mathrm{F}$ is $1,165,010.95 / 632,038.3$ or 1.843 times as much as can be stored at $100^{\circ} \mathrm{F}$, or the cavern volume could be reduced to $1,000,000 \mathrm{bbl} / 1.843=542,593.6 \mathrm{bbl}$ to store $632,038.3$ cubic feet of gas.

Based upon these preliminary calculations, we evaluated the costs of developing a facility for the storage of chilled compressed natural gas utilizing conventional gas processing and refrigeration equipment along with a conventionally mined storage cavern in a hard rock formation. 


\section{Section 5}

\section{PROCESS CONCEPTUAL DESIGN}

Efficient storage of gas in underground caverns requires process equipment which properly conditions the gas beforehand. (See Process Flow Drawing 861-MD-001.) The gas, to be stored, will likely be drawn from a large natural gas transmission line (trunkline) at a pressure, which may be too low for efficient storage in an underground cavern. The trunkline pressure may vary from 400 to 600 psig during the heating season to as high as $1,300 \mathrm{psig}$ during the summer months. The storage cavern requires gas from $650 \mathrm{psig}$ to 1,250 psig, depending upon the depth of the cavern, (from 1500 to 3,000 feet).

In the case of a cavern mined in rock, such as that being considered in this study, the maximum operating pressure is based on cavern depths of 1,500, 2,000, 2,500 and 3,000 feet. Therefore, the maximum cavern pressures are limited to $650,866,1,083$ and 1,250 psig, based on the hydrostatic head of water at the respective depths.

Since the gas in the trunkline may be at a pressure as low as 400 psig, the gas will have to be compressed in order to fill the cavern. The gas compression will be achieved by at least one, and likely several, gas compressors operating in parallel. The compressors may be driven by electric motors, gas turbines, or piston engines.

\section{PROCESS DESCRIPTION}

\section{Measurement}

The process begins by drawing pipeline-quality natural gas from one or more natural gas transmission lines, which may border the facility. The gas is first measured with custody transfer-type orifice meters, which are completely automated and can transmit measurement data via telephone, microwave system and satellite. The meter skid consists of four 12-inch meter tubes along with a climate-controlled instrument building. The skid is self-contained and requires a minimal amount of human intervention. Gas flow to the meter skid is controlled by a switching valve skid, which directs gas flow, depending on whether gas is being injected into the cavern or withdrawn.

\section{Compression}

Since the incoming gas is expected to be at pressures as low as 400 to 600 psig, the gas must be compressed in order to be stored in the cavern at 1,250 psig. In this particular study, two Solar Turbines (Caterpillar) C406 centrifugal compressors, each driven by Mars 90 gas turbines, were used for a total horsepower capability of over 20,000 HP. The maximum requirements occur during injection into the cavern depending upon the depth of the cavern. The maximum horsepower requirement during injection ranges from approximately 4,500 for the 1,500-foot depth cavern, to 17,000 HP for the 3,000-foot depth cavern. To compress 250 MMscfd from 350 psig to the 1125 psig required for storage will require $16,900 \mathrm{HP}$. 
These compressors will also be used during cavern withdrawal whenever the cavern pressure is lower than the delivery pressure at one or more transmission pipeline connections. A maximum flow rate of 250 MMscfd will occur during gas withdrawal from the cavern. At this flow rate, approximately 15,000 HP (maximum) of recompression would be required, assuming a 250 psig minimum cavern pressure (225 psig at the compressor suction) and a 600 psig maximum transmission pipeline pressure (650 psig compressor discharge pressure).

Each compressor/turbine unit is fully automated and is fueled with pipeline-quality natural gas. The units are housed in a sound-deadened, insulated building.

Before entering each of the two compressors, the incoming gas passes through two vertical separators, which scrub the gas of any liquids. The gas compressors are designed to compress gas and cannot tolerate any liquids.

Once the gas stream is compressed, it is cooled by fin-fan air coolers. At the higher pressures, liquids, such as water and heavy hydrocarbons, may condense. These liquids can harm the molecular sieve material used for drying the gas stream, prior to being chilled; therefore, two vertical separators are placed downstream of the compressor aftercooler.

\section{Dehydration}

The gas taken from transmission pipelines is conditioned for typical pipeline operating conditions; however, the gas is not likely to be sufficiently conditioned for cold storage operations. In general, pipeline-quality natural gas contains too much water for the expected storage temperature of minus (-) $20^{\circ} \mathrm{F}$ or lower. Too high of a water content in the gas may result in the formation of methane hydrates, a hybrid crystalline structure of water and methane molecules. The methane hydrates ("hydrates") are stable at high pressures (500-1000 psig and higher) and temperatures from about $60^{\circ} \mathrm{F}$ and below.

Prevention of methane hydrate formation is achieved by removing a quantity of water sufficient for the anticipated storage temperature. The proposed method for water removal prior to storage in the mine is by physical absorption of the water using molecular sieve desiccant. Molecular sieve is an engineered aluminum oxide (alumina) pellet, which efficiently attracts and holds on to water molecules. Water-laden gas passes through a pressure vessel containing a bed of molecular sieve pellets. The gas emerges with almost no water and can be refrigerated without the chance of forming hydrates.

The maximum water content of "pipeline quality" natural gas is 7 pounds $\left(\mathrm{lb}_{\mathrm{m}}\right)$ per million standard cubic feet (MMSCF) of gas. The water content must be reduced to less than $1 \mathrm{lb}_{\mathrm{m}}$ per MMSCF before the gas can be refrigerated. This reduction of water content is easily achieved using molecular sieve dehydration. The mole sieve dehydrator consists of two identical, skid-mounted pressure vessels, which are vertically oriented. Two vessels, i.e., beds are used since, while one bed is absorbing water, the second bed is being regenerated. 
When the first bed is completely water-laden, as determined by a hygrometer, it is automatically switched off line and regenerated. The second bed is switched on line, allowing for continuous water absorption.

Bed regeneration is carried out by taking a side stream of dehydrated gas and heating it to $550^{\circ} \mathrm{F}$ in a small, direct-fired heater. Since each of the two beds must be regenerated with a stream of heated natural gas $\left(+550^{\circ} \mathrm{F}\right)$, the pressure vessels containing the molecular sieve material (beds) are covered with high temperature insulation. The hot gas heats the molecular sieve material, resulting in water being driven out of the desiccant and carried away by the hot gas stream.

Once the hot gas exits a bed, it is cooled by a small air cooler (not shown), resulting in water condensation. The condensed water drops out in a small separator (Dwg. 861-MD-005) and the gas is routed to the suction of the inlet compressors.

\section{Refrigeration}

Once the gas is sufficiently dehydrated, it must be cooled for the purpose of achieving greater storage efficiency when compared to conventional, ambient temperature storage. In the case of a cavern, 1,500 to 3,000 feet below ground level, the ambient (cavern) temperature may be 80 to $100^{\circ} \mathrm{F}$ or higher. The quantity of gas stored at $-20^{\circ} \mathrm{F}$ is 77 percent greater than at $100^{\circ} \mathrm{F}$, for a given storage pressure of $1,250 \mathrm{psig}$, and a constant cavern volume. Therefore, chilling the gas prior to storage will allow for 5 Bscf of working gas storage in a 37 million cubic foot cavern. If the gas is not chilled, the same 5 Bscf of gas would require a cavern volume of 66 million cubic feet.

The gas will be chilled to approximately $-20^{\circ} \mathrm{F}$ before entering the cavern. The chiller will use refrigerantgrade propane as a refrigerant. The propane refrigerant is capable of chilling the gas to as low as $-35^{\circ} \mathrm{F}$. If a $-40^{\circ} \mathrm{F}$ storage temperature is desired, a different type of refrigeration system and refrigerant (propylene) must be used. In addition, consideration will have to be made for the metallurgy of the equipment handling the lower temperature.

The refrigeration system may be powered by electric motors or gas turbines. In this study, gas turbine drivers are assumed. The refrigeration system is a compression-expansion type system, consisting of a three stage evaporative cooling system. Each evaporator or "chiller" is a kettle-type shell-and-tube heat exchangers, with the gas stream passing through tubes immersed in boiling liquid propane in the shell of each heat exchanger. Each chiller operates at a different pressure - high, medium and low pressures. The high-pressure chiller is the warmest of the three chillers, while the low-pressure chiller is the coldest. Cooling the incoming gas in three steps results in greater energy efficiency when compared with a single-stage (one low-pressure chiller) refrigeration system.

The boiled propane is compressed by a three-stage, gas turbine-driven (4,500 HP Solar Centaur 40 - one per 1,300 ton unit) centrifugal compressor. It is then condensed in a fin-fan (air) cooler before being reduced in pressure in each of the three evaporators. A total of $40.7 \mathrm{MMBtu} / \mathrm{hr}$ of refrigeration will be required (three 
1,300 ton units are specified), assuming a $250 \mathrm{MMscfd}$ gas flow rate, a $120^{\circ} \mathrm{F}$ incoming gas temperature (compressor discharge) and $\mathrm{a}-20^{\circ} \mathrm{F}$ storage temperature.

After being chilled, the incoming gas stream will enter the cavern through a 20 -inch vertical riser placed in one of the cavern access shafts. The riser will carry the gas to an underground distribution header, installed along one end of the cavern. The chilled gas will exit the header, flowing across to the opposite end of the cavern to an identically configured header ("return header"). The gas then enters the return header and flows through piping along the cavern floor back to a second 20-inch vertical riser ("return riser"). The return riser will share the same cavern access shaft as the riser used for gas injection.

The purpose of the underground distribution and return headers, as well as their placement in the cavern, is for allowing even and thorough distribution of cold gas throughout the cavern. Contact of the cavern surfaces ("rock") with cold gas will chill the cavern and will aid in freezing any naturally occurring water within the pores of the rock. Also, as the rock is chilled, the influx of heat from the surrounding formation is reduced. Over time, a certain thickness of formation surrounding the cavern is chilled until thermal equilibrium is established.

Initially, as chilled gas is injected into the cavern, the gas will be warmed by the rock surrounding the cavern. The gas will, therefore, have to be recooled and then reinjected. During and after the cavern is completely filled with gas, the gas in the cavern will have to be recycled through the chiller in order to maintain the required $-20^{\circ} \mathrm{F}$ (or lower) cavern operating temperature. Also, the recycled gas stream may require dehydration initially before being rechilled, since water may be present in the cavern and could be picked up by the gas.

After the first year of storage operations, the cooling load required to maintain the cavern at $-20^{\circ} \mathrm{F}$ is estimated to be about 10 million Btu/hr. The cooling rate will decline with time, and after 10 years, the estimated cooling load is reduced to about 3.7 million Btu/hr. The cavern will experience beneficial cooling during gas withdrawal periods due to the expansion of the gas upon withdrawal. This is estimated to be about 15.2 million Btu/hr after 1 year of storage operations, and 13.8 million Btu/hr after 10 years of storage operations. Depending upon the frequency of the injection/ withdrawal cycles, much of the cavern cooling load will be provided by the gas expansion during the withdrawal periods. During injection and static operations, maintenance cooling will be provided by circulation through the refrigeration system.

Gas circulation is achieved through the use of a low-pressure boost centrifugal compressor, located on one of the three refrigeration skids. The recirculation compressor will be powered by the same turbine powering the main refrigeration compressor. Once the cavern is full, gas will be withdrawn via one underground header, compressed by the recirculation compressor, chilled and then reinjected into the cavern through the second underground header. 


\section{Gas Heating}

When the gas is withdrawn, it may require heating. A $60^{\circ} \mathrm{F}$ gas temperature is ideal since this is an industrystandard temperature used for measurement as well as a typical pipeline operating temperature.

Heating of the gas upon withdrawal is achieved, using a direct-fired, forced draft convection heater. The heat input to warm $250 \mathrm{MMscfd}$ from $-20^{\circ} \mathrm{F}$ to $+60^{\circ} \mathrm{F}$ requires using a $33.1 \mathrm{MMBtu} / \mathrm{hr}$ (gross heat input) heater. After the gas is heated it is either, metered and then transferred to the trunkline or it is first recompressed then metered. Since recompression heats the gas, the amount of added heat required from the heater is reduced or not required at all. The amount of recompression depends on the cavern pressure and the trunkline pressure, as well as gas flow rate (250 MMscfd is the design withdrawal flow rate).

\section{Emergency Shutdown System (ESD)}

Emergency shutdown will be manually activated at strategically located ESD activation stations. One ESD valve is located on the inlet/discharge pipeline at the facility fence line and two ESD valves are located on each of the two vertical risers, emerging from the cavern.

\section{FACILITY LAYOUT}

The facility plot will consist of an area somewhat larger than the border formed from the projection of outer dimension of the cavern. The area occupied by the 3,000-foot depth cavern is approximately 1,000 feet by 1,200 feet ( 27.5 acres). The area occupied by the shallower caverns will be greater. The area required for the surface facility is 4 to 7 acres. The layout Dwg. 861-GP-001 is an example layout, taking advantage of the ample land area required for the cavern. Since natural gas and refrigerant propane are being handled by mechanical equipment, leakage of these hydrocarbons can occur. Wider spacing between equipment areas may allow for greater safety.

The spacing and location of equipment will be determined on the basis of code requirements and the direction of the prevailing wind. The code requirements specifically address equipment spacing, e.g., a combustion sources, such the regeneration gas heater or flare vent stack, must be 150 feet or more from an area where the potential for hydrocarbon leakage exists. 


\section{Section 6 \\ SITE GEOLOGY}

An initial brief screening of five areas of the U.S. where additional natural gas storage appears most needed resulted in the selection of the South Atlantic area, comprised of Delaware, Maryland and Virginia as the preferred target area for this research study. The next step was to review the large selected three-state target area to identify a populous area which might benefit most if an economically viable natural gas storage facility could be developed nearby. The Washington, D.C. to Baltimore, Maryland area was selected as the focus for the refrigerated cavern study because of its population density and significant requirement for dependable year-round natural gas supply, plus the indicated coexistence of favorable rock for cavern construction and major cross-country gas supply pipelines. The area of prime interest identified in this study lies within Howard and Montgomery Counties, Maryland, just northwest of the corridor between the two cities (see Figure 6-1).

The scope of work in this study allowed only a broad geological screening effort to identify an area near major gas pipelines with one or more rock types potentially favorable for cavern construction. It was not the intent of this investigation to select a specific rock formation or site for an actual cavern feasibility study. The geological investigation consisted of a preliminary literature search and review. Time and budgetary constraints did not permit a field inspection visit to the area of interest.

Howard and Montgomery Counties lie within the Piedmont physiographic province (see Figure 2-1). The Piedmont Province is a belt of sedimentary, metamorphic and igneous rocks which extends from Alabama northeastward through Maryland to Pennsylvania. The age of formations in the study area spans the geologic time scale from Precambrian, represented by the basement Baltimore Gneiss, up through Quaternary sediments. Nomenclature of formations has evolved over several decades of geologic study. Figure 6-1 is a useful geologic map of the two counties of interest taken from Bulletin 14, the 1954 Maryland Department of Geology, Mines and Water Resources publication, The Water Resources of Howard and Montgomery Counties, which draws upon earlier maps of 1940 and 1953. At that time, the ages of several formations were uncertain. Figure 6-2 is a stratigraphic column for Howard County found in Maryland Geological Survey Bulletin 38, a 1995 publication titled, Water Resources of Howard County, Maryland. Note that in the newer publication some nomenclature has changed and all formations have been assigned to age categories.

The preferred rocks for deep storage cavern construction are high strength, low permeability, crystalline igneous and metamorphic rocks. An abundant representation of such rocks appears to exist in the two counties of interest. A roughly triangular prospective natural gas storage cavern area with a 25-mile southwest-northwest length and a 12-mile wide base, all within 6 miles of a major natural gas pipeline has been identified as the logical area for siting a refrigerated storage cavern. 
Of particular value to the selection of the prospective storage cavern area in this refrigerated cavern research exercise were the documented results of a major study of the potential for underground Pumped Hydro and Compressed Air Energy Storage (CAES) in the Washington D.C. to Baltimore area conducted by the Potomac Electric Power Company (PEPCO) and Acres American Inc. under the sponsorship of the U.S. Department of Energy (DOE) and the Electric Power Research Institute (EPRI),during the period 1977 1982.

The PEPCO study progressed through a thorough formal screening process, identifying rock formations of probable favorability for cavern mining and ruling out sensitive areas based on environmental and socioeconomic factors. That investigation resulted in the identification of seven favorable rock formations for cavern construction, the following five of which are indicated on Figure 6-1 to exist within the prospective cavern area selected for this study:
- Sykesville Boulder Gneiss
- $\quad$ Ellicott City Granodiorite
- $\quad$ Norbeck Quartz Diorite
- Kensington Quartz Diorite
- Guilford Quartz Monzonite

The following descriptions of these favorable formations were provided in PEPCO reports:

\section{Sykesville Boulder Gneiss}

Thick bedded to massive, pebble and boulder bearing, arenaceous to pelitic, metamorphic rock. Typically a garnet-oligoclase-mica-quartz gneiss; locally an intensely foliated gneiss or schist.

\section{Ellicott City Granodiorite}

Ranges from biotite granodiorite along margin of body to quartz monzonite in core.

\section{Norbeck Quartz Diorite}

Ranges from weakly foliated quartz diorite to strongly gneissic and schistose rock with recrystallized texture.

\section{Kensington Quartz Diorite}

Moderately to strongly deformed; igneous texture generally destroyed. Ranges from quartz diorite to granodiorite. Comprises thin concordant sheets or wedges along plunging crest of Baltimore anticlinorium.

\section{Guilford Quartz Monzonite}

Biotite-muscovite-quartz monzonite; occurs as discontinuous lenticular bodies. 
The Sykesville Boulder Gneiss Formation was selected as the prime rock candidate in the PEPCO study and a site near Sunshine in Montgomery County, underlain by that formation, was selected for testing by deep core drilling. One hole was core drilled to a hole length of 3274 feet (to a vertical depth of 2526 feet) in the Sykesville Formation and hydrologically tested (see location on Figure 6-1). It was concluded that geotechnical conditions at the location of the deep core hole are quite favorable for cavern construction.

All five of the above described formations should be considered as potential candidates for a refrigerated natural gas storage cavern. The Sykesville Boulder Gneiss occupies the largest areal extent within the selected prospective refrigerated cavern area, much of it is away from heavily urbanized zones, and it has already been proven favorable at one location. Therefore, based on currently available information, the Sykesville is considered to be the leading rock type candidate for a gas cavern.

\section{GEOTECHNICAL ASSUMPTIONS FOR CAVERN DESIGN}

Detailed design of access shafts and underground workings of a hard rock natural gas storage cavern requires a detailed knowledge of the sequence and types of overburden and rocks to be penetrated plus a knowledge of pertinent engineering properties, degree and orientation of fracturing, and stress conditions of the rocks to be excavated. In an actual construction project this information is accumulated in the geotechnical feasibility study which includes the drilling and testing of several core holes.

The current research project is focused on the prospective natural gas storage cavern area identified in Howard and Montgomery Counties, Maryland but no specific site has been selected and no feasibility study has been performed. Therefore, it was necessary to develop a list of geotechnical assumptions which form the basis for the conceptual cavern design exercise. Table 6-1 lists assumed generic properties and conditions chosen to be representative of a typical, structurally good quality, crystalline igneous or metamorphic rock in the area of interest. These geotechnical assumptions were derived partly from results of the deep PEPCO core hole and partly from data acquired in actual projects in similar rock elsewhere. The surprisingly cool temperature of $73^{\circ} \mathrm{F}$ at 2500 feet depth was measured in the PEPCO core hole. 


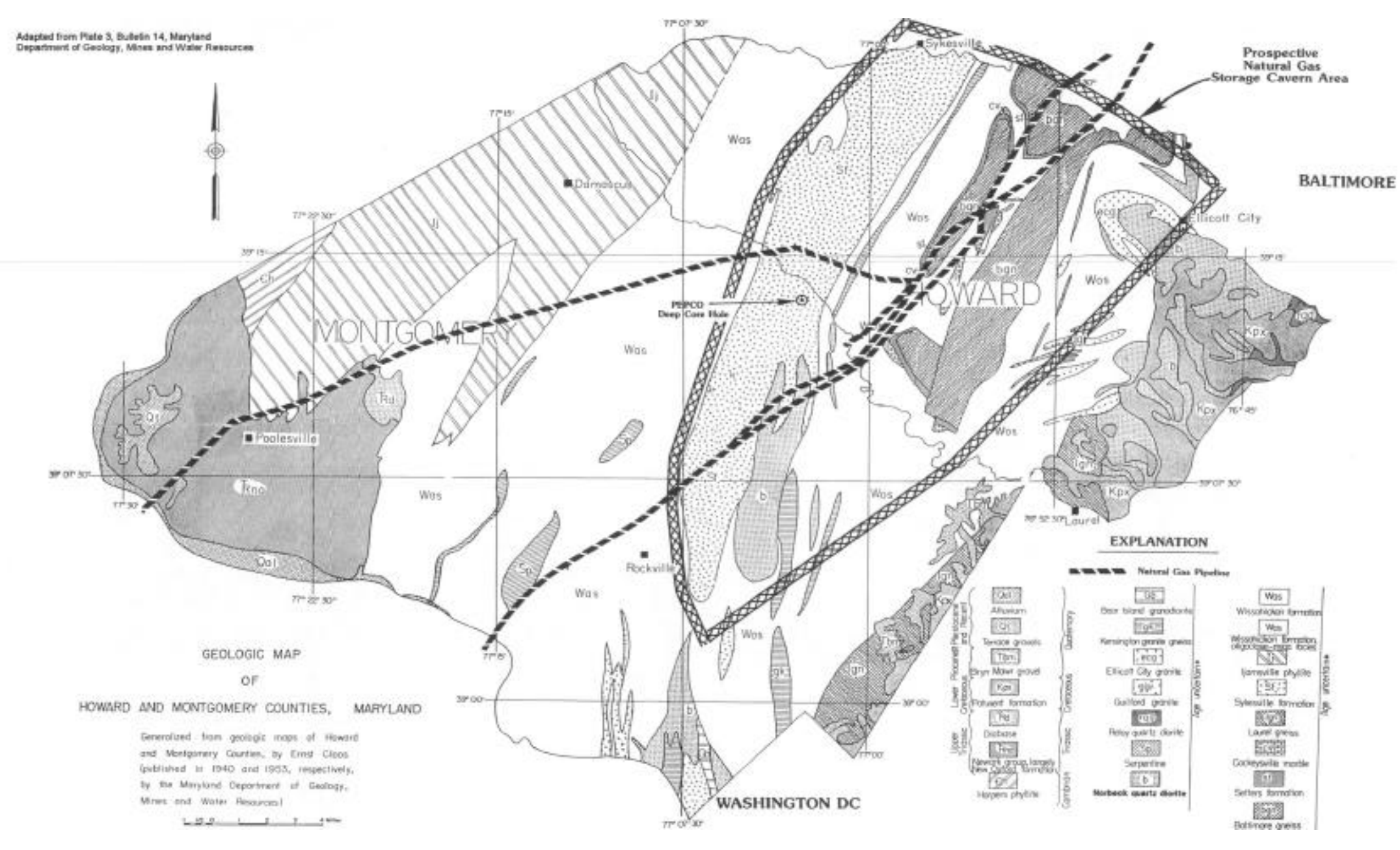

Figure 6-1 - Prospective Natural Gas Storage Cavern Area 


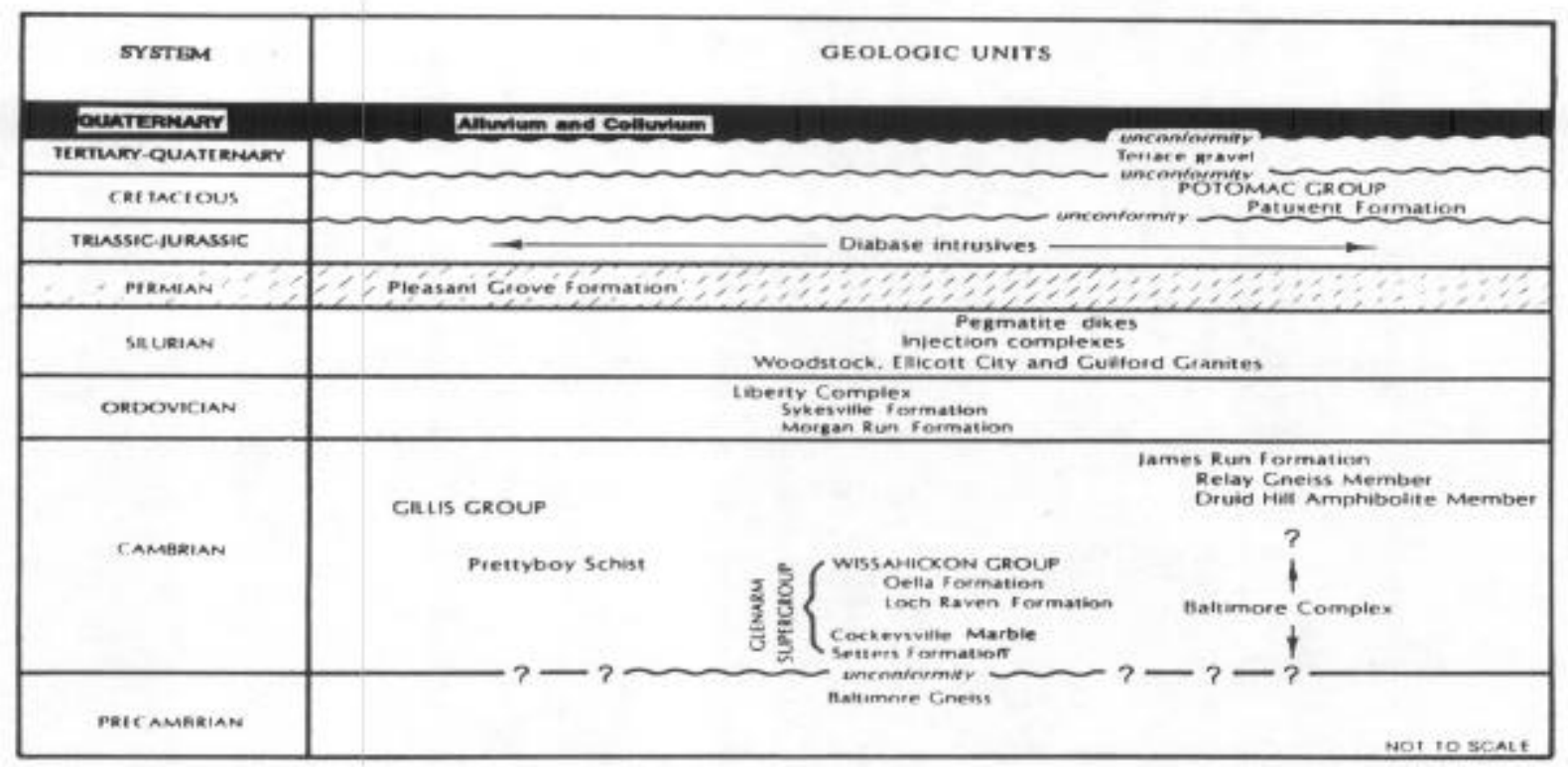

Source: Maryland Geologisal Survey Bulletin 38, Water Resources of Howard County, Maryland 1995.

Note: The Pleasant Grove Formation was sot deposited during Permian time, but rather includes older rock units that have been deformed by shearing and emplacement that probably oocurred during Perinias time.

Figure 6-2 Stratigraphic Column of Howard County, Maryland 


\section{Table 6-1}

\section{Geotechnical Assumptions for Conceptual Design of Refrigerated Natural Gas Storage Cavern}

1. Geological Column

$\begin{array}{ll}0-50^{\prime} & \text { Overburden } \\ 50-150^{\prime} & \text { Weathered crystalline rock (igneous or metamorphic) } \\ 150-3000^{\prime} & \text { Unweathered crystalline rock (igneous or metamorphic) }\end{array}$

2. Rock Properties and Hydrologic Conditions

Unconfined Compressive Strength: . . 2,000 - 20,000 psi (average 10,000 psi)

Tensile Strength: . . . . . . . . . . . . . . . . . 700 psi

Young's Modulus . . . . . . . . . . . . . . . . 7,500,000 psi

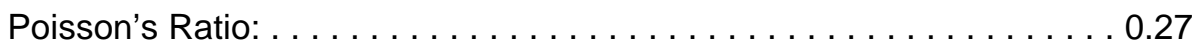

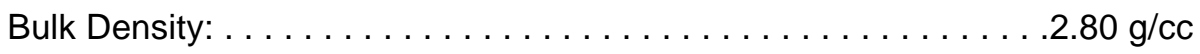

Porosity: . . . . . . . . . . . . . . . . . . . . . . . . .

Hydraulic Conductivity $(\mathrm{K}) \mathrm{.} \ldots \ldots \ldots \ldots \ldots 10^{-7} \mathrm{~cm} / \mathrm{sec}$ at $2500-\mathrm{ft}$. depth

Temperature at 2500' Depth: . . . . . . . . . . . . . . $73^{\circ} \mathrm{F}$

Temperature Gradient: . . . . . . . . . . . . . . $0.64^{\circ} \mathrm{F} / 100$ feet

Water Table: . . . . . . . . . . . \pm 30 feet below surface (in gentle hilly terrain); Near surface (in valley bottoms)

Average RQD index value: . . . . . . . . . . . 85 at $2500-\mathrm{ft}$. depth 


\section{Section 7 \\ CAVERN CONCEPTUAL DESIGN}

A conceptual design was prepared for this study to demonstrate that a facility can be feasibly constructed, without the requirement for unique or unproven construction techniques, and to provide a basis for a rough order of magnitude cost estimate and construction schedule.

For the actual construction of such a facility, it is necessary that a comprehensive geotechnical feasibility study be performed at the site to determine subsurface geologic conditions as a prerequisite for a detailed design. This geotechnical feasibility study would consist in part of drilling three or more core holes to a depth of 150'-200' deeper than the cavern floor for the investigation of rock properties and in-situ stress conditions. All of the rock properties, which are a part of the assumptions in this report, would need to be determined. In addition, the nature and orientation of all discontinuities such as joints, foliation and faults must be determined by detailed core logging.

\section{Shaft Sizes}

Shafts are the main arteries for the underground operations. They provide ventilating air, passage for hoisting of men and material, and various utilities such as electricity, water, and compressed air.

Shaft sinking entails the major cost of the underground cavern development. The cost is proportional to the size of the shaft, especially for the drilled shaft. Conventionally sunk shafts, however, must have adequate room for the miners to operate economically without getting into each others way. A minimum diameter is about 12 ' for a conventionally sunk shaft.

For ventilation purposes, two distinct passageways are required: one for the incoming fresh air, and the other for the outgoing contaminated air. The fresh air is needed by the miners, the operating equipment and for removal of dust-laden particles of broken rock. Mine Safety and Health Administration (MSHA) normally requires two shafts in the operating mines for this purpose. One shaft serves as the air intake shaft, and the other as the air return shaft. The second shaft also serves as a second means of egress from the mine in an emergency. However, MSHA has approved, in the past, a single, divided shaft for developmental purposes. One half of the shaft is used for the air intake and the other half as return. Emergency egress may be provided by a torpedo hoist.

Since the shaft-sinking cost is the major cost item, a single, partitioned shaft was considered for this facility. However, this necessitates smaller skips to operate in one half of the shaft. The return trip for a fully loaded skip, from a depth of $2500 \mathrm{ft}$ was calculated to be about 15 minutes. Considering that 4.1 million tons of broken rock would need to be hoisted to the surface from the underground, an inordinately long cavern 
development time would be required (six to seven years). For economic hoisting and development schedule, two larger skips would be required in a balanced mode -- one being loaded underground, while the other is being unloaded at the surface. Therefore, a single shaft concept for the facility will be unworkable.

Shaft size is determined by a variety of parameters including the size of hoisting equipment to be installed and the size of the equipment to be lowered into the underground workings to complete the excavations. An additional parameter is the quantity of ventilation air required to provide a safe environment for the underground workers during construction. The excavation equipment will most likely include two-boom electric-hydraulic drill jumbos, eight- to ten-cubic-yard front end loaders and forty- to fifty-ton haul trucks. Equipment of this size is required for efficient construction of the caverns. In order to accommodate these requirements, a shaft of 18 - to 20 -feet in diameter is recommended.

All of the material excavated from the caverns will be hoisted from the shaft bottom by means of a large double-drum mine hoist and skips that automatically load and unload. It is necessary to crush the material so that all of the material would be smaller than about twelve inches so that it can be easily loaded into the skips. This would be done through the use of a large jaw crusher installed at the shaft bottom. The crushing equipment will include a dump hopper of sufficient size so that the haul trucks can dump directly into the hopper with additional rehandling of the waste material. Once on surface, the waste rock would be hauled to a storage site or, depending on the ownership of the material, it could be further crushed and sold as aggregate.

\section{$\underline{\text { Shaft Construction }}$}

Shafts are constructed by three primary methods: conventional drill and blast techniques, blind hole drilling and raise boring. An additional method, "V-moling", is available, although used only infrequently. The three drilling methods are more mechanized than the conventional method, and do not require workers to be in the working are of the excavation.

Conventional drill and blast construction is the most commonly used for shaft excavation. This method is successfully employed in virtually any size or shape of shaft and is limited in depth only by the length of hoisting ropes being manufactured and the size of joisting equipment available. It is flexible and can be adapted to suit any type of ground conditions that may be encountered. The excavations can be constructed to a very accurate vertical tolerance, a condition that is required where hoisting equipment is to be installed. Blind hole drilling is limited to holes of 16 feet in diameter and 2000 feet in depth. Depth and diameter are limited by size of drilling equipment available. This method is better suited to softer rock formations. It cannot always be used in geologic settings where there are alluvial deposits containing boulders. Accurate vertical alignment cannot be assured. 
Raise boring is similar to blind hole drilling except that the cutting tool is placed at the bottom of the excavation and attached to a drill string set into a previously-drilled pilot hole. This method can be used for excavations up to 20 feet diameter and 2500 feet deep; the depth of excavation is limited by the size of equipment available. Shafts can be raised in any rock formation that does not require immediate support for the excavation. In order to use this construction technique, there must be access to the shaft bottom prior to drilling the pilot hole. Correct vertical alignment of the shaft can be assured, although this assurance can be difficult and expensive. Unless great care is exercised in drilling the pilot hole, the hole can deviate from vertical by 5 - to 10 percent. Even one percent deviation is unacceptable for shafts intended to be equipped with high-speed hoisting equipment.

V-moling a shaft is similar to blind drilling in that the cutting tool starts excavation at the top and proceeds downward. This method is limited to shafts of 28 feet diameter. It requires that a raise-bored pilot hole be completed prior to starting the main shaft excavation. Access to the bottom of the shaft is required prior to drilling the pilot raise.

Of these principal methods, the best suited for primary access to the caverns is conventional drilling and blasting. The service shaft can be excavated by use of raise boring, however, extra care will be required in drilling the pilot hole because this shaft will be equipped with hoisting equipment and a true vertical shaft is required.

The first step in shaft construction is mobilization and site preparation. Mobilization will consist of off-site and on-site activities. Off-site activities will include preparation of equipment, relocating personnel to the site, initial engineering and design activities, setup of job cost system and long-lead item ordering and tracking. On-site mobilization will include setup of offices, dryhouse, sanitary facilities, placing temporary utilities, set up the shop, surface equipment and warehouse. It will also include grading and drainage, building access roads and storage areas. At this time the contractor will also set up the shaft sinking equipment which will include the hoisting equipment, head frame and muck handling equipment. It is estimated that the contractor will require approximately $3000 \mathrm{kVA}$ electrical service.

Shaft sinking will begin with construction of the shaft collar, the initial reach of the shaft through the overburden and into competent rock. Depending upon the nature and depth of overburden, the collar will be excavated using a clam shell or backhoe, and supported with ring beams and timber lagging or liner plate and ring beams. The initial twenty feet of excavation is usually completed with a backhoe and is sufficiently large to accommodate a prefabricated ring beam and lagging support cylinder. The inside diameter of this structure will be two feet larger than the finished diameter of the shaft. After the support structure is in place, it will be backfilled with compacted fill and the shaft bottom leveled and prepared for placing the first twenty feet of shaft concrete. Reinforcing steel is placed as required. A concrete slab is placed around the shaft collar at grade and footings for the head frame are installed. The footings may be either driven or drilled 
piles or spread footings depending on soil conditions and head frame loading.

The shaft collar is then completed to competent rock using equipment that is appropriate for the material to be excavated. It may include clam shell, a small excavator or overshot mucking machine loading material into a singing bucket. The material is hoisted to surface using a crane then dumped. As the excavation advances, liner plate and ring beams or ring beams and timber lagging are installed for temporary support of the excavation. Depending upon soil loading conditions, the inside diameter of the temporary support is nominally two feet larger in diameter than the finished shaft. This activity is continued until the collar reaches competent rock.

The excavation is continued in to rock for approximately twenty feet, and the rock excavation is enlarged to form a bearing haunch that provides support for the collar concrete. The concrete forms are lowered into the shaft and the haunch is placed. Shaft lining concrete is then placed upward to join the collar lining was initially placed. Reinforcing steel is placed as required by final design.

While the shaft collar is under construction, the remainder of the shaft sinking plant is installed. This includes setting the mine hoist, work deck winches and form winches, and preparation of the shaft head frame. The Galloway (work stage) is assembled and made ready for installation and a concrete batch plant is set up if needed. When all activity in the shaft collar is complete, the head frame and hoisting equipment is erected and made ready for shaft construction.

The shaft sinking operation consists of a normal drill-blast-muck cycle, excavating approximately ten-footlong blast rounds. Drilling will be done with a shaft drill jumbo and mucking by Eimco 630 or Cryderman shaft mucker loading five-cubic yard (CY) sinking buckets for hoisting to the surface. Spot bolting with wire mesh installed concurrently with sinking as necessary to provide safe working conditions. Every twenty feet, the excavation cycle will be interrupted and a twenty foot long section of shaft concrete lining installed. The curb ring will be lowered from the previous pour and suspended form twelve hanging rods. After aligning and securing the curb ring, the forms will be stripped from the previous pour and lowered in sections, realigned and secured. The twenty foot section will then be concreted up to the previous pour. Concrete will be delivered using the hoist and concrete buckets or slick line. Separate form winches will be provided for handling the curb ring and shaft forms. The cycle will be interrupted for installation of the water rings at the appropriate elevations and construction of the crusher level station.

Development from the shaft into the mining level will be started using hand-held jack leg drills and a skidsteer loader. This equipment will be used to excavate an area of sufficient size to accommodate a mining jumbo and loading equipment. At this time, only the top heading of the excavation will be completed. After the equipment has been assembled, development will continue with the excavation of the crusher station. In addition to the crushing station development, a drift to the service shaft area will be excavated. 
Temporary lifting eyes will be located in the crown of the crusher area to assist with assembly of the crusher and hopper. A monorail hoist to service the crusher will be installed at that time as well. Ground support will most likely consist of rock bolts and welded wire mesh.

Mining on the storage cavern level will continue until the access to the service shaft has been completed and supported with rock bolts. After the initial excavation to the service shaft is complete, all of the crushing and material handling equipment for the crusher will be brought into the cavern and stored. The mining equipment used for initial development will then be removed from the cavern and the large production mining equipment brought into the cavern and assembled. The shaft will then be continued to its final depth and the cutouts for the skip loading equipment will be excavated and lined with twelve inches of plain concrete.

The shaft sinking equipment will then be removed and utility installation will begin. Shaft piping includes one six-inch dewatering line, one six-inch compressed air line, one 1-1/2 inch fuel line, and one 2-inch water supply line. Shaft cables include a high voltage power line, leaky feeder communications line, dial telephone cable, fiber-optic cabling and control cabling. All shaft cable and pipes will be suspended in the shaft on steel brackets bolted to the lining with epoxy anchor bolts. The cables will be installed from the top of the shaft and proceed downward. Cable reels are placed on the Galloway which is then slowly lowered. As the deck moves downward, the cables are spooled off the reels and secured to the cable hangers. Following completion of cable installation, the Galloway will be returned to the surface and the shaft set up for steel installation.

Steel installation is also conducted from the top of the shaft progressing downward. Control of the steel location is by the use of plumb lines positioned at known distances from the steel sets. The first set is accurately placed in the shaft collar and secured to the concrete. A set of shaft guides is then positioned in the shaft and secured to the collar steel set, the deck is lowered and the second set is brought to the deck. Templates will be used to accurately locate drill holes used to secure the buntons seats to the concrete. The bunton seats are loosely secured to the concrete and the buntons are placed and aligned to the plumb lines. The shaft guides are then bolted to the buntons and all bolts are tightened with an impact wrench. When all bolts are tight and steel alignment is correct, another set of bunton steel is brought into the shaft and the cycle repeated. This activity will continue until the steel has reached the crusher level.

Construction of the underground crushing station will commence when the shaft equipping sequence reaches the cavern level. This work will begin with the installation of the skip loading equipment so that the shaft steel can be installed simultaneously with that equipment. Electrical and mechanical installation of the crushing equipment will follow shortly thereafter with all activities in the crusher, and skip loading station being undertaken concurrently. At the completion of these activities, the crushing and skip-loading equipment will be tested, commissioned and put in service. Excavation of the remaining work in the storage 
cavern level will begin. Fan and fire door bulkheads will be installed, and the ventilation system installed, a dewatering sump completed and an underground equipment service area established.

\section{$\underline{\text { Service Shaft Construction }}$}

Once the production shaft has reached the storage cavern level, an access tunnel must be driven to the service shaft location in preparation for raise boring of the service shaft facility. The access drift will be sized to facilitate the movement of the raise bore head to the site. The service shaft site must be of sufficient dimension to allow ease of material handling required by raise boring activities. Sizing of the material handling equipment is dependent upon the haulage distance to the production shaft as well as the size of the raise bore opening.

It is assumed that the finished dimensions of the raise bored shaft will be approximately 2500 vertical feet in length and ten feet in diameter. When the underground raise bore station is completed, access area for the raise boring equipment will be completed on the surface. This includes the foundation for the raise bore and drilling of the pilot hole. The pilot hole must be drilled to very strict vertical tolerances as it will be the control for vertical alignment of the bored shaft.

After agreement that the pilot hole is within tolerance for verticality, the rise bore head is transported to the underground site and assembled to the size and configuration for the opening to be constructed. Rods are then connected to the cutter head and raising is begun. Material from the remaining process falls to the developed underground area, and is removed to the production shaft for hoisting to the surface for disposal. Material generated by raise boring can be classified as minus six inch rock.

After reaming the shaft to the surface has been completed, the raise boring equipment is demobilized from the site and the unitized concrete lining equipment is mobilized to the surface location. Concrete lining is performed from the surface collar downward in 20 foot lifts. When lining the service shaft has been completed, the lining equipment is removed and shaft furnishings are installed in much the same manner as in the production shaft.

\section{$\underline{\text { Storage Cavern }}$}

\section{$\underline{\text { Cavern Orientation }}$}

The orientation of the main storage cavern with regard to the geologic conditions is extremely important. This can only be done with information obtained from a site specific geotechnical feasibility study. The decision is largely based on the avoidance of undesirable conditions and must of necessity involve compromises. Ideally, the long axis of the main caverns should be parallel to the direction of the principal horizontal in situ stress and perpendicular to the most significant discontinuities such as fractures, joints, and faults. Obviously, perpendicularity to all negative discontinuities cannot be achieved in an actual situation, so the choice of orientation becomes a best compromise based on experience as to what conditions present 
the greatest problems to both the cavern stability and air tightness of the operating facility.

\section{Cavern Design and Construction}

The cavern volume for a 2500 -ft deep facility will be approximately 47 MMCF (for 5 billion cu. $\mathrm{ft}$ of working gas, at $-20^{\circ} \mathrm{F}$ and compressed to $1083 \mathrm{psi}$ ). However, if the gas is compressed to $1250 \mathrm{psig}$ (for 3,000-ft deep cavern), the space requirement will be less. This is discussed in some detail in the "Optimization" Section. For economic reasons, the cavern sizes should be as large as possible. For an opening size of 80' $x 80^{\prime}$, a total length of 7,234 lineal feet of cavern space is required. In order to reduce the haulage distance and to reduce the real estate cost of surface property, it is more convenient to break down into 7 tunnels, approximately 1033' long. However, if the shaft is located centrally to further reduce the hauling distance, seven tunnels, approximately 500' on each side of the shaft, are needed. Cross-cuts will be needed every 200 ' for ventilation purpose. These cross-cuts provide further storage space.

Large storage caverns, highway tunnels and other underground structures where the top of the excavation is higher than about thirty feet are commonly constructed using the "top heading and bench" method of excavation. This process is employed because mining equipment is not able to access the entire working face of the excavation. The excavation will be completed by mining the upper portion of the opening with one or more smaller openings sized to suit the equipment available.

In this cavern, the top heading would be mined with a heading approximately twenty-seven feet wide and thirty feet high driven down the center of the excavation. When the central heading has advanced approximately eighty feet, one of the remaining sides would be started and would remain that distance behind the first. As the headings advance an additional eighty feet, the remaining side is excavated again remaining an approximate distance of eighty feet behind. Roof support is installed and maintained to the working faces. When all of the top headings have been excavated, the remaining bench is excavated in either one or two lifts. In this cavern, it may be advantageous to mine the bench in two lifts rather than one because of the volume of muck generated. Blasted rock will be delivered to the hoisting shaft in haul trucks then transferred to the shaft material handling system.

The storage cavern could also be created by use of one or more tunnel-boring machines (TBM). These machines are commonly used for construction of circular tunnels ranging in diameter from 6- to 40 feet and are successfully used in virtually all rock types. In situations where the excavation must be immediately support, temporary support is erected within the tail shield of the machine. Ground support may consist of ring beams and lagging, liner plate and ring beams or pre-cast concrete tunnel liner. Excavated material is transported away from the machine in rail cars or on conveyor belts. It would not require crushing prior to being hoisted.

The largest available TBM will excavate an opening of approximately 1250 square feet. In order to create 47 million cubic feet of storage, 37,500 feet of tunnel would be required. The proposed $80-x 80$-foot caverns done by drilling and blasting require only 7500 feet of excavation. In addition, the production shaft required 
to support this TBM operation would need to be at least 30 feet in diameter. While it is technically possible to construct this shaft, it would be much more expensive than the shaft required to support the drill-blast cavern construction. Using the TBM method is not recommended.

The major pieces of equipment used for construction of the caverns would include two boom electrichydraulic drill jumbos, Cat 990 or equivalent front end loaders and 40-ton haul truck, similar to a Cat 769 haul truck. Support equipment would include a roof bolting jumbo, shotcrete machine, mechanic's trucks, lubrication trucks and an explosives truck. All equipment will have the necessary safety equipment for operating in an underground environment.

Ventilation air would be supplied through the service shaft which would have the main fan installed at the surface and operating on intake. The intake air would be routed through the service shaft because that shaft would be used as the primary entrance to the caverns for personnel. With the spread of underground equipment, the ventilation air required would be approximately 300,000 cubic feet per minute. Air flow in the cavern would be controlled by using ventilation stoppings, air regulators and doors. These features would be dismantled after the cavern excavation is completed.

The material transfer system would be comprised of the bump hopper and hydraulic rock breaker, a jaw crusher and scalping grizzly, skip loading surge hopper, skip loading flasks and much skips an hoist. Jaw crushers are the most efficient and economical equipment to reduce the size of blasted rock to a size that can be easily loaded into the muck skips. The grizzly would be installed under the dump hopper to allow undersized material to bypass the crusher, increasing the capacity of the crusher and improving the efficiency of the crushing plant. Oversize material will pass through the crusher. Any material that is too large to enter the crusher will be broken with the hydraulic rock breaker.

Undersized and crushed rock will be transferred to the skip loader surge bin with a conveyor belt mounted beneath the crusher. The surge bin will be monitored with load cells or photoelectric sensors so that the crushing plant will automatically stop to prevent overfilling the hopper. Material flows by gravity from the hopper to the skip loading flasks; flow control is through the use of guillotine gates that are automatically controlled by load cells in the skip flasks. When an empty skip arrives at the skip loader, the skip flask is opened and muck is loaded into the skip. If the flask is not full, the guillotine gate at the surge hopper would open and allow muck to fill the flask. When the skip flask is empty, the discharge gate is closed and a signal sent that enables hoist operation.

After all of the cavern excavation is completed, the mining equipment would be disassembled and removed. This would include removal of the muck skips, crusher, and skip loading equipment. Any temporary fixtures, such as ventilation bulkheads and the equipment repair facility would be dismantled as well. This hoisting equipment would remain in place to provide access while the gas storage equipment was being installed. The hoisting equipment could remain in place to provide access to the caverns for inspection and maintenance, or decommissioned and removed from the site. 
General arrangement of the system is shown in Drawing 861-LB-006. Shaft outfitting is shown in Drawing 861-LB-005. Cavern layout for a 2500' deep facility is shown in Drawing 861-LB-007. Cavern layout for 3000' deep facility is shown in Drawing 861-LB-008.

\section{$\underline{\text { Roof Control }}$}

For stability, the roof of the opening will be arched, avoiding sharp corners with the walls of the opening. Pattern bolting may be needed for the protection of the workers. For this purpose, 8' long bolts will be fully grouted into the roof. All lose rock will be brought down by a rigid boom scaler (Gradall). In the benched area, lose rock in the roof will be hand scaled with the help of a Cherry Picker. 
Ventilation

Initially, ventilation will be with a fan and tubing providing air at the working face. Once connection has been made between the two shafts, a fan delivering about 300,000 cfm will be installed at the surface in the man and material shaft. Brattice will be used to convey air to the working area. Floor mounted cyclone fans will circulate the air at the face to remove any noxious fumes.

\section{$\underline{\text { Shaft Seals }}$}

Once the cavern construction, gas injection and delivery system, and the gas recirculation system are complete, shafts will be sealed to contain the gas under pressure. The seal will consist of massive concrete structure (30-35' thick) keyed 5 ' into the sides of the shaft walls to resist the uplift pressure of 1100 to 1250 psi gas.

\section{Cavern Inerting System}

The normal air in the cavern atmosphere will contain about 21 percent oxygen, by volume, which may result in an explosion from an ignition of the gas mixed with air. The cavern, therefore, must be inerted. In order to inert the cavern, a partial vacuum should be applied and then repressurizing the cavern with inert gas. The inert gas could be obtained from liquid nitrogen, liquid carbon dioxide or exhaust gas from a fuel oil burner. Nitrogen and carbon dioxide are not available in large quantities and have high costs. Therefore, exhaust gas, which can be produced by a fuel oil burning gas generator, should be used.

The system would consist of a vacuum pump, five inert gas generators complete with pumps, cooling towers, and fuel supply system.

The first step in the inerting process would be to reduce the pressure in the mine from 14.7 psia to 7.0 psia. This pressure is well below that required to prevent combustion. After evacuation, five inert gas generators, producing $10,000 \mathrm{scfm}$ of exhaust gas will fill the cavern. Each exhaust gas generator would be equipped with a combustor and a quenching water system complete with a separate cooling tower and circulation pump to cool the discharge gases to $110^{\circ} \mathrm{F}$. An oxygen analyzer would be used to monitor the discharge of each inert gas generator for the presence of oxygen.

\section{Gas Distribution System in the Cavern}

After being chilled, the incoming gas stream will enter the cavern through a vertical riser placed in one of the cavern access shafts. The riser will carry the gas to an underground distribution header, installed along one end of the cavern. The chilled gas will exit the header, flowing across the opposite end of the cavern to an identically configured header ("return header"). The gas then enters the return header and flows through piping along the cavern floor back to a second vertical riser ("return riser"). The return rise may share the same cavern access shaft as the riser used for gas injection. 
The purpose of the underground distribution and return headers, as well as their placement in the cavern, is for allowing even and thorough distribution of cold gas throughout the cavern. Contact of the cavern surfaces ("rock") with cold gas will chill the cavern and will aid in freezing any naturally occurring water within the pores of the rock. Also, as the rock is chilled, the influx of heat from the surrounding formation is reduced. Over time, a certain thickness of formation surrounding the cavern is chilled until thermal equilibrium is established.

\section{Construction Equipment}

The following construction equipment will be required for the gas storage cavern:

- Double-Drum with Clutch Hoist for Production Shaft

- Single Divided Drum Hoist for Men and Material Shaft

- One Work Stage

- Two 20-ton Skips

- Mancage

- Two Double (or Triple) Boom Electrohydraulic Jumbo Drills

- One Vertical Drill

- ANFO Loading and Blasting Rig

- Two Front-End Loaders (Cat 990 or equivalent)

- Two 40-ton Trucks

- One Roof Bolter

- One Rigid Boom Scaler (Gradall)

- One 80' high Cherry Picker for Handscaling

- Jaw Crusher

- Conveyors and Hoppers

- Power Distribution System

- Compressor and Compressed Air Distribution System

- Dewatering Pump

- Construction Fan with Tubing for Shaft Sinking

- Lubrication Truck

- 300,000 cfm Fan for Cavern Ventilation

- One 5-Stage Centrifugal Compressor (900 HP) for Evacuating Air

- Five Inert Gas Generators (120,000 scfh/unit) with Cooling Towers 


\section{$\underline{\text { CONCLUSIONS }}$}

1) The most practical method of cavern construction is conventional drilling and blasting one or more top headings then benching the balance of the excavation. Hydraulic drilling equipment, front end loaders and haul rucks should be used.

2) The minimum shaft diameter required to support this construction is $18-20$ feet. Any smaller shaft diameter would not allow easy access for the mining equipment.

3) Material mined to create the caverns would need to be crushed prior to hoisting.

4) The smallest service shaft would be a 10 -foot-finished-diameter raise bored shaft. The service shaft would be used for the ventilation air supply.

5) The production hoisting equipment would be used to assist with installing the gas storage equipment and piping. 


\section{Section 8}

\section{GEOMECHANICAL REVIEW OF PROPOSED CAVERN DESIGN FOR STORAGE OF REFRIGERATED NATURAL GAS}

\subsection{INTRODUCTION}

This study has resulted in a preliminary design of the cavern and access shafts for storage of refrigerated natural gas in a mined storage chamber. The project has identified a potential location for the refrigerated gas storage cavern in the Ellicott City granodiorite in Maryland for further study.

The access shafts will have diameters of 18 feet and 10 feet from the surface to a depth of about 3,000 feet. The shafts will be used initially for access during construction of the cavern and then as entryways for the pipelines carrying the gas into and out of storage. The life expectancy of the shafts must equal the life expectancy of the storage facility.

The preliminary design for the underground facility is for a room-and-pillar mined cavern located at about 3,000-foot depth. The cavern will be comprised of a set of rooms, each 80 feet high by 80 feet wide. The rooms will be spaced on 280 -foot by 230 -foot centers. The center of the cavern will be dominated by a shaft pillar of 200 feet by 380 feet. The shaft pillar will contain the two access shafts that will be used for development of the cavern, and later, delivery of stored gas. The immediate rooms around the shaft facility will not be benched and will be about 25 feet high.

This chapter evaluates the preliminary mine design in order to determine:

Stability of the 80 -foot-wide rooms.

Maximum stable span of the rooms.

Required pillar thickness for the studied room spans.

Stability of the shaft and need for lining.

Effect of the refrigerated gas temperatures on the stability of the facility.

Assumed rock properties were used in the evaluation of the mined chambers. The study utilized both analytical approaches and finite element modeling to determine the stability of the openings. Published reports of empirical studies for support of the openings were used to recommend initial support methods for the refrigerated gas storage cavern. 


\subsection{TECHNICAL APPROACH}

\subsubsection{Potential Storage Site Properties}

The site properties for the refrigerated gas cavern are provided in Tables 8-1, 8-2, and 8-3.

Table 8-1. Geological Column

\begin{tabular}{||c|c||}
\hline Depth & Material \\
\hline \hline $0-50$ feet & Overburden \\
\hline $\begin{array}{c}\text { 50-150 feet } \\
\text { 150-3,000 } \\
\text { feet }\end{array}$ & Weathered crystalline rock \\
\hline
\end{tabular}

Table 8-2. Properties of Unweathered Crystalline Rock

\begin{tabular}{|l|c|}
\hline \multicolumn{1}{|c|}{ Property } & Value \\
\hline Unconfined compressive strength & $2,000-20,000 \mathrm{psi}$; Average $=10,000 \mathrm{psi}$ \\
\hline Tensile strength & $700 \mathrm{psi}$ \\
\hline Youngs modulus & $7,500,000 \mathrm{psi}$ \\
\hline Poissons ratio & 0.27 \\
\hline Bulk density & $2.80 \mathrm{~g} / \mathrm{cc}$ \\
\hline Porosity & $1 \%$ \\
\hline Temperature at 3,000-foot depth & $73{ }^{\circ} \mathrm{F}$ \\
\hline Average RQD index value & 85 at 3,000 -foot depth \\
\hline Water table & Within 30 feet of surface \\
\hline Hydraulic conductivity & $10^{-7} \mathrm{~cm} / \mathrm{sec}$ at 3,000 -foot depth \\
\hline
\end{tabular}

Table 8-3. Gas Operating Conditions

\begin{tabular}{||l|l||}
\hline \multicolumn{1}{|c|}{ Property } & Value \\
\hline \hline Gas storage pressure, maximum & $1,370 \mathrm{psi}$ \\
\hline Gas storage pressure, minimum & $250 \mathrm{psi}$ \\
\hline Refrigerated gas temperature & $-20^{\circ} \mathrm{F}$ \\
\hline
\end{tabular}


To determine the effect of the refrigerated gas temperatures on the strength of the granite, thermal properties of granite were obtained from literature sources. The sources include Carslaw and Jaeger [1959] and Kuriyagawa et al. [1977]. The thermal properties are given in Table 8-4.

Table 8-4. Thermal Properties of Granite

\begin{tabular}{||l|c|}
\hline \multicolumn{1}{|c|}{ Property } & Value \\
\hline \hline Coefficient of thermal expansion & $3.75 \times 10^{-6}$ \\
\hline Specific heat & $880 \mathrm{~J} / \mathrm{kg}-\mathrm{K}$ \\
\hline Thermal conductivity & $2.51 \mathrm{~W} / \mathrm{m}-\mathrm{K}$ \\
\hline
\end{tabular}

To apply the analytical and empirical methods to the evaluation of the design of the refrigerated gas storage cavern, several additional assumptions were made. These assumptions are:

1. There are two joint sets present at the site.

2. Neither joint set is horizontal.

3. Water inflow (free water in the joints) will be less than 10 gallons per minute (gpm).

\subsubsection{In Situ Stresses}

The in situ stress state (magnitude of the horizontal and vertical stresses as well as the orientation of the horizontal stresses) affects the size of openings that can safely be constructed underground and the orientation of the openings that will enhance their stability. Regions subjected to tectonic forces may have maximum stresses that are greatly in excess of the stresses imposed by the vertical load of the rock. Generally, the axis of underground openings should be oriented between $15^{\circ}$ and $30^{\circ}$ of the major principal stress [Selmer-Olsen and Broch, 1977].

A review of the literature [Lindner and Halpern, 1978; Zoback and Zoback, 1980; University of Karlsruhe, 1998] on in situ stress magnitude and orientation indicates that the horizontal in situ stress in the region of the proposed storage site is anisotropic. Based on data from Maryland and adjacent portions of Pennsylvania and Virginia, the maximum horizontal stress varies from about 1.08 to 3.16 times the minimum horizontal stress with an average of 2.18. The minimum horizontal stress varies from about 0.9 to 1.4 times the vertical stress with an average of about 1.06 . The assumptions for this study are that the maximum stress is equal to twice the minimum horizontal stress, and the minimum horizontal stress is equal to the vertical stress.

The orientation of the major principal stress varies from $\mathrm{N} 35^{\circ} \mathrm{W}$ to $\mathrm{N} 85^{\circ} \mathrm{E}$. The average orientation of the maximum horizontal stress is $\mathrm{N} 69^{\circ} \mathrm{E}$. 


\subsubsection{Room Size and Stability}

The evaluation of the proposed mined openings drew upon work from Bieniawski [1976], Barton et al. [1974; 1994], Hoek [1979] and Hoek and Brown [1980]. These papers present analytical formulas and empirical methods to evaluate the stability of underground openings. The empirical methods are based on case histories of existing tunnels and caverns.

Barton et al. [1974] developed a method to describe the competency of rock that is widely used by the Norwegian Geological Institute to describe rock conditions for underground construction. This system of classification is called the $Q$-system. The $Q$-system uses:

$$
Q=B_{Q D} / J_{n} Q D_{r} / J_{a} Q D_{w} / S R F \text { ! }
$$

where:

$$
\begin{aligned}
R Q D & =\text { rock quality determination } \\
J_{n} & =\text { number of joint sets } \\
J_{a} & =\text { degree of alteration or clay filling along the joints } \\
J_{r} & =\text { roughness of the joint surfaces } \\
J_{w} & =\text { estimate of potential water inflow } \\
S R F & =\text { estimate of rock loading. }
\end{aligned}
$$

Tables to apply numerical values to descriptions of the joint and rock properties are provided by Barton et al. [1974].

From this estimate of competency, Barton et al. [1974] prepared guidelines for the type and amount of support that may be required to support mined openings for long-term use. The development of the $Q$ system was largely based on experiences in developing underground structures in the Scandinavian countries. Barton [1976] describes successful application of the $Q$-system in the design of a powerhouse structure. Barton et al. [1994] discusses the application of the $Q$-system to the design and construction of an underground ice hockey stadium in Norway.

Barton et al. [1974] also developed empirical relationships between rock quality, $Q$, and roof and wall support pressures. For roof support pressure when there are less than three sets of joints in the rock, the relationship was found to be:

$$
\mathrm{P}_{\text {roof }}=\mathbf{Q} / 0 \times \mathrm{J}_{\mathrm{n}}{ }^{1 / 2} \times \mathrm{Q}^{-1 / 3} \mid / \mathrm{B} \times \mathrm{J}_{\mathrm{r}} \text { ! }
$$

where $P_{\text {roof }}$ is the permanent roof support in $\mathrm{kg} / \mathrm{cm}^{2}$. 
The wall support pressure is determined using the same equation, but the value of $Q$ is altered. The value of $Q$ is increased to reflect the "more favorable position of excavation walls as opposed to roofs" [Barton et al., 1974]. For $0.1<Q<10$, the equation-derived $Q$ should be adjusted to $2.5 Q$ for use in estimating wall support pressure, and for a calculated $Q>10, Q$ should be adjusted to $5 Q$.

Barton et al. [1974] developed 38 categories of support based on an analysis of about 200 case histories. They looked at the relationship between $Q$, excavation dimensions, and the support actually used in the case studies. They then developed a table of recommended support methods with numerous subcategories based on dimensions, number of joint sets, support pressure value, and RQD. The support categories were compacted and the support requirements were simplified in Barton et al. [1994] based on continuing study of new underground facilities.

Bieniawski [1976] also developed a similar classification system using somewhat different factors to describe the rock mass:

1. Uniaxial compressive strength

2. Drill core quality or $\mathrm{RQD}$

3. Joint spacing

4. Joint condition

5. Groundwater conditions

6. Joint orientation.

From these parameters, Bieniawski developed a rock quality, $Q$. The numerical value of $Q$ is derived by summing ratings associated with the various classification parameters. Bieniawski then converted his $Q$ into an RMR (rock mass rating) value for evaluation and analysis according to Equation 8-3.

$$
\mathrm{RM} R=9 \times \ln \mathbf{\mathbf { Q }}+44
$$

He drew upon the rock quality relationships along with case histories to estimate the standup time (period of stability) for ranges of unsupported cavern span. Bieniawski provides guidance for the type of support required for long-term stability of relatively shallow, narrow (approximately 10 meters) openings of the type used for vehicular tunnels.

Hoek [1979] proposed a preliminary method to evaluate sites for waste repositories. If this evaluation was favorable, it would then need to be verified by a detailed site investigation. Hoek looked at:

1. Structural conditions, strength, and deformation characteristics of the rock.

2. In situ state of stress.

3. Shape, size, and location in relationship to each other of the excavations.

4. Groundwater conditions. 
5. Thermal loading induced by the waste.

Hoek also provided a chart to equate rock quality, stress ratio, and stability methods required to maintain an opening.

\subsubsection{Pillar Size}

Hoek and Brown [1980] provide methods to determine the stresses in pillars as well the effect of varying the height-to-width ratio of the pillar. The stress on a rectangular pillar is:

$$
\sigma_{p}=\gamma z \mathbf{d}+w_{o} / w_{p} \mathbf{i} \mathbf{d}+I_{o} / I_{p} \mathbf{i}
$$

where:

$$
\begin{aligned}
\sigma_{p} & =\text { stress on the pillar } \\
\gamma & =\text { unit weight of the over burden } \\
z & =\text { depth to the excavation } \\
\mathrm{w}_{0} & =\text { room width } \\
\mathrm{w}_{\mathrm{p}} & =\text { pillar width } \\
\mathrm{I}_{0} & =\text { room width adjacent to the long side of the pillar } \\
\mathrm{I}_{\mathrm{p}} & =\text { pillar length. }
\end{aligned}
$$

Hoek and Brown [1980] provide a methodology to evaluate the impact of shape (varying the width/height ratio) on the strength of the pillar. The method requires an assessment of the rock quality, the pillar width/height ratio, and the uniaxial compressive strength of the rock. Most of this work relies upon experience with pillars in coal mines.

The rock quality and width/height ratio are used to obtain a ratio between the average pillar strength and the uniaxial compressive strength of the rock. The uniaxial compressive strength of the rock is multiplied by this ratio to derive the average pillar strength. The average pillar strength can then be used to determine the factor of safety for the pillar:

where:

$$
\text { F actor of safety }=\sigma_{15 . \text { av }} / \sigma_{p}
$$

$$
\begin{aligned}
\sigma_{1 s . a v} & =\text { average pllar strength } \\
\sigma_{p} & =\text { stress on the pillar. }
\end{aligned}
$$

\subsubsection{Shaft Stability}

In general, the requirement to support shafts is based upon both the functions and environmental conditions of the shaft. The functions of the shaft relate to the expected life of the shaft; its size, shape, and depth; and its intended use. The environmental conditions relate to the in situ stresses, geology, and hydrology of the location. The structural requirements for a shaft are dictated by the physical and mechanical properties of the in situ rock, hydrology, temperature, and tectonic conditions [Ostrowski, 1972]. Shaft support systems serve to reinforce weak or broken rock, withstand active lateral stresses, 
limit water inflow, facilitate installation of hoisting equipment, or reduce ventilation requirements. A shaft with a very limited life for personnel or rock movement would not utilize shaft lining for these two purposes.

Based on the geologic setting (Table 8-1) and the rock properties (Table 8-2), the requirement for internal support of the shafts was evaluated. Works by Ostrowski [1972], Abel et al. [1979], and Richards and Abel [1981] were used to evaluate the stresses acting on the shafts and the need for support in the shafts.

The stresses acting on a circular shaft based on Mohr-Coulomb criteria are [Abel et al., 1979]:

$$
\begin{aligned}
& \sigma_{r}=\sigma_{H} 巴 \mathbb{e} /\left.\mathbf{d}_{+}\right|^{\mathbf{t}} \mathbf{j} \\
& \sigma_{t}=\sigma_{H} \mathbb{e}+\mathbf{e} /\left.\mathbf{a}_{+}\right|^{\mathbf{j}} \mathbf{j}
\end{aligned}
$$

where:

$$
\begin{aligned}
\sigma_{\mathrm{r}} & =\text { radial stress acting on the shaft } \\
\sigma_{\mathrm{t}} & =\text { tangential stress acting on the shaft } \\
\sigma_{\mathrm{H}} & =\text { in situ horizontal stress } \\
\mathrm{r} & =\text { radius of the shaft } \\
\mathrm{I} & =\text { extent of the disturbed rock zone from the shaft wall. }
\end{aligned}
$$

Failure of the rock occurs at a stress level equal to:

$$
\sigma_{f}=\sigma_{o}+\boldsymbol{\partial} \times \tan \beta \mathbf{I}
$$

where:

$$
\begin{aligned}
\sigma_{\mathrm{f}} & =\text { tangential stress at failure } \\
\tan \beta & =\boldsymbol{D}+\sin \phi \boldsymbol{D}-\sin \phi \mathbf{9} \\
\phi & =\text { angle of internal friction of the rock } \\
\sigma_{\mathrm{o}} & =\text { estimated rock mass strength. }
\end{aligned}
$$

Abel et al. [1979] use an iterative process to solve Equations 8-6, 8-7, and 8-8 for $l$, the horizontal thickness of the disturbed rock zone (DRZ) around the shaft.

The analytical results from Abel et al. [1979] were verified by finite element modeling using SPECTROM-32 [Callahan et al., 1989]. The SPECTROM-32 modeling used the anisotropic stresses expected to be present in the host rock.

\subsubsection{Thermal Effects of Refrigerated Gas on Rock Strength}

Thermally induced stresses and strains will occur when storing chilled natural gas in an underground mine because of the changes in temperature of the host rock. The effects of these thermally induced 
stresses on the stability of the storage mine were evaluated using finite element simulations of the mine. SPECTROM-41 [Svalstad, 1989] is a finite element heat transfer analysis program and was used to predict temperature as a function of time in the granite surrounding the storage mine. This temperature information, in conjunction with the coefficient of thermal expansion of the granite, was used in the thermomechanical finite element program SPECTROM-32 to determine the effects of temperature changes on mine stability.

The geometry of the natural gas storage mine was approximated with an axisymmetric model. The axisymmetric model conserved the actual volume of the mine, which is represented as three concentric rings at a depth of 914 meters (3,000 feet), as shown in Figure 8-1. The finite element model of the mine is shown in Figure 8-2. It contains 7,433 nodes and 2,412 eight-noded elements. The model extends from the ground surface to a depth of 1,800 meters and has an outside radius of 2,500 meters. The great extents of the boundaries were chosen so that the modeled mine would not be influenced by the boundaries.

The entire model was assumed to be granite. The material properties used to model the granite and evaluate its stability are listed in Tables 8-2 and 8-4. The actual in situ stress state, which is known to be anisotropic, cannot be represented with axisymmetric models, and was therefore, modeled as being isotropic and equal to the weight of the overburden. This results in an isotropic stress of 0.0275 $\mathrm{MPa} /$ meter of depth based on granite's density of $2,800 \mathrm{~kg} / \mathrm{m}^{3}$. The in situ stress at the depth of the mine is about $25.1 \mathrm{MPa}$. The assumed initial in situ temperature of the granite as a function of depth is described by the following equation:

$$
\mathrm{T}=10.3+0.0164 \times \mathrm{D}
$$




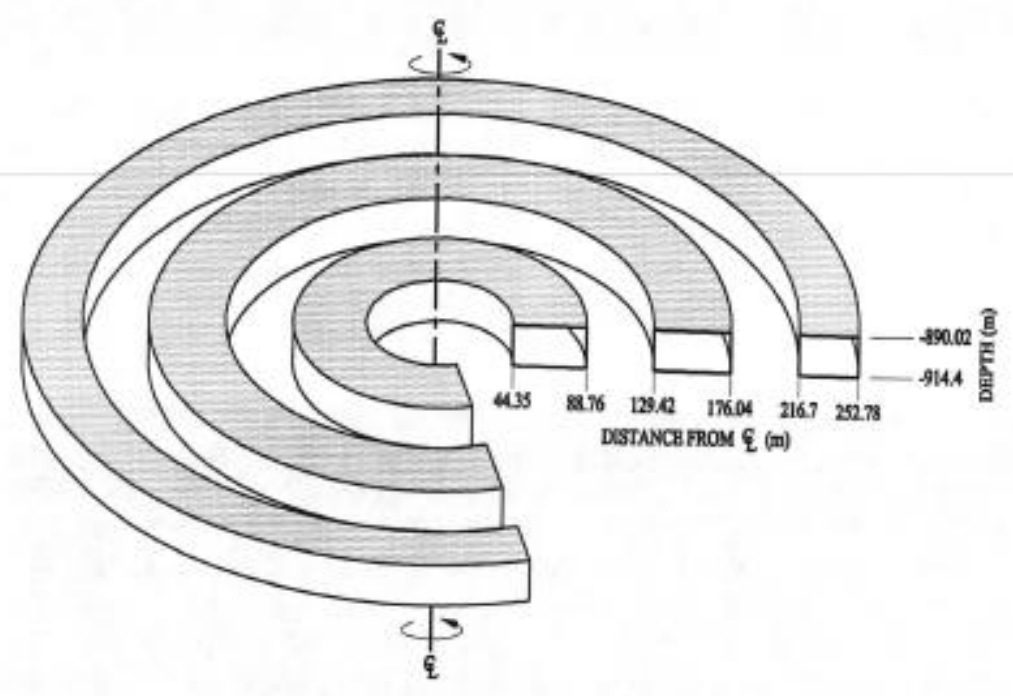

Figure 8-1. Schematic of Axisymmetric Model of Storage Mine. 


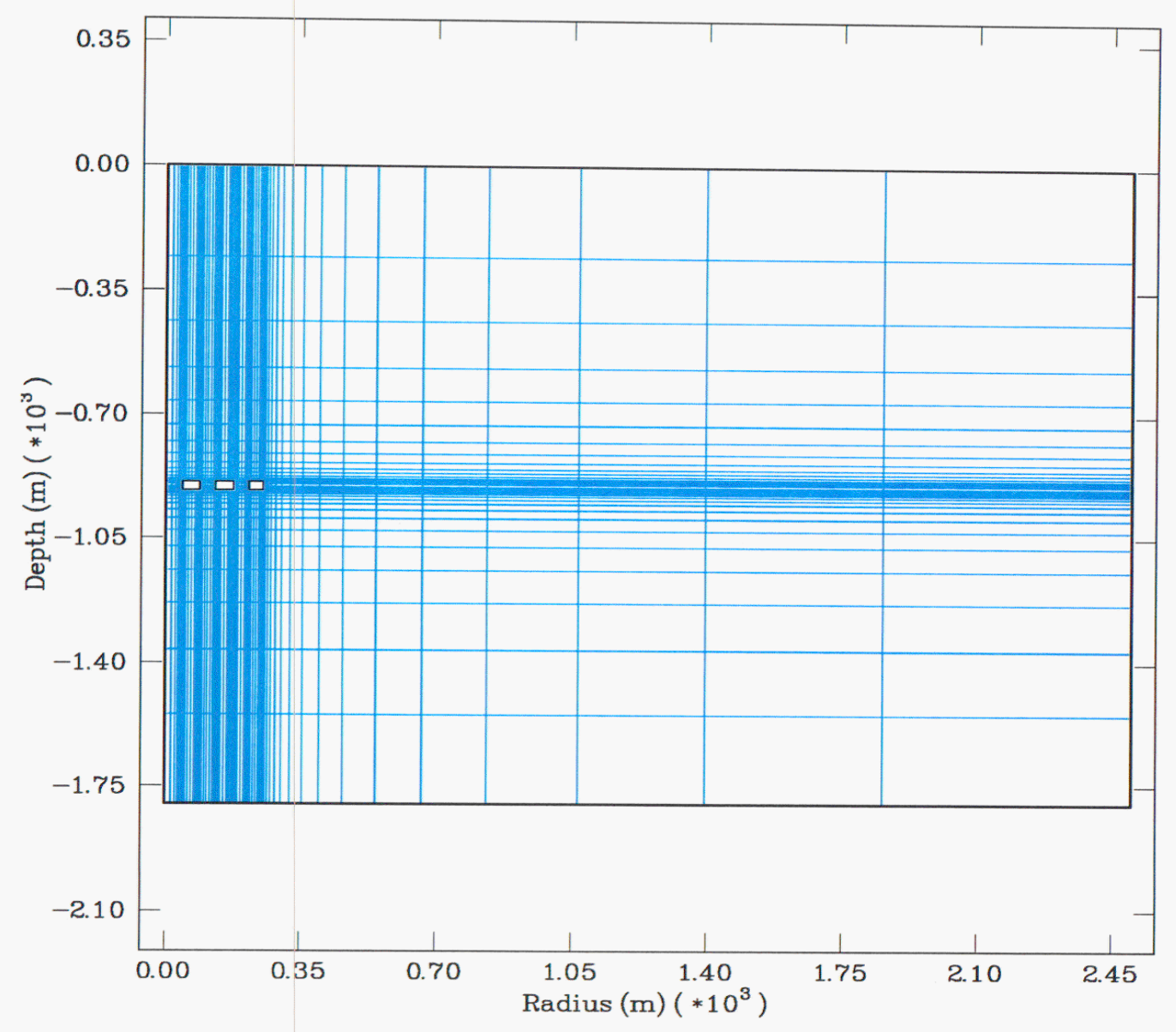

Figure 8-2. Finite Element Mesh of Storage Mine 
where the temperature is in degrees centigrade and $D$ is the depth in meters. The initial temperature of the granite at the mine level is about $25^{\circ} \mathrm{C}$. The gas pressure in the mine and the temperature of the gas were represented in the model by specifying normal tractions and fixed temperatures along the mine surfaces. The planned gas storage temperature in the mine is $-28.9^{\circ} \mathrm{C}\left(-20^{\circ} \mathrm{F}\right)$. The planned minimum and maximum gas pressures are $2.1 \mathrm{MPa}$ (300 psi) and 9.1 (1320 psi), respectively.

In an attempt to conservatively evaluate the thermal effects on mine stability, finite element simulations were made of two worst-case scenarios. The two scenarios are: (1) maintaining the minimum gas pressure for a long term of 5 years and (2) during gas withdrawal.

\subsection{DESIGN EVALUATION}

\subsubsection{Room Width}

The first step in evaluating the stability of the proposed rooms was to quantify the competency of the rock. Using Barton et al. [1974] as a guide, the following values were used from the rock properties in Table 8-2 and from tables provided in Barton et al. [1974]:

- $\mathrm{RQD}=85$

- $J_{n}=4$ for two joint sets

- $J_{r}=2$ for smooth, undulating joints

- $J_{a}=2$ for slightly altered joint surfaces

- $J_{w}=0.66$ for medium water inflow

- $\mathrm{SRF}=1.0$ for high stress and tight structure.

The values chosen to describe the joints, water inflow potential, and zones of weakness in the rock are conservative. However, the chosen descriptions and corresponding numerical values are not at the extreme side of the possible ranges. From these values, $Q$ of the rock mass was calculated (from Equation 8-1) to be 14.0. As seen in Figure 8-3, rooms excavated in this quality of rock would have to be less than about 33 feet in width to stand for an extended time without support. Bieniawski [1976] estimates that this quality rock would support a room width of about 23 feet without support. 


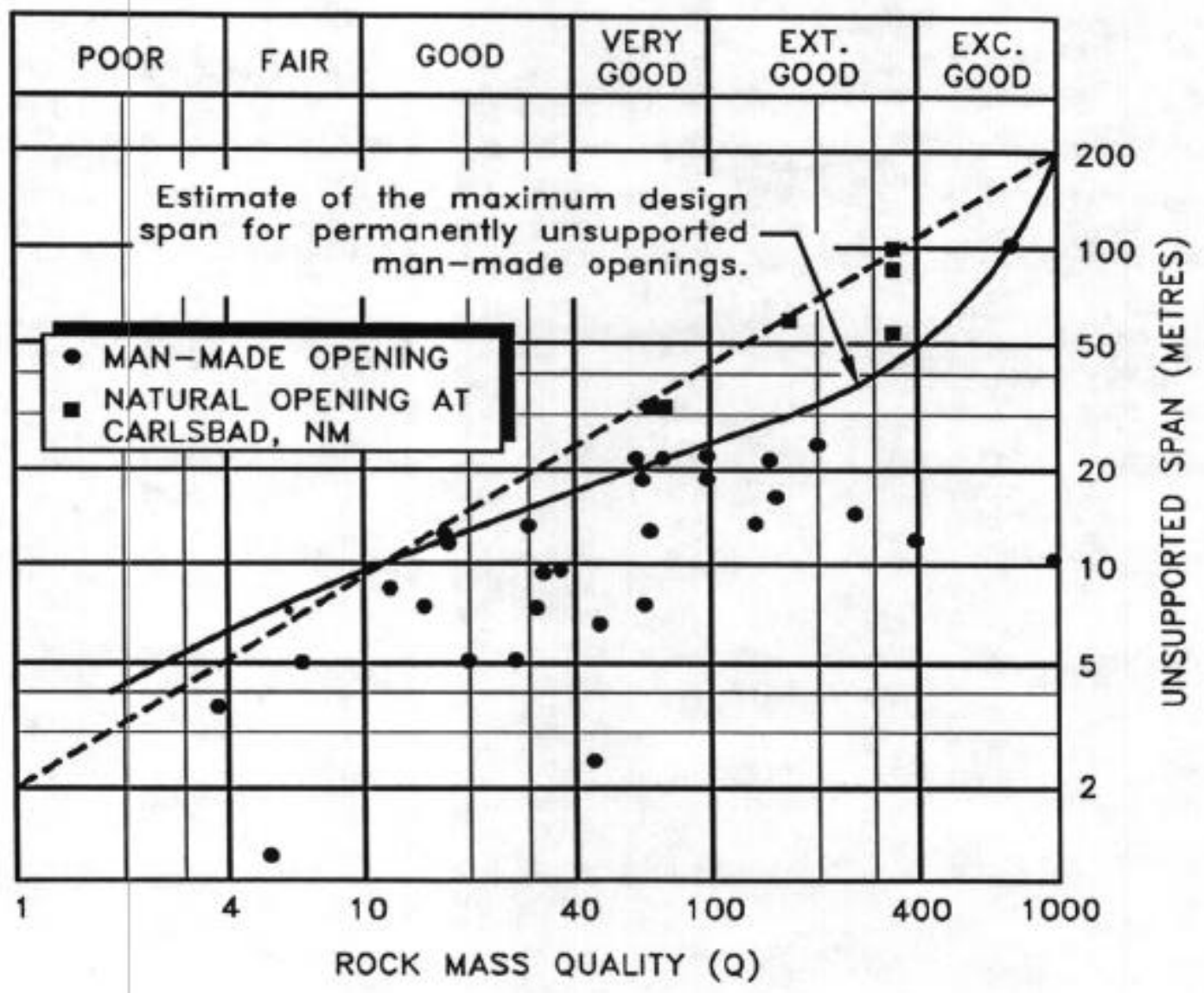

Figure 8-3. Estimate of Maximum Design Span for Permanently Unsupported Man-Made Openings 
Using these values of rock quality, wall support pressure, and the proposed room dimensions, recommendations for support were obtained from Barton et al. [1994]. The basic categories of support for the walls and the roof were obtained from Figure 8-4. (This figure is updated and the reinforcement categories are simplified from that in the Barton et al. [1974] report.) ESR listed in Figure 8-4 is the Excavation Support Ratio from Barton et al. [1974]. ESR is an empirical value to reflect the required longevity and safety of the mined openings. For this study, an ESR value of 1.3 was used. This value is recommended for storage rooms, water treatment plants, minor vehicular tunnels, etc. This data placed the walls in support category 2 and the roof in support category 4.

For wall support, the recommended rock support is spot bolting as needed. The recommended roof support is for systematic bolting with tensioned, grouted bolts on 4.5-6-foot (1.5-2-meter) centers, and unreinforced shotcrete $0.2-0.4$ inch (4-10 centimeter) thick. Rock bolt length will depend upon the spacing and orientation of rock joints but will be a minimum of 8 feet ( 2.5 meters).

Bieniawski [1976] does not provide data for recommended support for caverns that are over 10 meters in width. However, for 33-foot- (10-meter-) wide tunnels in this quality of rock, the recommendation is for 10-foot- (3-meter-) long bolts placed locally in the crown spaced on 8-foot (2.5-meter) centers with wire mesh as needed with the addition of 2 inches (50 millimeters) of shotcrete as needed.

Figure 8-5 shows that Hoek [1979] interprets the work of Barton and Bieniawski to say that light support would probably be required for the quality of rock and location of the proposed refrigerated gas storage cavern.

\subsubsection{Maximum Width}

Based on the work by Barton et al. [1974], a supported room span of up to 130 feet (40 meters) can be easily developed in the Ellicott granodiorite. The support requirements to maintain such rooms are uncertain but will not be less than that for the 80-foot-wide rooms. However, complexes of rooms of this width and at 3,000-foot depth have not been routinely constructed.

A 65-meter (215-foot) chamber has been constructed in Norway for an ice hockey rink [Barton et al., 1994]. This chamber is at a depth of about 25 meters (82 feet) in gneiss with an average $Q$ value of about 9 . The span is supported with rock bolts and shotcrete. Note that this is a single chamber, not a mined room and pillar complex. 

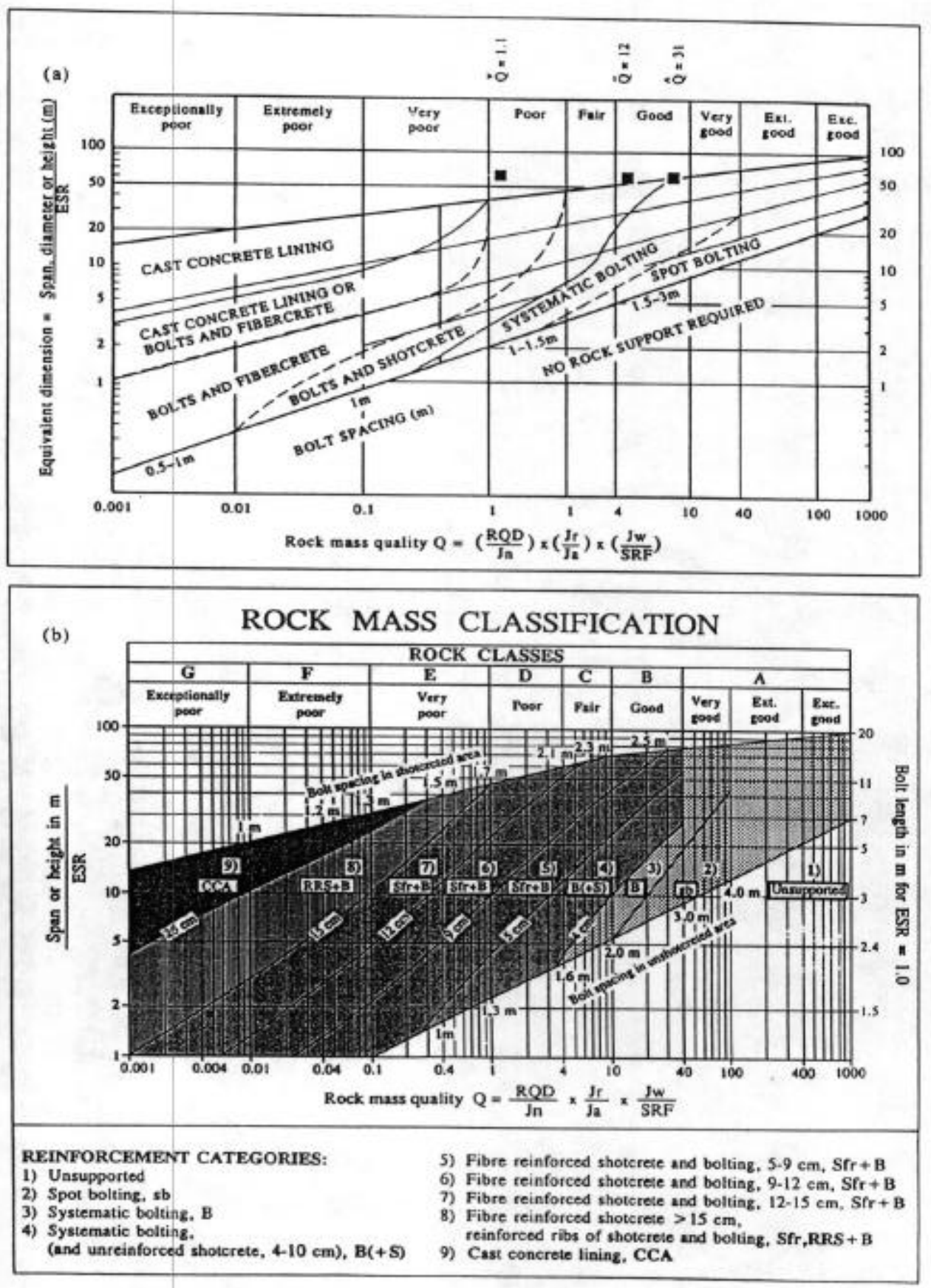

Figure 8-4. Tunnel Support Chart for Categories of Support (After Barton et al. [1994]). 


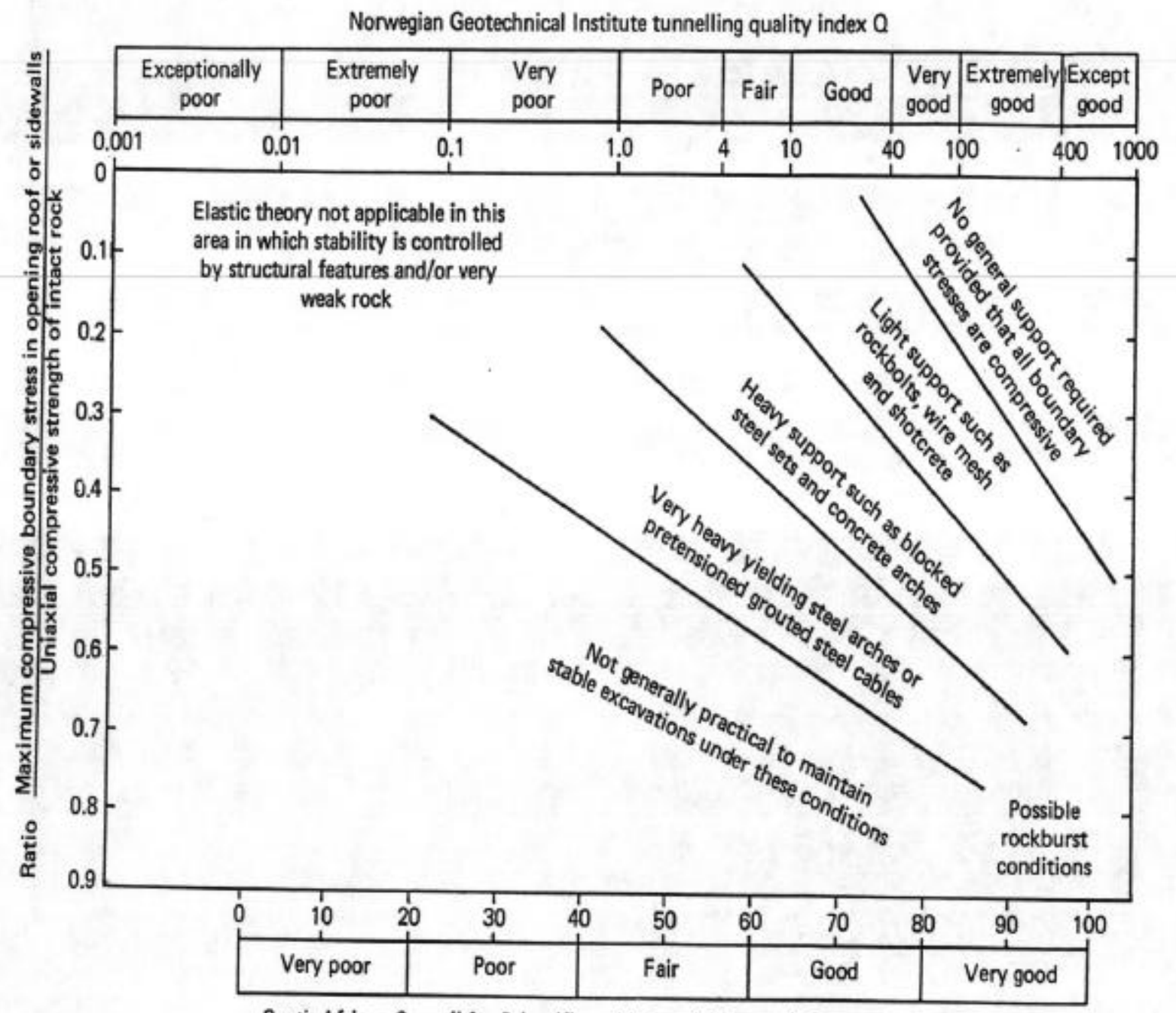

South African Council for Scientific and Industrial Research Geomechanics classification

Figure 8-5. Underground Excavation Stability as a Function of Induced Stresses and Rock Mass Quality 


\subsubsection{Pillar Width}

As presently designed, the total vertical stress on the pillars is about 7,800 psi as calculated from Equation 8-4. With a compressive strength of the rock of $10,000 \mathrm{psi}$, the factor of safety of the pillar is 1.28 .

The strength of a pillar is also influenced by its shape. In this case, the pillars are relatively short for their horizontal cross-sectional size. From Figure 8-6, the average pillar strength to uniaxial compressive strength ratio for a pillar with a width-to-height ratio of 1.875 (150 feet/ 80 feet) and in very good quality rock is about 1.45 . The average pillar strength is then about $14,500 \mathrm{psi}(10,000 \mathrm{psi} \times 1.45)$. The safety factor is then 1.86 (from Equation 8-5), taking into account the pillar shape.

\subsubsection{Shaft Stability - Analytical Approach}

For the analytical approach to estimating the stability of the shaft, the horizontal stresses were assumed to act isotropically on the shaft. The effective in situ stress at the base of the shaft was conservatively estimated to be 9,090 psi from:

$$
\sigma_{\theta}=3 \sigma_{H \max }-\sigma_{H \min }
$$

where:

$$
\begin{aligned}
\sigma_{\theta} & =\text { the near - field tangential stress } \\
\sigma_{\mathrm{H} \max } & =\text { the maximum horizontal stress of } 7,260 \mathrm{psi} \\
\sigma_{\mathrm{H} \min } & =\text { the minimum horizontal stress of } 3,630 \mathrm{psi} .
\end{aligned}
$$

The rock mass strength was estimated to equal the average unconfined compressive strength of the rock, $10,000 \mathrm{psi}$, because this value is a conservatively low value for granitic masses. (Granites typically have an unconfined compressive strength in excess of 30,000 psi.) The angle of internal friction of the rock was estimated as $50^{\circ}$ (from Lama and Vutukuri [1978]). The resulting stresses, from Equations 8-6 through 8-8, acting at the transition from "failed" rock (the plastic zone) to "intact" rock (the elastic zone) near the shafts are shown in Table 8-5 and Figures 8-7 and 8-8.

As seen in Figures 8-7 and 8-8, there is a small zone, marked DRZ, immediately adjacent to the shaft wall that is overstressed. This overstressed rock may cause some spalling that may require minor support. 


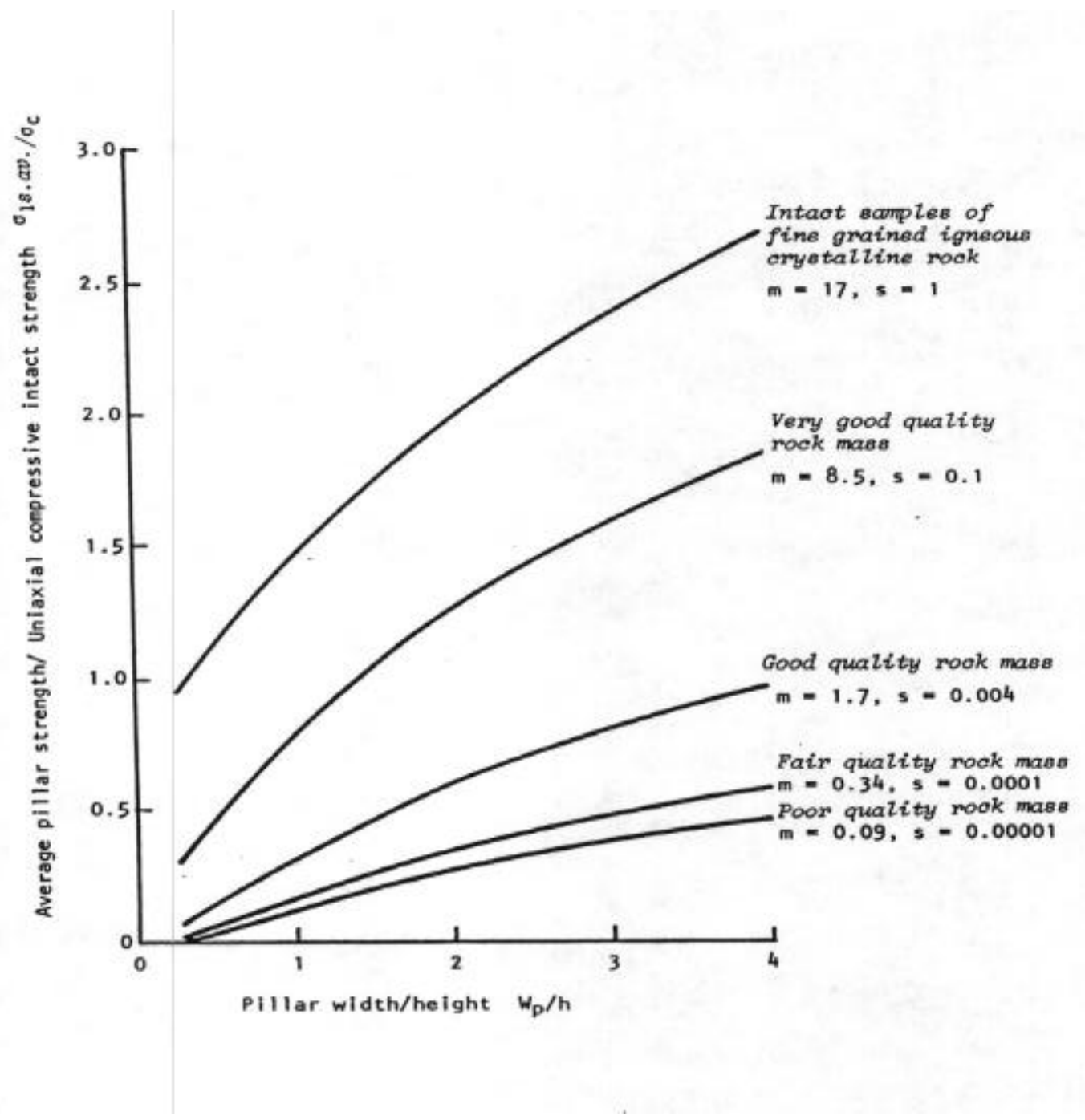

Figure 8-6. Influence of Pillar Width-to-Height Ratio on Average Pillar Strength (After Hoek and Brown 
Table 8-5. Stresses Acting Near the Shafts for Proposed Refrigerated Gas Storage Cavern

\begin{tabular}{||l|c|c||}
\hline \multicolumn{1}{|c|}{ Property } & $\begin{array}{c}\text { 18-Foot-Diameter } \\
\text { Shaft }\end{array}$ & $\begin{array}{c}\text { 10-Foot-Diameter } \\
\text { Shaft }\end{array}$ \\
\hline \hline Radial stress, psi & 960 & 961 \\
\hline Tangential stress, psi & 17,220 & 17,220 \\
\hline Thickness of DRZ, inches & 6.2 & 3.4 \\
\hline
\end{tabular}

To ensure that the estimated strength of the rock mass was not critical to the stability of the shaft, the estimated rock mass strength was reduced to 2,500 psi from $10,000 \mathrm{psi}$. This resulted in a slight increase in the extent of the DRZ to about 13 inches for the 18-foot-diameter shaft and 7 inches for the 10-foot-diameter shaft.

\subsubsection{Shaft Stability — Finite Element Modeling}

The thermomechanical finite element program SPECTROM-32 [Callahan et al., 1989] was used to simulate the elastoplastic response of the granite surrounding the shafts. Unlike the analytical solutions in which an isotropic stress field is assumed, the effect of the anisotropic in situ stress state in the granite could be explicitly simulated using SPECTROM-32. Taking advantage of the symmetry about the horizontal principal stress directions, only a quarter of a horizontal section through each shaft was represented in the finite element model. The far-field boundary of each finite element model was set at a radius equal to 20 the radius of the shaft.

An in situ stress state with maximum and minimum horizontal principal stresses of 6,060 and 3,030 psi and a vertical (out-of-plane) stress of 3,030 psi was specified to represent the assumed conditions at a depth of 3,000 feet in granite. Plane-strain conditions were assumed. Failure of the granite was represented using the Mohr-Coulomb criterion with an unconfined compressive strength of 10,000 psi and an internal friction angle of $50^{\circ}$. The residual (postfailure) strength of the granite was represented using the same criterion. The postfailure, plastic strains in the granite were based on the associative flow rule. Consequently, the rock dilated after failure, thereby representing the creation of porosity that is associated with fracturing.

The zones of failure predicted by SPECTROM-32 are shown in Figures 8-9 and 8-10 for the 10-footdiameter and 18-foot-diameter shafts, respectively. In these figures, the $x$-direction is parallel to the direction of the maximum horizontal principal stress. Figures 8-9 and 8-10 show that no failure is predicted on the wall of the shaft that is perpendicular to this direction. The depth of the failure zones increase as the angle from the $x$-direction increases until the failure zones are deepest on the wall that is perpendicular to the direction of the minimum horizontal principal stress (the $y$-direction). Even at their deepest, the failure zones predicted for the 10-foot-diameter and 18-foot-diameter shafts are only 4.8 and 9.4 inches deep, respectively. These values are about 50 percent greater than the DRZ predicted by the analytical method discussed above. Consequently, any spalling from the shafts is expected to require minimal support, such as rock bolting and meshing, and a concrete liner is not required to support the walls of the shafts under the assumed conditions. 


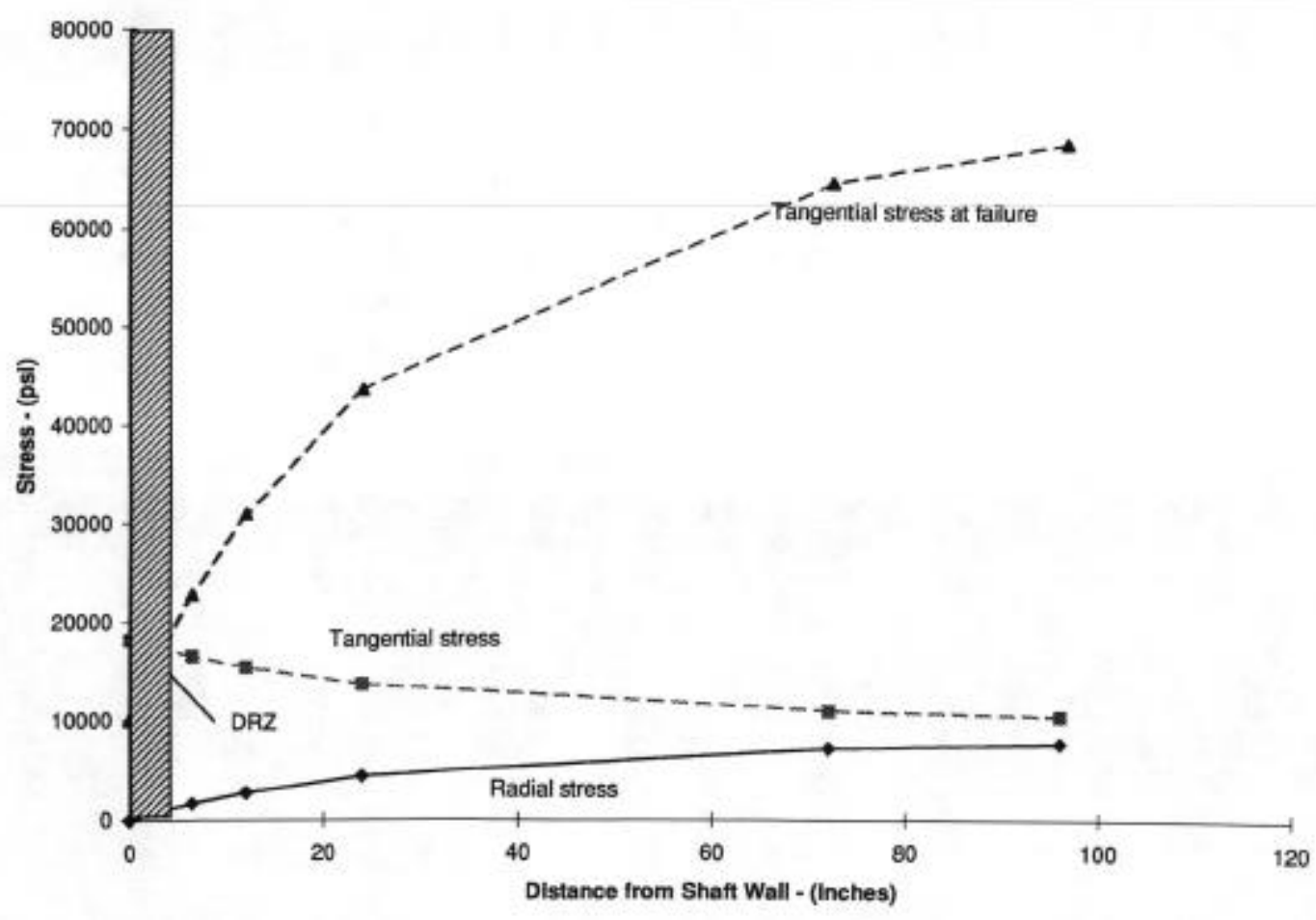




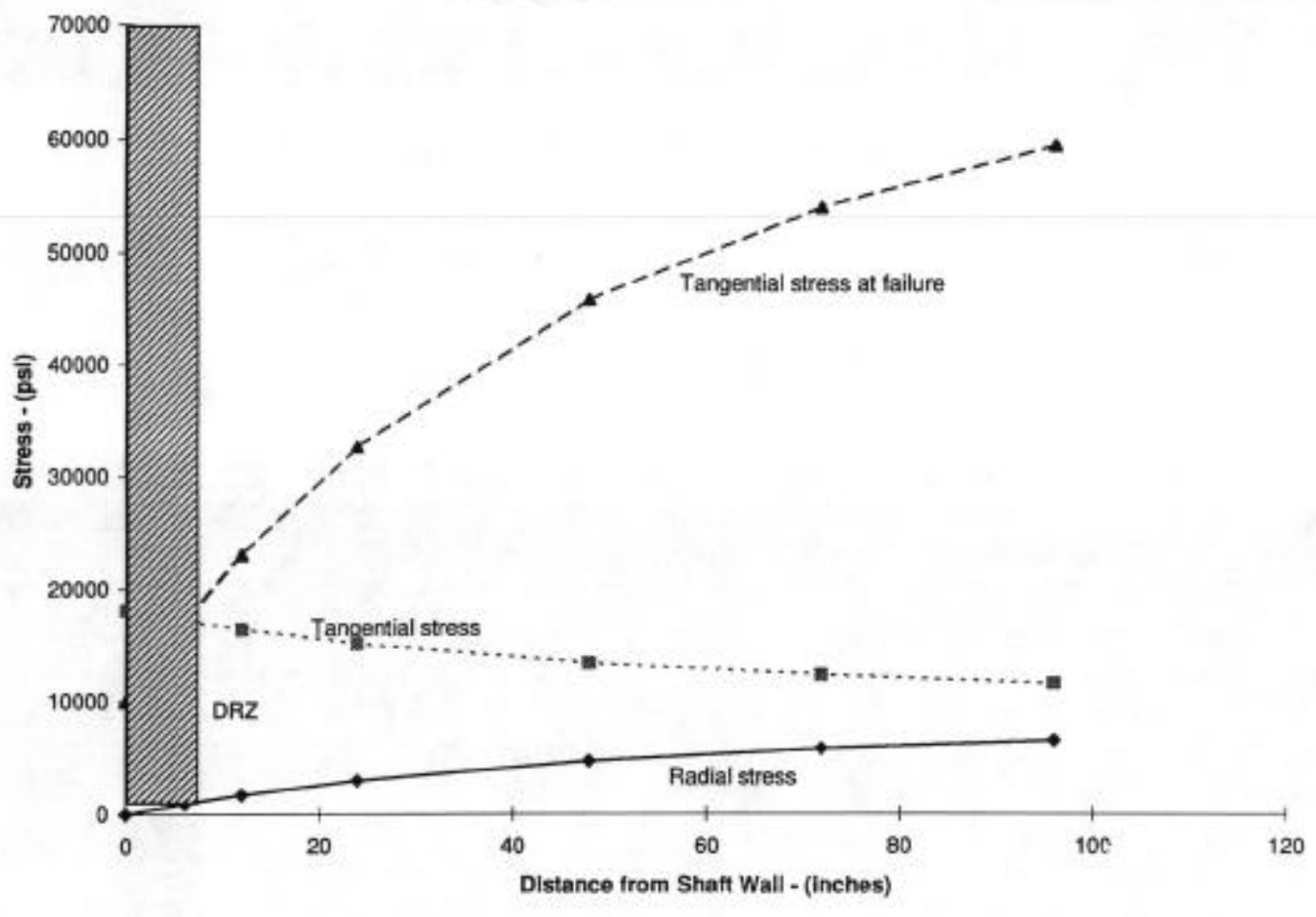




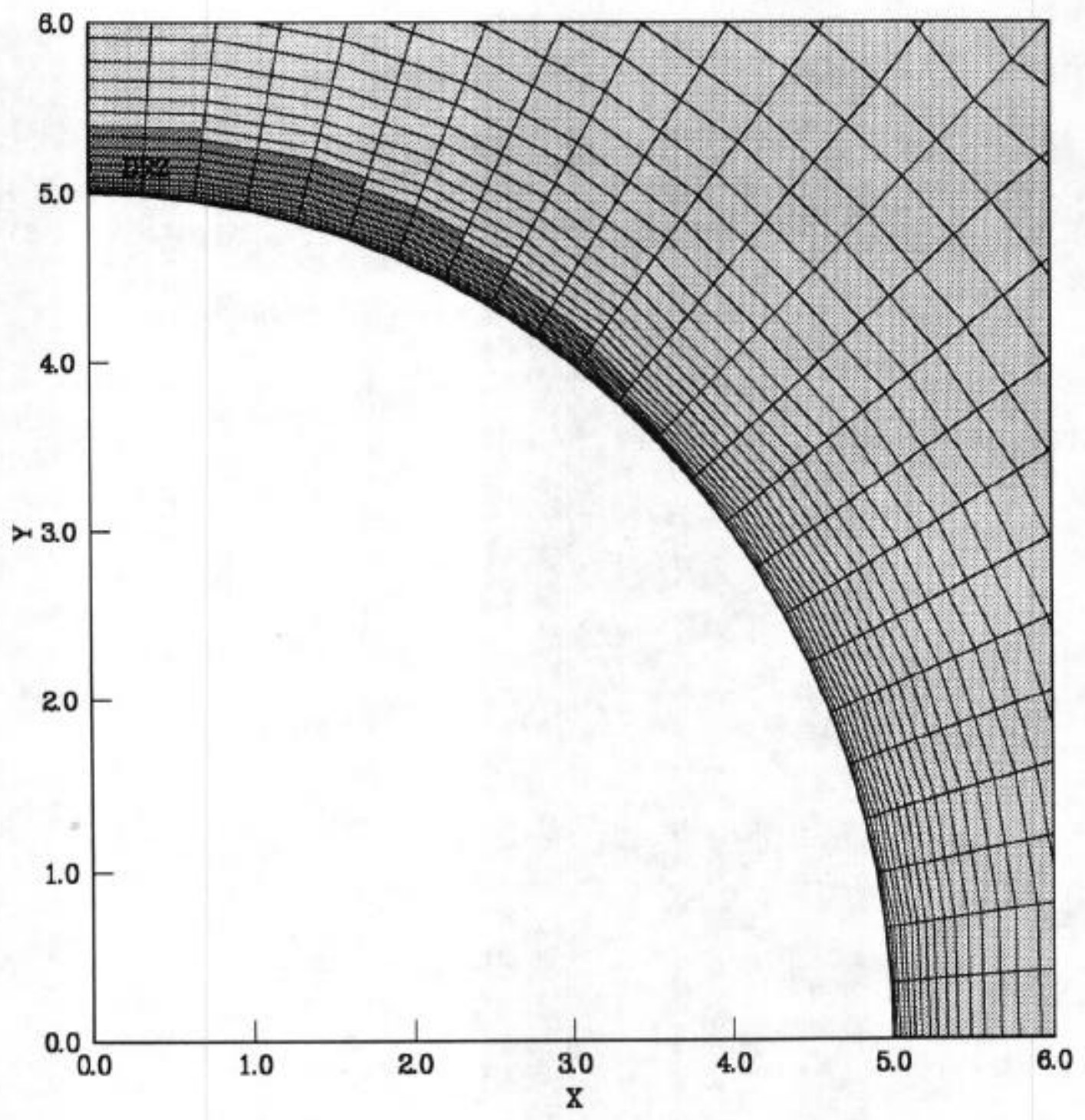

Figure 8-9. Influence of Pillar Width-to-Height Ratio on Average Pillar Strength (After Hoek and Brown) 10,000 psi Granite. 


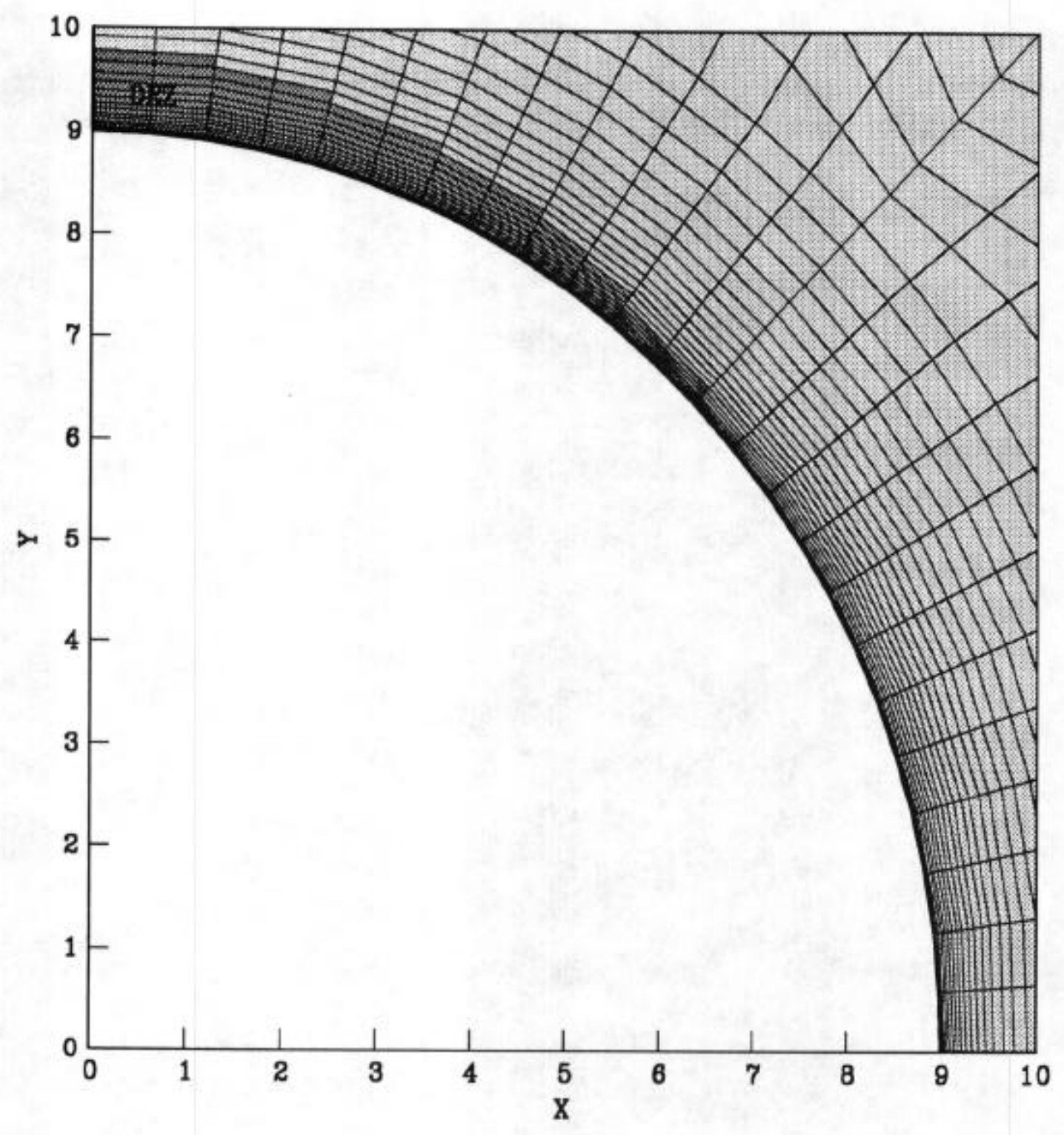

Figure 8-10. DRZ Predicted by SPECTROM-32 Around an 18-Foot-Diameter Shaft at 3,000-Foot Depth in 10,000 psi Granite. 


\subsubsection{Long-Term Thermal Effects at Minimum Gas Pressure}

In this simulation, the mine is modeled at the minimum gas pressure for a period of 5 years. The granite surrounding the gas storage mine is initially at the original in situ temperature. The mine is instantaneously excavated and filled with natural gas at a temperature of $-28.9^{\circ} \mathrm{C}\left(-20^{\circ} \mathrm{F}\right)$ at the minimum storage pressure of $2.1 \mathrm{MPa}(300 \mathrm{psi})$. The gas pressure and temperature are held constant. The stresses in the pillars are monitored as the host rock is cooled over a 5-year period. The mine will probably encounter the largest thermal gradients during this initial storage period when most of the surrounding granite is still at the original in situ temperature.

Figures 8-11 and 8-12 show temperature contours predicted by SPECTROM-41 in the granite surrounding the mine at several times during the 5-year simulation. The temperature gradients are initially very high near the room surfaces and decrease with time as the host rock is cooled. Cooling is a fairly slow process. As shown in Figure 8-12, the temperatures of the center of the pillars are nearly unchanged after 1 year. However, within 5 years, the pillars have cooled significantly and the temperature gradients at the room surfaces are somewhat lower.

Figures 8-13 and 8-14 show contours of the predicted Mohr-Coulomb factors of safety in the pillars at several times during the 5-year simulation. The Mohr-Coulomb factors of safety are based on an unconfined compressive strength of $69 \mathrm{MPa}(10,000 \mathrm{psi})$ and an internal friction angle of $50^{\circ}$. Because the simulations assume no thermal strains at time zero, the factors of safety shown at time zero do not reflect any thermal effects. All of the factors of safety are greater than two. As shown in the figures, the factors of safety near the room surfaces actually increase as the rock is cooled. Factors of safety in the center of the pillar decrease slightly with time.

Figures 8-15 and 8-16 show contours of the predicted maximum principal stress in the granite. A tensile stress is represented by a positive value with the sign convention used. Again, contours shown at time zero do not reflect any thermal effects. The maximum principal stresses are initially all compressive with a least compressive value about equal in magnitude to the gas pressure. However, contraction of the granite surrounding the mine as it cools results in the stresses becoming less compressive. After 1 year, the center of the roof of the centermost room is predicted to have a tensile stress of about $1 \mathrm{MPa}$. The maximum principal stresses change very little between 1 year and 5 years. 


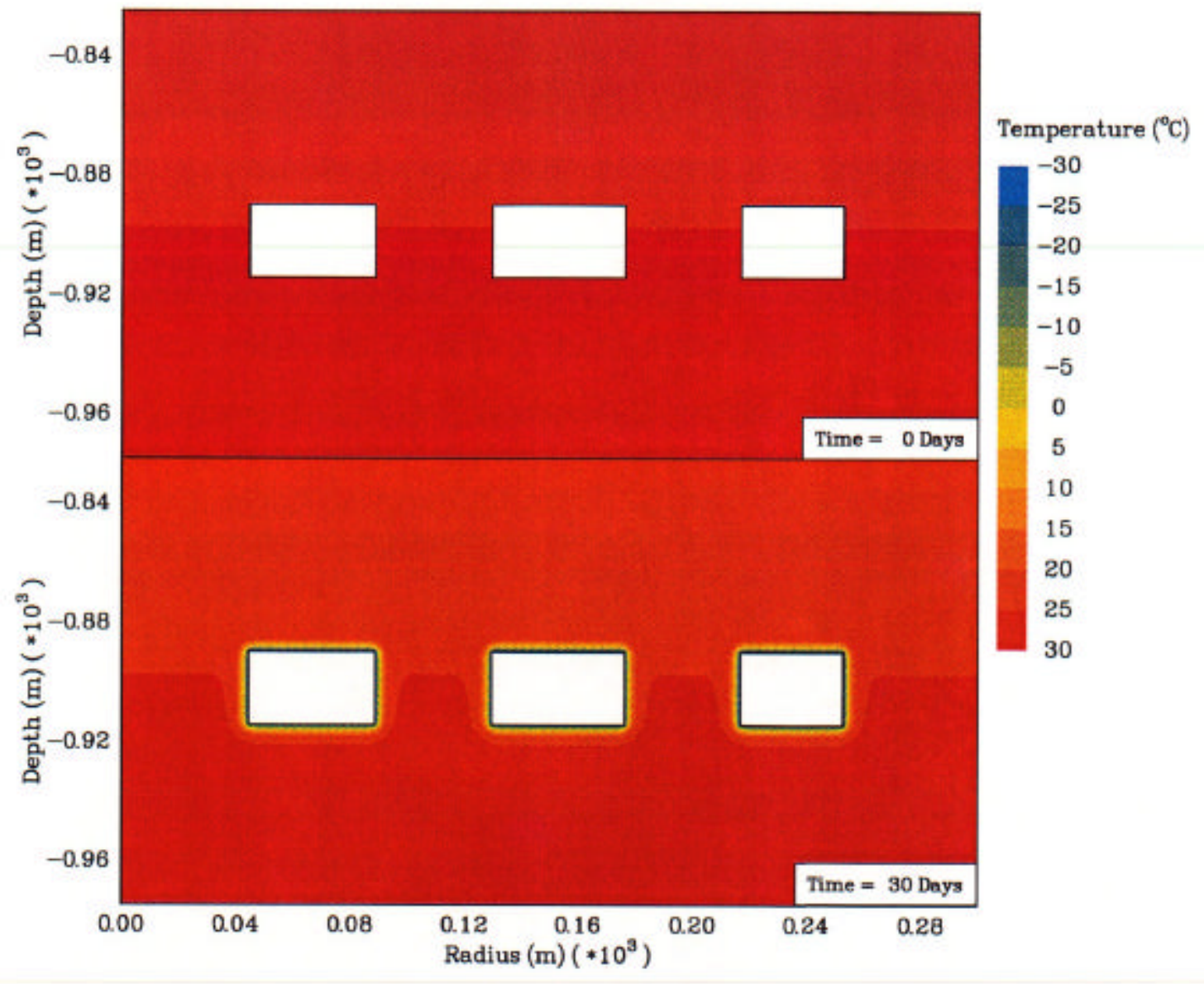

Figure 8-11. Temperature Contours at Time 0 and 30 Days After Filling With Gas at $-28.9^{\circ} \mathrm{C}$. 


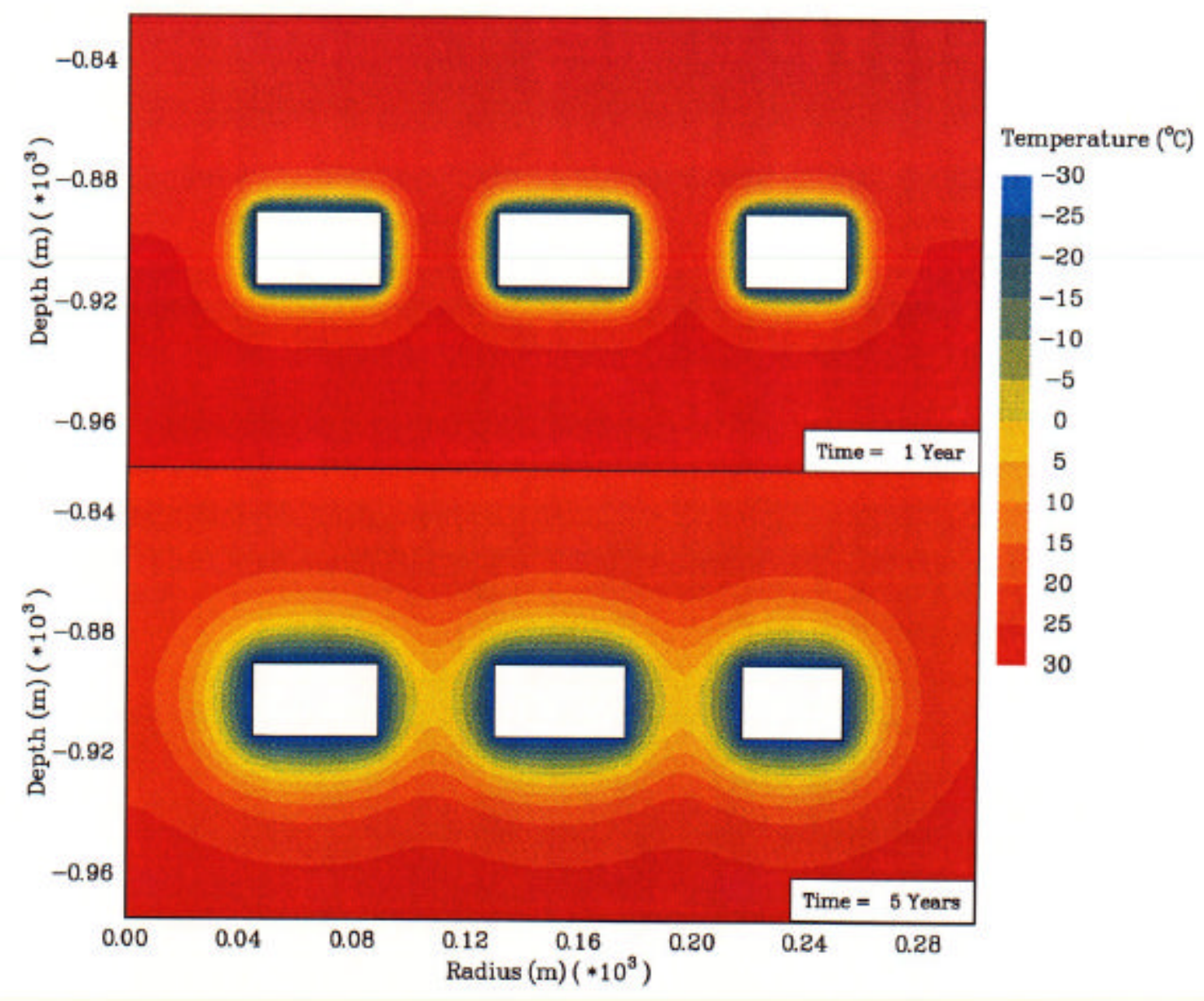

Figure 8-12. Temperature Contours at One and 5 Years After Filling With Gas at $-28.9^{\circ} \mathrm{C}$. 


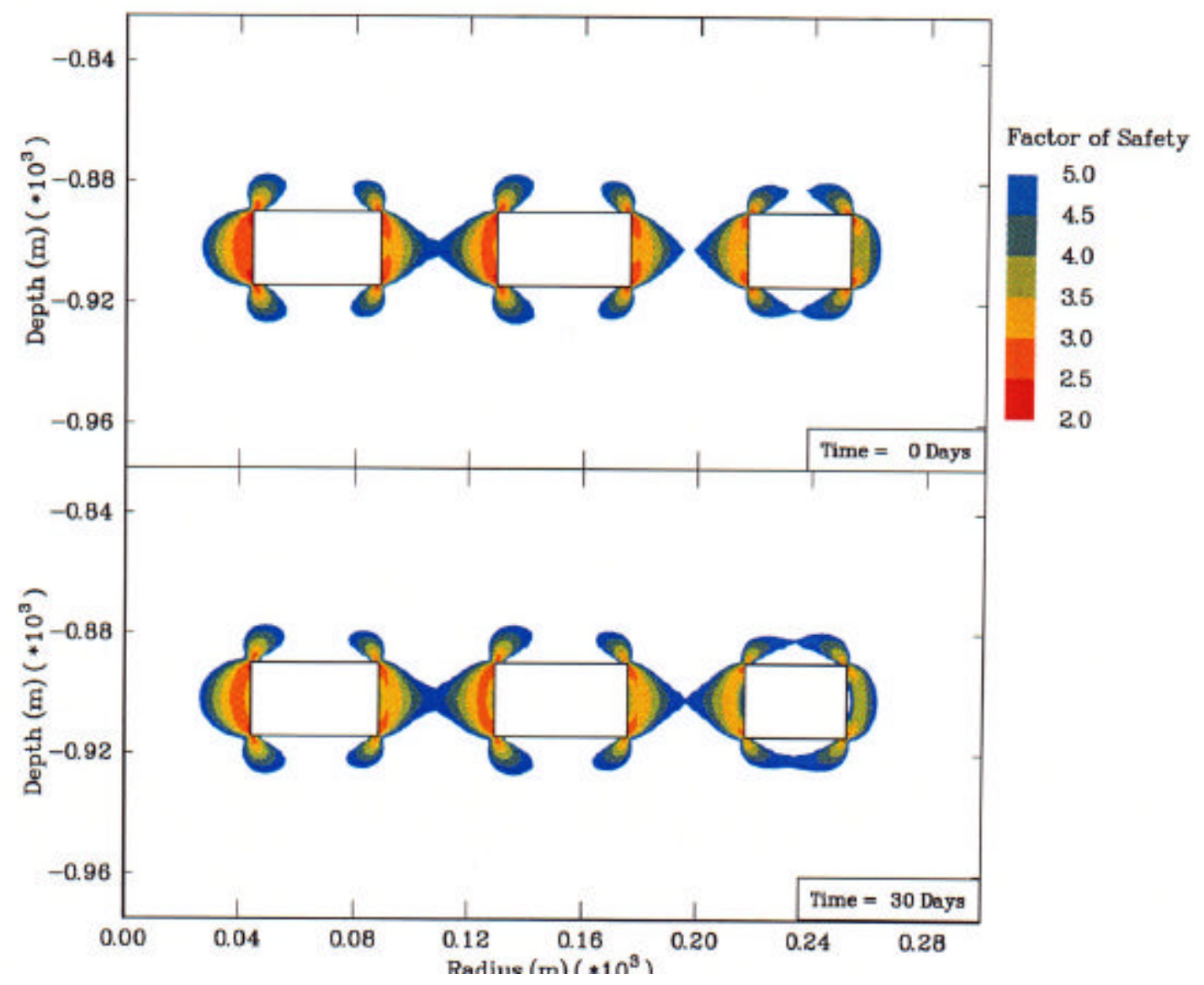

Figure 8-13. Mohr-Coulomb Factor-of-Safety Contours at 0 and 30 Days After Filling With Gas at $-28.9^{\circ} \mathrm{C}$. 


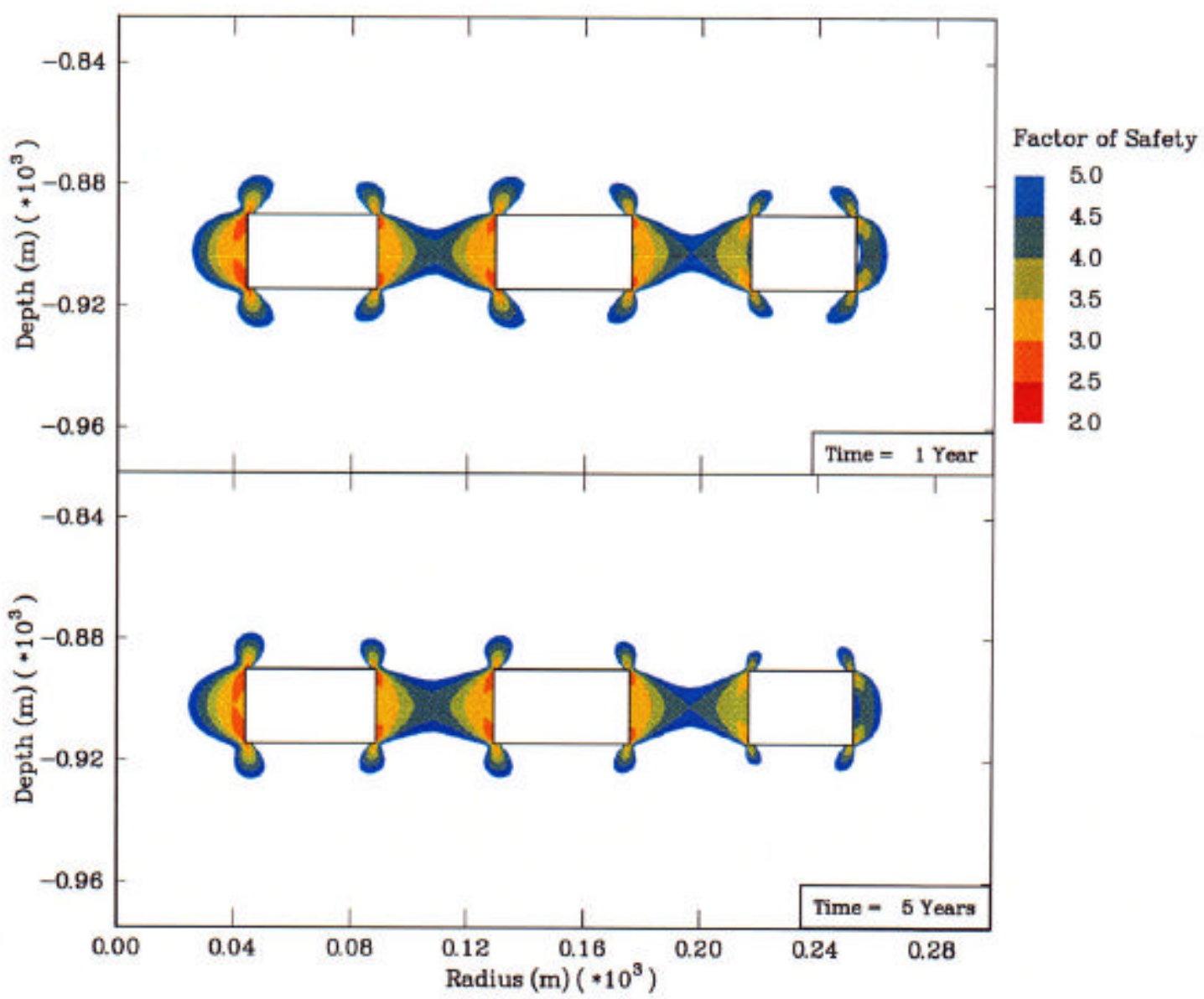

Figure 8-14. Mohr-Coulomb Factor-of-Safety Contours at 1 and 5 Years After Filling With Gas at $-28.9^{\circ} \mathrm{C}$. 


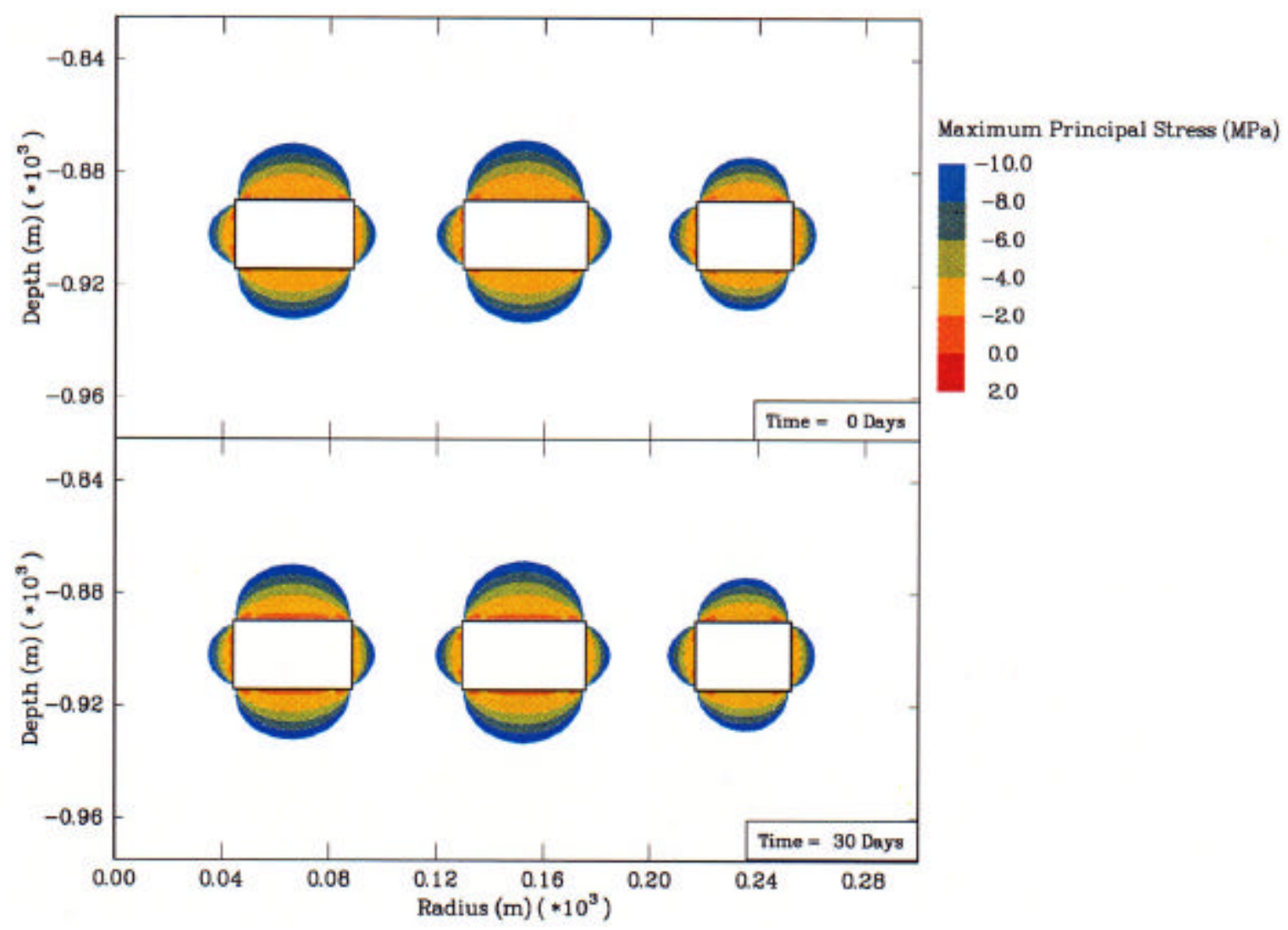

Figure 8-15. Maximum Principal Stress Contours at 0 and 30 Days After Filling With Gas at $-28.9^{\circ} \mathrm{C}$ Compressive Stresses are Negative). 


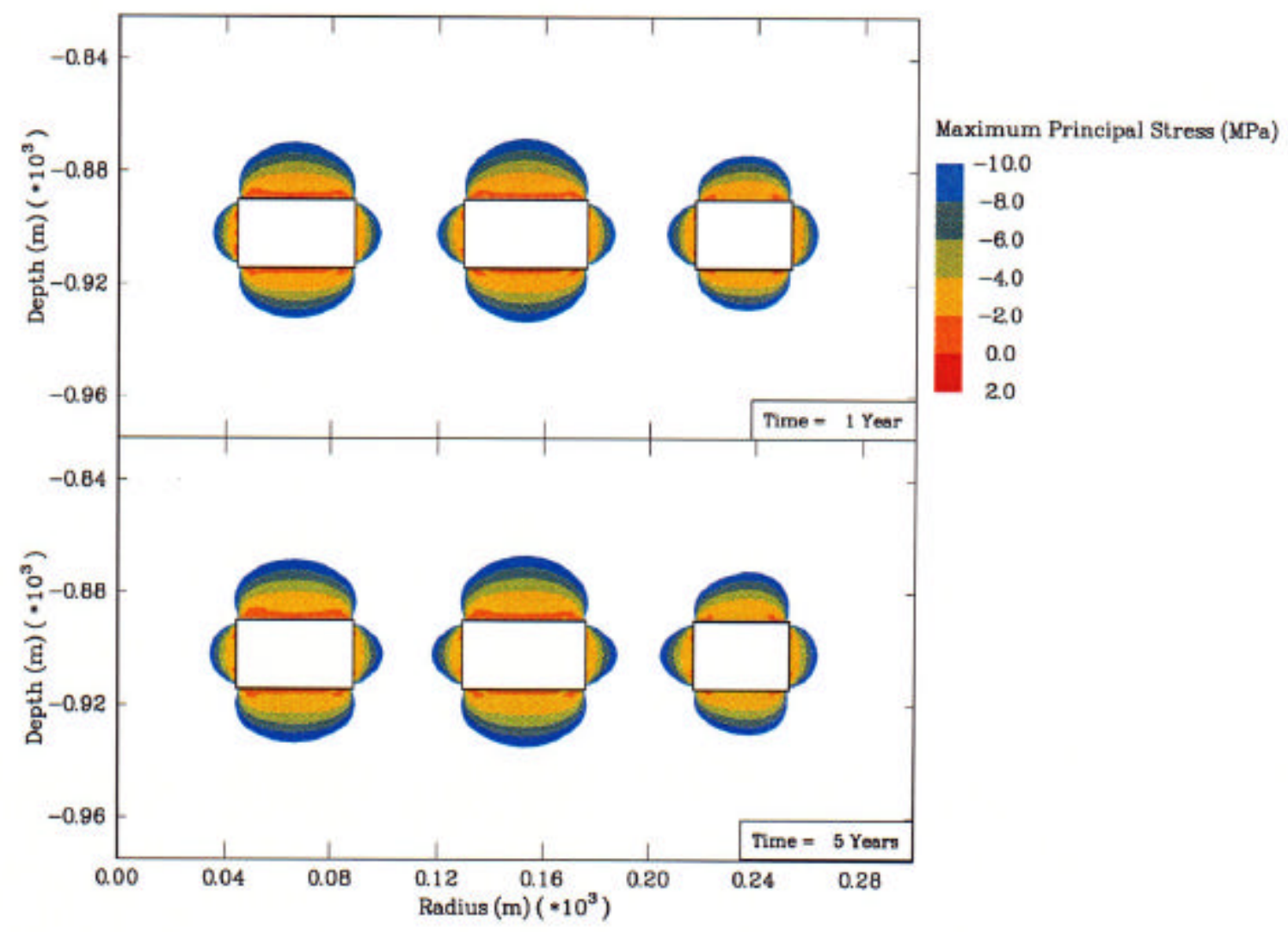

Figure 8-16. Maximum Principal Stress Contours at 1 and 5 Years After Filling With Gas at $-28.9^{\circ} \mathrm{C}$ Compressive Stresses are Negative). 


\subsubsection{Effect of Gas Withdrawal}

The second simulation was used to examine the thermal effects during gas withdrawal. During gas withdrawal, the expansion of the gas in the mine will result in lowering the temperature of the gas. In this simulation, the granite surrounding the gas storage mine is initially at the original in situ temperature. The mine is instantaneously excavated and filled with natural gas at a temperature of $-28.9^{\circ} \mathrm{C}\left(-20^{\circ} \mathrm{F}\right)$ at the maximum storage pressure of $7.1 \mathrm{MPa}(1,320 \mathrm{psi})$. The gas pressure and temperature are held constant for 180 days. At 180 days, the pressure is reduced over a 10-day period to the minimum pressure of $2.1 \mathrm{MPa}(300 \mathrm{psi})$. During the withdrawal, the gas temperature is assumed to drop linearly with time to $-43.9^{\circ} \mathrm{C}\left(-47^{\circ} \mathrm{F}\right)$. The stability of the mine was monitored during the depressurization.

Figure 8-17 shows contours of the predicted Mohr-Coulomb factors of safety in the pillars just before and at the end of the gas withdrawal. Because the mine is at maximum gas pressure, the factors of safety are all very high at 180 days. The factors of safety are lower after the drawdown but are still greater than 2.5 .

Figures 8-18 shows contours of the predicted maximum principal stresses in the granite before and after gas withdrawal. Before the withdrawal, at maximum gas pressure, all of the stresses are highly compressive. However, after the withdrawal, gas pressure is at the minimum value and the temperature in the mine has dropped $15^{\circ} \mathrm{C}$. This results in a large portion of the floor and roof of the two centermost rooms having tensile stresses. The maximum tensile stress has a value of about $3.5 \mathrm{MPa}$, which is lower than the tensile strength of the granite.

\subsection{GEOMECHANICAL SUMMARY AND RECOMMENDATIONS}

The mine design consists of a room-and-pillar layout with rooms 80 feet wide and 80 feet tall and with 150 -foot by 200 -foot pillars with a central shaft pillar for the storage of refrigerated natural gas. This design is adequate to develop a long-lasting facility in a granodiorite with the given rock properties.

Before construction is started or the design is finalized, additional geological exploration and geomechanical testing should be conducted. The design then should be refined with more definitive rock properties, including compressive strength, tensile strength, thermal properties, in situ stress state, joint set definition, and hydrologic measurements. The mine pillars, as designed, have a factor of safety in excess of 1.8. The roof span should be reinforced with systematic bolting and shotcrete. Support of the walls should, at a minimum, include bolting of potential loose blocks that result from jointing.

The mine pillars, given the factor of safety, cannot be reduced in width. The room spans can potentially be increased to 130 feet. However, if the room span is increased, the pillar size must also be increased proportionately. The room height could be increased to 100 feet and still maintain the factor of safety in the pillars at 1.75 . 


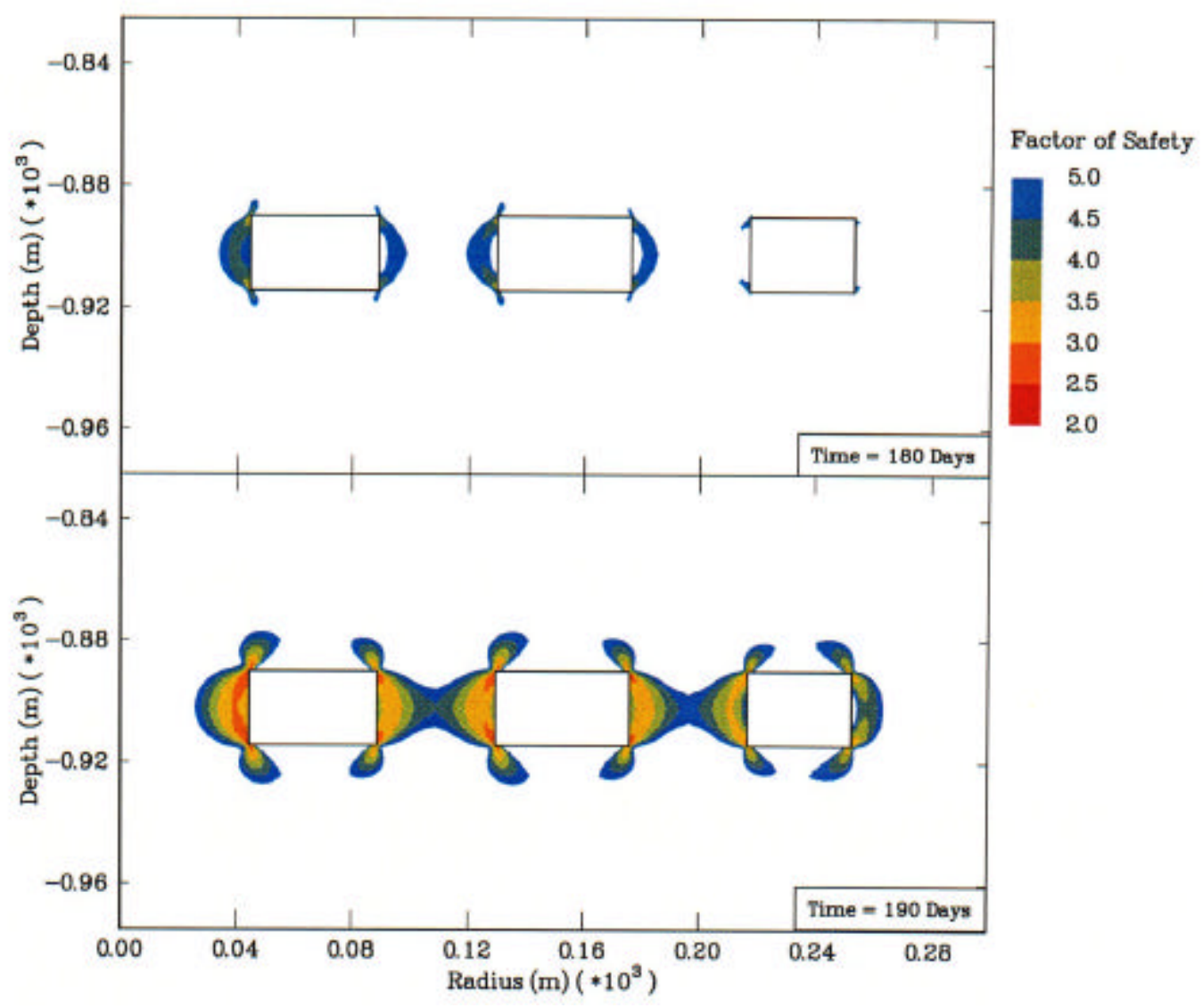

Figure 8-17. Mohr-Coulomb Factor-of-Safety Contours Before and After Drawdown From Maximum to Minimum Gas Pressure. 


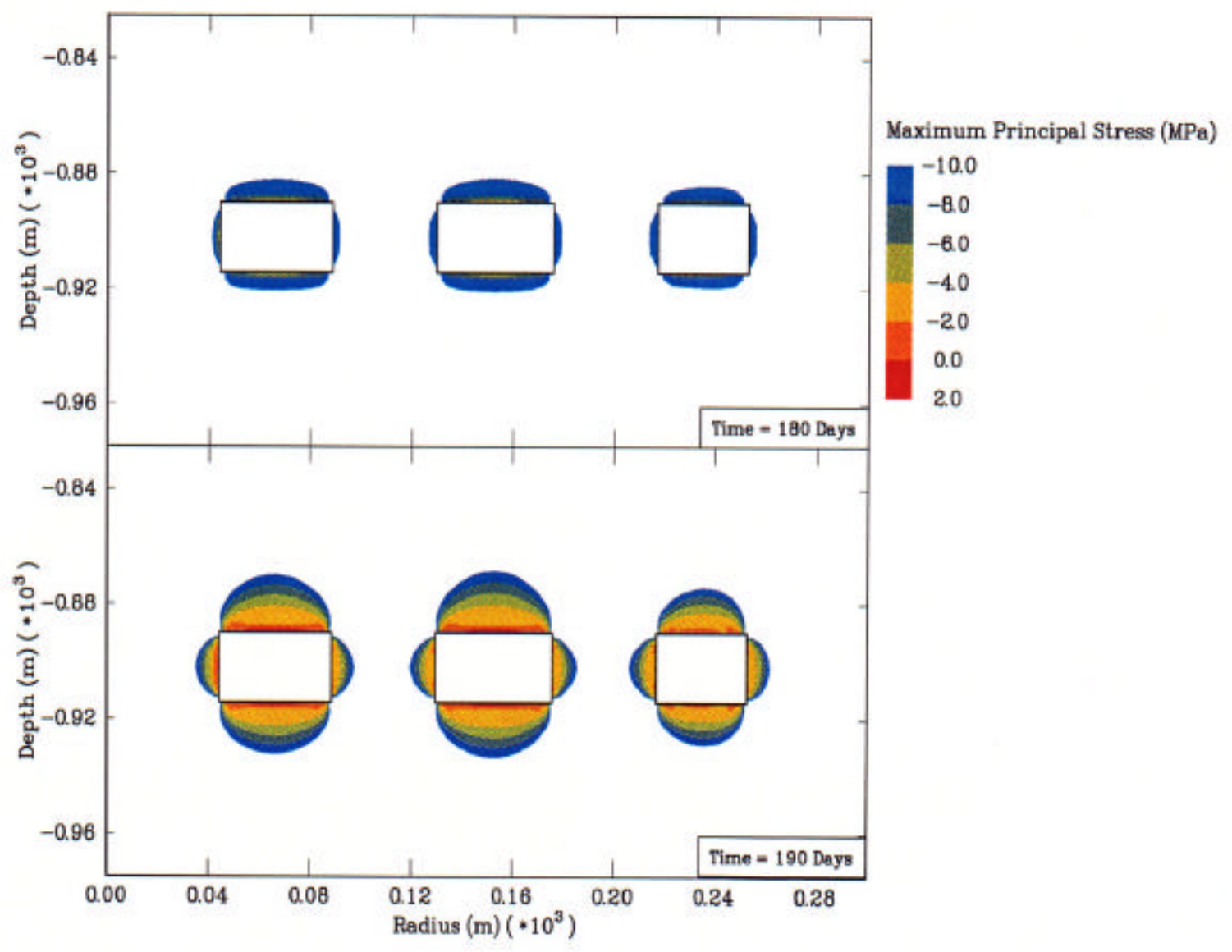

Figure 8-18. Maximum Principal Stress Contours Before and After Drawdown From Maximum to Minimum Gas Pressure. 
Based on the assumed rock properties for the site, there is no need to install a lining in the shafts for the refrigerated gas storage cavern. A narrow zone of damaged rock will develop around the shaft walls. This DRZ may require localized minor reinforcement or meshing to prevent spalling rock from injuring miners or damaging hoisting equipment while the storage cavern is being developed.

The results of the two simulations of the thermal effects on the rock strength suggest that the thermal effects do not have a large impact on the mine stability. The Mohr-Coulomb factors of safety were actually improved with time as the granite surrounding the mine cooled from the original in situ temperature. The cooling of the granite did result in some tensile stresses in the roof and floor of the mine. The largest tensile stresses predicted were about 3.5 MPa at the end of the gas withdrawal simulation, which is somewhat less than the $4.8 \mathrm{MPa}$ tensile strength assumed of intact granite.

The actual in situ stress state, which is known to be anisotropic, cannot be represented with axisymmetric models, and was therefore, modeled as being isotropic. Although this assumption may affect the nonthermal results of these simulations, the thermal effects are not believed to be significantly impacted.

This modeling only considers thermal effects due to the expansion (or contraction) of the granite due to temperature changes. It does not consider the effects of freezing groundwater in the pore space of the granite which may have a significant impact on the results. 


\subsection{CALCULATION OF COOLING LOAD FOR REFRIGERATED NATURAL GAS STORAGE}

The following section presents the results of analyses performed to estimate the cooling load required for a refrigerated natural gas storage cavern. The cooling requirements were estimated using finite element simulations of the mine with the heat transfer analysis program SPECTROM-41 [Svalstad, 1989]. Two sets of calculations were made. The first estimates the overall cooling load required to maintain a gas temperature of $-20^{\circ} \mathrm{F}$. The second estimates the potential beneficial cooling resulting from gas expansion during gas withdrawal.

\subsubsection{FINITE ELEMENT MODEL}

The geometry of the mined natural gas storage cavern was approximated with an axisymmetric model. The axisymmetric model conserved the actual volume of the mine ( 37.4 million $\left.\mathrm{ft}^{3}\right)$ which is represented as three concentric rings at a depth of $3,000 \mathrm{ft}$, as shown in Figure 8-19. The room width and wall surface area of the mine model are also representative of those in the mine plan. The finite element model of the mine is shown in Fig. 8-20. It contains 6,343 nodes and 2,052 eight-noded elements. The model extends from the ground surface to a depth of 6,000 feet and has an outside radius of 7,500 feet. These extensive boundaries were chosen so that the modeled mine would not be influenced by the boundaries.

The host stratigraphy was assumed to be entirely granite. The thermal material properties used to model the granite are shown in Table 8-6. The assumed initial in situ temperature of the granite as a function of depth is described by the following equation:

$$
T=50.5+0.009 \times \mathrm{D}
$$

where the temperature is in degrees Fahrenheit and $\mathrm{D}$ is the depth in feet. The initial temperature of the granite at the mine level is about $77^{\circ} \mathrm{F}$.

Table 8-6. Material Properties for Granite

\begin{tabular}{||l|l|l||}
\hline \multicolumn{1}{|c|}{ Property } & \multicolumn{1}{|c||}{ Value } & Source \\
\hline \hline Thermal Conductivity & $1.45 \mathrm{Btu} / \mathrm{ft}-\mathrm{R}$ & Carslaw and Jaeger [1959] \\
\hline Specific Heat & $0.21 \mathrm{Btu} / \mathrm{lbm}-\mathrm{R}$ & Carslaw and Jaeger [1959] \\
\hline Density & $175 \mathrm{lbm} / \mathrm{ft}^{3}$ & PB-KBB Inc. [1998] \\
\hline
\end{tabular}

\subsubsection{OVERALL COOLING LOAD}

The plan for the refrigerated storage cavern is to store natural gas at a temperature of $-20^{\circ} \mathrm{F}$. Because of the large difference between the temperature of the stored natural gas and that of the surrounding granite, a large amount of heat will be transferred from the granite to the stored gas. Through time, the granite surrounding the mine will cool and less heat will be transferred to the gas. External cooling will have to be provided to counteract the heat transferred from the surrounding granite or the temperature of the stored gas will increase. 
To estimate the cooling load required to maintain the gas temperature at $-20{ }^{\circ} \mathrm{F}$, a finite element simulation was performed in which the nodes at the mine surface were fixed at $-20{ }^{\circ} \mathrm{F}$ and the heat required to maintain this fixed temperature boundary condition was tracked. The cooling load was tracked over a total simulation time of 10 years. Fig. 8-21 shows the cooling load as function of time. The cooling load versus time is nearly linear on the log-log plot, indicating that the cooling load initially drops very quickly when the temperature gradients in the granite are large, but drops much slower as these temperature gradients decrease. Fig. 8-22 shows the temperature gradients surrounding the mine at 1 and 10 years. At the end of the first year, the cooling load is about 10 million Btu/hr, and after 10 years, the cooling load reduced to about 3.7 million Btu/hr. 


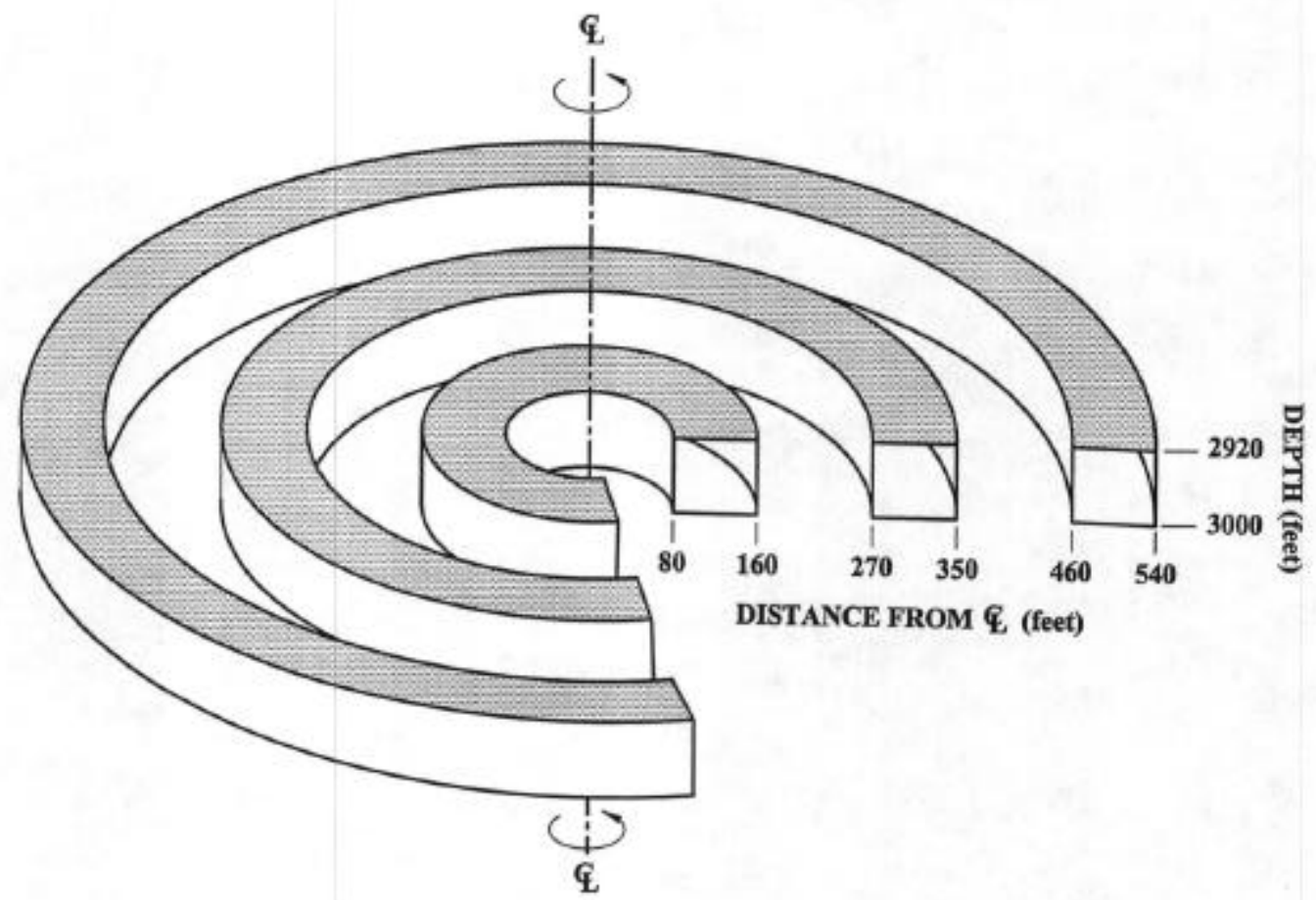

Figure 8-19. Schematic of Axisymmetric Model of Storage Caverns 


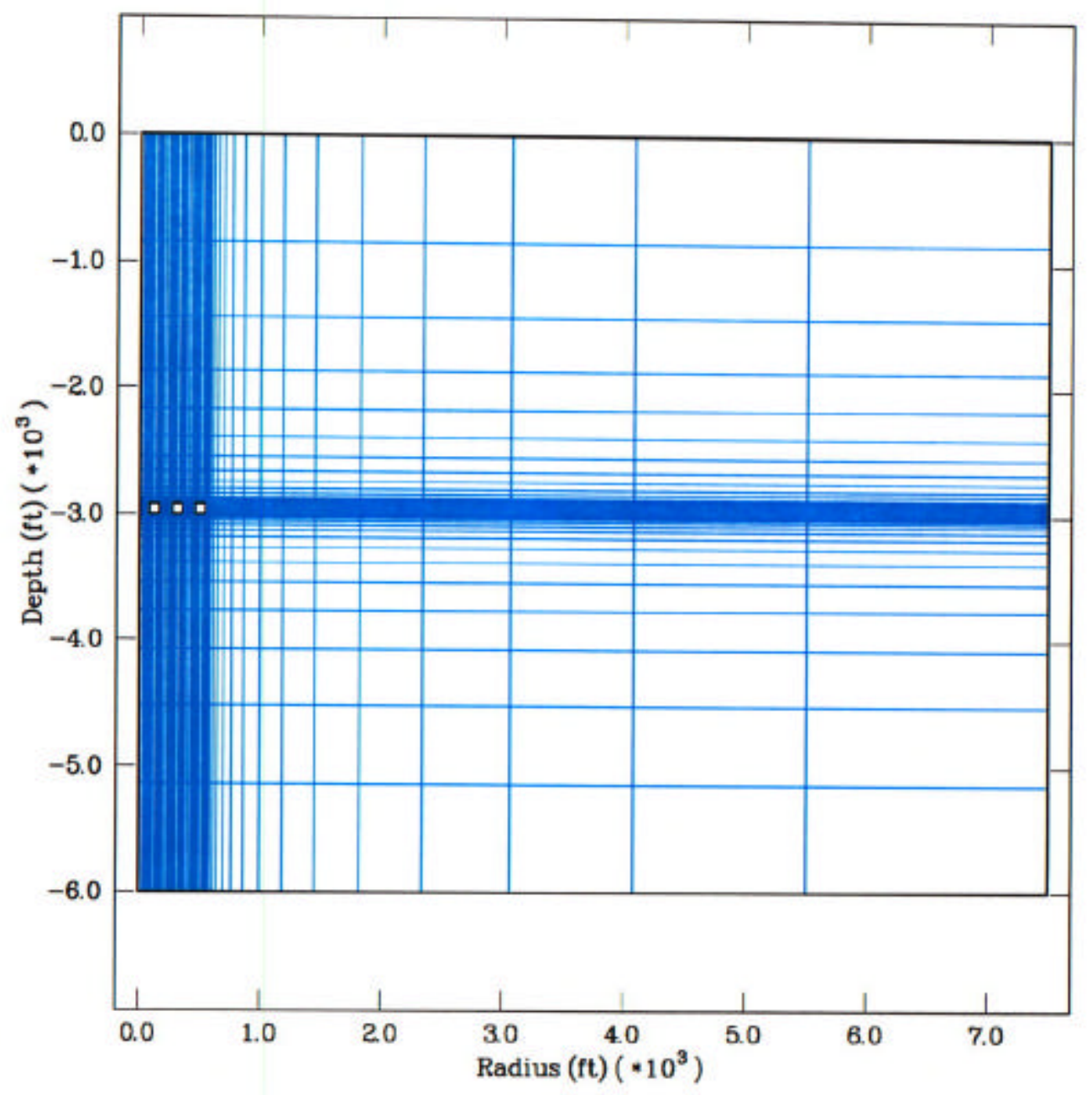

Figure 8-20 Finite Element Model of Storage Cavern 


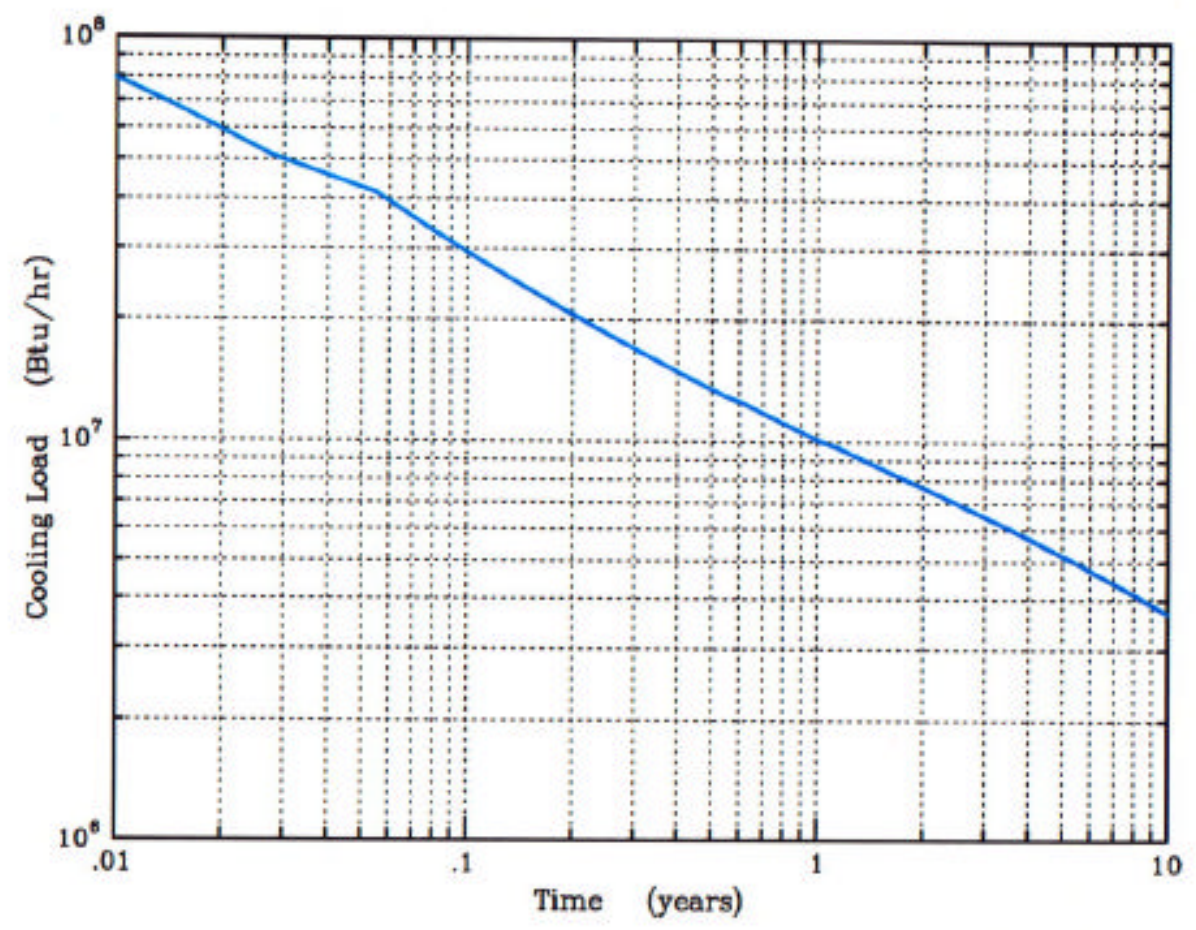

Figure 8-21. Cooling Load Required to Maintain Storage Cavern at -20 F 


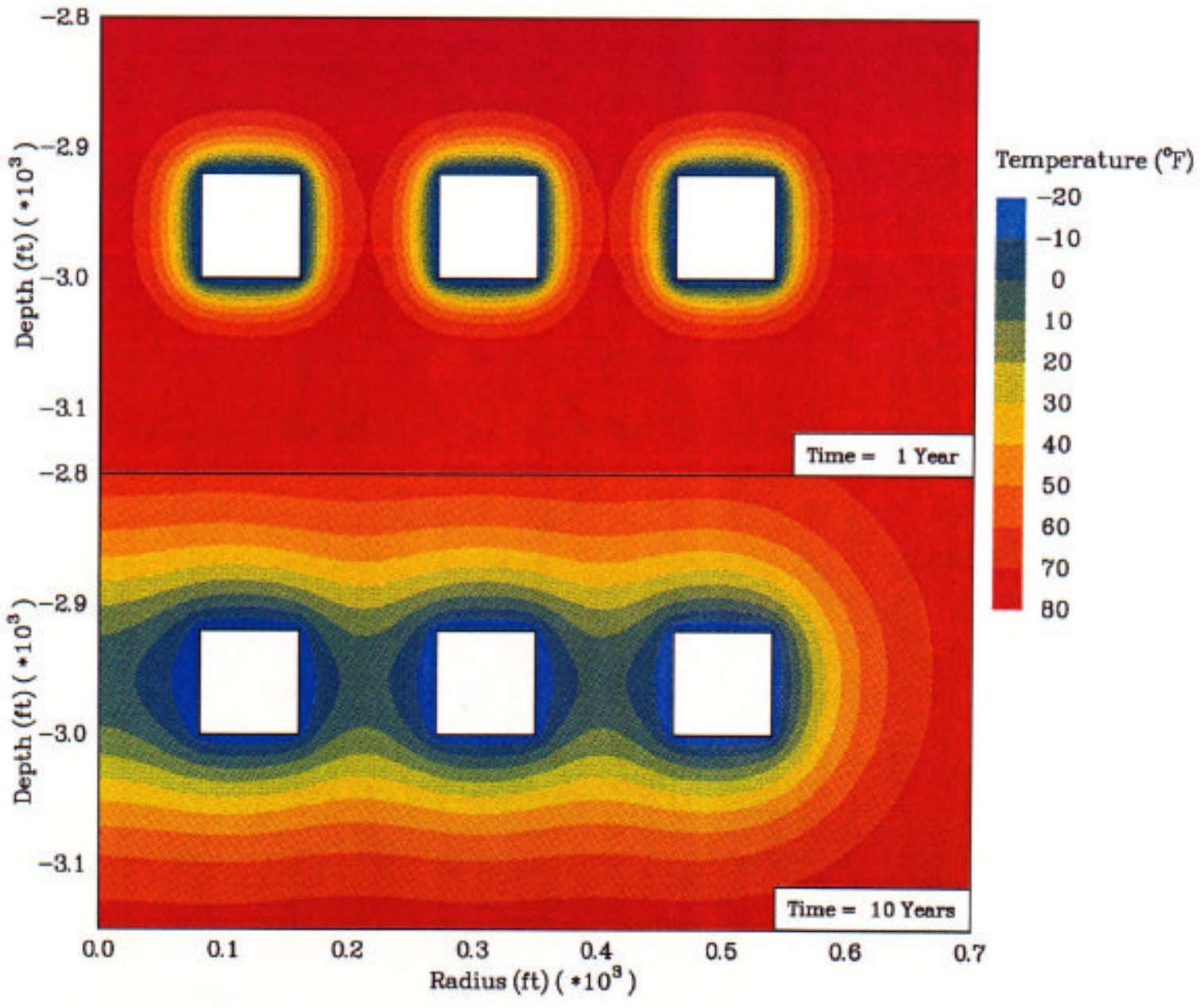

Figure 8-22. Temperature Contours Around Mine at 1 and 10 Years. 


\subsubsection{EFFECT OF GAS WITHDRAWAL}

During gas withdrawal, thermal energy stored in the gas is converted to mechanical energy by depressurization and the associated decrease in density of the gas. The heat that is consumed during withdrawal results in cooling the gas and surrounding granite. The total thermal energy consumed during gas withdrawal based on ideal gas behavior is described by:

$$
\text { - } q_{e x}=R T V_{c}\left(\frac{\partial \rho}{\partial t}+\vec{v} \bullet \Delta \rho\right)
$$

where:

$$
\begin{aligned}
& R=\text { gas constant }(\mathrm{Btu} / \mathrm{lbm}-\mathrm{R}) \\
& \mathrm{T}=\text { temperature }(\mathrm{R}) \\
& \mathrm{V}_{\mathrm{c}}=\text { cavern volume }\left(\mathrm{ft}^{3}\right) \\
& \rho=\text { gas density }\left(\mathrm{lbm} / \mathrm{ft}^{3}\right) \\
& \overrightarrow{\mathrm{V}}=\text { gas velocity vector }
\end{aligned}
$$

In this analyses, the gas velocities and the gas density gradients within the cavern are assumed to be small, and thus, the second term of Equation 1 is ignored. To account for the nonideal behavior of the gas, the gas constant was calculated as:

$$
R=\frac{Z \bar{R}}{M_{w}}
$$

where:

$$
\begin{aligned}
& Z=\text { compressibility factor of the gas } \\
& \overline{\mathrm{R}}=\text { universal gas constant }(1.987 \mathrm{Btu} / \mathrm{lb}-\text { mole- } \mathrm{R}){ }^{1} \\
& \mathrm{M}_{\mathrm{w}}=\text { molecular weight of the gas. }
\end{aligned}
$$

The compressibility factor, $Z$, was calculated using an empirical relationship developed by Coker [1993]. The gas was assumed to be pure methane $\left(M_{w}=16.04\right)$. The resulting equation used to estimate the heat consumed during expansion is given by: 


$$
\text { - } q_{e x}=\frac{Z \bar{R} T \bullet m}{M_{w}}
$$

The gas was initially assumed to be at a pressure of 1,250 psia and a temperature of $-20^{\circ} \mathrm{F}$. The withdrawal rate of 250 million scf/day results in a mass flow rate of about $450,000 \mathrm{lbm} / \mathrm{hr}$. Although the temperature drops during withdrawal using Equation 3, the compressibility factor increases (from about 0.72 to about 0.86 ), resulting in a nearly constant rate of heat consumed (16.7 million Btu/hr) by gas expansion during the 20-day withdrawal period.

Of the total heat consumed, a portion will be taken from the granite and a portion will be taken from the gas. This heat balance is described by:

$$
\bullet q_{e x}=\bullet q_{g r}+\rho V_{c} C_{p} \frac{\Delta T}{\Delta t}
$$

where $\bullet q_{g r}$ is the heat flow from granite and the second term is the heat flow from the gas. Finite element simulations were made to estimate $\bullet q_{g r}$, which will reduce the overall cooling load. In the finite element simulations, the total heat consumption rate $\left({ }^{\bullet} q_{e x}\right)$ was represented as a negative heat generation rate in cavern. The heat flow rate from the granite $\left({ }^{\bullet} q_{g r}\right)$ was solved using Equation 5 above. The following assumptions were made in modeling the gas in SPECTROM-41:

- Convection in the gas, which could not be simulated, will result in very low thermal gradients within the gas. To account for this, an arbitrarily high value was used for the thermal conductivity of the gas.

- Although the density of the gas decreases during withdrawal, this could not be simulated, and an average density of $3.58 \mathrm{lbm} / \mathrm{ft} 3$ was used in the simulations.

- The specific heat $\left(C_{p}\right)$ was assumed to be $0.538 \mathrm{Btu} / \mathrm{lbm}-\mathrm{R}$ [Van Wylen and Sonntag, 1978].

Finite element simulations of gas withdrawal were performed at various times. In each simulation, the gas temperature was maintained at $-20^{\circ} \mathrm{F}$ until the start of the withdrawal period. At the start of the withdrawal period, a negative heat generation rate of 16.7 million Btu/hr was applied in the cavern for the 20-day withdrawal period. The beneficial heat loss from the granite $\left(\bullet q_{g r}\right)$ was calculated using Eq. 5 and the predicted temperature change in the gas from the finite element simulation. Table 8-7 shows the estimated cooling benefit from a 20-day gas withdrawal period at various withdrawal initiation times. At times less than 90 days, the heat consumed during withdrawal is not large enough to maintain the gas temperature at $-20^{\circ} \mathrm{F}$. After 90 days, the heat consumed during gas withdrawal is more than enough to maintain the gas temperature, and in fact, lowers the temperature of the gas to below $-20{ }^{\circ} \mathrm{F}$.

Examination of the cooling load plot in Fig. 8-21 and the values from the Table 8-7 suggests that after about 3 years, the cooling provided by gas withdrawal (roughly 14.5 million Btu/hr) is about double the cooling load (about 6.5 million Btu/hr). Thus, if gas were continuously cycled (i.e. continuous 20-day withdrawal, 20-day injection cycles), the gas temperature could be maintained entirely with the cooling provided during the withdrawal periods. 
Table 8-7. Cooling Provided During Gas Withdrawal

\begin{tabular}{|c|c||}
\hline $\begin{array}{c}\text { Time at Initiation } \\
\text { of Withdrawal }\end{array}$ & $\begin{array}{c}\text { Cooling Rate (Btu/hr } \mathbf{x} \\
\mathbf{1 0}^{\mathbf{6}} \text { ) During Withdrawal }\end{array}$ \\
\hline \hline 30 Days & 18.6 \\
\hline 90 Days & 16.7 \\
\hline 180 Days & 15.8 \\
\hline 1 Year & 15.2 \\
\hline 5 Years & 14.1 \\
\hline 10 Years & 13.8 \\
\hline
\end{tabular}

\subsubsection{SUMMARY}

Because of the large difference between the temperature of the stored natural gas and that of the surrounding granite, a large amount of heat will be transferred from the granite to the stored gas. The cooling load after 1 year of storage operations is estimated to be about 10 million Btu/hr. After 10 years of storage operations, the estimated cooling load is reduced to about 3.7 million Btu/hr. The estimated cooling provided during gas withdrawal periods is estimated to be about 15.2 million Btu/hr after 1 year of storage operations and decreases to about 13.8 after 10 years of storage operations. Based on these estimates, and assuming the cavern is active, much of the cooling load will be provided by gas expansion during the withdrawal periods. 


\section{Section 9}

\section{HEALTH AND SAFETY}

The design of the cavern and surface process equipment must reasonably allow for safety during construction and after the facility is commissioned. Of particular concern is underground construction due to an element of unpredictability with respect to geology. Since cavern construction takes place hundreds of feet below ground in confined areas, any mishaps, such as a collapse, can have grave consequences. Many procedures have been developed for minimizing the risks associated with underground construction.

Underground construction standards have been developed over many years, and if followed, allow for safe cavern construction as well as safe operations, once the cavern is constructed. There are construction and operating standards which have been adopted industry-wide and are required by government agencies such as OSHA and MSHA.

The design of the surface process equipment meets or exceeds standards developed by various industry groups. Of these industry groups, the American National Standards Institute (ANSI) and the American Society of Mechanical Engineers (ASME) dominate with respect to setting integrity standards for piping components, pressure vessels, heaters, pumps, compressors, and various types of materials and hardware. Reputable equipment manufacturers follow these and other applicable standards and their equipment is usually inspected and certified by third-party inspectors.

Although process equipment is designed, tested and certified, there is a possibility the equipment may be improperly installed and operated. Proper engineering and a systematic safety analysis (process hazard analysis, known as "PHA" or "HAZOP" will reduce safety risks to acceptable levels. A HAZOP is conducted once a process and instrumentation diagram (“P\&ID") is developed.

During the HAZOP, the P\&ID is completely reviewed by engineers and plant operations personnel. What-if scenarios during facility operation are discussed and potential hazards are identified. The process may then be reconfigured to eliminate or reduce the chance of the hazard occurring.

In the case of constructing the surface facilities for a natural gas storage facility, the health and safety risks to construction workers are burns, falls, overexertion, heat exhaustion, radiation exposure, exposure to solvents, electrocution, falling debris and other hazards. Steel erection involves the use of welding machines and cutting torches. Improper or worn out tools and equipment can result in burns to the skin and eyes.

The improper use of or not using respirators when priming and painting steel surfaces can result in overexposure to poisonous solvents. Also, the erection of steel structures with cranes, in the presence of power lines, may pose an electrocution risk.

The erection of process piping also requires welding and torch cutting as does structural steel but also requires the use of $\mathrm{x}$-ray equipment for certifying welding integrity. The $\mathrm{x}$-ray equipment contains a 
radioactive (gamma ray) source, which can result in serious injury to construction workers if the material is improperly handled. The exposure to radiation may also have a long-term effect on anyone who is exposed, especially construction workers.

Risks relating to operating the facility may impact operations personnel as well as the general public. Construction personnel may only be exposed to operations-related risks during facility testing and commissioning. The risks, although low, include gas leaks due to ruptured piping, well leaks, equipment malfunction, operator error and other external factors. The gas leaks may result in fires, which may damage adjoining property and subjecting emergency workers to health and safety risks.

Other risks include spills of hazardous chemicals such as used lubricating oil and the glycol used for removing water from the gas. These spills can pollute the ground water with toxic chemicals and potentially carcinogens. However, the inventory of glycol and lubricants is small when compared to a chemical processing plant or petroleum refinery; therefore, any spill would likely be classified as minor.

In summary, an underground natural gas storage facility is relatively safe when compared to other types of hydrocarbon processing facilities. Natural gas contains little, if any, hydrocarbons which are considered poisonous or carcinogenic. Since natural gas is less dense than air at atmospheric conditions, it will rise and disperse if it leaks from the cavern or surface piping/equipment. Industry experience with underground natural gas storage facilities has been quite favorable with respect to immediate and long term safety and health to both facility operators and the general public.

The following cavern safety systems/features are recommended during operations:

1. EMERGENCY SHUTDOWN (ESD) VALVES

ESD valves must be installed in the piping, either at the top of the cavern wellheads or in the piping within approximately 50 feet of it. ESD valves must be Fail Safe Closed, e.g., valve equipped with air open/spring close pneumatic actuators. Valves should be equipped with valve position indicators to indicate and confirm valve position both locally and in the control room. If actuators are equipped with manual overrides, lock-outs must be provided or handwheels or closing mechanisms removed.

2. ESD VALVE OPERATION

Product and brine ESD valves can be manually opened and closed independently, as required. However, any ESD condition closes both valves. Valves should remain closed until the system is checked and reset.

3. $\quad$ ESD CONDITIONS

A. Loss of electrical signal to ESD valves and instrumentation. 
B. Loss of ESD valve actuator supply pressure, e.g., pneumatic or hydraulic pressure.

C. Fire in the vicinity of the wells.

D. Manual emergency close from Facility ESD Stations or Control Room.

E. Signal from any one of ESD instruments.

4. ESD INSTRUMENTATION

A. Production System Instrumentation

1. Instrumentation to protect against overpressuring the cavern, e.g., high pressure switch on product line or product injection pump discharge.

2. Instrumentation to detect uncontrolled release of product from the cavern through product system. Minimum of two instruments are recommended to provide redundancy, preferably measuring different parameters. Examples of product system ESD instrumentation are:

- Low pressure

- Excess flow

- Differential pressure, e.g., wellhead vs. meter station pressure

3. Fire detection. Examples of fire detection instrumentation and methods are:

- Fusible fittings in ESD actuator supply tubing. Fire causes fittings to melt, releasing pressure from actuator and closing ESD valve.

- Infrared detectors

- Video surveillance by operator

4. ESD instrument set points should be established a safe margin above or below the maximum or minimum operating levels, respectively.

5. ESD instruments may require field adjustable time delays to prevent nuisance closures.

5. LEAK DETECTORS

Leak detectors, or gas detectors, designed to detect the presence of hydrocarbon vapor in the atmosphere should be located at all transfer areas, e.g., main transmission line to the storage piping, pumps. In general, it is recommended that a low level set point, \% Lower Explosive Limit (LEL), initiate an alarm and a high level set point initiate an ESD. 
6. MANUAL ESD

Manual ESD stations should be located in the control room, at strategic locations around the facility, and at each storage well. These ESD stations allow the operator to initiate an ESD, in the event of an emergency, either station-wide or at a particular storage well.

7. ESD MANUAL RESET

ESD stations at the storage wells should be equipped with a manual reset, which compels the operator to inspect the well before resetting the system to resume normal operations.

8. $\quad$ ALARMS

Visual alarms and audible alarms for ESD should be provided at the control room and the storage well areas.

9.

WELLHEAD PROTECTION

Barriers or other systems should be installed around wellheads to protect against mechanical damage.

10. MONITORING STORAGE OPERATIONS

All gas injection and withdrawal operations should be continuously monitored by a qualified operator.

11. EMERGENCY RESPONSE PLAN

The facility should have a current emergency response plan in place to give operators the proper direction to follow in the event of an emergency at the facility and to provide important information for emergency response personnel.

12. EMPLOYEE SAFETY TRAINING PLAN

The facility should have a current employee safety training plan to provide training for operators and other site personnel regarding safety designs and procedures.

13.

TESTING AND MAINTENANCE PROGRAM

A testing and maintenance program should be established to insure all safety systems are tested regularly and maintained properly.

All pertinent safety standards promulgated by OSHA and MSHA (30 CFR 57) for shaft sinking and development of underground caverns must be followed during the construction of the facility. These standards apply to ground control; fire prevention and control; ventilation and control measures; welding/cutting/and compressed air; explosives; conveying as other transportation systems; drilling; loading, 
hauling, and dumping; electricity; machinery and equipment; personal protection; materials storage and handling; lighting; personnel hoisting; and safety programs. Shaft sinking is a specialized work and only wellexperienced underground construction companies should be allowed to bid on the cavern construction job. Every person working underground must be well trained in the underground operations. He/she must wear articles of personal protection at all times while underground. This should include hard-toe shoes, safety belt, self-rescuer, safety glasses, hard hat and lighting. Before entering any working place, it must be thoroughly inspected by a responsible person for ventilation, presence of any noxious or flammable gases, any loose rock or other hazardous conditions. Loose rock must be brought down by a scaling bar or a scaling machine. 


\section{Section 10}

\section{CONSTRUCTION COST ESTIMATES AND SCHEDULE}

Cost estimates were prepared for mine shafts to four different depths: 1,500', 2,000', 2,500' and 3,000'. The depths determine the pressure to which the gas can be compressed under the hydraulic seal; greater the depth, greater the confining pressure. The following assumptions were made in preparing these estimates.

1) The shaft collars would extend 150 feet through overburden and weathered rock.

2) All excavations are assumed to be dry and only minor amounts of drill water will be pumped.

3) Each shaft will be lined with 12-inches of plain (non-reinforced) concrete.

4) Domestic and process water will be furnished by others. Sewer service is available for domestic waste water.

5) No allowance has been included for handling or controlling ground water or waste process water.

6) Electricity will be furnished by others.

7) Construction activities will be under the jurisdiction of MSHA rather than OSHA.

8) Waste rock will be hauled to an approved disposal site by a subcontractor. An allowance for haulage is included.

9) All cavern and miscellaneous excavations are supported with 8-foot rock bolts.

10) Performance and payment bonds premiums are not included.

11) On-site explosives storage is permitted.

12) Pollution insurance premiums above our standard $\$ 5$ million are not included.

13) The direct, fully-burdened labor rate is $\$ 35.00$ per hour.

14) Transit-mix concrete is available for the delivered-price of $\$ 100.00$ per yard.

15) Hoisting equipment and head frames will be left in place to install mechanical equipment. The crushing and skip loading equipment will be abandoned in place at the cavern level.

16) There is no salvage value allowed for any equipment acquired for the project.

17) The project will be exempt from sales and use taxes.

18) All permits will have been obtained by others, prior to the start of construction. The contractor will be responsible for his licenses, and explosives used and storage permits. 
19) Site preparation, grading and access roads will have been completed prior to contractor mobilization.

20) Design costs for excavations, shaft furnishings, foundations, head frames and the like are not included. No allowance for appropriately-sized hoisting and crushing equipment and head frames is included.

21) There are no costs included for operation of the facility after construction.

22) A mutually-acceptable construction contract will be negotiated.

Table 10-1, Table 10-2, and Table 10-3 provide cost estimates for storage caverns at 1,500, 2,000, and 2,500 ft depth. Table 10-4 provides additional information on man-hours, labor and material cost, EOE and indirect costs, and the assumptions made in arriving at these costs. Table 10-5 provides the cost estimate for a 3,000 ft deep facility.

\section{$\underline{\text { Schedule }}$}

Project duration is driven by the ability to hoist waste rock. It has been assumed that the contractor could hoist at an average rate of 400 tons per hour, 16 hours per day. This rate is conservative, but takes into account that the material handling system requires regular maintenance. The rate also assumes that there will be unscheduled maintenance due to mechanical failure plus the fact there will be times when the material handling system is available, but there is no muck to hoist because of the problems elsewhere in the project.

Table 10-6 provides a schedule for a 2,500 ft deep facility, whereas Table 10-7 provides the schedule for $3,000 \mathrm{ft}$ deep facility. Increasing the depth of the cavern makes it necessary to construct the raisebore in two 1,500 foot lifts. The shaft will be sunk to 1,500 feet, a drift driven to the Service Shaft location and the raise pulled to surface, then lined to the $1,500 \mathrm{ft}$ level. When the Production Shaft has been completed to the $3,000 \mathrm{ft}$ level, the raise will be completed from the $3,000 \mathrm{ft}$ level to the station at 1,500 ft. Table 10-7 reflects this activity. 
Table 10-1

Estimated Cost of a Storage Cavern - 1,500-Foot Depth

115.7 Million Cubic Feet Storage

1500 Foot Depth

One 8-20-Ft-Diameter Conventional Shaft

One Ten-Ft-Diameter Raise Bored Shaft

4 Million Cubic Feet Miscellaneous Excavation

Project Duration 80 Months

\begin{tabular}{|l|r|r|r|r|r|}
\hline \multicolumn{1}{|c|}{ COST ITEM } & QUANTITY & UNITS & & UNIT COST & \multicolumn{1}{c|}{ TOTAL } \\
\hline Mobilization & 1 & LS & & $7,215,000$ & $7,215,000$ \\
\hline Sink \& Line Shaft & 1,500 & LF & & 6,713 & $10,069,500$ \\
\hline Raise Bore \& Line Shaft & 1,500 & LF & & 2,613 & $3,919,500$ \\
\hline $\begin{array}{l}\text { Material Handling } \\
\text { Equipment }\end{array}$ & 1 & LS & & $4,123,000$ & $4,123,000$ \\
\hline $\begin{array}{l}\text { Assemble Mining } \\
\text { Equipment }\end{array}$ & 1 & LS & & $2,695,000$ & $2,695,000$ \\
\hline Excavate Top Heading & $1,851,300$ & BCY & & & \\
\hline Excavate Bench & $2,581,900$ & BCY & & 46.12 & $85,381,956$ \\
\hline TOTAL & & & & 40.21 & $103,818,199$ \\
\hline Contingency & & & & & $208,222,155$ \\
\hline TOTAL PROJECT COST & & & & & $29,101,800$ \\
\hline
\end{tabular}


Table 10-2

Estimated Cost of a Storage Cavern - 2,000-Foot Depth

68.7 Million Cubic Feet Storage

2,000 Foot Depth

One 18-20-Ft-Diameter Conventional Shaft

One Ten-Ft-Diameter Raise Bored Shaft

4 Million Cubic Feet Miscellaneous Excavation

Project Duration 59 Months

\begin{tabular}{|c|c|c|c|c|}
\hline COST ITEM & QUANTITY & UNITS & UNIT COST & TOTAL \\
\hline Mobilization & 1 & LS & $7,215,000$ & $7,215,000$ \\
\hline Sink \& Line Shaft & 2,000 & LF & 6,713 & $13,426,000$ \\
\hline Raise Bore \& Line Shaft & 2,000 & LF & 2,613 & $5,226,000$ \\
\hline $\begin{array}{l}\text { Material Handling } \\
\text { Equipment }\end{array}$ & 1 & LS & $4,123,000$ & $4,123,000$ \\
\hline $\begin{array}{l}\text { Assemble Mining } \\
\text { Equipment }\end{array}$ & 1 & LS & $2,695,000$ & $2,695,000$ \\
\hline Excavate Top Heading & $1,159,500$ & $\mathrm{BCY}$ & 46.12 & $53,476,140$ \\
\hline Excavate Bench & $1,385,000$ & $\mathrm{BCY}$ & 40.21 & $55,690,850$ \\
\hline TOTAL & & & & $141,851,990$ \\
\hline Contingency & & & & $19,577,100$ \\
\hline TOTAL PROJECT COST & & & & $161,429,100$ \\
\hline
\end{tabular}


Table 10-3

Estimated Cost of a Storage Cavern - 2,500-Foot Depth

\begin{abstract}
47 Million Cubic Feet Storage
2500 Foot Depth

One 18-20-Ft-Diameter Conventional Shaft

One Ten-Ft-Diameter Raise Bored Shaft

4 Million Cubic Feet Miscellaneous Excavation

Project Duration 48 Months
\end{abstract}

\begin{tabular}{|c|c|c|c|c|}
\hline COST ITEM & QUANTITY & UNITS & UNIT COST & TOTAL \\
\hline Mobilization & 1 & LS & $7,215,000$ & $7,215,000$ \\
\hline Sink \& Line Shaft & 2,500 & LF & 6,713 & $16,782,500$ \\
\hline Raise Bore \& Line Shaft & 2,500 & LF & 2,613 & $6,532,500$ \\
\hline $\begin{array}{l}\text { Material Handling } \\
\text { Equipment }\end{array}$ & 1 & LS & $4,123,000$ & $4,123,000$ \\
\hline $\begin{array}{l}\text { Assemble Mining } \\
\text { Equipment }\end{array}$ & 1 & LS & $2,695,000$ & $2,695,000$ \\
\hline Excavate Top Heading & 791,400 & $\mathrm{BCY}$ & 46.12 & 36,502 \\
\hline Excavate Bench & $1,137,185$ & $\mathrm{BCY}$ & 40.21 & $45,725,000$ \\
\hline TOTAL & & & & 119,419 \\
\hline Contingency & & & & $15,994,000$ \\
\hline TOTAL PROJECT COST & & & & $135,413,000$ \\
\hline
\end{tabular}


Table 10-4

Cost Estimate Detail for 2,500-Foot Deep Cavern

\begin{tabular}{|c|c|c|c|c|c|c|c|c|c|c|}
\hline Bid Item & Qty. & Unit & Mnhrs. & Labor & Materials & EOE & Total & Ind. Cost & Total & Unit Cost \\
\hline Mobilization & 1 & LS & 22,000 & 770,000 & $3,500,000$ & 52,000 & $4,322,000$ & $2,996,000$ & $7,212,000$ & $7,212,000$ \\
\hline Sink \& Line Shaft & 2,500 & LF & 70,000 & $2,450,000$ & $3,385,000$ & 215,000 & $6,050,000$ & $11,027,000$ & $16,672,000$ & 6,669 \\
\hline Raisebore Shaft & 2,500 & LF & 25,000 & 875,000 & $1,804,000$ & 24,000 & $2,703,000$ & $3,937,000$ & $6,495,000$ & 2,598 \\
\hline Material Handling Eqpt. & 1 & LS & 22,600 & 791,000 & 234,000 & 127,000 & $1,152,000$ & $3,079,000$ & $4,120,000$ & $4,120,000$ \\
\hline Assemble Mining Eqpt. & 1 & LS & 16,000 & 560,000 & 32,000 & & 592,000 & $2,179,000$ & $2,693,000$ & $2,693,000$ \\
\hline Exc. Top Heading & 791,400 & $\mathrm{BCY}$ & 151,600 & $5,306,000$ & $4,462,000$ & $3,728,000$ & $13,496,000$ & $23,884,000$ & $36,502,000$ & 46.12 \\
\hline Exc. Bench & $1,137,185$ & $\mathrm{BCY}$ & 201,600 & $7,056,000$ & $3,052,000$ & $2,133,000$ & $12,241,000$ & $31,761,000$ & $45,725,000$ & 40.21 \\
\hline Total Field Cost & & & 938,496 & $38,172,000$ & $28,925,000$ & 8,784000 & $106,636,000$ & & $119,419,000$ & \\
\hline $\begin{array}{l}\text { Contingency }=15 \% \text { of the } \\
\text { total field cost }\end{array}$ & & & & & & & & & $15,994,000$ & \\
\hline $\begin{array}{l}\text { TOTAL PROJECT } \\
\text { COST }\end{array}$ & & & & & & & & & $135,413,000$ & \\
\hline
\end{tabular}

NOTES: 1 ) Direct burdened labor rate is $\$ 35.00$ per hour.

2) Salaried labor at rates used in ARSCo Bid.

3) Drill steel \& bits @ 0.85 per DLF.

4) Loader and truck EOE @ $\$ 40.00$ per hour.

5) Dynamite @ \$1.50 per pound.

6) ANFO @ $\$ 1.00$ per pound.

7) Drill EOE @ 0.35 per DLF.

8) Raise bore cutters @ $\$ 50.00$ per LF.

9) Transit-mix concrete @ $\$ 100.00$ per yard.

10) Electrical service not included.
11) Work scheduled on seven days per week.

12) No bond premium included.

13) Indirect cost include plant \& equip., G\&A costs, muck haul and margin.

14) Cavern excavation rate based upon hoisting 400 tons per hour. 
Table 10-5

\section{Cost Estimate Detail for 3,000-Foot Deep Cavern}

\begin{tabular}{|c|c|c|c|c|c|c|c|c|c|c|}
\hline Bid Item & Qty. & Unit & Mnhrs. & Labor & Materials & EOE & Total & Ind. Cost & Total & Unit Cost \\
\hline Mobilization & 1 & LS & 22,000 & 770,000 & $3,500,000$ & 52,000 & $4,322,000$ & $3,498,000$ & $7,212,000$ & $7,212,000$ \\
\hline Sink \& Line Shaft & 3,000 & LF & 81,000 & $2,835,000$ & $3,906,000$ & 258,000 & $6,999,000$ & $14,439,000$ & $21,813,000$ & 7,271 \\
\hline Raisebore Shaft & 3,000 & LF & 28,200 & 987,000 & $2,186,000$ & 64,000 & $3,237,000$ & $5,026,000$ & $8,393,000$ & 2,798 \\
\hline Material Handling Eqpt. & 1 & LS & 22,600 & 791,000 & 234,000 & 127,000 & $1,152,000$ & $3,594,000$ & $4,120,000$ & $4,120,000$ \\
\hline Assemble Mining Eqpt. & 1 & LS & 16,000 & 560,000 & 32,000 & & 592,000 & $2,544,000$ & $2,693,000$ & $2,693,000$ \\
\hline Exc. Top Heading & 584,765 & $\mathrm{BCY}$ & 105,300 & $3,685,500$ & $3,298,000$ & $2,754,000$ & $9,737,500$ & $18,772,000$ & $28,996,500$ & 49.59 \\
\hline Exc. Bench & 822,642 & $\mathrm{BCY}$ & 148,000 & $5,180,000$ & $2,205,000$ & $1,547,000$ & $8,932,000$ & $26,385,000$ & $36,002,000$ & 43.76 \\
\hline Total Field Cost (include P\&E and G\&A costs) & & & 832,000 & $34,341,500$ & $25,237,000$ & $7,205,000$ & $97,538,500$ & & $109,229,500$ & \\
\hline Contingency $=15 \%$ of the total field cost & & & & & & & & & $14,629,000$ & \\
\hline $\begin{array}{l}\text { TOTAL PROJECT } \\
\text { COST }\end{array}$ & & & & & & & & & $123,858,500$ & \\
\hline
\end{tabular}

NOTES: 1 1) Direct burdened labor rate is $\$ 35.00$ per hour. 2) Salaried labor at rates used in ARSCo Bid.

3) Drill steel \& bits @ 0.85 per DLF.

4) Loader and truck EOE @ $\$ 40.00$ per hour.

5) Dynamite @ \$1.50 per pound.

6) ANFO @ $\$ 1.00$ per pound.

7) Drill EOE @ 0.35 per DLF.

8) Raise bore cutters @ $\$ 50.00$ per LF.

9) Transit-mix concrete @ \$100.00 per yard.
10) Electrical service not included.

11) Work scheduled on seven days per week.

12) No bond premium included.

13) Indirect cost include plant \& equip., G\&A costs, muck haul \& margin.

14) Cavern excavation rate based upon hoisting 400 tons per hour. 


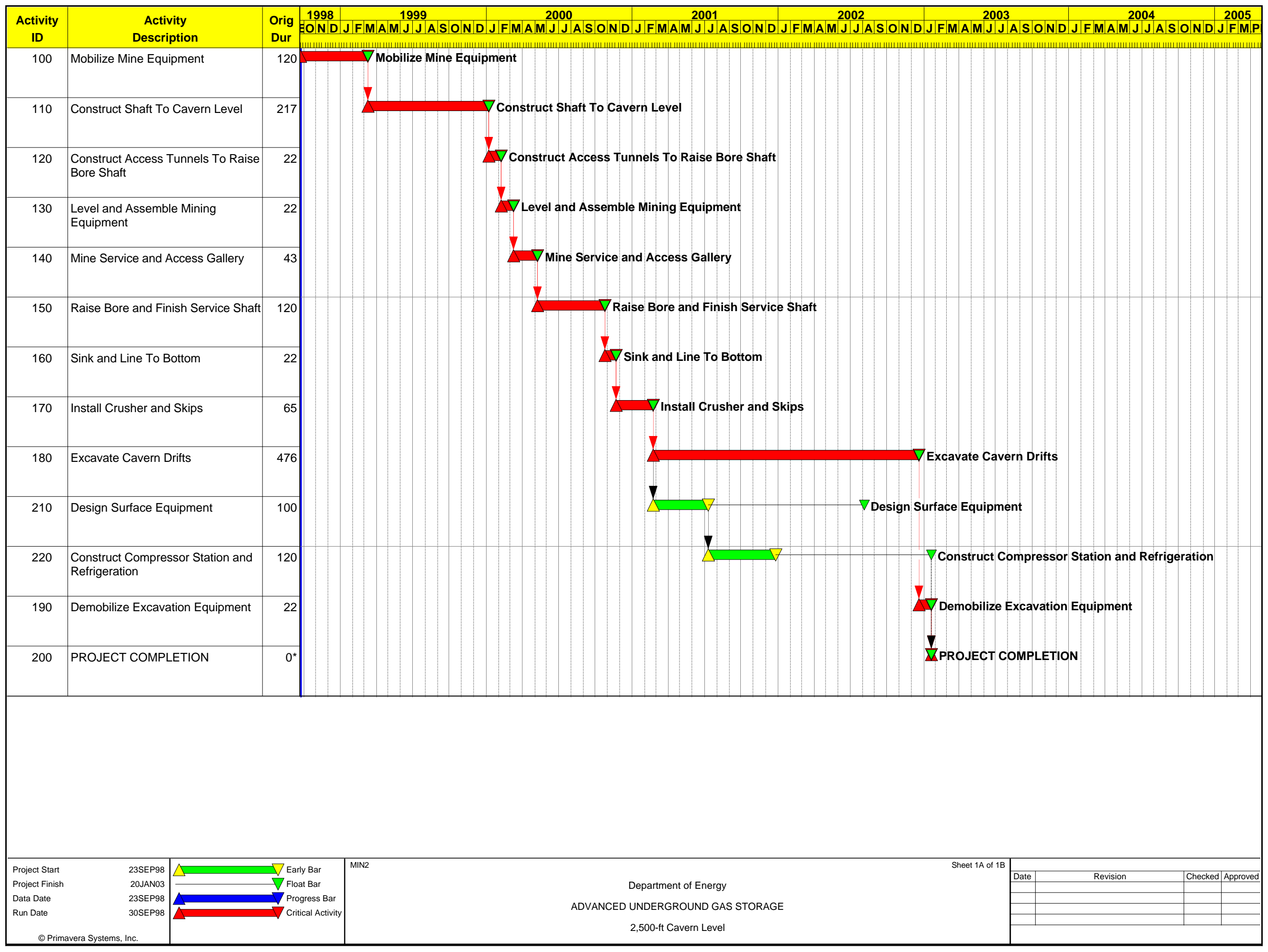




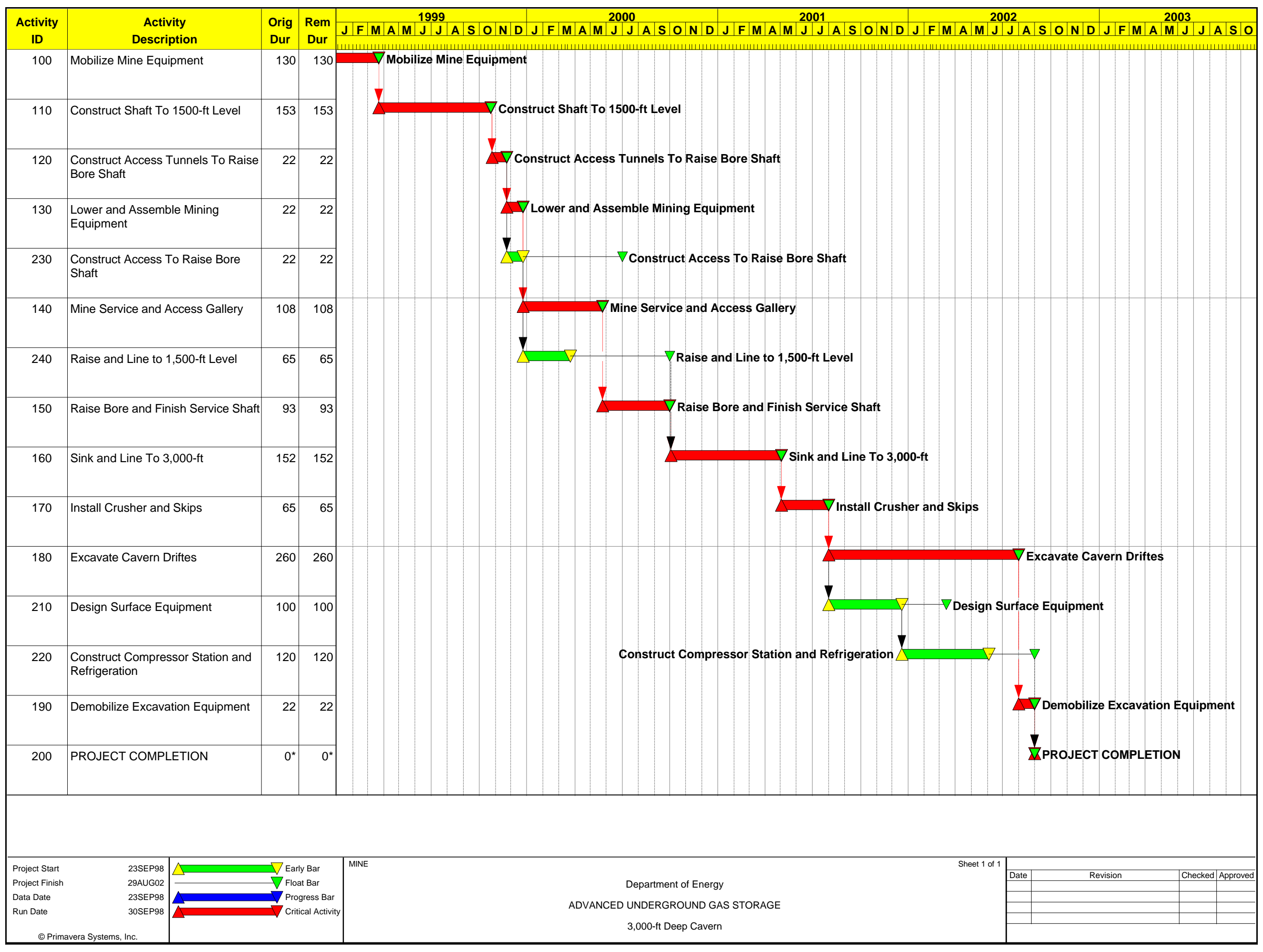




\section{Process Equipment Cost}

The refrigeration, compressor and process equipment would consist of two 13,000 HP centrifugal gas compressors, three 1300 ton gas turbine refrigeration systems, one $200 \mathrm{HP}$ recirculation gas compressor, one skid-mounted 250 MMSCFD molecular sieve dehydration system, one 66.2 MMBtu/hr line heater, one 1300 psig 250 MMscfd motor skid, four vertical scrubbers (1440 psig MAWP), and miscellaneous gate valves, check valves, pipes, etc. The cost of this equipment is estimated to be $\$ 31,971,400$.

Table 10-8 provides a complete cost summary of the refrigerated-mined cavern project at the 3,000-foot depth. The costs include the mining costs, process equipment, structures and foundations, and the infrastructure needed at the site.

More details on the costs are presented in the Appendix of this report regarding how the total costs were arrived at.

\section{OPERATING COSTS OF REFRIGERATED MINED CAVERN}

The cost of operating the refrigerated cavern storage system is based upon the assumptions listed in the design parameters shownin Section 3. It is further assumed that the maximum number of injection and withdrawal cycles will be completed. With 5 billion standard cubic feet of working gas storage, a maximum flow rate of $250 \mathrm{MMscfd}, 9$ fill/empty cycles can be completed annually. The costs are based on the cavern being fully injected to $1250 \mathrm{psig}$, and then emptied to the minimum pressure of $250 \mathrm{psig}$, at the maximum fill and withdrawal rate of 250 MMscfd.

During injection, the delivery pressure from the transmission lines, is assumed to be $350 \mathrm{psig}$. Therefore, the injection compressors are utilized for 19 of the 20 days for injection. Deliveries to the transmission lines form the storage cavern are assumed to be at 650 psig. This will require the compressors to be used during the 20 day withdrawal cycles for about 6 days. The refrigeration system will be used during injection to chill the gas to storage temperatures, and will operate continuously at a maintenance level to keep the cavern at $-20^{\circ} \mathrm{F}$. During the withdrawal cycle, the product gas will be heated to $60^{\circ} \mathrm{F}$ by the forced draft heater. Additional fuel gas will be required by the dehydration system for regeneration of the molecular sieve beds. There will also be "base load" energy requirements for the facility to operate compressor lubrication systems, air coolers, instrumentation, plant lighting, space heating and cooling, and other miscellaneous plant utilities. 
Table 10-8

\section{Cost Summary of Refrigerated Mined Cavern Project \\ (3,000-Foot Deep Mine)}

Working Gas Storage of 5.0 Billion Standard Cubic Feet

Maximum Injection Rate of 250 MMSCFD

Maximum Withdrawal Rate of 250 MMSCFD

Injection Cycle - 20 Days

Withdrawal Cycle - 20 days

\begin{tabular}{|c|c|}
\hline Conventional Mining and Shaft Sinking $(6,292,335$ barrels of space $)$ & $112,346,209$ \\
\hline Refrigeration System, Compressors, and Process & $31,971,424$ \\
\hline Electrical and Instrumentation Equipment & $2,243,333$ \\
\hline Compressor Building (210-feet X 50-feet) and Control & 903,540 \\
\hline Compressor Building Foundation and Slab & 68,064 \\
\hline Concrete Supports for Compressor Station Piping & 19,698 \\
\hline Control Building Foundation & 153,256 \\
\hline Mechanical Separators Foundations & 5,570 \\
\hline Mole Seives Foundations & 4,999 \\
\hline Pressure Reducing Station Foundations & 4,999 \\
\hline Gas Storage Facility Final Design (Eight Months) & $1,078,342$ \\
\hline Gas Storage Facility Construction \& Commissioning & $\underline{4,815,600}$ \\
\hline SUBTOTAL & $153,615,034$ \\
\hline Contingency on All Costs @ 10\% & $\underline{15,361,503}$ \\
\hline SUBTOTAL & $168,976,538$ \\
\hline Contractors' Profit at $10 \%$ on Surface Facilities & $\underline{3,537,488}$ \\
\hline TOTAL PROJECT COST & $172,514,026$ \\
\hline COST OF FACILITY PER MMSCF OF BASE GAS STORAGE & $\$ 34.50$ \\
\hline MINING COST PER BARREL OF MINED SPACE & $\$ 20.00$ \\
\hline
\end{tabular}


The following table (Table 10-9) shows the energy costs for the operation of the facility after the startup phase is completed. The table covers a range of gas prices for fuel since the price will vary subject to market conditions and the terms of the supply contract.

Table 10-9

Energy Costs

\begin{tabular}{|c|c|c|c|c|c|c|}
\hline & Gas Cost - \$/MMBtu: & $\$ 2.00$ & $\$ 2.25$ & $\$ 2.50$ & $\$ 2.75$ & $\$ 3.00$ \\
\hline 20 Day Injection Period & $\begin{array}{c}\text { Fuel Required } \\
\text { MMBtu's }\end{array}$ & $\begin{array}{r}\text { Energy } \\
\text { Cost }\end{array}$ & $\begin{array}{c}\text { Energy } \\
\text { Cost }\end{array}$ & $\begin{array}{r}\text { Energy } \\
\text { Cost }\end{array}$ & $\begin{array}{r}\text { Energy } \\
\text { Cost }\end{array}$ & Energy Cost \\
\hline Compression & $\$ 9,864.4$ & $\$ 19,729$ & $\$ 22,195$ & $\$ 24,661$ & $\$ 27,127$ & $\$ 29,593$ \\
\hline Refrigeration & $\$ 16,491.6$ & $\$ 32,983$ & $\$ 37,106$ & $\$ 41,229$ & $\$ 45,352$ & $\$ 49,475$ \\
\hline Dehydration & $\$ 1,920.0$ & $\$ 3,840$ & $\$ 4,320$ & $\$ 4,800$ & $\$ 5,280$ & $\$ 5,760$ \\
\hline Plant Baseline & $\$ 1,221.6$ & $\$ 2,443$ & $\$ 2,749$ & $\$ 3,054$ & $\$ 3,359$ & $\$ 3,665$ \\
\hline Total Injection & $\$ 29,497.6$ & $\$ 58,995$ & $\$ 66,370$ & $\$ 73,774$ & $\$ 81,118$ & $\$ 88,493$ \\
\hline 20 Day Withdrawal Period & & & & & & \\
\hline Compression & $\$ 2,748.6$ & $\$ 5,497$ & $\$ 6,184$ & $\$ 6,872$ & $\$ 7,559$ & $\$ 8,246$ \\
\hline Refrigeration & $\$ 245.0$ & $\$ 490$ & $\$ 551$ & $\$ 613$ & $\$ 674$ & $\$ 735$ \\
\hline Gas Heating & $\$ 14,928.0$ & $\$ 29,856$ & $\$ 33,588$ & $\$ 37,320$ & $\$ 41,052$ & $\$ 44,784$ \\
\hline Plant Baseline & $\$ 1,221.6$ & $\$ 2,443$ & $\$ 2,749$ & $\$ 3,054$ & $\$ 3,359$ & $\$ 3,665$ \\
\hline Total Withdrawal & $\$ 19,143.2$ & $\$ 38,286$ & $\$ 43,072$ & $\$ 47,858$ & $\$ 52,644$ & $\$ 57,430$ \\
\hline \multicolumn{2}{|c|}{ Total Cost per In/Out Cycle } & $\$ 97,282$ & $\$ 109,442$ & $\$ 121,602$ & $\$ 133,762$ & $\$ 145,922$ \\
\hline \multicolumn{2}{|c|}{ Total Energy Cost per Year } & $\$ 875,534$ & $\$ 984,976$ & $\$ 1,094,418$ & $\$ 1,203,860$ & $\$ 1,313,302$ \\
\hline
\end{tabular}




\section{Labor Costs}

The labor costs are shown in Table 10-10. These costs are based on the plant being manned 24 hours per day by two operators included is a salaried supervisor and one "day" clerical position. The labor rates and hours assumed are shown in the table. Two relief operators are included for filling operator positions during absenteeism for vacations, sicknesses and other reasons. An overtime rate was assumed for $3 \%$ of the work year for the hourly personnel.

Table 10-10

\section{Labor Costs}

\begin{tabular}{|l|c|c|c|r|r|r|}
\hline \multicolumn{1}{|c|}{ Position } & No. & $\mathrm{Hrs} /$ Day & Days/Wk & \multicolumn{1}{c|}{$\$ / \mathrm{Hr}$} & $\mathrm{OH} @ 35 \%$ & \multicolumn{1}{c|}{ Cost/Yr } \\
\hline Supervisor & 1 & 8 & 5 & 35.00 & 47.25 & 98,280 \\
\hline Shift Operators & 8 & 12 & 4 & 20.00 & 27.00 & 488,808 \\
\hline Relief Operators & 2 & 12 & 4 & 18.00 & 24.30 & 109,982 \\
\hline Clerical & 1 & 8 & 5 & 13.00 & 17.55 & 37,315 \\
\hline TOTAL & & & & & & 734,385 \\
\hline
\end{tabular}

- $2190 \mathrm{hrs}$ per year on $12 \mathrm{hr}$ shift schedule

- Overtime figured at $3 \%$ of annual schedule at base rate. 


\section{Maintenance and Operating Supplies}

Maintenance and operating supplies for the facility are assumed to be provided on an as-needed basis with maintenance provided by independent contractors. Some routine maintenance items will be performed by the operators and relief operators. The maintenance cost provided is a rough estimate. Experienced operators can provide a more detailed analysis.

\section{Cost Summary}

Table 10-11 is a summary of some of the major annual operating costs for the Refrigerated Mined Cavern Gas Storage Facility. Other costs associated with running a facility were not included in the scope of this estimate. Other costs that should be considered include taxes, insurance, depreciation, working capital, management and other overhead charges.

Table 10-11

Annual Operating Costs

\begin{tabular}{|l|c|c|}
\hline \multicolumn{1}{|c|}{ Cost Parameter } & Monthly Cost & Annual Cost \\
\hline Labor & & $\$ 98,280$ \\
\hline 1 Supervisor & $\$ 8,190$ & $\$ 488,808$ \\
\hline 8 Shift Operators & $\$ 40,734$ & $\$ 109,982$ \\
\hline 2 Relief Operators & $\$ 9,165$ & $\$ 37,315$ \\
\hline 1 Clerical & $\$ 3,110$ & $\$ 734,385$ \\
\hline Labor Subtotal & $\$ 61,199$ & $\$ 120,000$ \\
\hline Maintenance Mat'l \& Labor & $\$ 10,000$ & $\$ 36,000$ \\
\hline Operating Supplies & $\$ 3,000$ & $\$ 1,094,418$ \\
\hline Energy (as fuel gas) & $\$ 91,202$ & $\$ 1,984,803$ \\
\hline TOTAL & $\$ 165,400$ & \\
\hline
\end{tabular}

* Assumes $\$ 2.50$ per MMBtu. 


\section{Section 11 \\ OPTIMIZATION}

The conceptual mine design was reviewed in relation to its components, such as drift and pillar size and shaft diameter. Potential savings in the construction cost were considered by modifying dimensions of these variable components.

As far as the underground cavern design is concerned, the two variables that can be changed to affect the cost of the facility are the shafts and underground excavation. Consideration was given to varying the sizes of these components to determine their impact on the total facility cost. Other cost factors, such as "mobilization," "material-handling equipment," and "assembling equipment" are essentially constant, although minor variations could occur. The method of shaft construction also influences the cost. However, as explained in tasks 4 and 6, "constructibility," drilling an 18-ft main shaft for the type of rock in the region under consideration, and at the required depth (in excess of 2,500 ft) was ruled out.

The shaft construction cost can be reduced either by having smaller diameter shafts, or by reducing the depth of the shafts. The size of the shaft is dictated by the amount of rock that has to be excavated for the designed storage capacity. The storage of 5 billion cubic feet of working gas at $-20^{\circ} \mathrm{F}$ at a depth of 2,500 $\mathrm{ft}$, for instance, requires excavation in excess of 50 million cubic feet, or 1.9 million cubic yards of rock. To excavate this large volume underground requires the use of multi-boom jumbo drills, a number of 40-50 ton trucks, front-end loaders with 5-7 yard buckets, jaw crushers, scalers, etc. The shaft size must be at least 18-ft diameter to lower this equipment into the mine. Even with this size shaft, some of the equipment must be cut into smaller pieces, lowered into the cavern, and reassembled by welding, etc., at the shaft bottom. The hoisting rate must be at least 400 tons per hour to remove the excavated material from the cavern to the surface in a reasonable time. The skips for this duty, once again, require an 18-ft shaft. At the rate of 400 tons per hour hoisting for 16 hours per day, cavern construction alone will take about 22 months, with a total construction time of approximately four years. During all this time capital investment will be tied up with no return. If the shaft size were to be made smaller, say $14 \mathrm{ft}$, the shaft construction cost may be $10 \%$ less, but the facility construction time will exceed 5 years, resulting in a corresponding increase in the facility construction cost. Thus, for a reasonable schedule and for economic reasons, the optimum size of one of the shafts should be at least $18 \mathrm{ft}$. Since the second shaft is needed for ventilation purposes and for providing a second means of ingress/egress to and from the cavern, its size can be reduced for economy. The optimum size of this shaft is approximately $10 \mathrm{ft}$ to fit a mancage within. The most economic method of construction of this size shaft is raise boring. Raise boring cost is about $40 \%$ of the conventionally sunk shaft.

Shaft construction cost is approximately $15 \%$ of the total cavern development cost. In normal mining operations in massive deposits, shaft depth can be varied to realize economic benefits. However, in this gas storage project, shaft depth is intimately linked to the size of the cavern. The size of the cavern depends 
on the compressed volume of the gas to be stored (gas storage pressure). The gas is stored at about $95 \%$ of the hydrostatic head $(0.433 \mathrm{psi} / \mathrm{ft})$ in order to maintain the hydraulic seal. Hydraulic head is related to the depth of the cavern. Thus, at shallow depths, larger excavated cavern volume is needed than storage at greater depth for the same volume of gas due to lower compression possible.

Previously design relative to 2,500 ft deep shafts and caverns, their constructibility, and costs were described in Section 10. For this optimization study, shaft depths of $1,500 \mathrm{ft}, 2,000 \mathrm{ft}$, and $3,000 \mathrm{ft}$ were also considered and compared to the base case of $2,500 \mathrm{ft}$.

$1,500 \mathrm{ft}$ deep shafts (one $18 \mathrm{ft}$ conventionally sunk shaft and the other $10 \mathrm{ft}$ raise-bored) cost about $\$ 9.0$ million less than the 2,500 $\mathrm{ft}$ deep shafts. Hoisting distance is reduced and as such, hoisting cost per ton is reduced. However, at this depth the gas can be compressed only to less than $645 \mathrm{psi}$ and the storage volume for 5 billion standard cubic feet of working gas, at $-20^{\circ} \mathrm{F}$ increases to 4.4 million cubic yards compared to 1.9 million cubic yards needed at 2,500 ft depth. The cost of cavern excavation increases to $\$ 177.2$ million. The total cavern development cost at $1,500 \mathrm{ft}$ depth will be approximately $\$ 23$ million compared to the cavern development cost of $\$ 135.4$ million at 2,500 ft base case. Additionally, gas taken out of the reservoir will probably need additional compression before delivery to the commercial gas pipelines. The construction schedule would be stretched out to 80 months compared to the base case of 48 months.

The 2,000 $\mathrm{ft}$ deep storage cavern will require a storage volume of 2.5 million cubic yards to store 5 billion ctt of working gas at approximately $850 \mathrm{psi}$ at a temperature of $-20^{\circ} \mathrm{F}$. The shaft sinking cost will be reduced by $\$ 5$ million, but the total cavern development cost will be $\$ 157.3$ million, about $\$ 22$ million more than the base case. The construction schedule will be 59 months, or 11 months longer than the base case. The conclusion from the discussion of these two cases is that cavern construction at depths less than $2,500 \mathrm{ft}$ will be more expensive.

A cavern depth of $3,000 \mathrm{ft}$ was then considered. Although it is not a common practice to routinely sink shafts to this depth, some shafts in excess of $3,000 \mathrm{ft}$ depth have been constructed in the U.S. for metal mining. Thus, it will not be beyond the state of the art to sink shafts to this depth for gas storage with a conventional drill and blast method. For raise boring, however, it is the general consensus that 2,500 $\mathrm{ft}$ is the limit for a single lift raisebore. However, raise boring can be constructed in multi-lifts for deeper shafts. Thus, a 3,000 $\mathrm{ft}$ raisebore can be constructed in two $1,500 \mathrm{ft}$ lifts. For this purpose the main production shaft (18-ft diameter shaft) will initially be sunk to $1,500 \mathrm{ft}$ level. A drift will then be driven to the Service shaft (10 ft diameter shaft) location. The raise will be pulled to the surface, then lined to the $1,500 \mathrm{ft}$ level. When the Production shaft has been completed to the $3000 \mathrm{ft}$ level, the raise will be completed from the $3,000 \mathrm{ft}$ level to the station in the Service shaft at 1,500 ft. Hoisting from 3,000 ft level will take longer. The increased hoisting distance and the weight of the hoisting rope will require greater horsepower hoists, which are available in the market. The dimensions of the rooms and pillars underground will remain the same. The pillar safety factor will be reduced to about 1.9 , which is more than adequate. The required storage cavern 
volume will be 36 million cft or 1.34 million cyd. Storage cavern at 3,000 ft depth will cost about $\$ 124$ million, a saving of $\$ 11$ million over the 2,500 ft deep facility. Cost includes plant and equipment, G\&A, removal of excavated material offsite, and margin. The construction schedule will be 47 months, essentially the same as for the 2,500 ft. Further details of the cost and schedule are provided in Table 11-1.

The results of the above discussion for the storage of 5 billion SCF of gas at $-20^{\circ} \mathrm{F}$ are summarized in the following table.

Table 11-1

Comparative Cost and Schedule of Cavern Location

\begin{tabular}{|l|r|r|r|r|}
\hline & $\begin{array}{c}\text { Shaft Depth } \\
\mathbf{1 5 0 0} \mathbf{f t}\end{array}$ & \multicolumn{1}{c|}{$\begin{array}{c}\text { Shaft Depth } \\
\mathbf{2 0 0 0} \mathbf{f t}\end{array}$} & \multicolumn{1}{c|}{$\begin{array}{c}\text { Shaft Depth } \\
\mathbf{2 5 0 0} \mathbf{f t}\end{array}$} & \multicolumn{1}{c|}{$\begin{array}{c}\text { Shaft Depth } \\
\mathbf{3 0 0 0}\end{array}$} \\
\hline Mobilization & $\mathbf{7 , 2 1 5 , 0 0 0}$ & $\mathbf{7 , 2 1 5 , 0 0 0}$ & $7,212,000$ & $7,212,000$ \\
\hline $\begin{array}{l}\text { Sink \& line 18 ft } \\
\text { shaft }\end{array}$ & $10,003,500$ & $13,330,000$ & $16,672,000$ & $21,813,000$ \\
\hline Rise-bore shaft & $3,897,000$ & $5,196,000$ & $6,495,000$ & $8,393,000$ \\
\hline $\begin{array}{l}\text { Material handling } \\
\text { eqpt. }\end{array}$ & $4,123,000$ & $4,123,000$ & $4,120,000$ & $4,120,000$ \\
\hline $\begin{array}{l}\text { Assembling } \\
\text { mining eqpt. }\end{array}$ & $2,695,000$ & $2,695,000$ & $2,693,000$ & $2,693,000$ \\
\hline Cavern Exc. & $181,714,000$ & $104,197,640$ & $82,227,000$ & $64,998,500$ \\
\hline Total mining cost & $209,647,500$ & $136,764,640$ & $119,419,000$ & $109,229,500$ \\
\hline Contingency & $31,447,125$ & $20,514,696$ & $15,994,000$ & $14,629,000$ \\
\hline $\begin{array}{l}\text { Total cavern } \\
\text { development cost }\end{array}$ & $241,094,625$ & $157,279,336$ & $135,413,000$ & $123,858,500$ \\
\hline SCHEDULE & 80 months & 59 months & 48 months & 47 months \\
\hline
\end{tabular}

In addition to compression, the underground cavern volume also depends on the chilled temperature that the gas is subjected to. The cavern volumes and the costs given above are for the storage of gas chilled to a temperature of $-20^{\circ} \mathrm{F}$. These volumes will be further reduced if the temperatures are reduced.

Calculations were made to determine the required cavern volume if the same quantity of gas could be chilled to $-30^{\circ} \mathrm{F}$ and $-40^{\circ} \mathrm{F}$ and stored at 2500 and $3000 \mathrm{ft}$ depths. (Description: How to accomplish it, its impacts, required changes to the process equipment, etc.). The cavern volumes required for the storage of 5 billion cubic feet of working gas at various depths and temperatures are provided in the following table. 
Table 11-2

Required Cavern Volumes at Various Depths and Temperatures

\begin{tabular}{|l|c|c|c|}
\hline Depth & $\begin{array}{c}\text { Cavern Volume at }-20^{\circ} \mathrm{F}, \\
\text { million cubic yards }\end{array}$ & $\begin{array}{c}\text { Cavern Volume at-30} \\
\text { million cubic yards }\end{array}$ & $\begin{array}{c}\text { Cavern Volume at }-40^{\circ} \mathrm{F}, \\
\text { million cubic yards }\end{array}$ \\
\hline 2500 & 1.87 & 1.75 & 1.56 \\
\hline 3000 & 1.34 & 1.21 & 1.08 \\
\hline
\end{tabular}

The process equipment cost was estimated only for chilling the gas to a temperature of $-20{ }^{\circ} \mathrm{F}$ for the following reasons.

1. A colder temperature would require possible process design changes regarding refrigerant type and equipment design.

2. The metallurgy for the piping and equipment throughout the chilled system would have to be re-evaluated for service below $-20^{\circ} \mathrm{F}$, including piping in the mined cavern. 


\section{Section 12}

\section{EVALUATION OF SUCCESS CRITERIA}

In preparing an evaluation of the commercial feasibility of any gas storage project, one must evaluate how the project compares with the alternatives available to the market place, both physically, in terms of operational capability, and economically with regard to the relative costs of other services. In order to accomplish this, one must first become familiar with the types of storage available, and the services (and their related costs) that are provided in the market today.

\section{Types of Storage}

Natural gas storage has been in widespread use across North America for the better pat of this century, with the development of the Zoar project near Buffalo, New York in 1916 representing the first commercial gas storage development in the United States. At present there are more than 400 operating gas storage projects in the United States.

In general there are three major categories of gas storage projects, each of which tends to lend itself to specific service applications:

- Underground Reservoir Storage

- Underground Storage in Salt Deposits

- $\quad$ Liquefied Natural Gas (LNG) Storage

Underground reservoir storage is by far the most common type of gas storage in the U.S., representing over $98 \%$ of installed capacity. The majority of the reservoir storage fields in operation are depleted gas and/or oil fields that have rock properties suitable for the safe containment and redelivery of injected gas volumes. Examples of important rock properties for gas storage development would include a finite containment structure or trap, an impermeable cap rock above the storage zone(s), and a reasonably permeable and porous zone in which the gas will be stored. These fields also tend to make attractive candidates due to the existence in most cases of reservoir data acquired during the production life of the field. The analysis of production and well data from depleted fields is one of the key steps in evaluating the suitability of a candidate field, and in ultimately designing the gas storage facility.

A second type of reservoir storage is in underground aquifers. These tend to be fairly deep (greater than 2,000 ft), salt water aquifers that have little commercial value, but which have rock properties suitable for gas storage. Aquifer storage projects are much less common than depleted gas and/or oil field projects, representing approximately $12 \%$ of the total installed capacity in the U.S. ${ }^{1}$

\footnotetext{
${ }^{1}$ Id., p. 46.
} 
Reservoir storage sites tend to provide seasonal gas storage services characterized by fairly long injection and withdrawal cycles and relatively large total stored volumes of gas. Typically, a reservoir storage facility would hold from several to tens of billion cubic feet (BCF) of working or customer gas that would be cycled into and out of the reservoir once annually. The typical operating pattern for these facilities is a 150 to 200 day injection cycle, during the spring and summer months, followed by a winter withdrawal cycle of 120 to 150 days. There are, however, examples of reservoir storage facilities with shorter cycle times (e.g., 30 to 90-day withdrawal cycles) and these generally offer customers more flexibility in terms of daily injection and withdrawal rates.

Natural gas is also commonly stored in underground salt deposits, either in large caverns leached into a salt dome or in bedded salt formations. These facilities tend to be much smaller than reservoir storage sites in terms of overall volume but almost universally provide a higher rate of re-delivery and re-injection per unit volume. The injection and withdrawal characteristics of salt storage are precisely what make this type of storage valuable in the marketplace.

For instance, a typical salt cavern development might have on the order of 3.0 BCF of working gas capacity, with the ability to withdraw the entire volume in 10 days with replacement in 20 days, allowing the customer to cycle the space or inventory approximately once a month on average. This type of operating profile makes salt storage valuable for curing imbalances on the pipeline system and for handling commodity prices in the daily and monthly spot market. Depending on the location of the facility, the storage might also have peaking service benefits (if in the market area) or reliability service benefits (if in either the market area or the production area). In general, a 10-day firm withdrawal service seems to fit the needs of the high deliverability market fairly well -- i.e., for gas balancing, short term price optimization and reliability. In fact, most supply interruption and/or needle peaking events in the gas industry tend to last form a few to several days at most. Our experience has been that salt service customers tend to require a withdrawal to injection ratio of about $1: 2$ or $1: 3 .^{2}$

Imagine, for instance, an electric generation facility in the market area with a variable day-to-day output profile characterized by a high degree of swing in daily gas load. A properly designed salt storage service would enable the generation facility to purchase steady base load gas supplies and swing the imbalance volumes into and out of storage. Moreover, a properly structured storage contract might enable the same customer to purchase interruptible or recall-able supplies and/or transportation, utilizing the storage as a backstopping mechanism to hedge against periods of short-term price increase or interruptions. Overall, the use of salt storage as a supply management tool in this manner can result in the customer achieving

\footnotetext{
${ }^{2}$ The Hattiesburg Gas Storage project located in Mississippi and developed and operated by the current principals of Brant Energy L.L.C. ("Brant"), provided in its initial phases a 10 day withdrawal and 20 day re-injection service. In marketing a subsequent expansion of that facility we learned that customers believed a 30 day re-injection cycles would be preferable.
} 
significant savings and improvements in supply reliability. ${ }^{3}$

Liquefied natural gas, or LNG, is an expensive form of natural gas storage that is used to meet two market requirements -- needle peaking and/or supply reliability (backstopping). Typical LNG projects are designed to provide between 3 and 10 days of supply per year which is called upon the coldest days of the year and/or when other system supplies are curtailed unexpectedly. Due to the high cost associated with liquefaction, these projects are expensive when compared to other types of storage, but service a niche that often cannot be met with other forms of storage due to location and/or geologic factors. Overall, LNG represents a very minor share of the U.S. market, equating to less than 1 percent of U.S. consumption and 9 percent of underground storage withdrawals in $1993 .{ }^{4}$

On a volume basis, most of the LNG consumed in the U.S. is imported from Algeria into Eastern U.S. markets. The LNG is brought in large shiploads and stored in cryogenic tanks at very low temperatures. The product is then distributed to local satellite storage (tank) systems by truck and vaporized into the pipeline system as it is demanded. However, most U.S. LNG projects, particularly those operating in the Midwest and west involve liquefying and storing relatively small amounts of pipeline supplies during a long, 200+ day liquefaction season that normally occurs during the summer. These projects typically store from about one to five BCF of LNG and offer around 10 days of vaporization service per year.

\section{$\underline{\text { Comparison to Alternatives }}$}

The operating parameters, along with the capital and operating costs, were reviewed for the Refrigerated Mined Cavern (RMC) natural gas storage facility proposed for the Ellicott City area of Maryland. Capital cost numbers were modified to include the following:

$\begin{array}{ll}\text { Land and storage rights } & \$ 0.500 \text { million } \\ \text { Mineral rights } & 0.500 \\ \text { Permitting and regulatory } & 0.750 \\ \text { Marketing } & 0.200 \\ \text { Legal } & 0.200 \\ \text { Overhead and project management } & 0.750\end{array}$

Total capital cost additions

\section{\$2.900 million}

${ }^{3} \mathrm{~A}$ major Hattiesburg combination gas/electric utility would cycle its capacity in precisely this way. Typically, the customer would buy base loaded gas for the month and inject into storage on weekends when the electric plant was off-line, Withdrawals would commence on Monday morning and the ensuing weekday activity would closely track the operating profile of the electric plants served.

${ }^{4}$ EIA, March 1995, p.52. 
Including contingencies, this raised the total capital investment to approximately $\$ 178$ million.

Table 12-1 compares the unit capital costs for several depleted field, aquifer, salt cavern, and LNG projects with the proposed RMC project.

Table 12-1

Representative Unit Capital Costs for New Gas

Storage and LNG Projects

\begin{tabular}{|c|c|c|c|c|c|c|}
\hline Type of Project & Location & Project Name & $\begin{array}{c}\text { Working Gas } \\
\text { Capacity } \\
\text { (BCF) }\end{array}$ & $\begin{array}{c}\text { Total Cost } \\
\text { (\$MM) }\end{array}$ & $\begin{array}{l}\text { Unit Cost } \\
\text { (\$/MCF) }\end{array}$ & Notes \\
\hline Depleted Field & California & Putah Sink & 15.000 & 40.000 & 2.67 & (1) \\
\hline Depleted Field & Colorado & Douglas Creek & 10.000 & 30.000 & 3.00 & (1) \\
\hline Depleted Field & Utah & $\begin{array}{l}\text { Clay Basin } \\
\text { Expansion }\end{array}$ & 15.200 & 49.600 & 3.26 & (1) \\
\hline \multirow[t]{2}{*}{ Depleted Field } & Oklahoma & Manchester & 15.000 & 30.000 & 2.00 & (1) \\
\hline & & & & Average >> & 2.73 & \\
\hline Aquifer & Indiana & $\begin{array}{l}\text { Carbon- } \\
\text { Calcutta }\end{array}$ & 3.900 & 12.275 & 3.15 & (1) \\
\hline \multirow[t]{2}{*}{ Aquifer } & Illinois & $\begin{array}{l}\text { Hillsborough } \\
\text { Expansion }\end{array}$ & 4.500 & 36.600 & 8.13 & (1) \\
\hline & & & & Average >> & 5.64 & \\
\hline Salt Cavern & Alabama & $\begin{array}{l}\text { S. Alabama- } \\
\text { McIntosh }\end{array}$ & 2.700 & 30.000 & 11.11 & (1) \\
\hline Salt Cavern & Mississippi & $\begin{array}{l}\text { Hattiesburg } \\
\text { phase } 1 \& 1 \mathrm{~A}\end{array}$ & 3.500 & 47.000 & 13.43 & (2) \\
\hline \multirow[t]{2}{*}{ Salt Cavern } & Louisiana & $\begin{array}{l}\text { Napoleonville } \\
\text { Phase } 1\end{array}$ & 4.600 & 45.000 & 9.78 & (1) \\
\hline & & & & Average >> & 11.44 & \\
\hline LNG & North Carolina & Pine Needle & 4.000 & 107.000 & 26.75 & (2) \\
\hline \multirow[t]{2}{*}{ LNG } & Maine & Granite Slate & 2.000 & 44.222 & 22.11 & (2) \\
\hline & & & & Average $>>$ & 24.43 & \\
\hline \multicolumn{2}{|c|}{ Refrigerated mined Cavern } & Mid-Atlantic & 5.000 & 178.000 & 35.60 & \\
\hline
\end{tabular}


Although the capital costs of the RMC project are substantially higher than the others shown, it should be noted that, while LNG peaking service and depleted reservoir storage, which are both typically one-cycle per year, are available to the market area to be served by the RMC project, the multi-cycle service afforded by aquifer and salt cavern storage are not. Operationally, the RMC facility is similar to salt cavern storage characterized by high deliverability with multiple cycles possible within a given year. Specifically, the RMC facility proposed by PB-KBB has 5.0 BCF of working gas capacity with firm withdrawal capacity of 250 MMCFD and firm injection capacity of 250 MMCFD. This configuration permits the entire facility to be drawn down over a 20 day period and similarly refilled over a 20 day period. The maximum number of physical cycles that can be achieved annually is 9.1 .

While the facility physically most resembles salt cavern storage, its proposed location within a "market area" means that it should also be compared to other peaking sources when analyzing the RMC from a service feasibility perspective. The most common market area natural gas peaking service along the Eastern Seaboard is LNG. However, LNG facilities tend to differ from salt caverns and the proposed RMC facility in that they tend to be designed with a single cycle capability, i.e., a very long liquefaction cycle (on the order of 200 days) with a single vaporization cycle (analogous to withdrawal) of approximately 10 days.

In general, the flexibility afforded by market area, multi-cycle, high deliverability gas storage is preferable to the single cycle of an LNG service for several reasons:

\section{Multiple demand peaks can be met within a given year.}

While typically the true "peaks" are observed during winter heating season, the increased use of gas fired generation can also create short-term summer demand (air conditioning load) situations where withdrawals form a high deliverability storage facility become economic.

\section{Baseload gas supply planning can be better optimized.}

A multi-cycle, high deliverability service means better and more frequent "backstopping" or insurance capability for interruptible supply contracts.

\section{Daily and monthly balancing.}

Multi-cycle, high deliverability storage is commonly used for daily and monthly balancing (matching nominations and receipts to deliveries on the pipeline or distribution system), thereby avoiding costly imbalance penalties.

\section{Gas supply cost management}

Besides merely allowing for greater interruptibility in flowing supplies, a multi-cycle high deliverability storage service does afford short-term opportunities to capture value associated with gas price volatility that may 
be observed within the daily market.

On a unit cost basis, the RMC project is considerably higher than salt cavern storage and somewhat higher than LNG. However, it is Brant's understanding that within the market area of study, there is not adequate salt for the development of an underground natural gas storage project. Hence the higher costs of the RMC project may be justified if multi-cycle, high deliverability services are demanded.

\section{Cost of Service Rate Development}

A simplified cost-of-service model was used to take basic capital and operating cost data for the RMC project to develop monthly demand charges and per cycle costs. A fifteen year planning horizon was used to develop annual and levelized rates. Major assumptions include:

- A typical utility or regulated capital structure of $50 \%$ debt and $50 \%$ equity

- 30 year book depreciation period for the purposes of calculating rates

- Completed capital cost of $\$ 178$ million

- Income tax rate of $38.25 \%$

- Storage capacity of 5.0 BCF, with injection and withdrawal capacity of $250 \mathrm{MMCF} /$ day

Using these assumptions, preliminary rates have been calculated as follows:

- 15 Year Levelized Demand Charge $\$ 9.919 / \mathrm{Mcfd} / \mathrm{Mo}$

- Single Cycle Unit Cost $\$ 5.980 /$ Mcf

- Unit Cost at Maximum Cycles (9.1) $\$ 0.681 / \mathrm{Mcf}$

An advantage that the RMC project has over the most likely competitive service, LNG, is its ability to cycle many times throughout the year. The high capital costs of both services result in fixed demand charges which are substantially higher than reservoir, aquifer or even salt cavern services. Because of the RMC project's ability to cycle gas through the facility several times a year, versus once for LNG service, it is possible to spread these costs over a much larger volume of gas thereby reducing the unit cost of service substantially.

\section{Comparison to Alternatives}

Table 12-2 summarizes rates for a series of selected older and newer (proposed) LNG and salt storage projects. The 15-year levelized rate for the RMC project is depicted for comparative purposes.

It would appear that the proposed RMC project falls within the range of rates for projects delivering similar high deliverability services. The 15 year levelized rate developed appears to fall somewhat above market area salt storage and well within the range of existing and proposed LNG facilities. LNG, due to its proximity 
to the marketplace, as well as its high deliverability capability, would most likely be the primary competitor for the RMC project. The preliminary RMC rates, which are in the range of LNG service, would appear to enable the project to be competitive in the market.

As stated above, the RMC project, with a 20-day injection an 20-day withdrawal period, tends to resemble high deliverability salt cavern storage service more than LNG service. However, given the possible location of the project within a market area, the project may be able to capture a market value that would represent a hybrid between LNG and salt cavern storage. This would need to be market tested in some detail before drawing definitive conclusions. 
Table 12-2

\section{Comparison of Rates for Refrigerated Mined Cavern}

Natural Gas Storage vs. Selected LNG and

\section{Underground Salt Cavern Storage Facilities}

\begin{tabular}{|c|c|c|c|c|c|c|c|c|c|}
\hline Existing LNG Facilities & $\begin{array}{c}\text { Days of } \\
\text { Withdrawal/ } \\
\text { Vaporization }\end{array}$ & $\begin{array}{c}\text { Monthly Demand } \\
\$ / \text { dth/day }\end{array}$ & $\begin{array}{l}\text { Monthly } \\
\text { Volume } \\
\text { Charge } \\
\$ / \text { dth }\end{array}$ & $\begin{array}{c}\text { Variable } \\
\text { Withdrawal } \\
\text { Charge } \\
\text { \$/dth }\end{array}$ & $\begin{array}{c}\text { Variable } \\
\text { Injection } \\
\text { Charge } \\
\$ / \text { dth }\end{array}$ & $\begin{array}{c}\text { Fuel } \\
\%\end{array}$ & $\begin{array}{c}\text { Fuel @ } \\
\$ 2.50 \\
\$ / d t h\end{array}$ & $\begin{array}{c}\text { Single Cycle } \\
\text { Unit Cost } \\
\$ / d t h\end{array}$ & $\begin{array}{c}\text { Cost/Cycle } \\
\text { @ Max. \# of } \\
\text { Cycles } \\
\$ / \text { dth }\end{array}$ \\
\hline Transco LNG @ Carlstadt, NJ & 10 & 0.9058 & 0.1745 & 0.2025 & 0.2025 & $7.44 \%$ & 0.186 & 3.772 & $\mathrm{n} / \mathrm{a}$ \\
\hline East Tennessee Natural Gas & 10 & 7.1856 & 0.0000 & 0.0000 & 0.0000 & $15.69 \%$ & 0.392 & 9.015 & $\mathrm{n} / \mathrm{a}$ \\
\hline Eastern Shore Natural Gas & 10 & 8.6701 & 0.1745 & 0.2025 & 0.2025 & $7.44 \%$ & 0.186 & 13.089 & $\mathrm{n} / \mathrm{a}$ \\
\hline South Caroline Pipeline Co. & 10 & 5.620 & 0.0000 & 0.2500 & 0.0500 & $0.00 \%$ & 0.000 & 7.044 & $\mathrm{n} / \mathrm{a}$ \\
\hline \multicolumn{10}{|l|}{ Proposed LNG Facilities } \\
\hline Cove Point LNG (MD) & 10 & 4.940 & 0.0000 & 0.0005 & 0.0005 & $20.50 \%$ & 0.513 & 6.442 & $\mathrm{n} / \mathrm{a}$ \\
\hline Granite State LNG (ME) & 10 & 6.0600 & 0.0260 & 0.0000 & 0.0546 & $2.20 \%$ & 0.055 & 7.682 & $\mathrm{n} / \mathrm{a}$ \\
\hline Pine Needle LNG (NC) & 10 & 4.850 & 0.0000 & 0.0000 & 0.0000 & $0.00 \%$ & 0.000 & 5.820 & $\mathrm{n} / \mathrm{a}$ \\
\hline \multicolumn{10}{|l|}{ Existing Salt Cavern Storage } \\
\hline Hattiesburg Gas Storage (MS) & 10 & 2.6300 & 0.0000 & 0.0100 & 0.0100 & $1.50 \%$ & 0.038 & 3.214 & 0.321 \\
\hline \multicolumn{10}{|l|}{ Proposed Salt Cavern Storage } \\
\hline Avoca Gas Storage (NY) & 10 & 3.7500 & 0.0000 & 0.0100 & 0.0100 & $2.00 \%$ & 0.050 & 4.570 & 0.563 \\
\hline Tioga Gas Storage (PA) & 10 & 4.200 & 0.0000 & 0.0100 & 0.0100 & $1.20 \%$ & 0.030 & 5.090 & 0.602 \\
\hline Refrigerated Mined Cavern & 20 & 9.9190 & 0.0000 & 0.0000 & 0.0000 & $1.16 \%$ & 0.029 & 5.980 & 0.681 \\
\hline
\end{tabular}


APPENDICES 
CONCEPTUAL DRAWINGS 


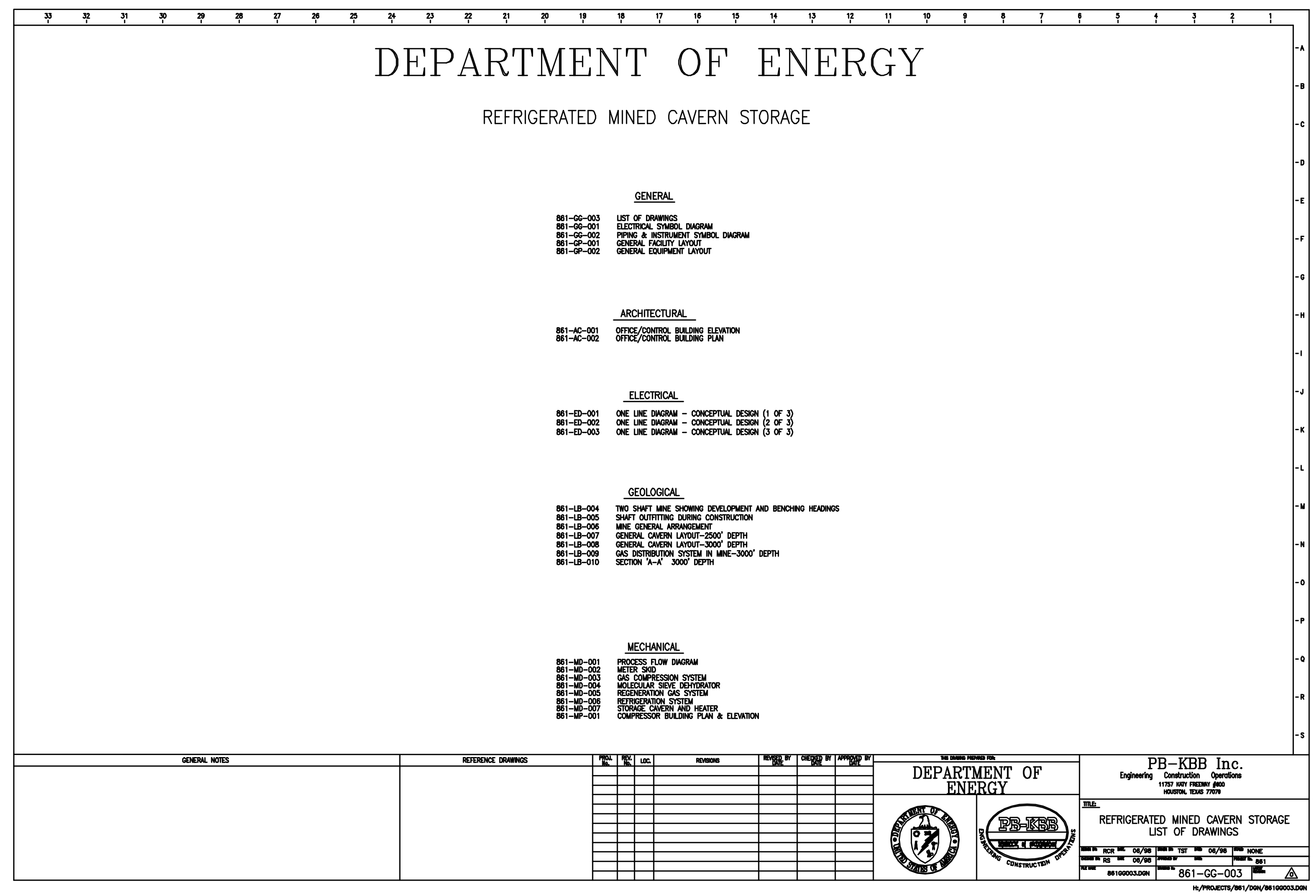




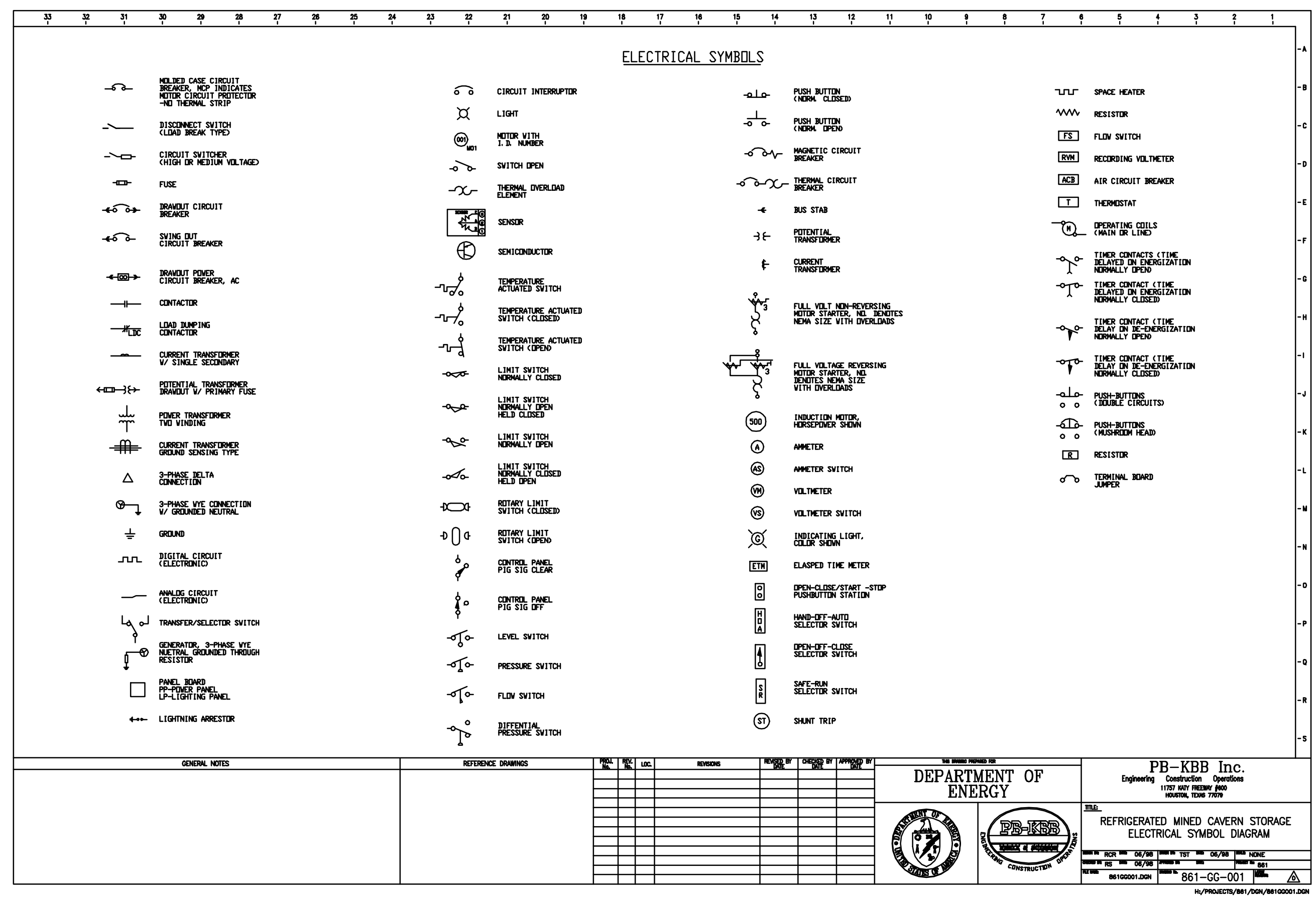




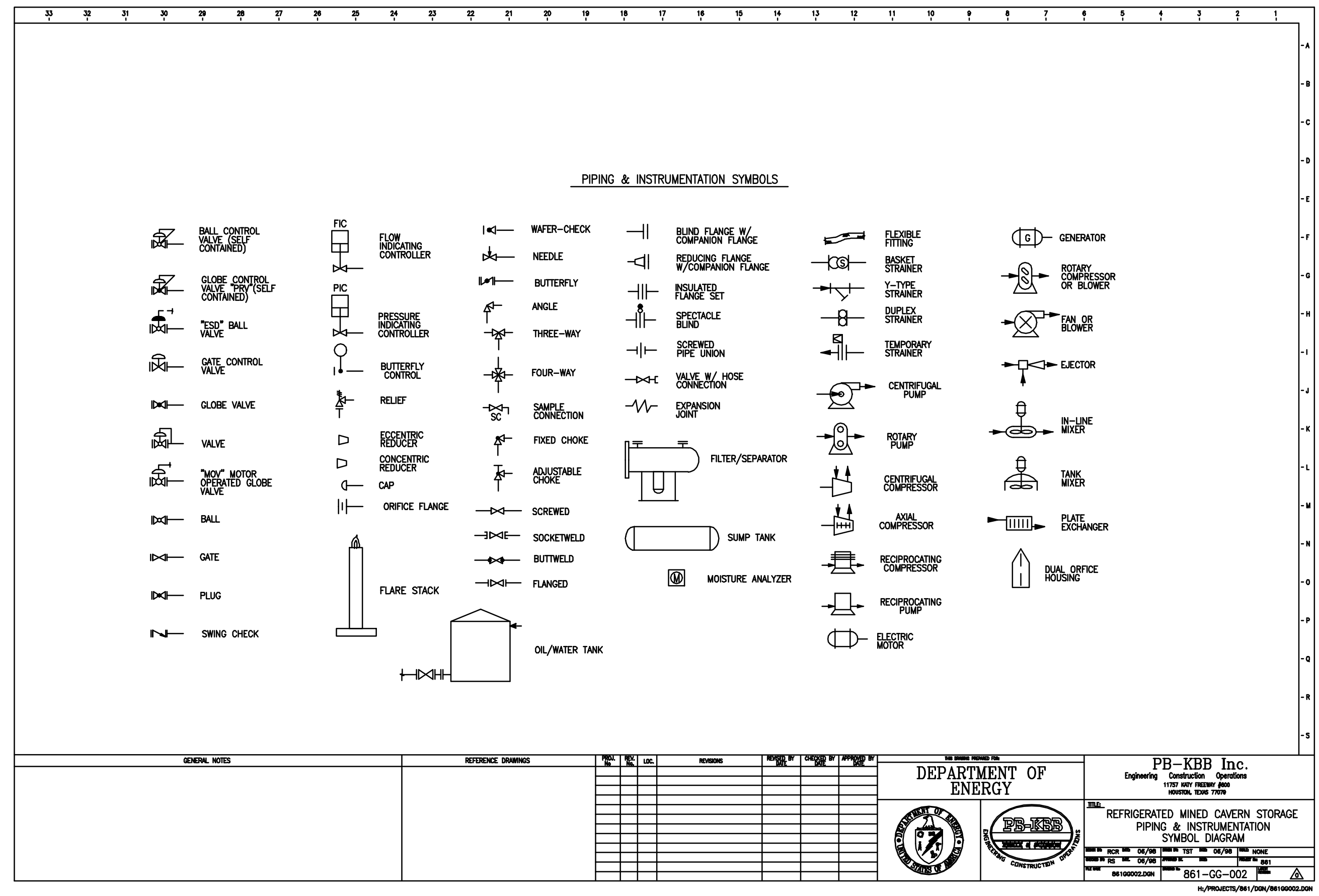




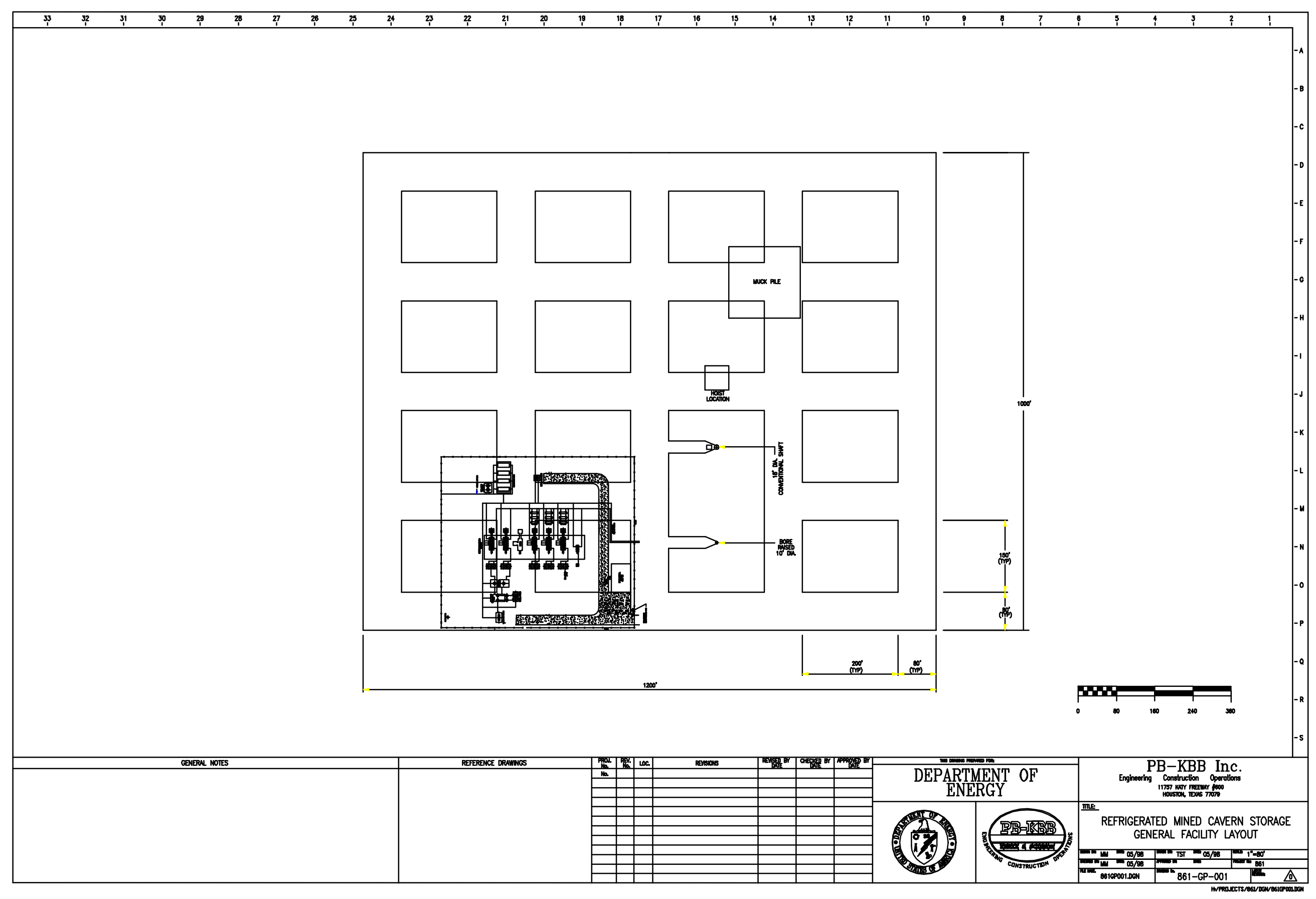




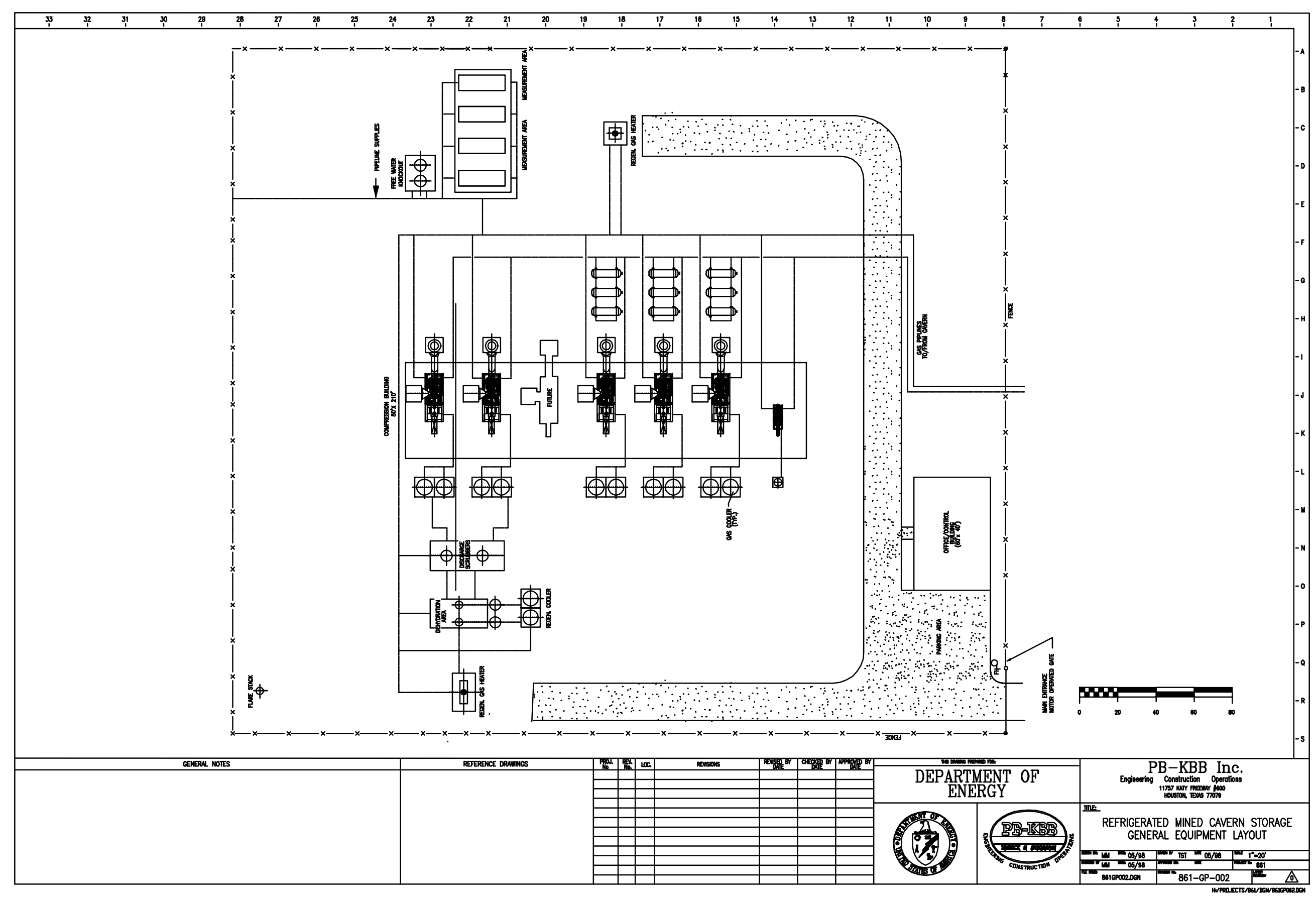




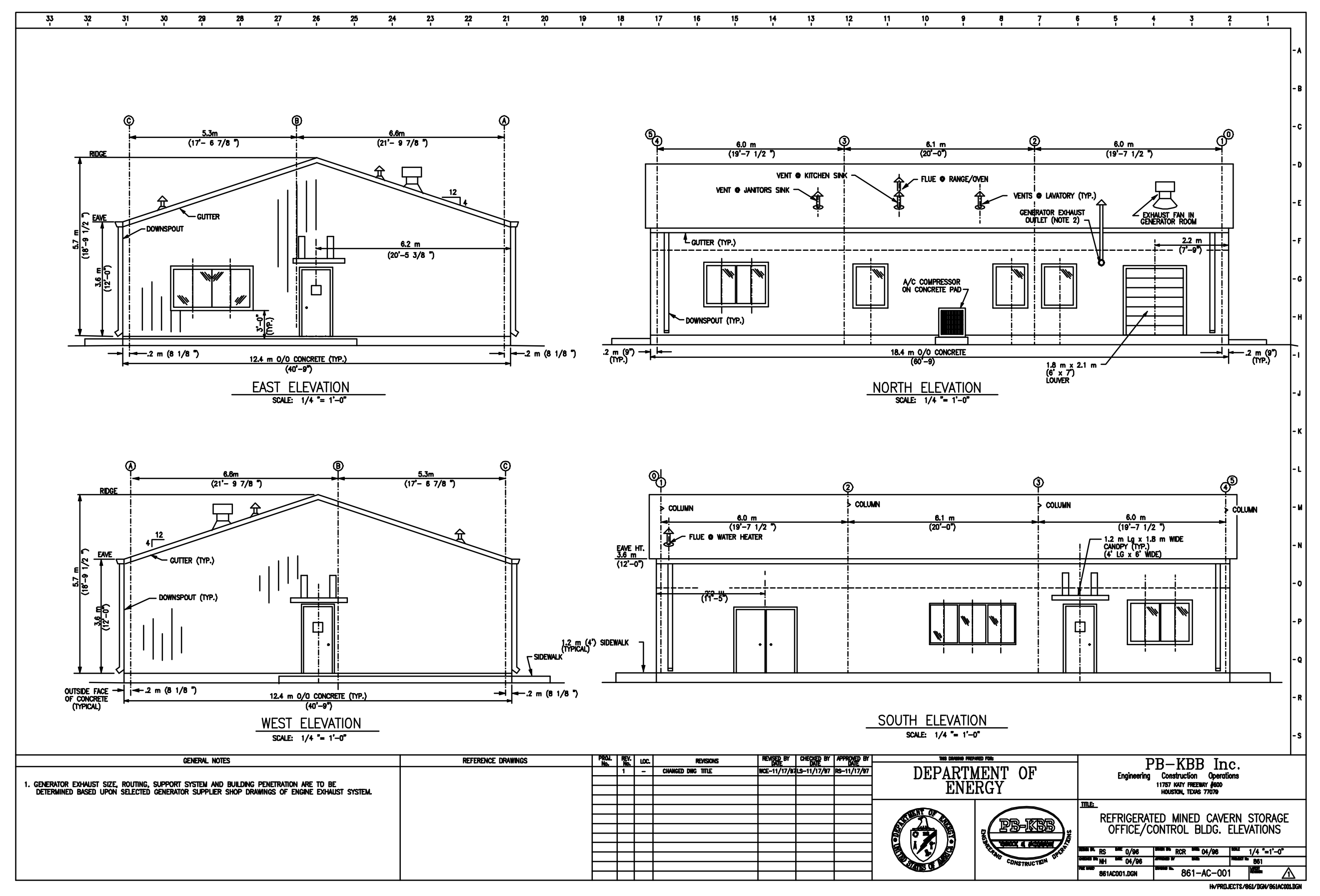




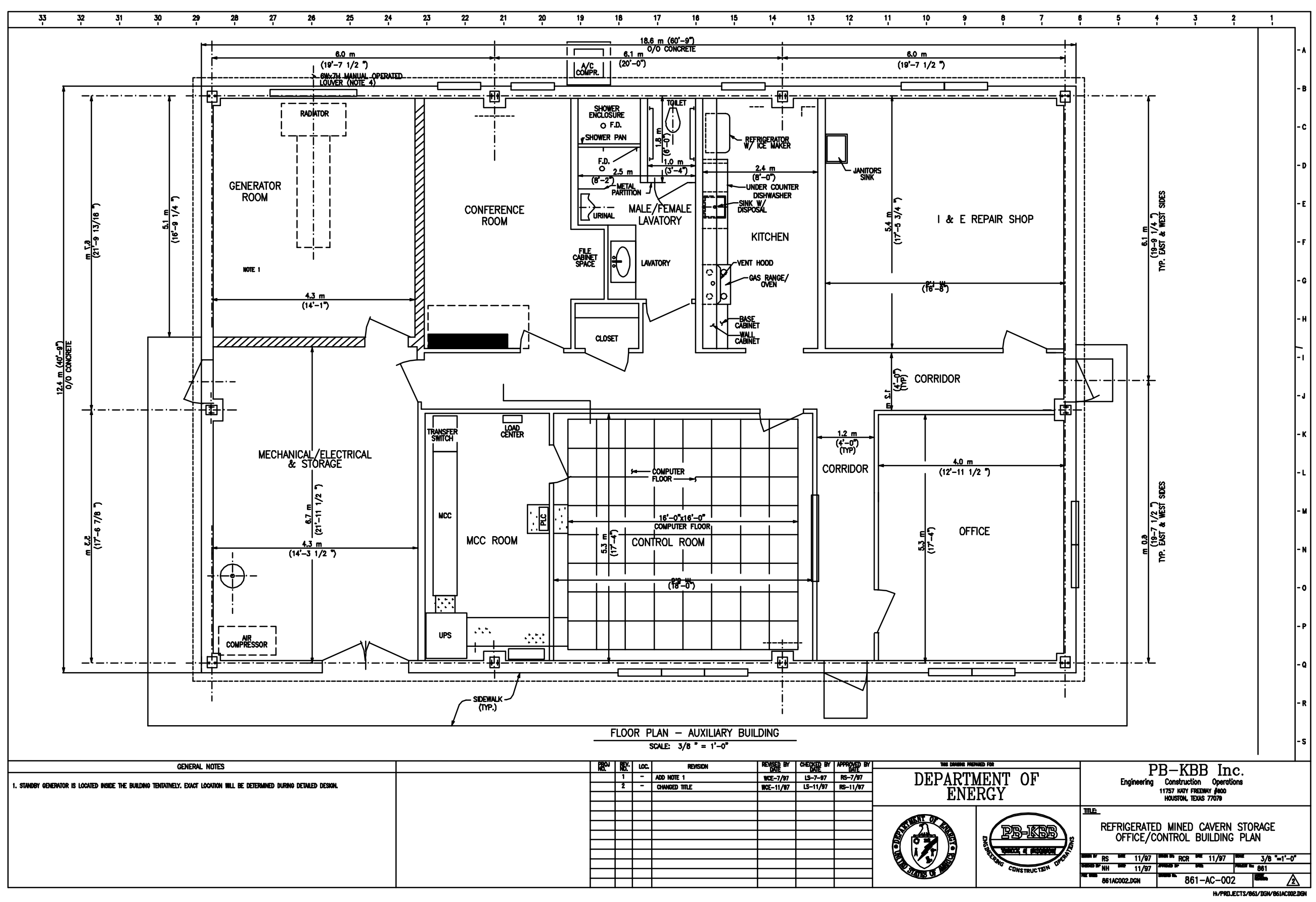




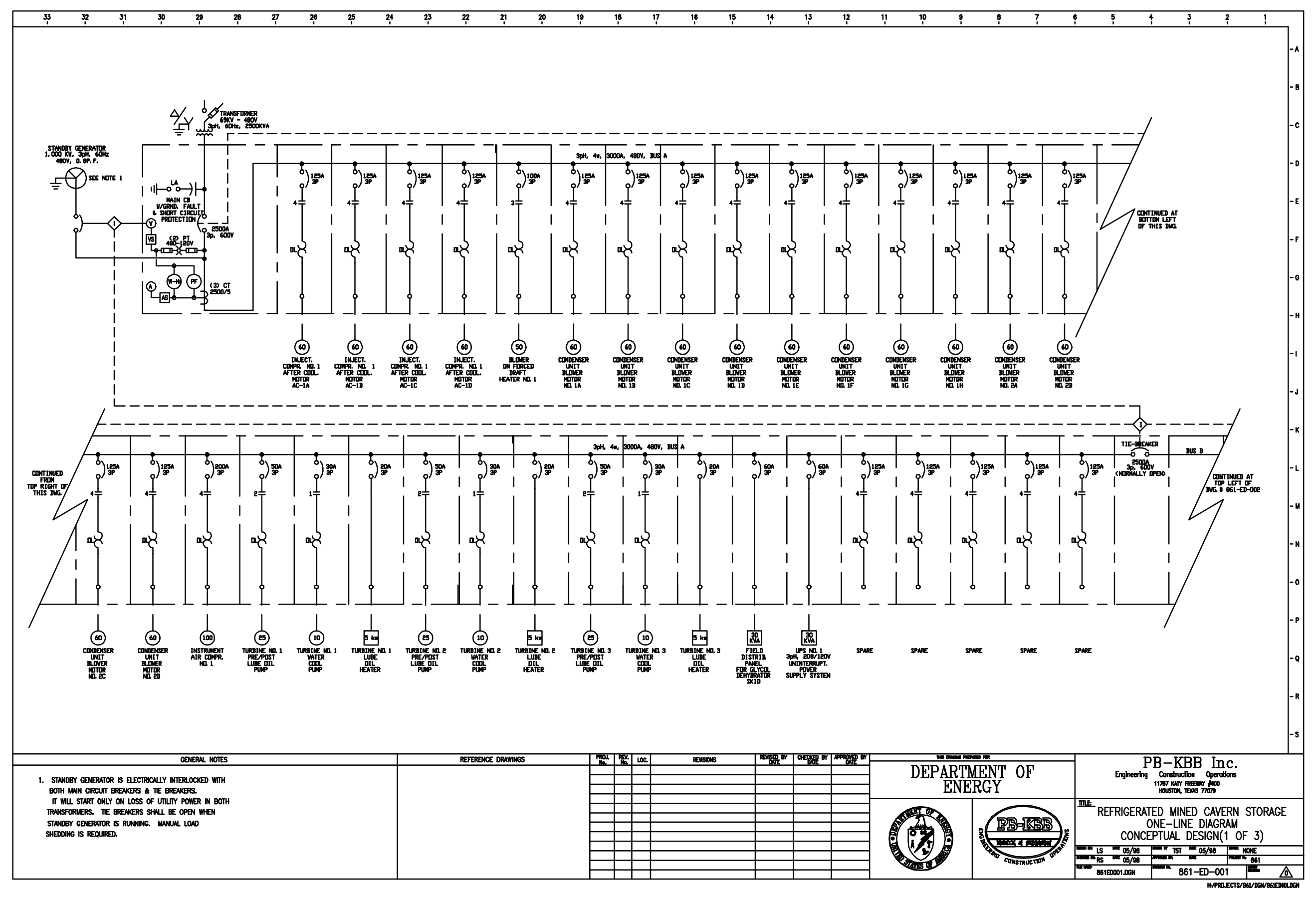




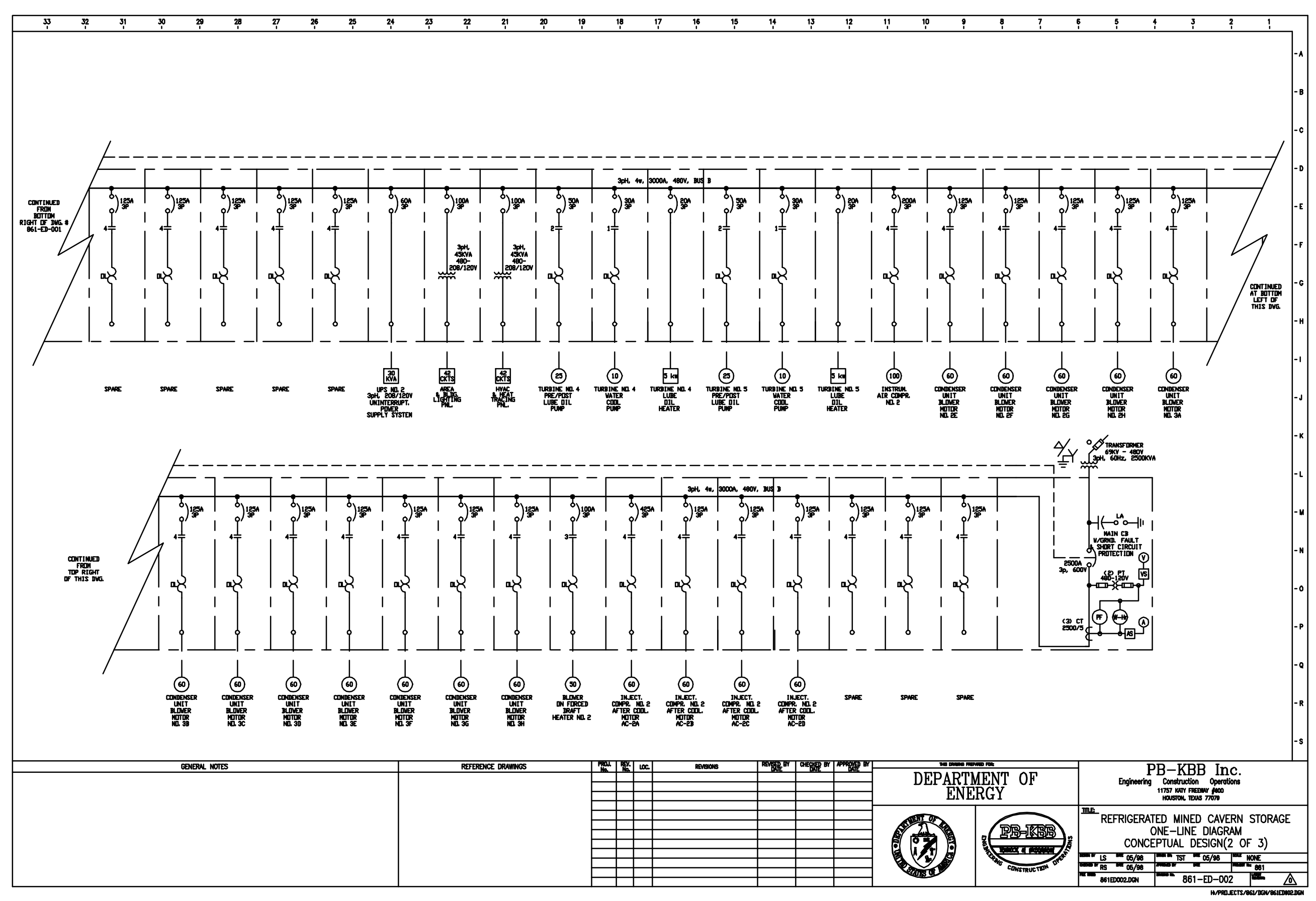




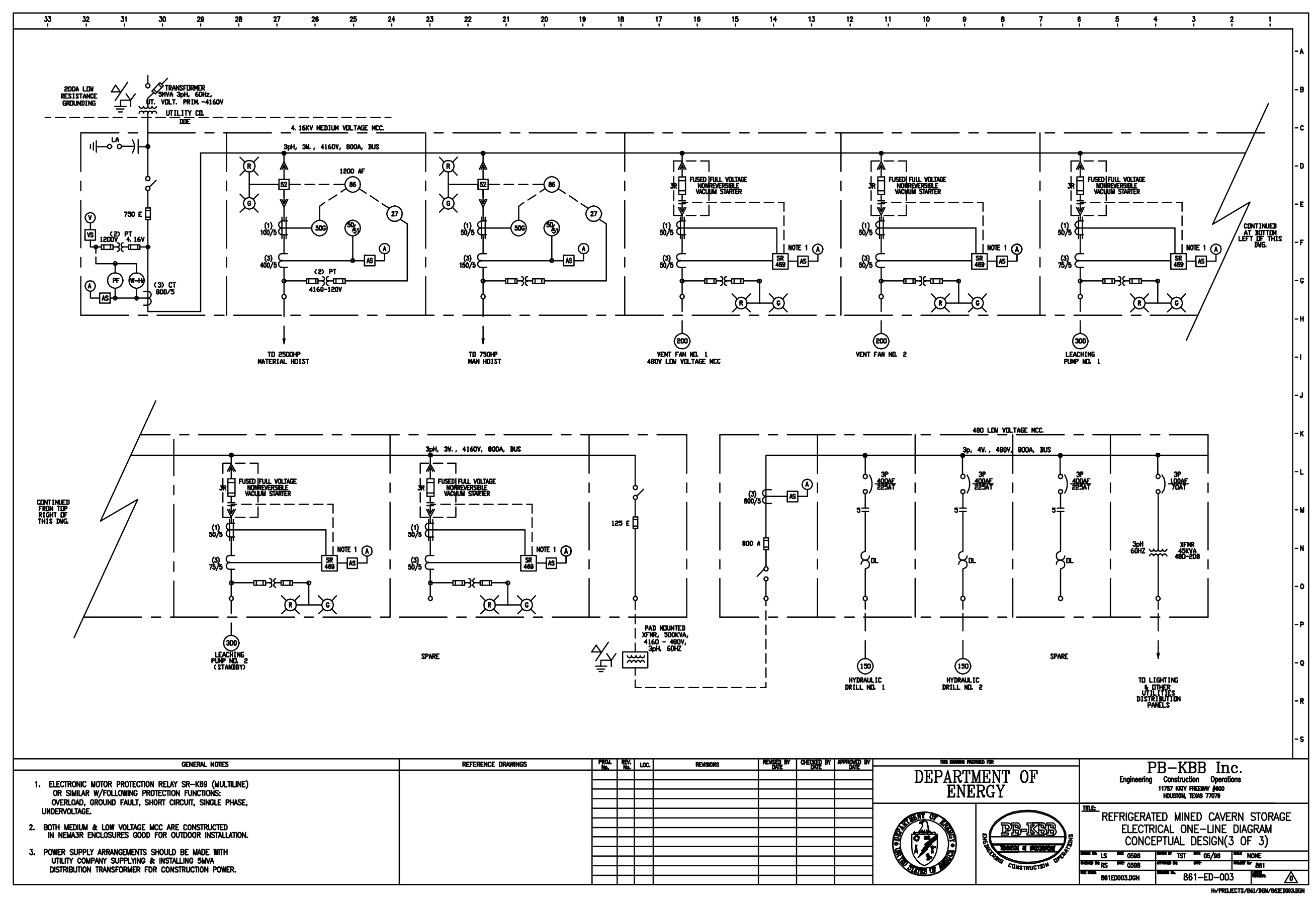




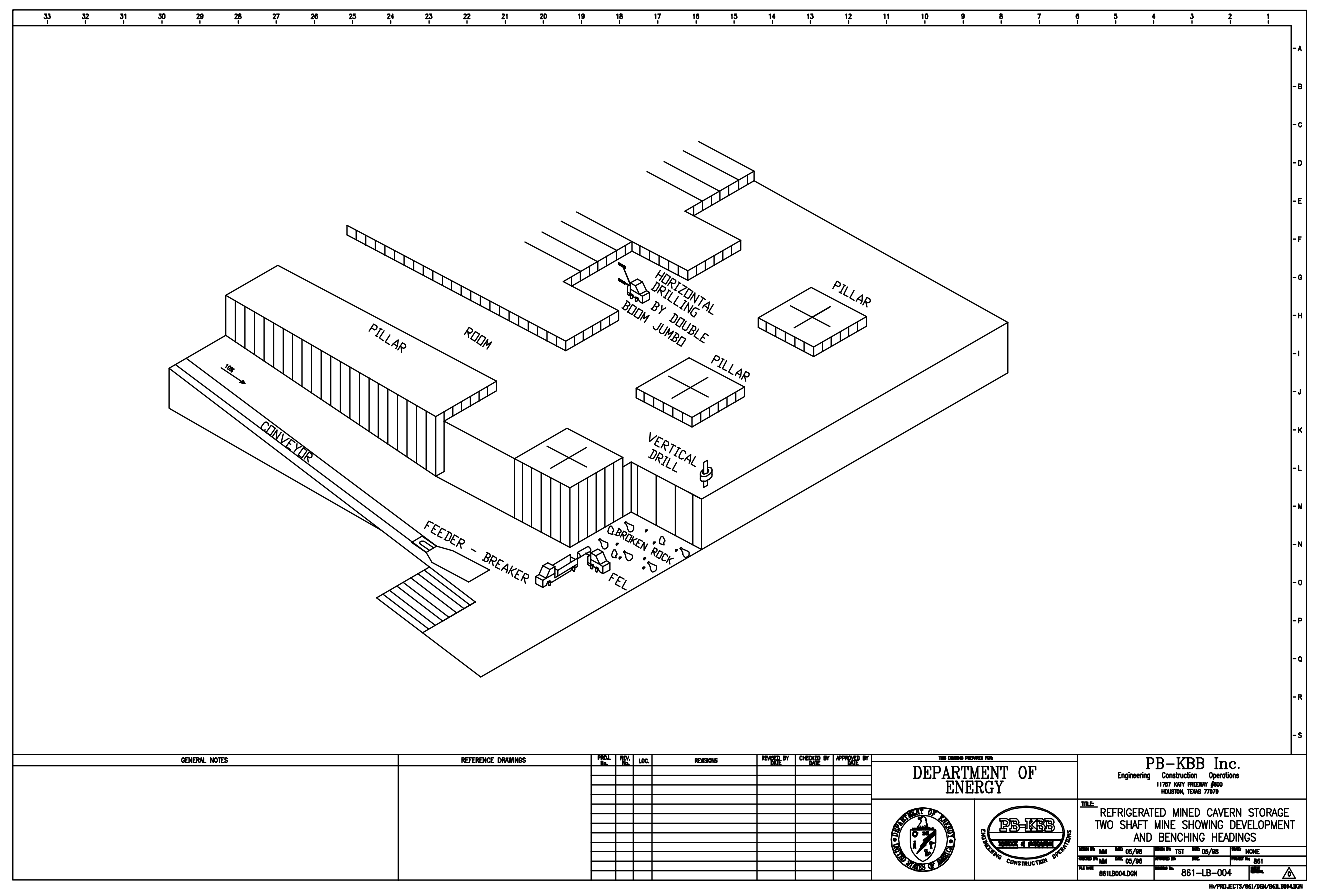




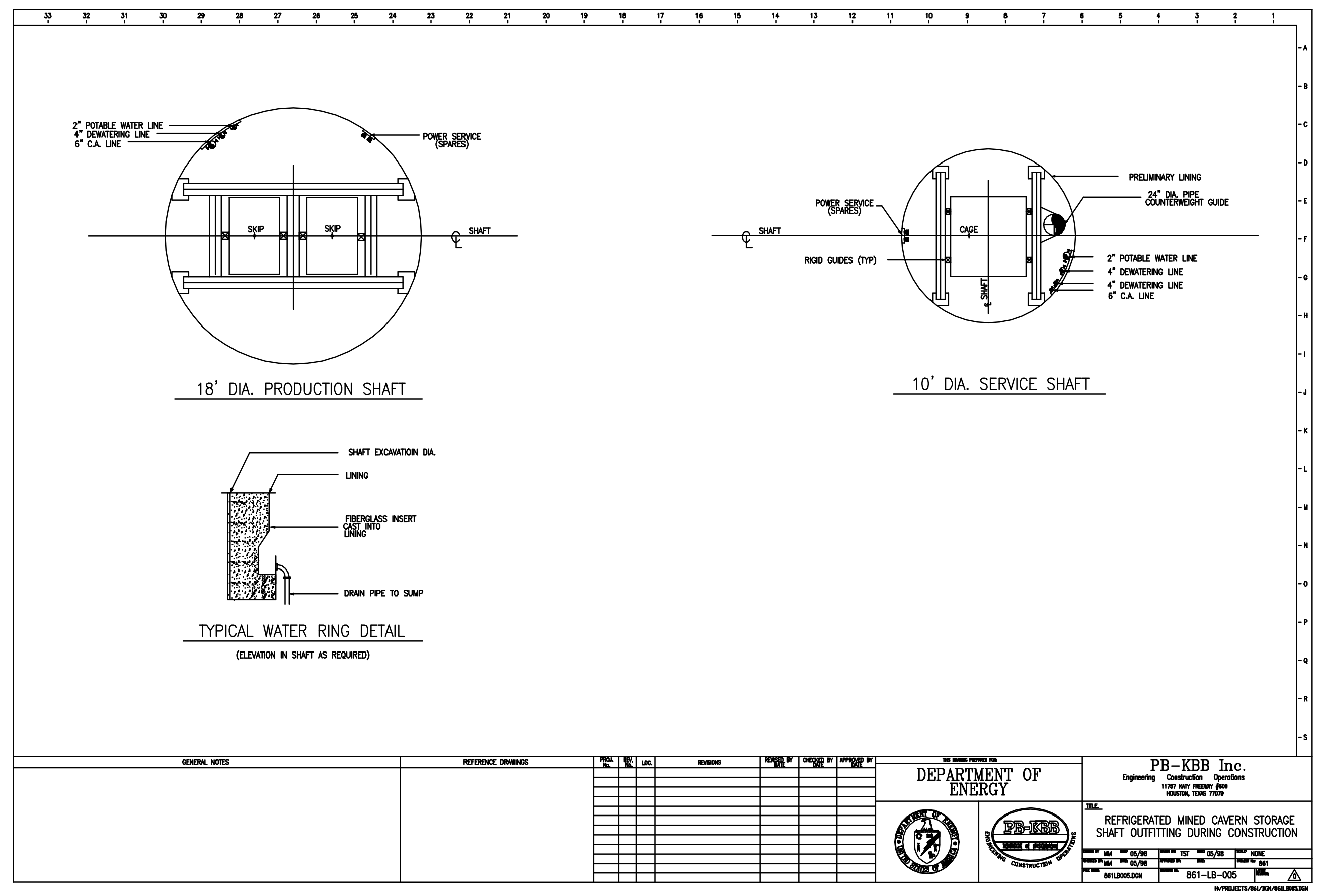




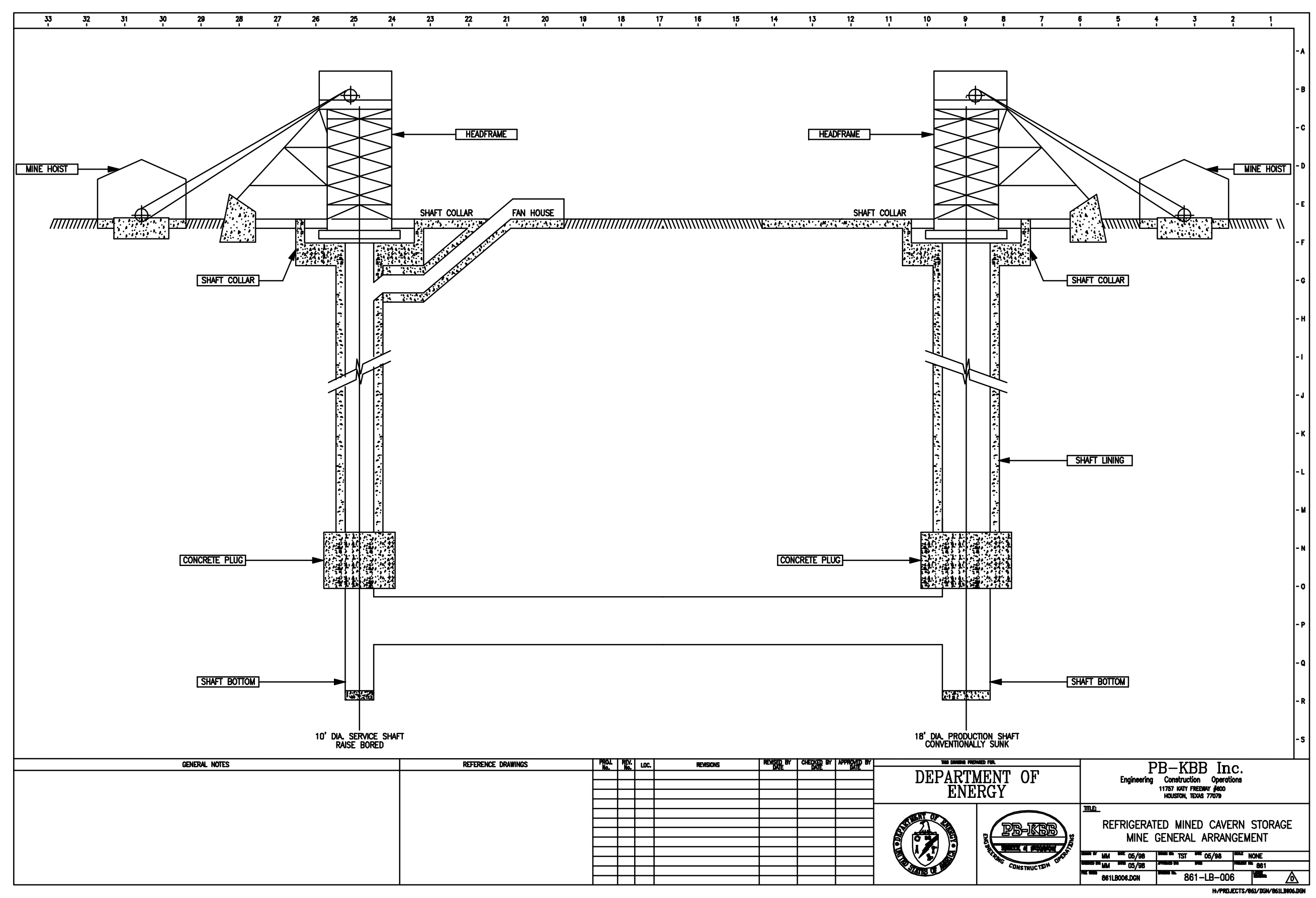




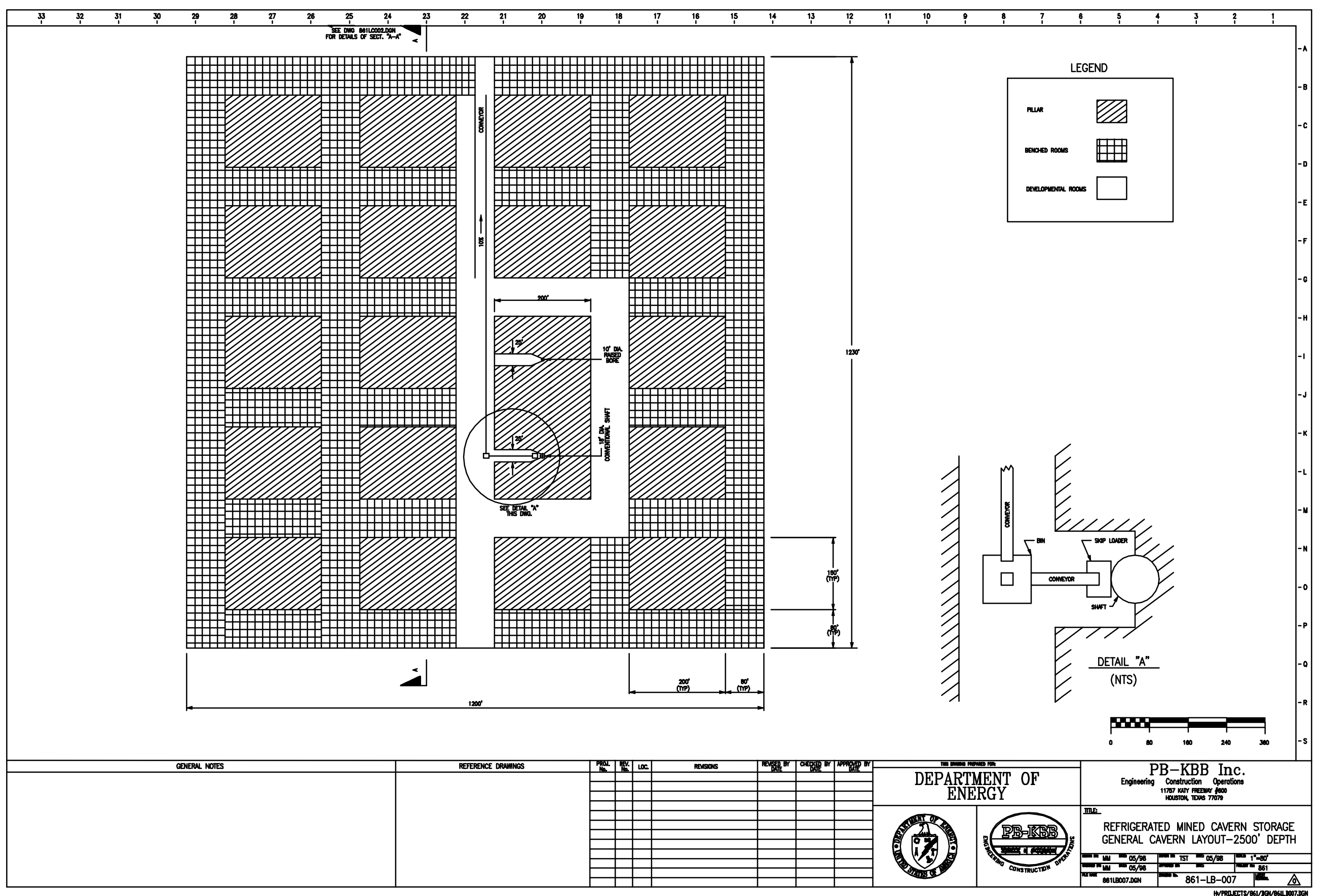




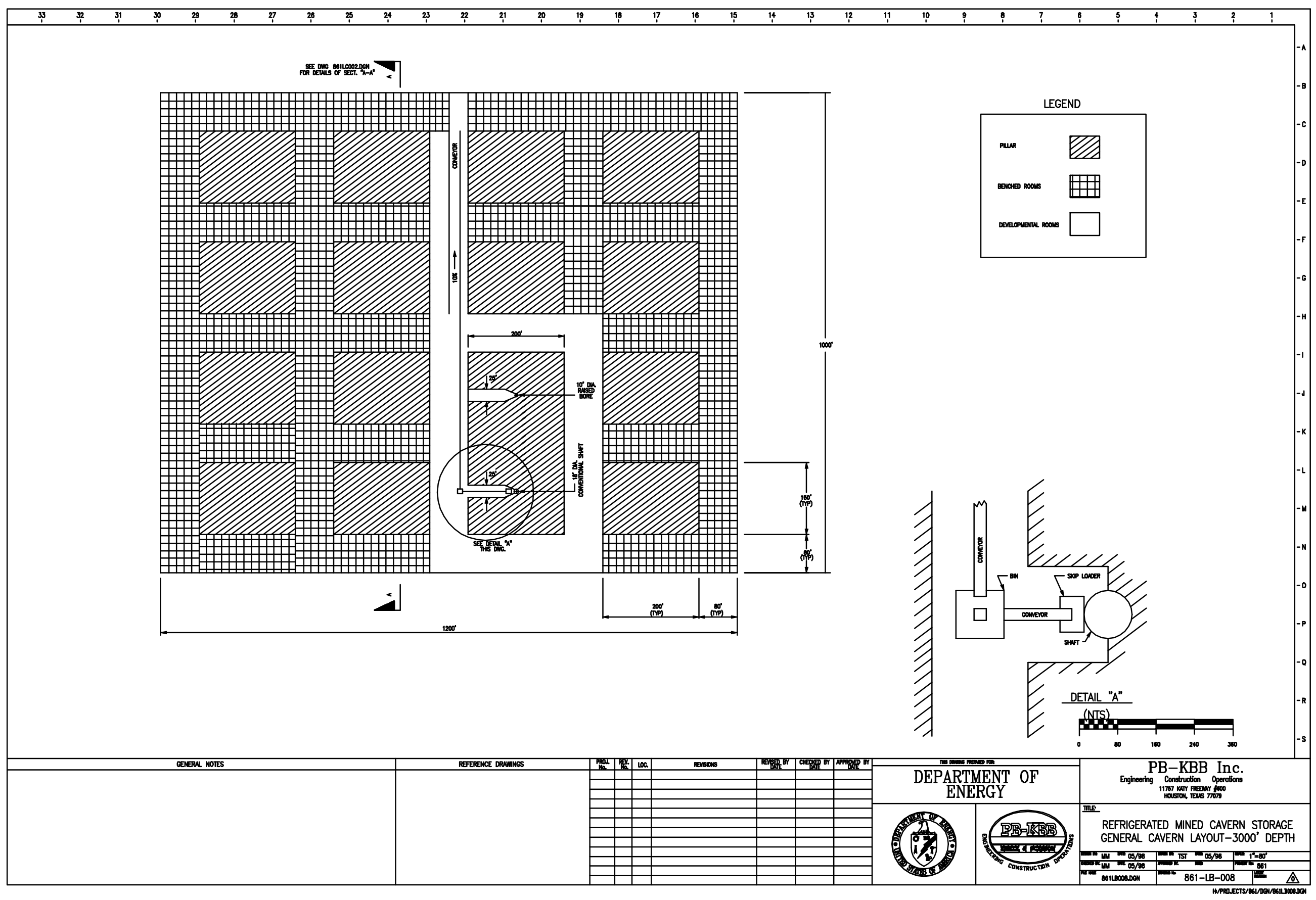




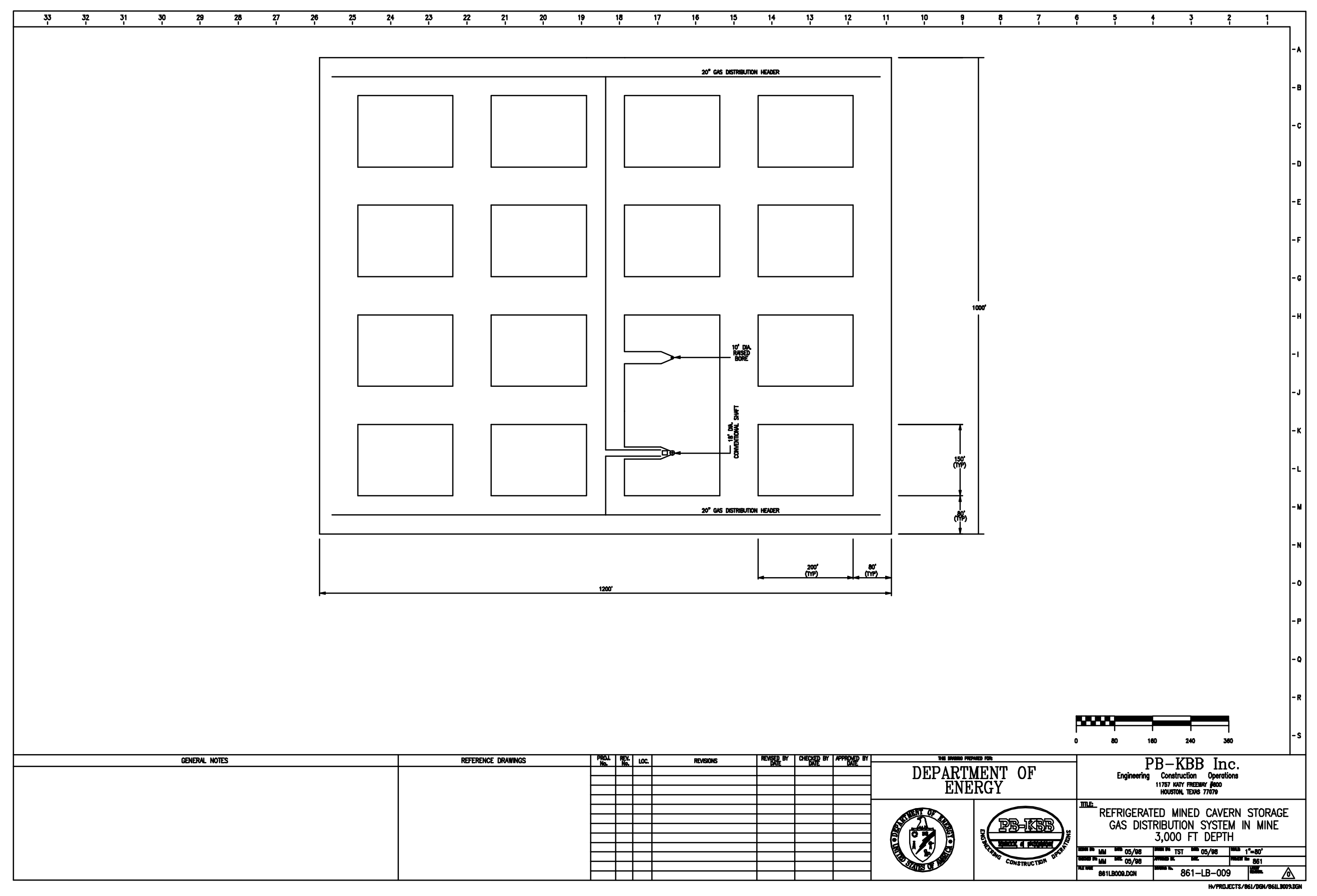




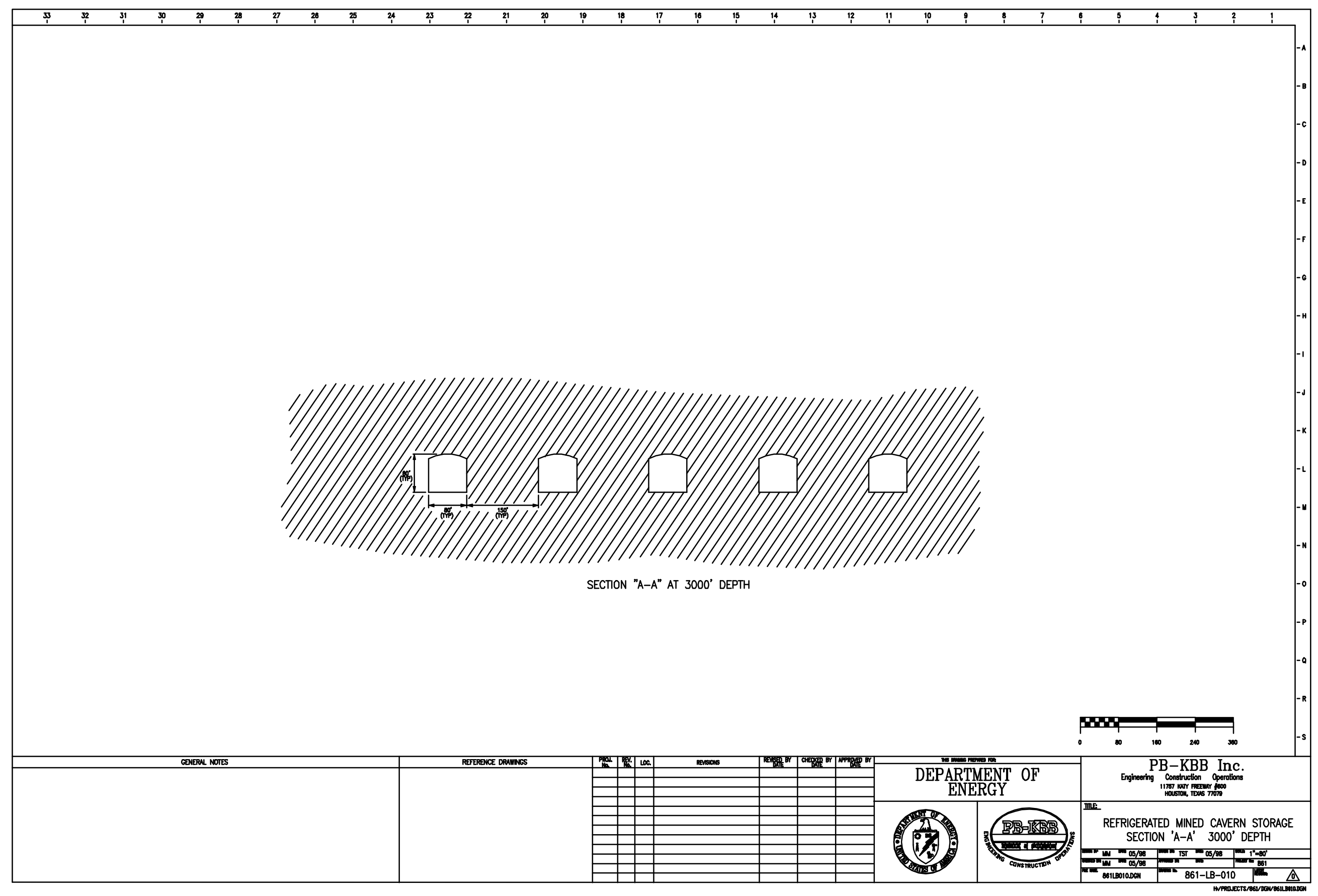




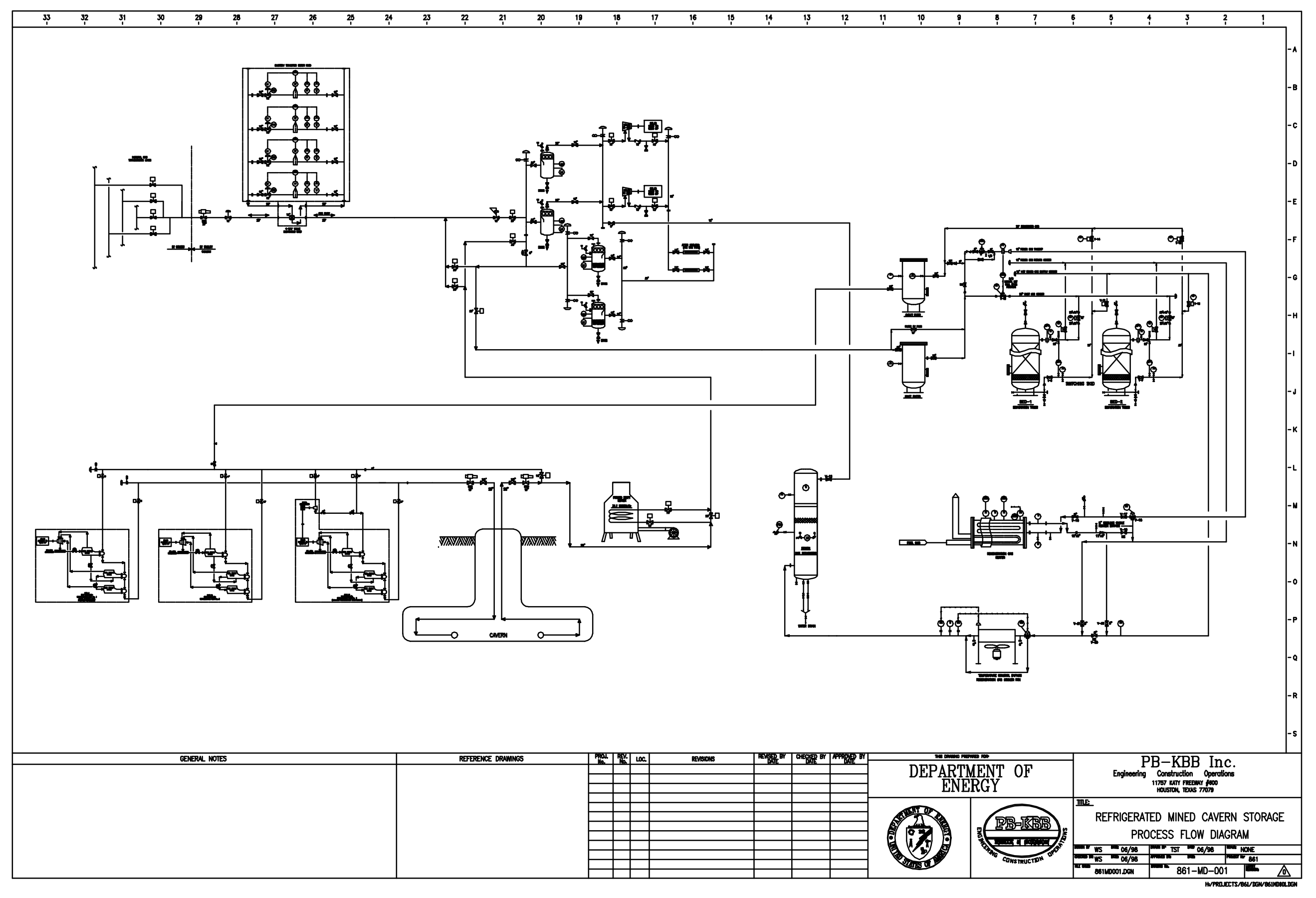




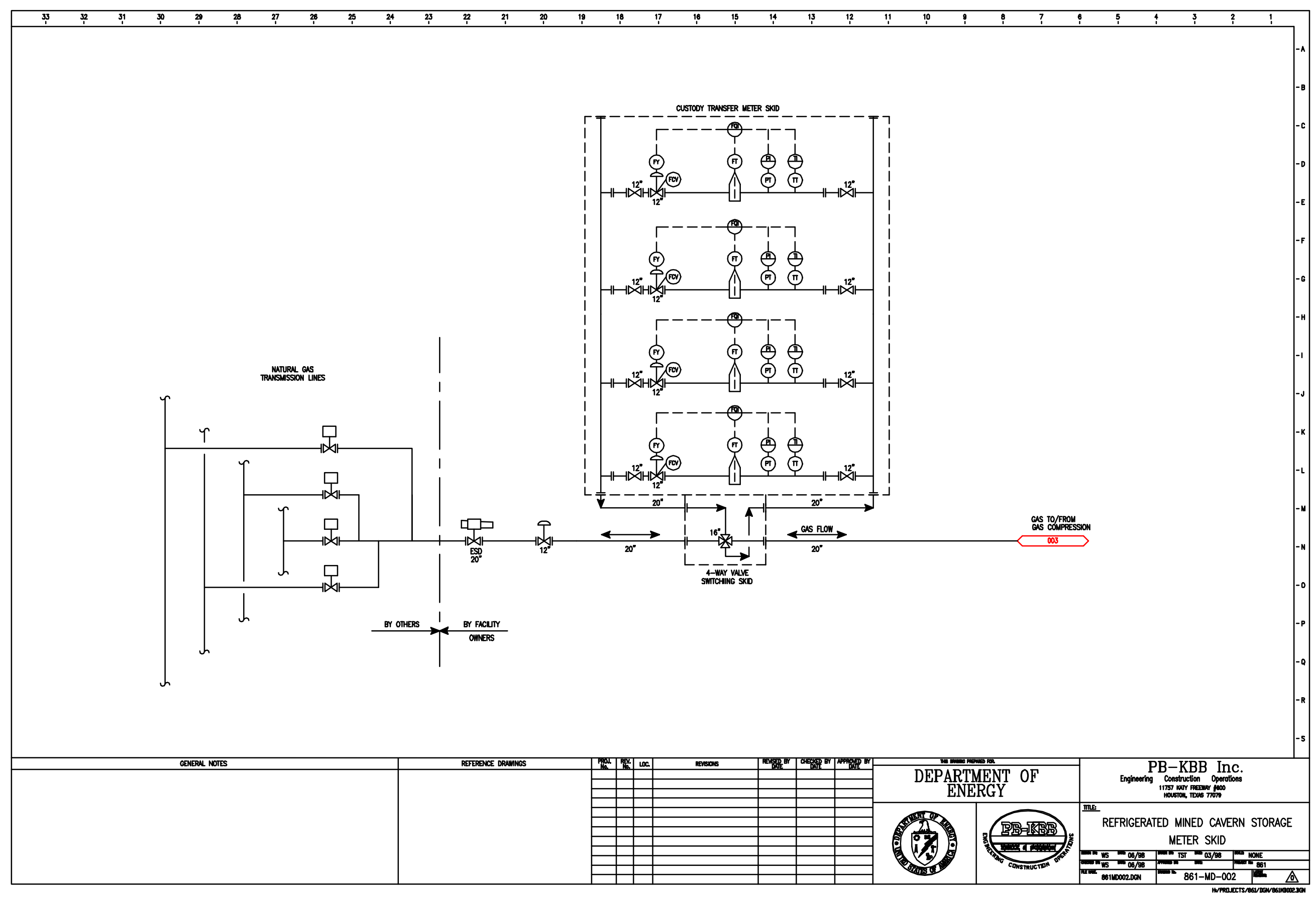




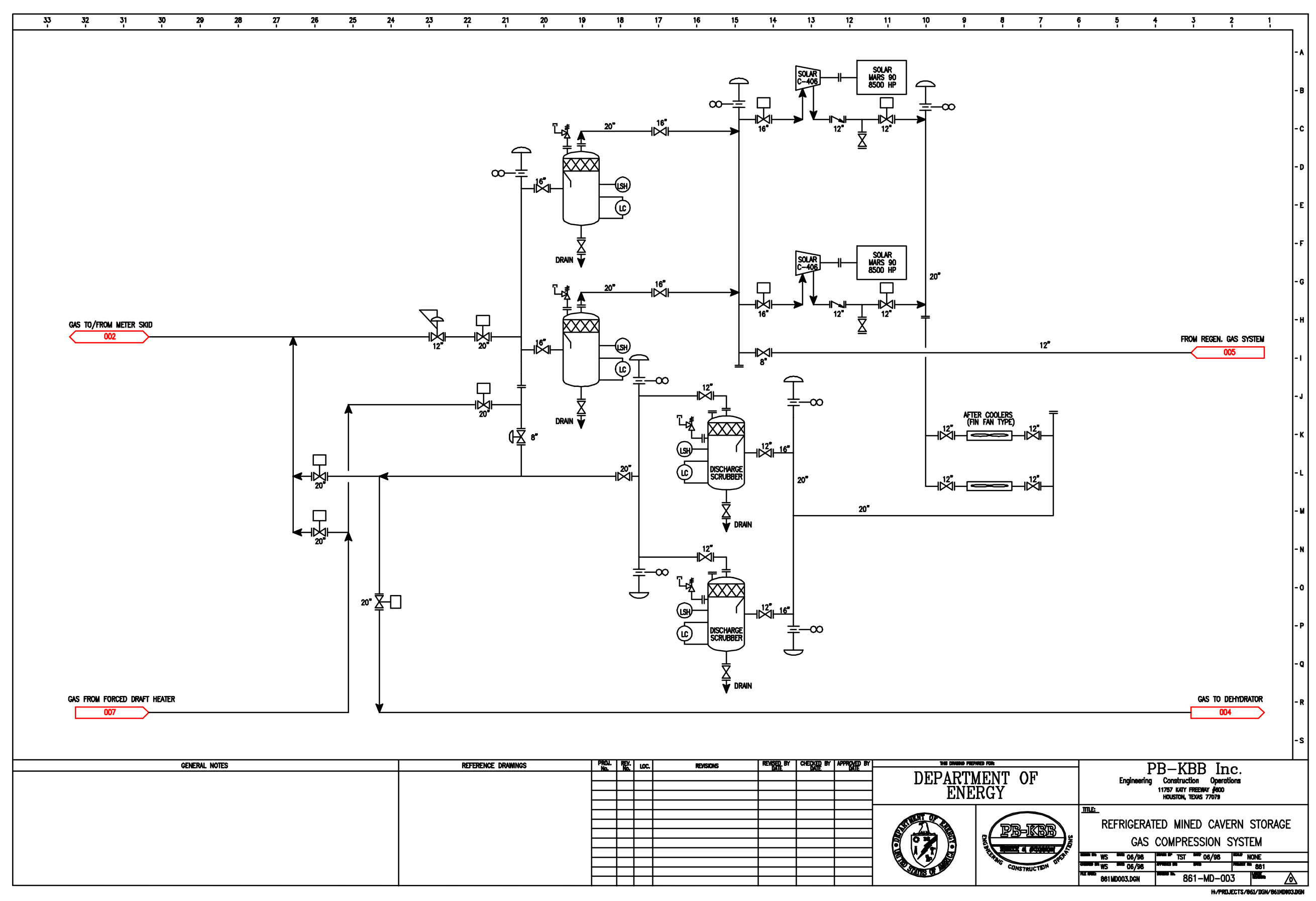




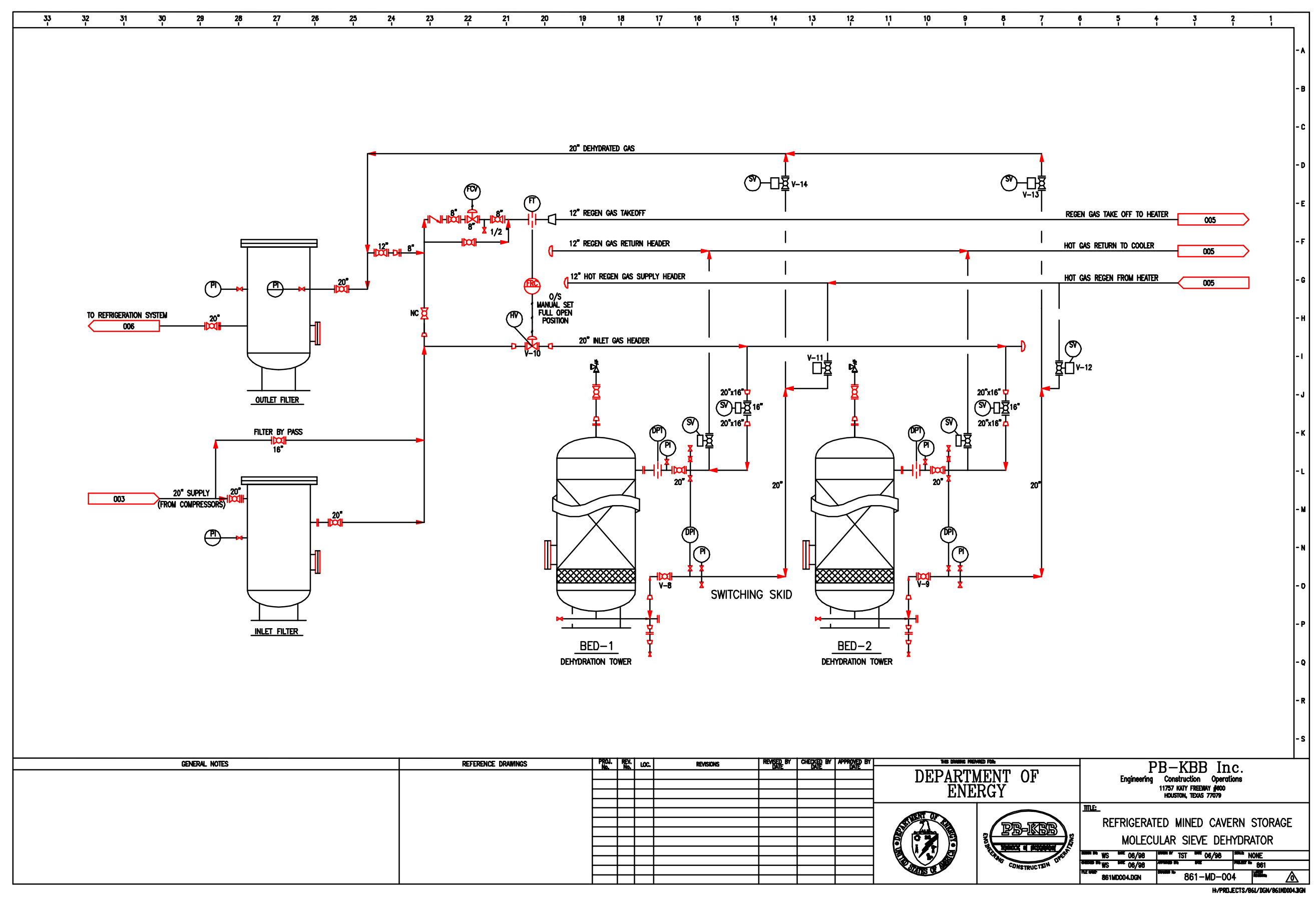




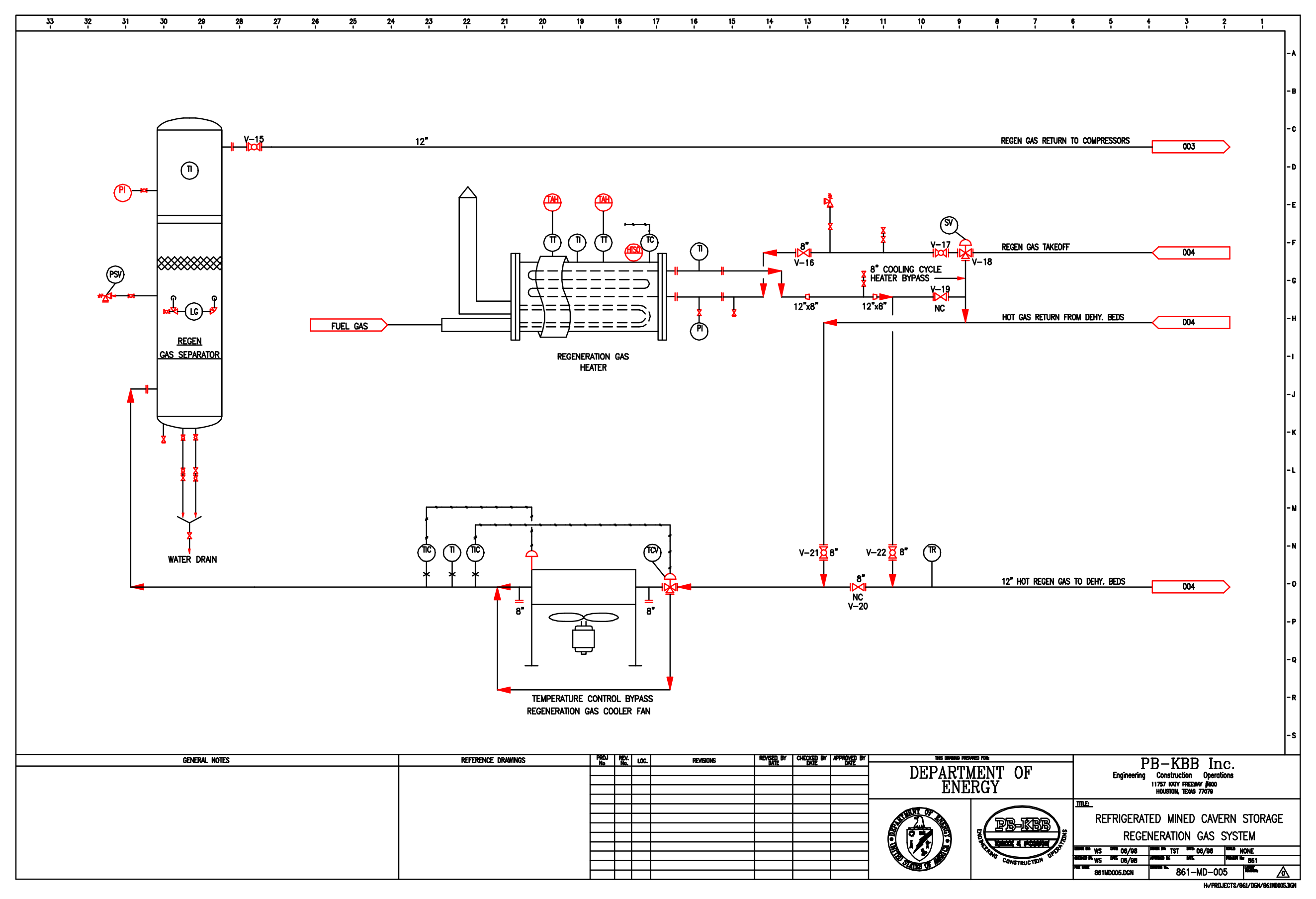




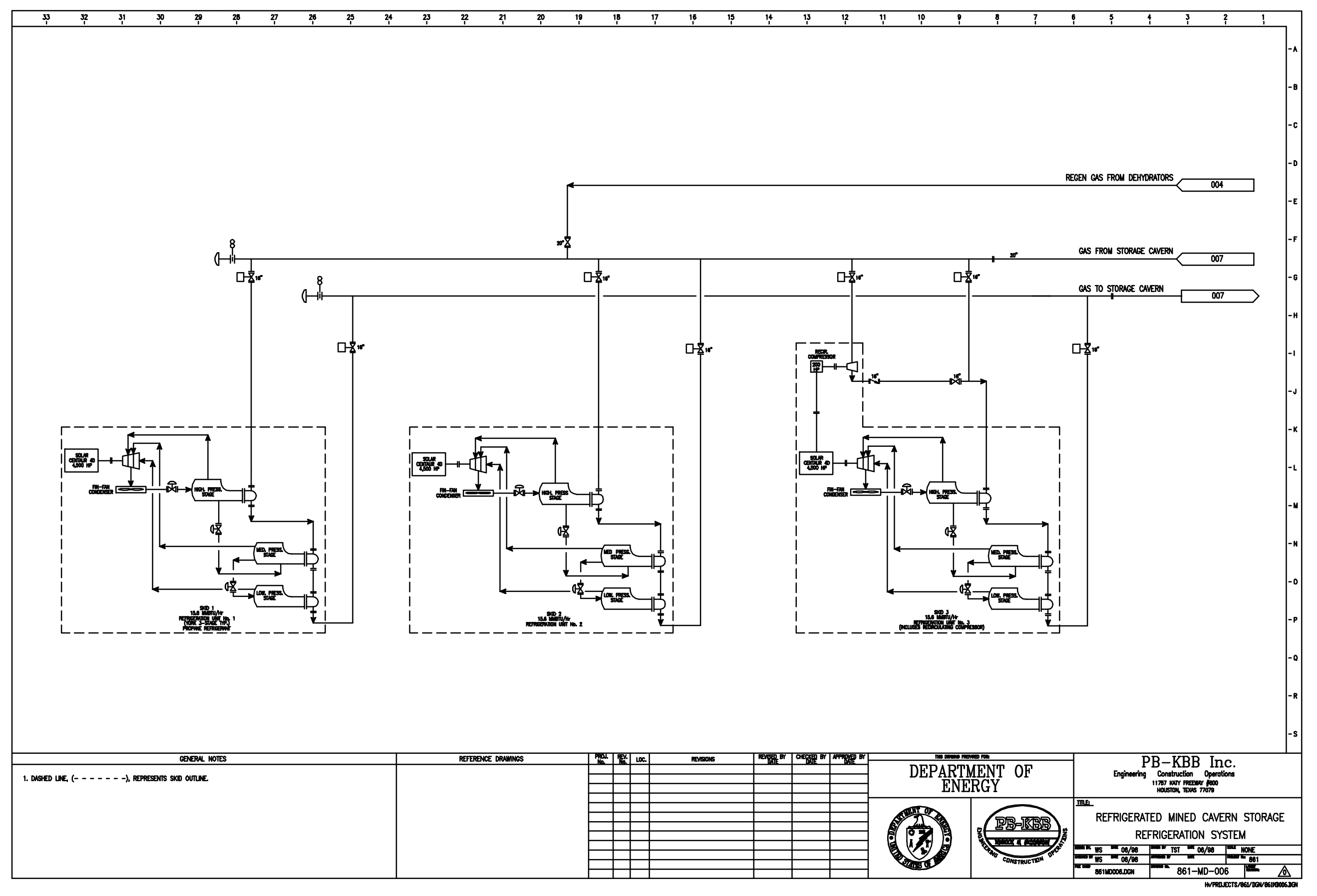




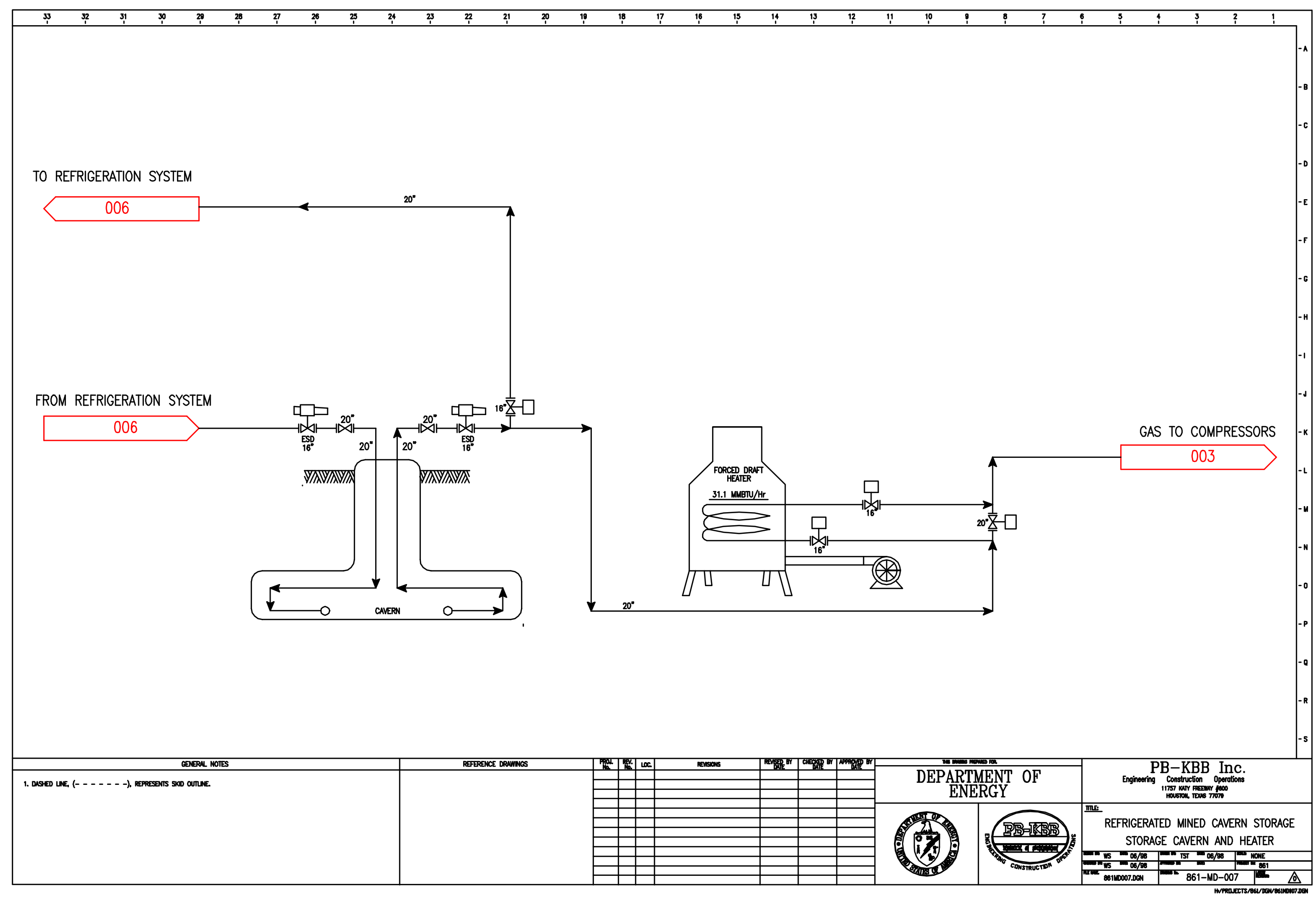




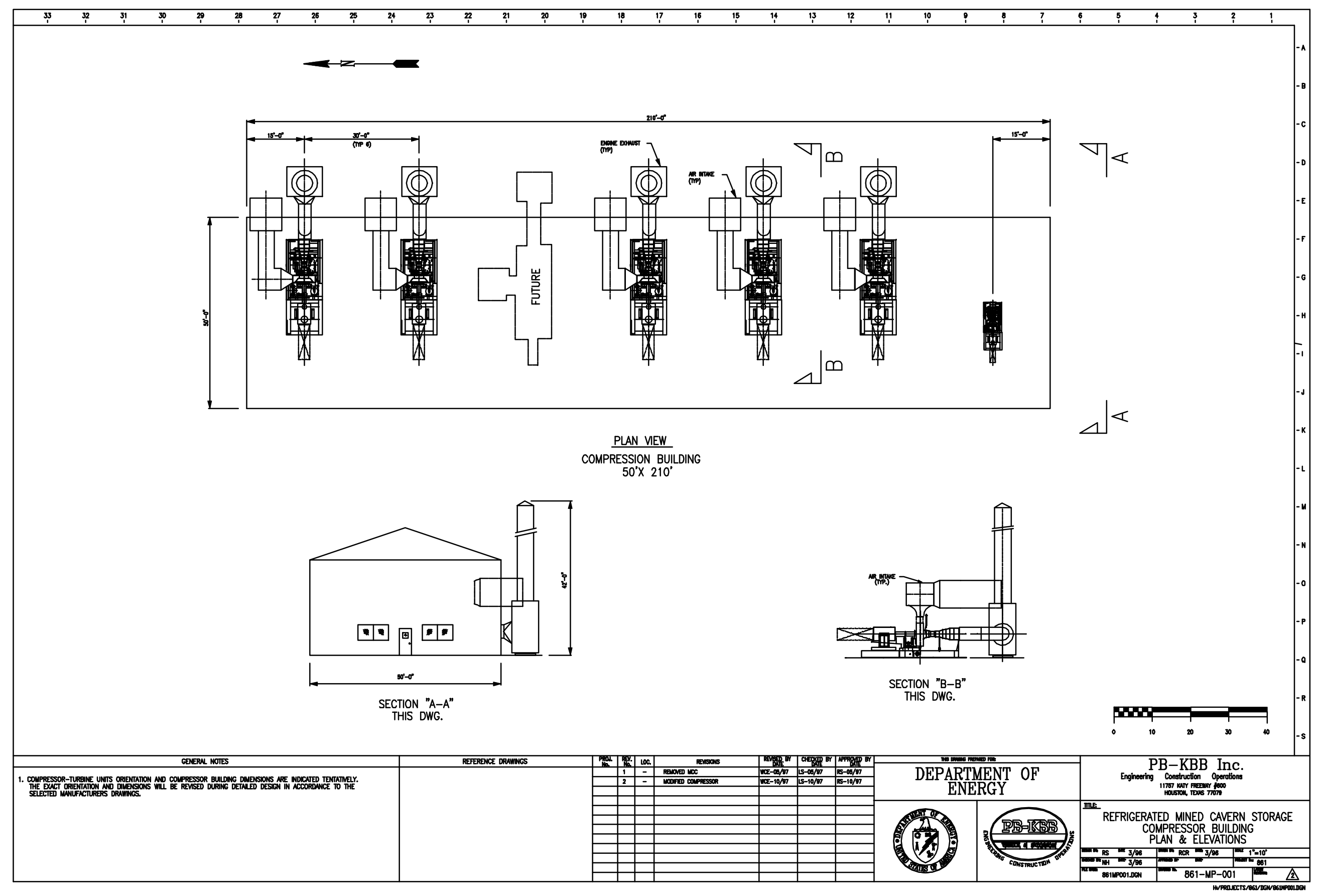




\section{COST ESTIMATE DETAIL}




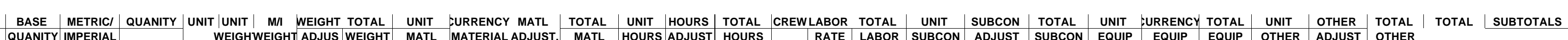

CONVENTIONAL MINING AND SHAFT SINKING $(6,292,335$ BBLS SINK AND LINE MAIN SHAFT; 18-FOOT I.D. CONCRETE LINED ; 3.000.FEET MATERALL HANDLING EQUPMENT, MINE HOIST, CRUSHER, HAUL TRUCKS, ECT.

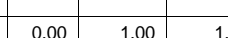

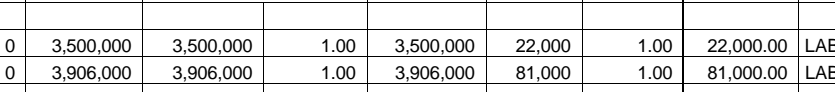

(20)

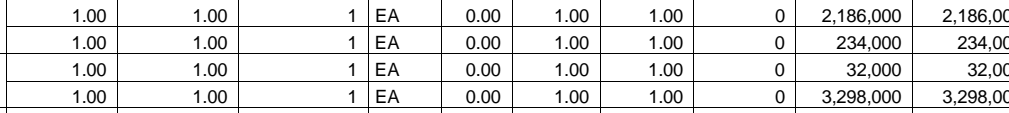

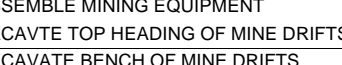

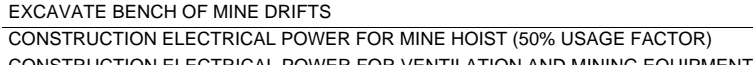
SUBTOTAL MIINING AND SHAFT SINKING
REFRDEGRATIN SYTEM COMPRSSORS, AND PROCESS

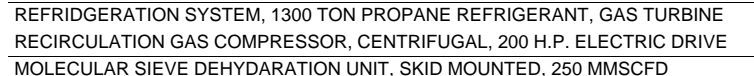

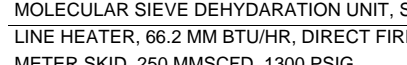

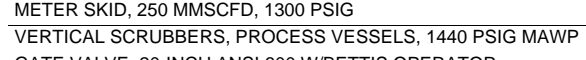

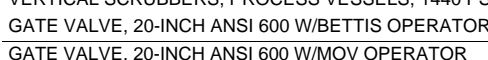

GATE VALVE, 20-INCH ANSI 600 WIBEVEL GEAR OPERATO

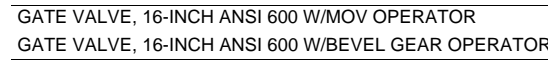

GATE VALVE, 12-INCH ANS 600 W.MOV OPERAT

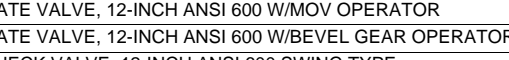

GATE VALVE, 8-INCH ANSI 600 WIBEVEL GEAR OPERATOR
GATE VALLE, 12-INGH ANSI 600 FINALCONTROL ELEMENT

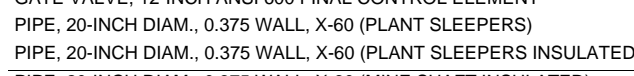

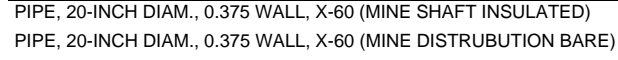

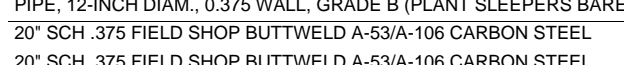

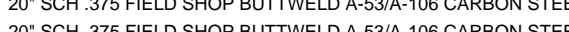

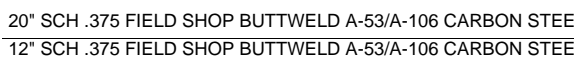

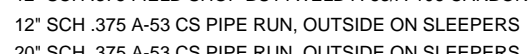

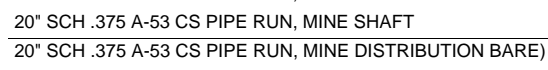

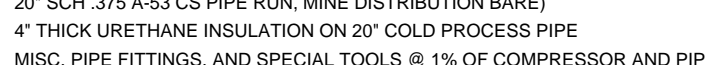

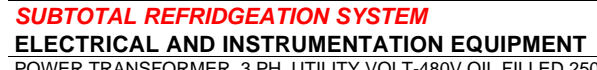

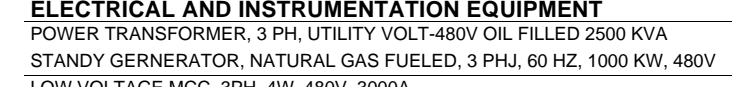

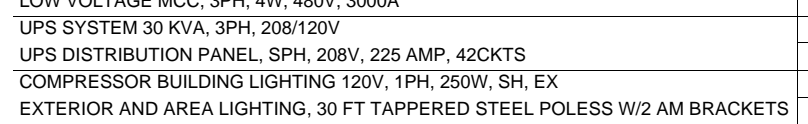

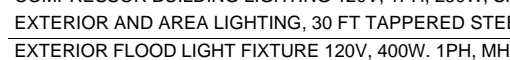

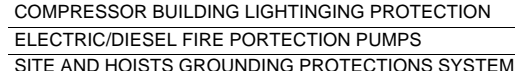
(n)

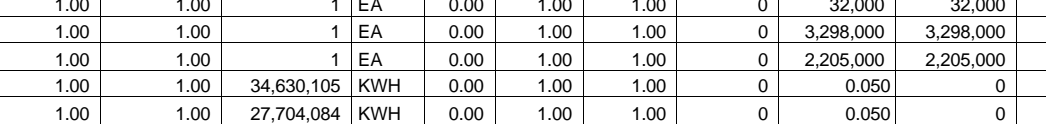

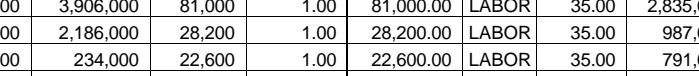
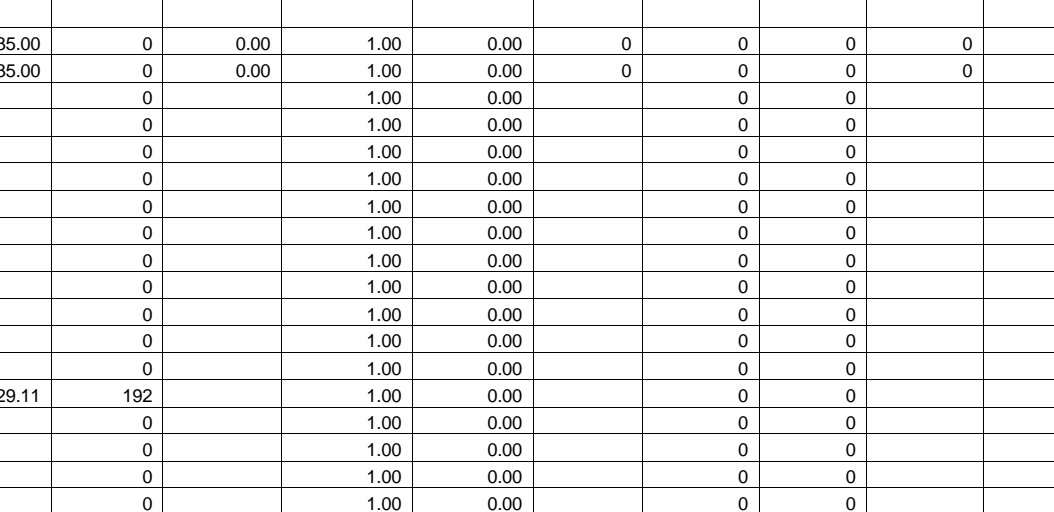


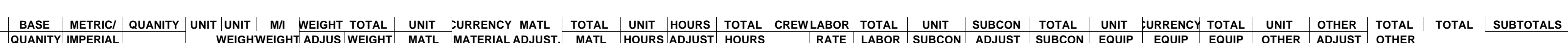

SUBTOTAL COMPRESSOR BUILDING FOUNDATION AND SLAB

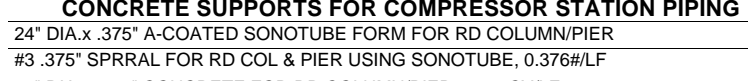

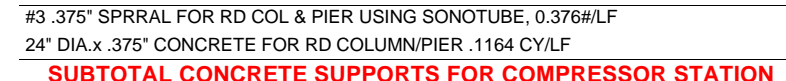
SUBTOTAL CONCRETE SUPPORTS FOR COMPRESSOR STATION
CONTROL BULLDING FOUNDATION

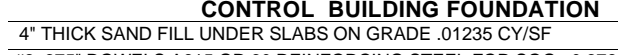

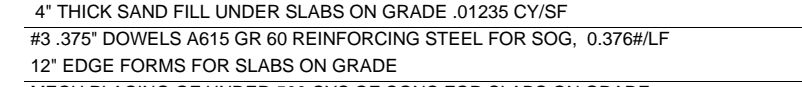

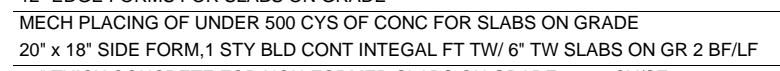

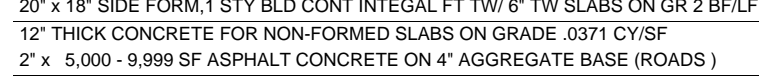
MECNANICAL SEPERATORS FOUNDATION

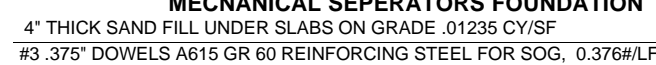
12 " EDGE FORMS FOR SLABS ON GRADE
MECH PLACING OF UNDER 500 CYS OF CONC FOR SLABS ON GRADE

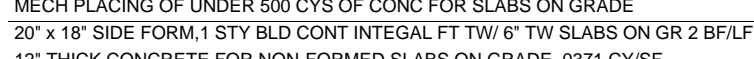

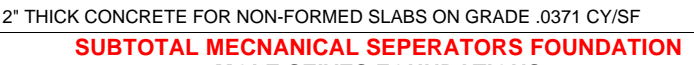
\begin{tabular}{l} 
MOLE SEVES FOUNDATIONS \\
\hline "THCK SAND FLL UNDER SLABS ON GRADE O1235 CYYSF
\end{tabular}

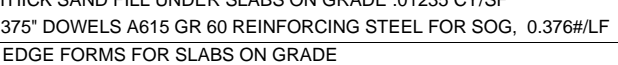

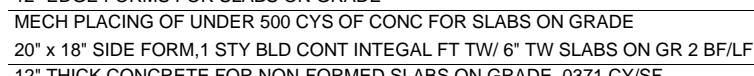

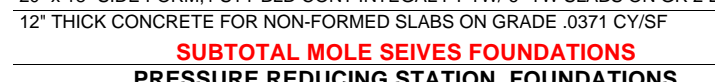

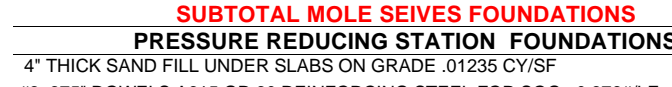

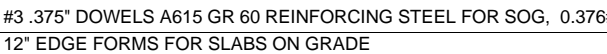
MECH PAACING OF UNDER

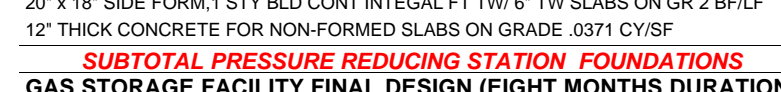
CCHANCAL ENGINEEF

CIVL ENGINER CHEMICAL ENGINEE

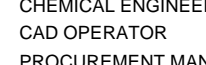

PROCUREMENT MANAGER
PROJECT COST AND SCHEDULING

PROJECT SECRETARY
PRCUREMENT CLERK

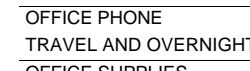

SUBTOTAL FINAL DESIGN
GAS STORAG FACILTY CONSTRUCTION AND COMMIIIONING (50

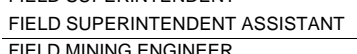

FEED OFFICE CLERK

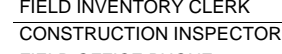

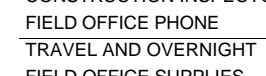
\begin{tabular}{l} 
TRAVEL AND OVERNGHT \\
FELD OFICE SUPPLES \\
\hline SUBTOTAL CONSTRUCTION SUPERVISIIO
\end{tabular}

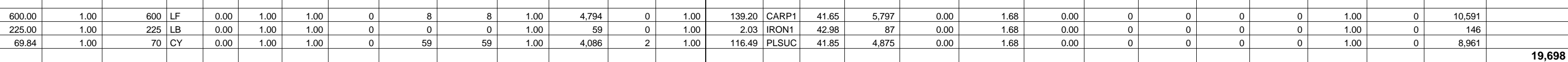

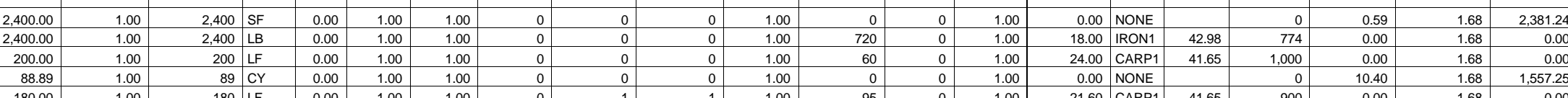

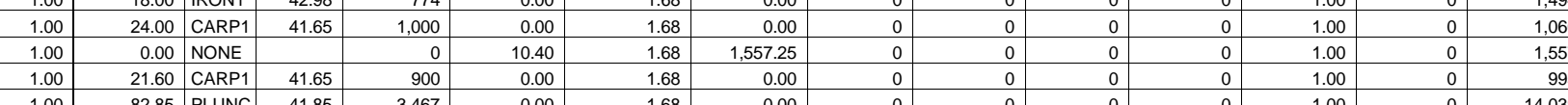

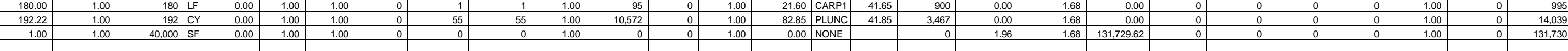

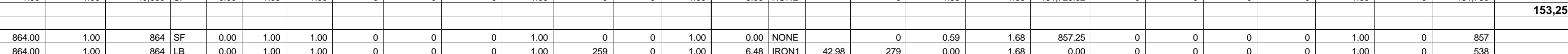

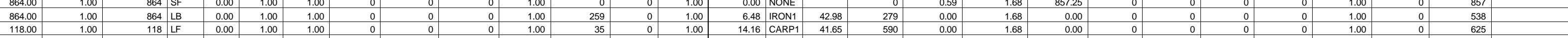

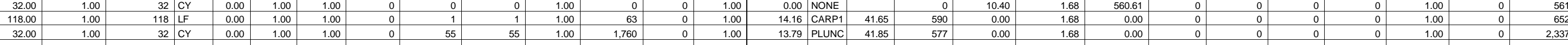

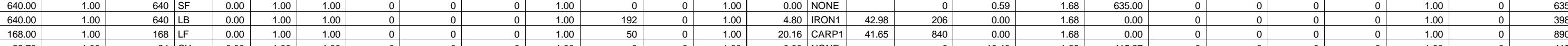

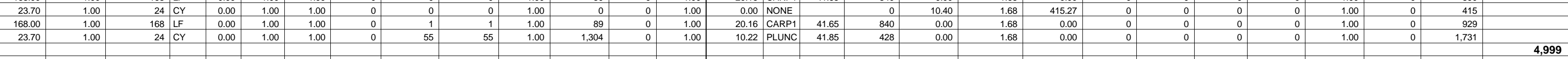
surer

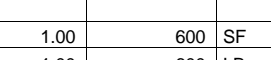
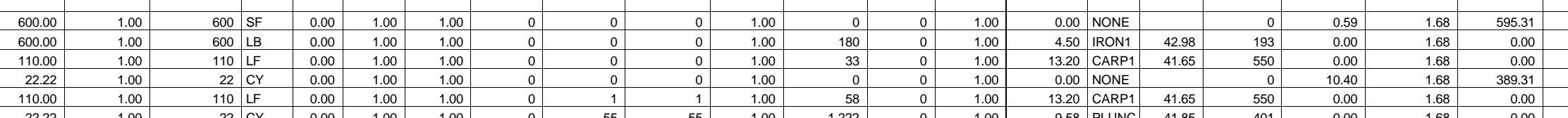

$+\frac{1}{10}$

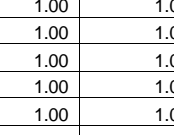

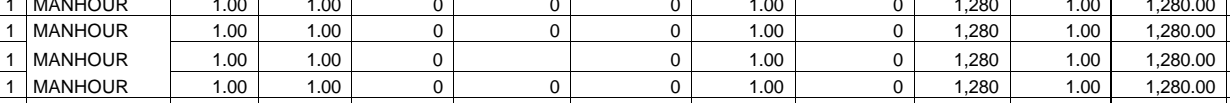

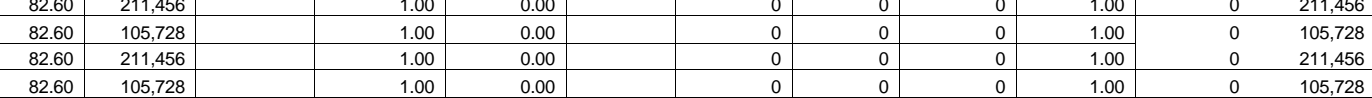

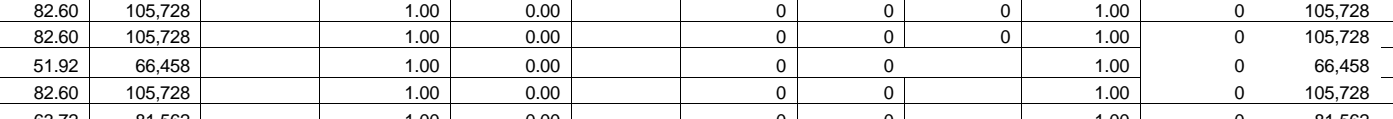




\section{REFERENCES}




\section{REFERENCES FOR SECTION 8 GEOMECHANICAL}

Abel, J. F., J. E. Dowis, and D. P. Richards, 1979. "Concrete Shaft Lining Design," Proceedings, 20th U.S. Symposium on Rock Mechanics, University of Texas-Austin, Austin, TX, June 4-6, Center for Earth Sciences and Engineering, University of Texas-Austin, Austin, TX, pp. 627-633.

Barton, N., 1976. "Recent Experiences With the Q-System of Tunnel Support Design," Proceedings, Symposium on Exploration for Rock Engineering, Johannesburg, Vol. 1, pp. 107-117.

Barton, N., R. Lien, and J. Lunde, 1974. "Engineering Classification of Rock Masses for the Design of Tunnel Support," Rock Mechanics, Vol. 6, pp. 189-236.

Barton, N., T. L. By, P. Chryssanthakis, L. Tunbridge, J. Kristiansen, F. Lf set, R. K. Bhasin, H. Westerdahl, and G. Vik, 1994. "Predicted and Measured Performance of the $62 \mathrm{~m}$ Span Norwegian Olympic Ice Hockey Cavern at Gjøvik,"International Journal of Rock Mechanics and Mining Science and Geomechanics Abstracts, Vol. 31, No. 6, pp. 617-641.

Bieniawski, Z. T., 1976. "Rock Mass Classification in Rock Engineering," Proceedings, Symposium on Exploration for Rock Engineering, Johannesburg, Vol. 1, pp. 97-106.

Callahan, G. D., A. F. Fossum, and D. K. Svalstad, 1989. Documentation of SPECTROM-32: A Finite Element Thermomechanical Stress Analysis Program, DOE/CH/10378-2, prepared by RE/SPEC Inc., Rapid City, SD, for the U. S. Department of Energy, Chicago Operations Office, Argonne, IL, Vol. I and II.

Carslaw, H. S. and J.C. Jaeger, 1959. Conduction of Heat in Solids, 2nd Edition, Oxford University Press, Walton Street, Oxford, United Kingdom.

Hoek, E., 1979. "The Role of Modeling in the Design of Nuclear Waste Repositories - The Design Engineer's Viewpoint," Proceedings, Workshop on Thermomechanical Modeling for a Hardrock Waste Facility, UCAR 10043, Lawrence Livermore Laboratories, Lawrence, CA, pp. 33-43.

Hoek, E. and E. T. Brown, 1980. "Underground Excavations in Rock," The Institution of Mining and Metallurgy, London.

Kuriyagawa, M., I. Matsunaga, N. Kinoshita, and K. Hibi, 1977. "Rock Behavior of Underground Cavern With the Storage of Cryogenic Liquified Gas," Subsurface Space (Rockstore 80), S. Magnus Bergman (ed.), Pergamon Press, New York, NY, pp. 665-672.

Lama, R. D. and V. S. Vutukuri, 1978. Handbook on Mechanical Properties of Rocks, Vol. IV., Trans Tech Publications, Clausthal, Germany.

Lindner, E. N. and J. A. Halpern, 1978. "In Situ Stress in North America: A Compilation," International Journal of Rock Mechanics and Geomechanical Abstracts, Vol. 15, pp. 183-203.

Mirza, M., 1998. Rock Mechanics, letter to J. L. Ratigan, RE/SPEC Inc., Rapid City, SD, from PB-KBB Inc., Houston, TX, February 13.

Ostrowski, W. J. S., 1972. "Design Considerations for Modern Shaft Lining," Transactions of the Canadian Institute of Mining and Metallurgy, Vol. LXXV, pp. 184-198.

PB-KBB Inc., 1997. Literature Search for Selecting Target Areas - Task 1, report to Federal Energy Technology Center, Houston, TX, December 24.

Richards, D. P. and J. F. Abel, 1981. "Shaft Lining Design in Rock," Transactions of AIME, Vol. 270, pp. $1801-1805$. 
Selmer-Olsen, R. and E. Broch, 1977. "General Design Procedure for Underground Openings in Norway," Storage in Excavated Caverns (Rockstore 77), S. Bergman (ed.), Vol. 2, Pergamon Press, Elmsford, NY, pp. 219-226.

Svalstad, D. K., 1989. Documentation of SPECTROM-41: A Finite Element Heat Transfer Analysis Program, DOE/CH/10378-1, prepared by RE/SPEC Inc., Rapid City, SD, for the U.S. Department of Energy, Chicago Operations Office, Argonne, IL.

University of Karlsruhe, 1998. World Stress Map, on the Internet at http://www-gpi.physik.unilar;srije.de/wsm/.

Zoback, M. L. and M. Zoback, 1980. "State of Stress in the Conterminous United States," Journal of Geophysical Research, Vol. 85, pp. 6113-6156.

\section{REFERENCES FOR COOLING LOAD CALCULATIONS (SECTION 8)}

Carslaw, H. W. and J. C. Jaeger, 1959. Conduction of Heat in Solids, 2nd Edition, Oxford University Press, Walton Street, Oxford, United Kingdom.

Coker, A. K., 1993. "Program Calculates Z-Factor for Natural Gas," Oil \& Gas Journal, pp. 7475.

PB-KBB Inc., 1998. Personal communication with PB-KBB Inc., Houston, TX.

Svalstad, D. K., 1989. Documentation of SPECTROM-41: A Finite Element Heat Transfer Analysis Program, DOE/CH/10378-1, prepared by RE/SPEC Inc., Rapid City, SD, for the U.S. Department of Energy, Chicago Operations Office, Argonne, IL.

Van Wylen, G. J. and R. E. Sonntag, 1978. Fundamentals of Classical Thermodynamics, 2nd Edition, John Wiley \& Sons, New York, NY. 